\title{
Speed, Scale and Sustainability
}

Citation for published version (APA):

Sonntag, V. (2003). Speed, Scale and Sustainability. [Doctoral Thesis, Maastricht University]. unigraphic, Universiteit Maastricht. https://doi.org/10.26481/dis.20030619vs

Document status and date:

Published: 01/01/2003

DOI:

10.26481/dis.20030619vs

Document Version:

Publisher's PDF, also known as Version of record

\section{Please check the document version of this publication:}

- A submitted manuscript is the version of the article upon submission and before peer-review. There can be important differences between the submitted version and the official published version of record.

People interested in the research are advised to contact the author for the final version of the publication, or visit the DOI to the publisher's website.

- The final author version and the galley proof are versions of the publication after peer review.

- The final published version features the final layout of the paper including the volume, issue and page numbers.

Link to publication

\footnotetext{
General rights rights.

- You may freely distribute the URL identifying the publication in the public portal. please follow below link for the End User Agreement:

www.umlib.nl/taverne-license

Take down policy

If you believe that this document breaches copyright please contact us at:

repository@maastrichtuniversity.nl

providing details and we will investigate your claim.
}

Copyright and moral rights for the publications made accessible in the public portal are retained by the authors and/or other copyright owners and it is a condition of accessing publications that users recognise and abide by the legal requirements associated with these

- Users may download and print one copy of any publication from the public portal for the purpose of private study or research.

- You may not further distribute the material or use it for any profit-making activity or commercial gain

If the publication is distributed under the terms of Article $25 \mathrm{fa}$ of the Dutch Copyright Act, indicated by the "Taverne" license above, 


\section{Speed, Scale and Sustainability}

An Inquiry into Technological Momentum and the Strategic Use of Advanced Manufacturing Technologies

\section{PROEFSCHRIFT}

ter verkriiging van de graad van doctor aan de Universiteit Maastricht, op gezag van de Rector Magnificus, Prof. dr. A.C. Nieuwenhuijzen Kruseman, volgens het besluit van het College van Decanen, in het openbaar te verdedigen op donderdag 19 juni 2003 om 12.00 uur

Victoria A. Sonntag 
Promotor:

Prof. Dr. R. Cowan

Co-promotor:

Dr. R. Kemp

Beoordelingscommissie:

Prof. Dr. L. Soete (voorzitter)

Prof. Dr. J. Hagedoorn

Dr. F. Hinterberger (Sustainable Europe Research Institute, Vienna)

ISBN 90-5681-171-1 




\section{Contents}

The Argument iii

Acknowledgements $\quad$ V

1 Standpoints 1

1.1 Issues in Sustainability 3

1.2 The Direction of Research 13

2 The Theoretical Landscape 20

2.1 Production System Models $\quad 21$

2.2 Manufacturing Strategy Models 34

$3 \quad$ The Strategic Use Model 50

3.1 The Evolutionary Economics Framework 50

3.2 The Need for Resources 53

3.3 Technology Use, Trade-offs, and Path Dependence 56

3.4 The Model's Implications 61

$4 \quad$ AMT Trajectories Analysis $\quad 65$

4.1 Researching Trajectories 66

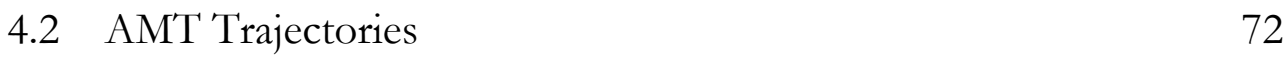

4.3 The New Regime 79

$5 \quad$ Economies of Speed 83

5.1 Time-Based Strategies $\quad 84$

5.2 Speed and the Organisation of Production 89

5.3 The Economies of Speed 95

6 Speed, Scale and Sustainability 104

6.1 The Pattern of Consumption 105

6.2 Assessing the Impacts of AMTS on Sustainability 113

6.3 New Directions in AMT Use 120 
7 The Role Of Manufacturing Strategy: The Model's Validation 128

7.1 The Validation Framework 128

$\begin{array}{lll}7.2 & \text { Interview Findings } & 136\end{array}$

7.3 Strategic Practices in AMT Use 151

8 The Strategic Uses of AMTs: Industry Survey Results 157

8.1 Survey Content and Methodology 157

8.2 Industry Profiles - Descriptive Statistics 162

8.3 Regressions 168

8.4 Consumption Growth and The Strategic Use of AMTs 174

$9 \quad$ AMT-Related Trade-Offs: Evidence from the Interviews and Survey 186

9.1 Emergence of the AMT Regime 187

9.2 Dynamics of Technology Use in the AMT Regime 190

9.3 Evidence for Emerging Trade-Offs 196

9.4 Sustainability in Light of AMT Trade-Offs 201

10 Towards Balanced Consumption 205

10.1 The Sustainable Worldview 205

10.2 Policy Options for Qualitative Economic Development 209

10.3 Assessing the Options 212

10.4 Towards Balanced Consumption 215

11 Sustainability as Process 218

Appendices

A AMT Descriptions $\quad 225$

B $\quad$ AMT Trajectory Descriptions $\quad 231$

C Breakout of Interviews 235

D Model Validation Data 241

E Trajectory Data from Interviews 258

$\begin{array}{ll}\text { References } & 267\end{array}$

$\begin{array}{ll}\text { Samenvatting } & 287\end{array}$

$\begin{array}{ll}\text { Curriculum Vitae } & 293\end{array}$ 


\section{The Argument}

Firms adapt to change in their environments by using new technologies, changing the structure of those environments in the process.

In recent decades, the application of computer and microelectronics-based technologies in production has changed the way firms compete with consequence for the ways we consume. As the speed of production climbs, the number of product variants multiplies, new products appear instantaneously, and consumption grows.

These parallel changes in production and consumption exemplify the emergent socioeconomic theory that technology systems and their environments co-evolve. The theory, as applied to the development of manufacturing capabilities, implies that firms learn new ways to achieve their business goals as an effect of the integration of new technology into the production system. Firms select technologies which provide the technological means of achieving their competitive priorities, but technologies also condition the knowledge and practices of their users. Thus the direction of technological advance in manufacturing systems is both an effect and a cause of operational choices concerning production technology use. Consecutive generations of production technologies follow a path-dependent course of development that mirrors changes in the terms of market competition brought on through shifts in strategy.

There is cause for concern that many current practices in the strategic use of advanced manufacturing technologies lead to higher throughputs and ever larger scales of production. In particular, faster product introductions and greater product variety amplify demand to the point of overconsumption in the highly industrialised countries. To move away from current unsustainable patterns in the production and consumption of material goods, we need to experiment with how advanced manufacturing technologies can be used to create technological momentum, not only in the direction of greater competitiveness, but also greater sustainability. 


\section{Acknowledgements}

I am beyond grateful to Danielle, my daughter, for her willingness to share the adventure, her zest, and her appreciative inquiry into life - she thus conspires to keep me wide awake.

Special thanks are due to my mother, Selma, and my aunties, Alice and Ruth, who not only are the model of strong women but who also fully supported my taking off to become one.

My promoters, René Kemp and Robin Cowan, were as steady as they come. Without their intelligent guidance, I should have taken more than a few detours. Also, in my opinion, René deserves the thanks of us all for his work on transition management, which just may be what we all have been waiting for - an understanding of how to go about system change.

My blessings include having had, at critical and various stages along the way, a fair share of mentors. In particular, C.A. Welch, Ed Wenk, and Sandi Benbrook shaped my thought not only through their wisdom, but also through their exceptional kindness.

Christopher Freeman's monumental work inspired this journey. I was lucky to have met him during my first days as a $\mathrm{PhD}$ student and was awed to discover that he personifies the good will that makes his work so powerful. We need such rare beings to remind us of what we are here for.

A great many generous women have been here for me - cheering me on (in both senses). Women are truly phenomenal, among them: Delphine, Esther, Sima, Catherine, Nancy, Christie, Shirley, Janet and Celia, Louise, Pam, Oxana, and Sunny. I love you all dearly.

I am also indebted to the following people for the experiences that make learning so extraordinary: Noi (Nantawan) Kwanjai, who, more than anyone I know, seems to think like me, only more skilfully; Robert Kirby, Anthony Arundel, and Paul Parkman, friends who paid heed to my meanderings with wit and patience; Ewa Charkiewicz, sustainability scholar and (more significantly) sustainability practitioner; Demetria Giannisis, manufacturing culture savant; and Jack Duffy and Rodney Smith, dharma teachers.

The Maastricht Economic Research Institute on Innovation and Technology (MERIT) was home for some while. To those who made it a very comfortable home indeed (certainly, that angel, Corien), I give my thanks. To those who made it an intellectually challenging place to be, I also give thanks.

I feel wonderfully fortunate to have been involved in a program - the MERIT/UNU PhD Programme - with such a diversity of students, many of whom I will count friends for life. The respect everyone showed each other has been a continuous inspiration. Lastly, as continuing to learn is a goal, I owe deep thanks to my friends from the Goodenough Community, Buddhist Peace Fellowship, the Unitarian Universalists for a Just Economic Community, and the emerging network of local economy enthusiasts, who help me to put the ideas developed in the course of this research into practice.

May you all know peace and harmony in your life. 



\section{Chapter 1 Standpoints}

Economic growth may one day turn out to be a curse rather than a good, and under no conditions can it either lead into freedom or constitute a proof for its existence.

Hannah Arendt: On Revolution

The present day system for producing goods informs our perceptions of "the way things are" perhaps more than any other single basis of modern society. For one thing, it is difficult to imagine we have recourse to anything but a highly industrialised existence without radically changing the way we live. Few of us are truly independent of needing (or wanting) at least some of the fruits of technological progress - products brought to us by the modern industrial complex. Even when we are satisfied with what we already have, the idea of risking our present comfort by making changes can be frightening. This dependence aside, most of our livelihoods are intricately tied, either directly or indirectly, to the modern industrial enterprise. It seems that we are beholden to this system to the degree that it is hard to separate our everyday lives from it.

At the same time, we have a resolute and venerable tradition of critically examining the consequences of industrialisation for our well-being. ${ }^{1}$ Thoreau, Carlyle, Kropotkin, Gandhi, Marcuse, and Schumacher, among others, have challenged the accepted doctrine of progress through industrial growth. The sum of these critiques centres on the question: Is what we have truly what we want?

The implicit challenge in this question is not to convincingly protest (or deconstruct) the present order. That's relatively easy, given the waste and want that surround us. What is hard is to envision a compelling alternative to industrialised society and, even harder, a way to get there. Indeed, some consider that our failure to do so constitutes a lasting crisis in the social sciences that explains the dominance of neo-classical economics in political discourse. Rather than ask what kind of society we are or want to be, we have narrowed our vision of well-being to economic growth (Block, 1990).

Alternatively, according to others, such matters will resolve themselves through the free reign of the forces of technology. There is a widespread belief that we are in the midst of a technological metamorphosis in which the knowledge society will replace the 250 plus year old socio-economic system born of the industrial revolution. While few can 
doubt that we are undergoing an information technology led economic transformation, there is less certainty about what it will bring. The popularised vision of the knowledge economy promises a never ending bonanza of innovations that provide for an ever more efficient use of resources. Yet, it takes a serious stretch of imagination to think that producing things "faster, cheaper, better", or even more resource efficiently, marks a social transformation. Harvey (1990), in his significant contribution to social criticism, The Condition of Postmodernity, showed that though life may be getting faster and more complex, the capitalist system of market relations is still very much intact.

Nor can we say that having more things, however innovative they may be, keeps the economy stable, the environment protected, or social injustice in check. On the contrary, many people, from across the political spectrum and of all spiritual beliefs, believe that materialism is out of control. For them, and I include myself in this persuasion, expanding the present day industrial system-cum-economy is not the solution it is purported to be: well-being is not the same as increased product consumption. ${ }^{2}$ We might then do well to ask: If not more, then what?

We know that we have to move beyond what its dissentients call the Industrial Growth Society (Macy and Brown, 1998). Yet, the risk in reducing the consideration of the social implications of industrial growth to an anti-consumerist argument is evident. For one thing, jobs and social spending within the current economic system are tied to growth. It behoves us then, in questioning growth, to ask how we can ensure jobs and social prosperity without it. As of yet, serious proposals on how to address these issues are few, indicating how much research needs to be done. Similarly, few sustainability researchers have given consideration to business viability in an economy no longer centred on quantitative growth. This thesis proposes to address this need through investigating how technology choice can be used in the service of increasing market opportunities without increasing consumption.

In relation to said opportunities, we know that we are in a time of industrial transformation propelled by the forces of technological and social change. But is the direction we are moving in where we want to go? And, more fundamentally, is it even possible to change the direction of the current transformation, when we are not certain where it is we want to be, without having been there before?

This thesis engages these questions, not by assuming to give answers, but decidedly from the standpoint of the questions' importance to the formation and development of the thesis. ${ }^{3}$ They are, so to speak, the framework conditions for this inquiry into recent changes in the organisation of production and their consequence for our future. Particularly, I am concerned that current practices in the strategic use of production technologies, namely, faster product introductions and increased product variety, reinforce growth in material goods consumption with real harm to the environment, community, and personal happiness.

In this introductory chapter, my aim is to situate this concern within contemporary discourse on growth, meeting needs, and technological choice. Such an exposition of standpoints is meant to illuminate the context of the inquiry - to get us out of the box, before we attempt to see what is inside it. In other words, the challenge is to step outside the paradigm of growth. The standard of objectivity in this approach derives from the recognition that all knowledge is socially situated. ${ }^{4}$ 


\subsection{Issues in Sustainability}

My analysis of how changes in the organisation of production affect consumption patterns touches on three interrelated issues that inform the underlying themes of this thesis. This section relates each of these issues to the discourse on sustainability - the current epicentre of new directions in thinking about our collective fate.

I define sustainability as the intentional care and preservation of human and natural resources necessary to our present and future well-being. ${ }^{5}$ Simply put, sustainability is about how we choose to live as social beings.

An important conviction defining my own perspective on sustainability is that I take human resources to include the wherewithal for developing new technologies. I see technological creation as a profound expression of the human spirit that transcends profit-making and resource acquisition. But I also believe that many of the institutions currently governing technological advance are undemocratic and profit-seeking to the exclusion of being socially and environmentally conscious. Still, my standpoint contrasts with some who cast modern technology as what we need to dismantle on our way to a sustainable society. It is not my intent, however, to discount the positions of technology's critics, which are significantly more complex and less naive than perceived by many technology advocates. Rather, I claim a position on the middle way between those with and without faith in modern technology. These differences in perspectives are addressed further in the discussion on technological choice below.

Sustainability concerns necessarily apply to many societal developments, each with its own logic and attendant discourses. As focussed on production, sustainability analyses have primarily addressed the use of resource efficient and clean production technologies, what is commonly called sustainable production. ${ }^{6}$ This thesis, in contrast, deals with sustainable consumption - the prudent use of resources in meeting needs. ${ }^{7}$

What are called the three pillars of sustainability - environmental quality, social equity, and economic stability - figure to varying degrees in my analysis. Because the immediate subject is the reciprocal changes in production technologies and product market structure, the bulk of the thesis most directly concerns economics. Impacts on social equity and environmental quality are treated mainly as second-order consequences and are discussed in greatest depth in the chapters on sustainability (Chapters 6 and 10). Also, the thesis most directly bears on developments in the highly industrialised countries as this is where advanced manufacturing technologies (AMTs) have their widest application and their greatest effect on consumption levels. ${ }^{8}$ A critical assumption driving the analysis is that achieving sustainability will require the affluent industrialised societies to establish a constant or diminishing level of energy and materials throughput (Daly, 1996; Hinterberger and Meyer-Stamer, 1997; Sachs, 1998).

To be sure, the debate on whether industrial growth is unsustainable is far from over. In response to the critics of growth, more than a few economists have challenged the critics' assumptions in turn. What is valuable about this debate is that it has pushed our understanding of system change closer to the point where we might be able to effect it.

Since Galbraith $(1958,1967)$ and the Club Of Rome (Meadows et al., 1972) our knowledge of what constitutes the limits to growth has greatly expanded. The criticality of environmental services, the natural processes which regulate the eco-system's balance, such as $\mathrm{CO}_{2}$ absorption, is now evident, whereas before the debate had revolved around 
exhausting material supplies and pollution effects. Modelling of the bio-physical constraints has also advanced to the point where, as Christopher Freeman (1992) has said, "The basic environmentalist argument that there are physical limits on this planet to the growth of population and of social artefacts is irrefutable. So too is the argument that if growth were to continue indefinitely on particular materials-intensive, energy-intensive and capital-intensive path, physical limits of resource availability would sooner or later be encountered." (p. 161, emphasis Freeman's)

The critique of the no-growth position is not then whether there are limits to growth but rather whether we have possibilities of intelligent technical change (Freeman, 1992). ${ }^{9}$ In this regard, the application of system's theory to reframing the debate has been one particularly fruitful avenue of research (Norgaard, 1994, Hwang, 1998). Between the opposing standpoints that technology can or cannot overcome the limits to growth, a middle view is emerging in which technological change is understood in terms of adaptability. What matters, in this view, is our ability to guide the direction of technological change. It holds that both technological optimism and pessimism are deterministic in outlook, because they obscure the question of how social/environmental/economic interactions shape our perception of the problems and the possible solutions. From this standpoint, all development models are normative.

(Note, however, that by comparison to the paradigm exploration in this chapter, the development of the model of path dependence in technology use, that forms the core of this thesis, is effectively positive in orientation in that it describes change processes and the specific results thereof, as opposed to looked-for outcomes. ${ }^{10}$ In consequence, the thesis' normative conclusions on adaptability have validity across all companies regardless of their particular goals about growth.)

As defined, sustainability is a more inclusive standard than economic growth. It provides a conceptual framework for assessing well-being that locates the economic system concentrically within the social system, and society within the natural environment (Hinterberger et al., 2000), rather than subordinating social and environmental concerns to economic determinations. This, necessarily, has implications for any analysis of the production/consumption system. First, the economy, the environment, and society are understood to be interdependent forces acting on the state of our well-being. This implies the need for a research approach based on a dynamic systems perspective. ${ }^{11}$ Second, sustainability concerns are not treated as economic externalities or spillovers but as integral to the core socio-economic processes of production and consumption. This means the analysis must make a full valuation of social and environmental services as regards the sustenance of the system. The standard economic fallacy here would be to assume that this valuation can be deduced from economic costs alone, in turn, leading to an unwarranted belief in the existence of technological/economic fixes to problems arising from excessive growth. Third, in addition to the standard economic and engineering criteria of efficiency and productivity, an understanding of the function of flexibility and diversity in healthy systems must enter into the analysis (Schütz, 1999).

In many respects we have just begun the transition to systems thinking. The need is for more inclusive analyses and new approaches to understanding complexity and nonlinearity. We need ways of comprehending interconnectedness. In the context of this thesis, the discussion that follows is the "seed bed" for the development of such an understanding. 


\section{Industrial Growth}

It is often remarked that the forces of globalisation and technological change have combined to intensify competition (The Group of Lisbon, 1995). Certainly, over the past few decades, many countries have aspired to increase their industrial competitiveness through policies designed to accelerate the pace of technological change. Industrial modernisation, which essentially pertains to the computerisation of production, has been a primary focus. ${ }^{12}$

The mission of industrial modernisation programmes is to increase manufacturing competitiveness through assisting the adoption of advanced manufacturing technologies (AMTs) and business practices, particularly by small- and medium-sized enterprises (SMEs), although the programmes also do much to help large companies by rationalising their supply chains. In Europe, these services are now mainly provided by the European Commission-sponsored innovation relay centres and in the U.S. through the manufacturing extension network. The start of the U.S. national network dates to 1993, whereas Japan and some of the European countries offered modernisation services as early as the 1970s. Still, modernisation programmes are a relatively new element in the scheme of global competition.

As these services have matured, interest has grown in making service delivery less of an art and more systematic in its approach. This naturally focuses attention on which factors distinguish technology adopters from non-adopters as a way of determining which firms to target for services. Such an analysis quickly reveals the complexity of the technology adoption process. For one thing, studies show that technology adoption does not automatically lead to better company performance (Beaumont and Schroder, 1997; Rischel and Burns, 1997; Swamidass and Kotha, 1998). How a company uses a technology for strategic purposes will make a big difference in the benefits it realises.

In point of fact, in stating the case for industrial modernisation services before a U.S. congressional committee, Harvard Business School Professor Ramchandran Jaikumar (1987) pointed out the wide gaps in different countries' technological proficiency when it comes to using technologies for new ends. At that time, for example, although both Japanese and U.S. manufacturers were using equivalent AMTs, the Japanese firms introduced, on average, 22 times more new parts per year than their U.S. counterparts, while simultaneously out-producing U.S. firms at 120 to 88 parts per day (Jaikumar, 1986). This performance gap stemmed from a difference in the use of the AMTs. While U.S. manufacturers were focussed on using the equipment for precision machining, Japanese firms were using AMTs to extend product variety (Mazzoleni, 1997). The Japanese, of course, won considerable market share with their strategy, precipitating a world-wide shift in manufacturing practices (Womack et al., 1991).

Use patterns, then, influence the outcomes of adoption. Moreover, the companies most likely to adopt additional AMTs are those that have profited from them in the past (Kelley and Helper, 1997). Thus, rapid technology diffusion is not just a matter of removing the barriers to adoption (e.g., the lack of information on new technologies), as was thought in the earliest days of industrial modernisation services. Instead, technology adoption appears to be bound up with company practices, that is, there is an internal company dynamic that facilitates adoption. 
Many industrial modernisation practitioners believe it is the company's growth that is the decisive factor. ${ }^{13}$ In their observation, company growth spurs competitive behaviour, including AMT adoption. Growth then is not just the goal of competition but integral to the competitive posture itself.

A story from my own experience of working with companies illustrates this dynamic. One of these made high-end manufactured housing that featured crafts-style joinery, the kind of home that might adorn the pages of a glossy lifestyles magazine. The company's employees considered themselves artisans and took great pride in their work and the company enjoyed a steady growth in sales. Over time though, the company's success in establishing a profitable niche market resulted in a growing number of competitors, many of them companies established by ex-employees. To counter this competition, the company sought to lower its costs with the purchase of a very sophisticated programmable machine capable of churning out the many one-offs (single unique pieces) used in customising its product. In turn, to recoup their high capital investment and achieve their cost goals, the company had to pump up the volume of sales. In effect, the company needed to grow in order to make their investment pay off. The product line now includes do-it-yourself pergolas and garden sheds. The five artisans displaced by the machine were offered jobs as sales representatives.

As this story makes clear, the relation of technology adoption to growth is complex. It's not certain what is cause and what is effect. Confronting this same issue, modernisation programmes have tried to sort out their missions relative to their mandates. Is the object to help those companies that lag behind? Or is it to optimise service effectiveness by targeting growth-oriented companies? Should services be concentrated in cities, where most companies are, or in small towns, where the jobs are needed? And, should services aim first at increasing a company's innovative capacity or its productivity (Luria, 1997)? There are no clear or easy answers.

Donella Meadows, the lead author of The Limits to Growth (1972), the Club of Rome study that awakened the public to the danger of increasing resource consumption, once told a joke in her syndicated column, the Global Citizen, where two guys are sitting in the woods when a bear comes crashing into their camp site (Meadows, 2000). One of them starts putting on his running shoes. The other says, "Are you crazy? You'll never outrun that bear." The first replies, "I don't have to. I just have to outrun you."

Meadows goes on to show how this joke, (whose poor taste she acknowledges), captures the dilemma of technological competitiveness. To take, as one example, the forest products industry. The industry's capacity far exceeds the available supply of trees, yet, "Folks who know the industry well were saying, in effect, that the mills expand because they have to, to adopt new labour-saving and wood-saving technology, to cut costs, to underbid each other in the marketplace." The same problem exists for U.S. corn farmers, whose yields are the "envy of the world". They "will do or buy just about anything that will help them grow more corn. Fertiliser, herbicide, pesticide, gene-spliced seed, newfangled tractor, more land, whatever boosts output, they go for it. They also know - it's amazing to hear every blessed one of them say it - that as they put more corn on the market, the price of corn goes down, down, down. The more corn they grow, the lower the price, the more they have to grow, just to make the same income. ... Each one knows that if he's the first to adopt the new technology, his yield gets a bit ahead of the others, and he survives. If he doesn't, his is the next farm on the auction block." 
In sum, Meadows writes, we "have created an economy that keeps our most basic and necessary producers on the edge of ruin, living in fear, preying on each other, wasting financial, human, social, and natural assets at an enormous rate." She concludes her thought piece by asking whether it might not be better to go after the bear instead (Meadows, 2000). ${ }^{14}$

On a more dispassionate note, falling rates of return on capital are what an economist would predict as the outcome of growth through technological innovation (Nelson, 1995). But where the economist assumes growth is a benefit, others see social and environmental costs. The story line depends on the perspective. The terms of the equation can be rearranged to suit the argument.

Many modernisation programmes have implemented services to improve manufacturers' resource efficiency and their environmental management practices. But, missing from the U.S. policy discussion on modernisation, is any consideration of how industrial growth, in and of itself, harms the environment and what should be done about it. The European approach to competitiveness has been far more advanced on the question of environmentally responsible resource use, but there is also a decided reluctance to challenge the growth paradigm (Global Action Plan International, 2001; United Nations Commission on Sustainable Development, 2002). Why is this?

It is fairly certain we have reached a crossroads on deciding the environment's fate. The most serious environmental challenges we face today - global warming, disruption of the global nitrogen cycle, loss of bio-diversity - concern the scale and intensity of human activities. However, despite considerable gains in resource efficiency, per capita materials and energy consumption continues to grow or hold steady in the highly industrialised countries (World Resources Institute, 2000).

Moreover, many companies, I think, are aware of the trap in "growing to compete" and would like out. Yet, they feel they have no choice but to put more product onto the markets. Possibly high value-added production is an answer, as industrial modernisation policy is wont to suggest. However, this has been the strategy in the highly industrialised countries for some decades.

A broader societal and environmental perspective suggests that the long-term solution lies in a better understanding of how the means are connected to the end. Analysis would go beyond economic growth as the sole measure of well-being and contribute to an understanding of how technological change and industrial growth affects our prospects for realising sustainability. A humane worldview would challenge the dominance of the industrial growth paradigm.

Many European countries are now beginning to develop such an approach. The Japanese are also consciously deliberating growth's ecological and social consequences, (see, for example, Hitomi, 1996 and 1997). ${ }^{15}$ Hiroyuki Yoshikawa, the President of Tokyo University and former Dean of the Faculty of Engineering at the same university, has come closest to exposing the dilemma of industrial growth brought on through the evolution of production technologies. He is also uniquely situated to comment as the genitor of the Intelligent Manufacturing System (IMS) project, an industry-led, international research and development (R\&D) program established to develop the next generation of manufacturing and processing technologies. Yoshikawa (1995) has put the problem in this way: "Productive activities have brought affluence to mankind, yet at the same time they have also led to a deluge of artificially produced items and have acted as a large de- 
stabilising force on the ecosystem." (pp. 204-205) Yoshikawa believes that these "artificially produced items" are the result of excessive competition leading to superficial differentiation and manufacturer-induced wants that are not "real".

That meeting needs is not solely a question of more goods and services bears strongly on what are choices are and how we go about making those choices.

\section{Sufficiency}

The problem of meeting needs with scarce resources lies at the heart of economics. Throughout most of history this problem has been associated with underproduction. With industrialisation, the problem appears in a new form as overproduction or - from a different perspective - underconsumption (Princen, 1999). Presently, the highly industrialised countries produce enough to meet their basic material needs many times over, yet consumption of material goods hasn't stopped there. Instead, it continues to rise. Slowly, awareness of the problem as one of overconsumption is beginning to take hold. ${ }^{16}$

Each of these conditions, from underproduction to overconsumption, represents an imbalance in production and consumption relative to needs and resources. Overconsumption places a particular burden on environmental resources: we are exceeding the limits of the environment's ability to replenish itself and its capacity to absorb wastes. With respect to needs, overconsumption occurs at both ends of the development scale, but for different reasons. In resource poor economies, overconsumption results from having to overuse what resources are available; in the highly industrialised countries, overconsumption is characterised by waste and surfeit.

As a political situation, however, it is more often the uneven distribution of goods and resources, not imbalances in production and consumption, that fires the current debate on overconsumption. After all, from the standpoint of technological feasibility, the means exist to dispel material want throughout the world. But while the modern industrial system has led to incredible gains in material wealth, the vast majority continue to suffer extreme deprivations. As Sen (1981) showed, for example, it is not a shortage of food alone that causes famines, but also differences in opportunities afforded by the economic system. In this view, poverty persists as a matter of where we put our resources to use.

This thesis takes the position that the problem of unequal, socially unjust resource distribution is firmly linked to imbalances in the production and consumption of goods. Why this is so, coincident to recent directions in the strategic use of production technologies, is the focus of inquiry. As regards the problem of overconsumption, attention is directed at the scale and speed of production as a proximal cause of imbalance. In this respect, the organisation of production is a critical, if under-considered, factor in the current research on sustainability. ${ }^{17}$ The interest here is to understand this link in the context of other influences.

This problem of aligning production and consumption in meeting needs has engendered different solutions over time. Following the Great Depression and World War II, the imbalance in production and consumption found a new solution in public sector policies to stimulate demand and private sector expenditures on advertising. The shifts in policy and business strategy coupled to the post-war pent-up demand for consumer goods quickly led to an astonishing growth rate, but also to the emergence of what its critics de- 
cried as the "consumer society" (Leuchtenburg, 1983). Whether, in fact, the consumer society represented a new stage in materialism for those that could afford it, many more belonged to this class than had in previous generations. Moreover, modern advertising made its impact. Besides promoting a particular company's product, ads also were intended to instil a "psychology of consumption". Under this influence, pre-war values originating in the experience of scarcity, such as frugality and self-denial, were superseded by a sensitisation to the expectations of others (Frank, 1997). The child was made to feel guilty, not so much by violating inner standards, as by a failure to be popular and popularity was linked through advertising to what you owned.

This psychology has evolved to the point where often our immediate sense of self derives from what we own or consume. Very few of us, it seems, are immune to this influence. ${ }^{18}$ Philosopher Albert Borgmann (1995) has written that as consumption replaces practice, we move from "a life of engagement that is oriented within the physical and social world" to "a life of distraction that is isolated from the environment and other people" (p. 92). In affluent societies, product consumption for the sake of psychological needs that can't be satisfied by more consuming is common behaviour (Vlek et al., 2000) and even a psychological disorder. Oniomania is the term for addiction to shopping. According to a recent newspaper story, one-fourth of teenage girls in Italy and France are said to suffer from it. In Britain, there are an estimated 2.5 million compulsive shoppers (Insley, 1999).

Theoretically, in economics, saturation of the markets sets the upper bound on consumption. But just as technological innovation seemingly addresses the problem of scarcity of resources, it also looks to have removed the ceiling on consumption, or such is my observation and a direction of inquiry in this research.

Undoubtedly, those of us who can afford it exceed the limits of what we need at some time or other. Yet, at some level, we have a sense of what is reasonable. Still, our needs are not our neighbour's. Consider this man's dilemma: "Not that I didn't have a backpack at home. I have three. But I wanted something that could be converted into a sophisticated travel bag for a two-day stopover in London on my way back from India.... But other than the good price, I really only cared about one thing: it was black. Black is very London." (Morris, 1998) Most of us, I hope, could resist a fourth backpack. But what happens when you substitute backpack for kitchen gadget, book, pair of shoes, bowling ball, or whatever product it is that suits your particular want? And do we really need so many vacuum cleaners? According to a Wall Street Journal article, the average American household has three or more (Ansberry, 1999).

A growing number of folks are consciously choosing not to consume more. Many identify with the responsible consumption (aka voluntary simplicity or sustainable lifestyle) movement which aims to reduce consumerist dependencies. Academic researchers have joined in by challenging the bases of lifestyles that lead to increased consumption (see, for example, Schor, 1998). But, since decreased consumption means a quantitative decrease in production, the success of these efforts may well hinge on whether individuals, by assuming responsibility for personal consumption habits, can effect a change in the organisation of production as well. This is likely to be more of a challenge than currently guessed at by those in the responsible consumption movement for reasons I argue later in this thesis. 
Moreover, determining the amount of consumption that is sufficient to one's needs turns out to be a difficult proposition. For one thing, consumption is embedded in our everyday lives, such that decisions on how much to consume are entangled with other priorities (Røpke, 1999). For example, many people are motivated to buy cell phones for reasons of safety, but then use them in an unsafe manner when driving their cars. Another complication is that the material embodied in the physical product is only a small fraction - about 2 to $6 \%$ - of the material consumed in bringing the product to market. We tend to discount costs of which we have no direct experience. ${ }^{19}$ We are also regularly reminded of the consequences of slow growth for our standard of living and jobs. We are urged to buy more to keep the economy intact.

On their part, producers claim that they are only giving consumers what they want, that to survive they have to be responsive to consumer demand. ${ }^{20}$ This may indeed be the situation of the individual manufacturer (given current strategies) but it begs the question of what are real needs are. ${ }^{21}$

With the rise of mass customisation - the manufacture of highly individualised product on a volume basis - comes the current excess in individualised consumption. According to The Economist (see photo), this is our future. But, from a sustainability standpoint, "Keeping the customer satisfied" appears to be about keeping the customer buying more.

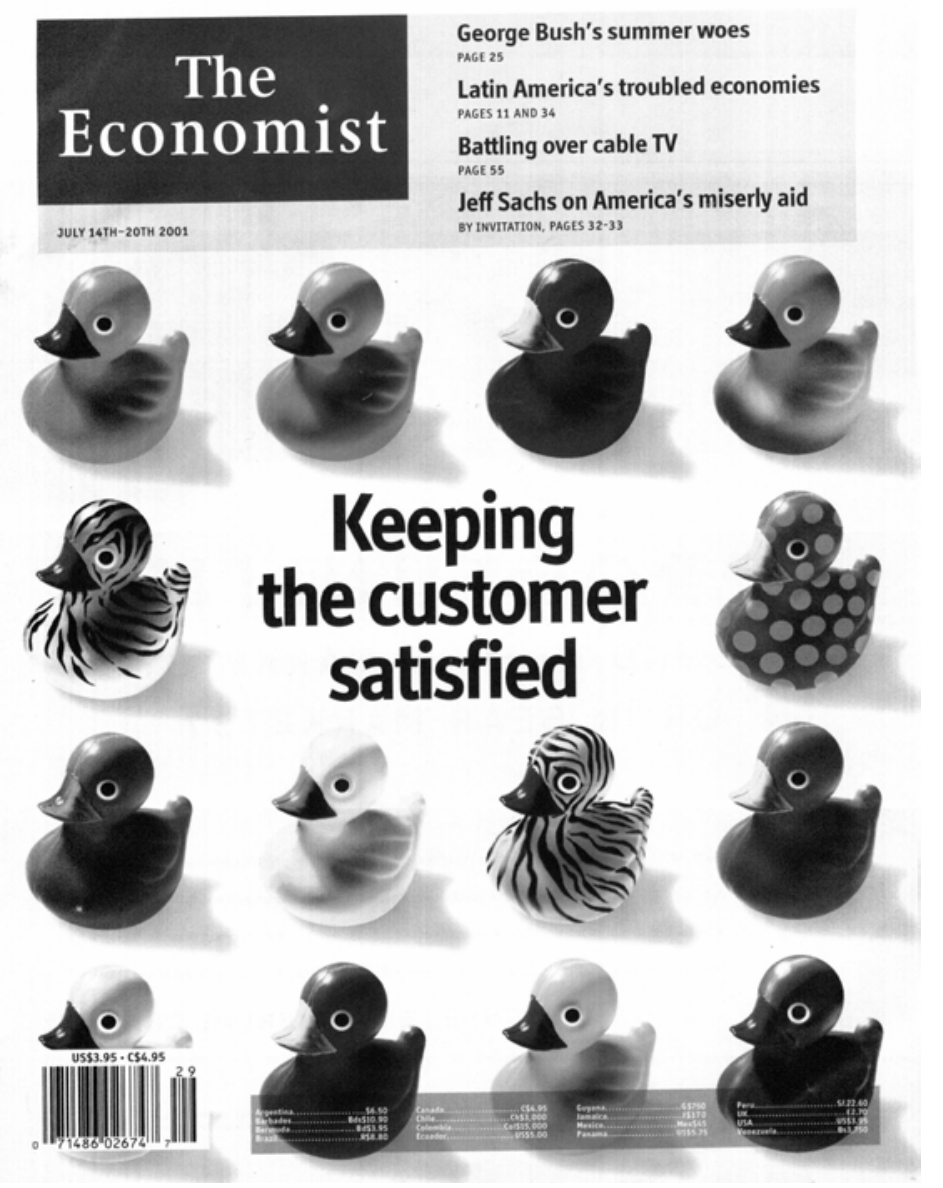

The Economist's 14 July 2001 issue featured mass customisation as the cover story. An interesting psychology presents itself in this photograph. Are the consumer's needs satisfied by buying the one duck that appeals most? Or is there now a need to have more than one duck (maybe all of them), because what appeals is their variation? 
The problem and the opportunity is that we are more than consumers, yet we live in societies that require little more of us. The ideal of sufficiency - having/taking enough, yet no more - has been offered as a way of living joyfully within limits (Meadows, 2001). Yet choosing to live with less materially requires a fundamental change in our worldview. Today industrial growth seems to have a momentum of its own, predicated on technological change, impervious to any reasoning that suggests limits. Before us is the choice of what uses we put our technologies to, but must technological change always be in the service of growth?

\section{Technology Choice}

Choices imply trade-offs. The dilemma of making choices that balance immediate competitive requirements with long-term business objectives is one that companies confront routinely.

To take, as one example, a company that consulted with the manufacturing extension centre I directed. ${ }^{22}$ This company was started with the idea of creating demand for a relatively low-value post-consumer recycled material as a source of locally processed, highquality material. The strategy was meant to overcome the disadvantage of transportation adding to the cost of the materials. Smaller communities will often choose not to recycle if they are located too far from a processor. Ideas about mini-mills and closed-loop local economies were at that time gaining currency and newly available processing technologies had the potential to make the operation viable. But faced with the challenge of a small market, the company decided to move from the mid-sized community in which it started operations to the big city in order to improve its economies of scale.

The question of why we haven't been able to envision a seemingly viable alternative to the industrial growth society is a disturbing one. There is a history of movements espousing ecologically sound, locally controlled, small-scale, humane technologies, that have largely failed to change the status quo. Winner (1986) claims that political naiveté undermines their populism. Alternative technology advocates tend to assume that radical change will catch on like disposable diapers or some other popular consumer item. ${ }^{23} \mathrm{He}$ also points out how difficult it is to counter pro-technology beliefs with scepticism, since only technical arguments count with technology advocates. Perhaps most disquieting is Winner's supposition that we have become inured to the perversities of technological "progress": half of the world goes without clean water while the United States proposes billions for the development of technologically dubious, but ultra-sophisticated, star wars missile defence systems; the Kyoto protocol on climate change is abandoned or watered down on the grounds that it will slow the economy, yet all predictions indicate that the costs to repair the damage will be magnitudes greater than the costs of prevention. Under such conditions, the pressure on the individual is to be realistic, to "get on with it", to ignore the pain - indeed, to do anything else is foolish and wasted effort.

It's not my object here to argue here that attempting change is futile. The commitment and persistence of a great many social and environmental activists suggests otherwise. Many believe we are at a turning point where a sustainable future is in sight. Still - how do we get there? The answers to this most critical question are only beginning to emerge. My concern is that we develop the ability to transform the system. To this end, Winner's and others' analyses of the socio-political barriers to change need on-going consideration, but we also need to comprehend the technological and material bases of the system. The 
introduction to Albert Borgmann's (1995) essay on the moral significance of material culture is worth quoting at length for its relevance to this need. (One can substitute economics and economists for philosophy and philosophers in this passage with great effect.)

"Modern philosophy has been at two removes from the real world. First, in aspiring to theory, it has distanced itself from practice. Theory can inform practice, but practice is richer than theory, and above all, self-sustaining. Practice can survive without theory while theory arises from a practice and perishes without the nourishment of a practice. Practice, as philosophers have always seen it, is in turn removed from its tangible setting. Yet material culture constrains and details practice decisively. Practice, abstracted from its tangible circumstances, is reduced to gesturing and sometimes posturing."

My experience confirms the primacy of the material world. Though we pretend to unlimited technological choice, the reality, if not technological determinism, is certainly limited technological agency. Firms seeking to change their ways of doing business to more environmentally friendly and socially just purposes come up against basic issues staying competitive, the availability of alternative technologies, the lack of resources that limit their choices. But even more fundamentally, firms' choices are constrained by the direction of technological advance that is materially embedded in the production/ consumption system.

The technologies which have the greatest chance of survival are those which tend to conserve/entrench existing market relations and existing firm competencies (Abernathy and Clark, 1985). Under these conditions, the fact that environmental responsibility and social justice have no strategic value as technological properties per se circumscribes their potential to drive system transformation. To put it another way, environmental friendliness and social justice are just market needs, (and niche markets at that), not conditions of production, like scale and speed.

Still, the possibility of radical change exists. We are in the midst of one such transformation now with the succession of mass production by mass customisation. Such transformations are achieved by coupling firm incentives to the means of appropriating a return on technological opportunity (Dosi, 1988), that is, by "bring[ing] technological opportunities into line with the potentialities of market" (Morroni, 1992, p 22). To wit, transformation is the province and provenance of strategy and the trade-offs we are willing to make (Wenk, 1986).

Choice is then a matter of exercising technological agency. It is a practice that involves the use of technologies for new purposes. It is linking change in the material world, technological change, to the way we want to live. It is conscious adaptability. Through strategic choices, experiments, and experience, we can create technological momentum towards sustainability.

One of the most widely believed myths about the existing paradigm is that all that counts in business is the bottom line. My experience in working with numerous companies tells me differently. Many firms are satisfied with a reasonable rate of return - sufficient profitability, if you will - if they are also able to achieve other goals: to sustain the communities to which they belong, to become environmental stewards, to give the people that work for them opportunities for development, to make a socially beneficial product as widely available as possible. These other goals are often what defines the 
company. They are inspired, and inspire, through the practice of values that go beyond the bottom line. Yet, to realise these goals is often a struggle - the momentum lies in another direction. This inquiry is about the possibilities of changing direction.

\subsection{The Direction of Research}

This thesis concerns the strategic uses of advanced manufacturing technologies in relation to the organisation of production and evolving consumption patterns. From the definition of sustainability as the care and preservation of resources necessary to humanity's well-being, it follows that the organisation of production, as a key determinant of market structure, must be central to any consideration of how to realise a sustainable future. More specifically, the question posed in this thesis is how to create technological momentum in the direction of reducing the speed and scale of resource consumption.

The substantive approach to this inquiry links speed, scale, and sustainability by means of a model describing how firms adapt to technological change, the application of this model to the analysis of current AMT use, and an analysis of product market changes. Figure 1.1 relates the textual interrelation of these elements.

Figure 1.1 The Co-Evolutionary Process

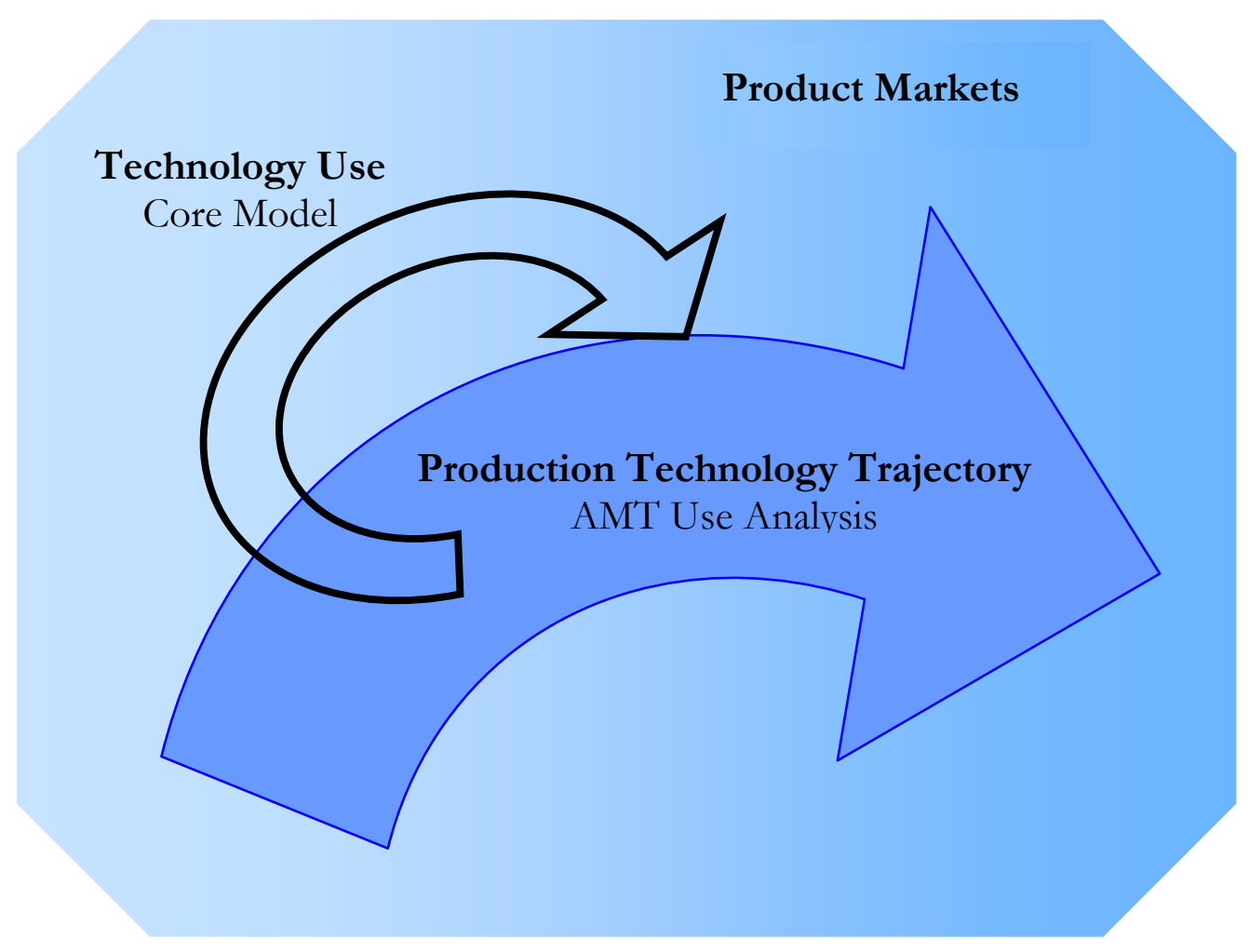

The figure conveys that production technologies and product markets co-evolve. This process works to channel production technology development along developed pathways according to firms' past success in adapting to market needs through technology use. As experience in the use of new technologies accumulates, distinctive patterns in market organisation emerge, which in turn cause more firms to adopt these technologies. In effect, 
new production technologies open the way for firms to exploit market opportunities in new ways, changing consumption patterns in the process.

Figure 1.2 shows the interrelation of the methods and analysis that guided the thesis research. The nested boxes in the figure signify a gradation in the level of analysis from the micro-level study of firm behaviour, through a meso-level analysis of industry conditions, to an assessment of sustainability at the macro-level. While the thesis does not strictly apply a systems analytic, there is a decided focus on interpreting system relationships. Following the definition of a system as a set of components and forces interacting among themselves and with an environment to produce some characteristic holistic behaviour that is often self-regulating and/or adaptive, a systems orientation implies methodologies amenable to dynamics, non-linearity and a substantial number of variables.

The general research sequence is described in the figure in two cycles, the first utilising qualitative methods (literature survey and interviews) and the second a combination of qualitative and quantitative methods (roadmaps content analysis and industry survey).

Figure 1.2 Research Structure

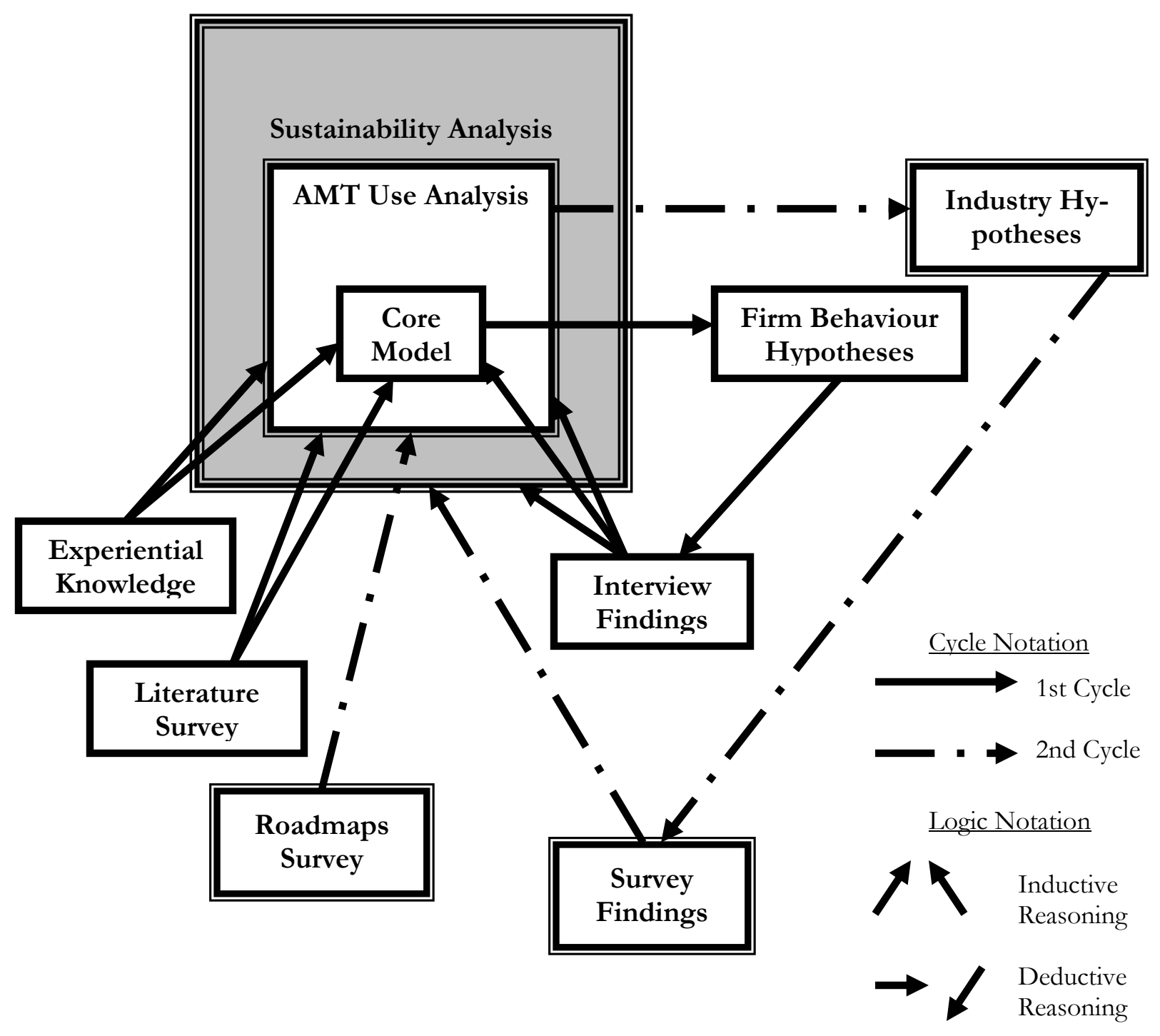


The first cycle begins with the development of a core model based on my own experiential knowledge in technology planning and previous research on manufacturing strategy. From this, hypotheses on firm behaviour as regards the organisation of production are drawn. Data on firm behaviour are then collected in interviews and used in the model's validation by comparison to the hypotheses. This cycle is primarily characterised by the use of qualitative methods based on searching for patterns in the relationships under study (Neuman, 1997).

The second research cycle involves the application of the core model to an analysis of current AMT use. This phase of the research draws on the content analysis of technology roadmap documents and foresight studies describing the direction of manufacturing technologies development. (Technology roadmaps and foresight analyses represent a consensus view of an industry's stakeholders on desirable directions for future technology development. The particular construction and intent of roadmaps opens their interpretations of technology use to systematic analysis.) Findings from the interviews are also used to inform the analysis of AMT use. In turn, the trajectory analysis forms the basis for a set of hypotheses on the strategic use of AMTs. Statistical analyses of industry survey data are conducted to test these hypotheses.

The end point of the research cycles is the synthesis of the core model and the analysis of AMT use patterns in the sustainability analysis.

Figure 1.3 on page 15 shows the embodiment of the research approach in the thesis' structure. ${ }^{24}$ By chapter, the research objectives are:

- To review the literature on the organisation of production and manufacturing strategy. (Chapter 2)

- To present a model of technological change which explains the interaction of product market development and the strategic use of manufacturing technologies. (Chapter 3)

- To describe the direction of development in advanced manufacturing technologies (AMTs) and the associated trade-offs. (Chapter 4)

- To examine why firms adopt strategies based on reducing the time it takes to develop and manufacture products. (Chapter 5)

- To analyse the impacts of current directions in the strategic use of AMTs on consumption patterns and sustainability. (Chapters 6)

- To present evidence, gathered in a series of interviews with technology users, suppliers, and service providers, on the core model's exposition of the role of manufacturing strategy in firms' adaptation to change. (Chapter 7)

- To present industry survey findings on the linkages between changing product market conditions and the strategic use of AMTs. (Chapter 8)

- To examine the evidence for AMT-related trade-offs. (Chapter 9)

- To present a policy analysis of the problem of over-consumption in the highly industrialised economies as it is linked to the increasing pace and scale of industrial activities. (Chapter 10)

- To consider the possibilities for creating technological momentum towards sustainability. (Chapter 11) 
Figure 1.3 Thesis Structure

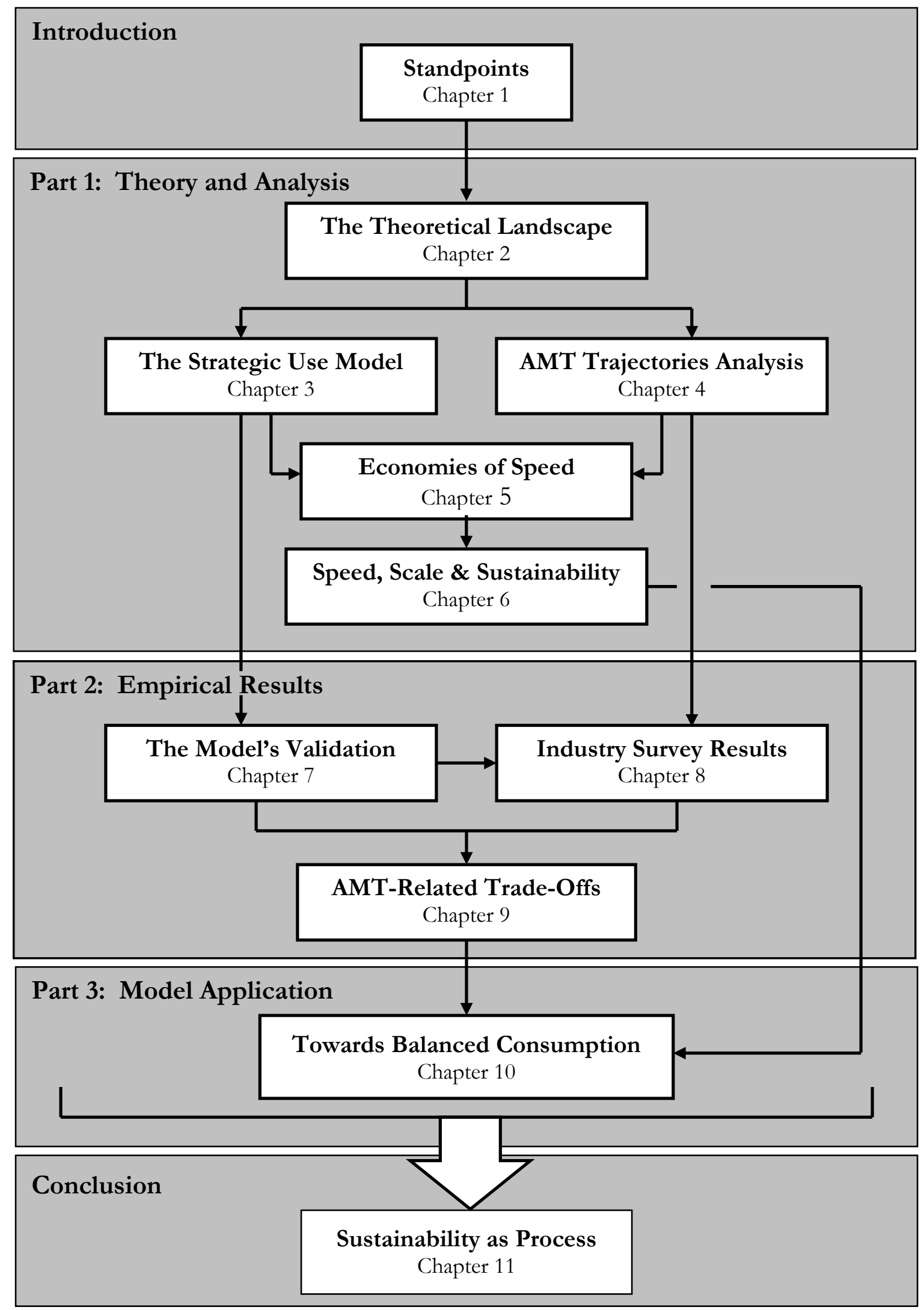




\section{Chapter 1 End Notes}

1 See Almond et al. (1982) and Winner (1986) for scrutiny of both advocates and critics of economic/technological progress.

2 As I write this introductory chapter, the drama over the rolling energy blackouts in California is playing in the media. One rarely mentioned factor in the so-called crisis is the hefty rise in average residential use rates - 5\% from 1995 to 1998 (California Energy Commission, 2000). Meanwhile, President Bush of the United States has rationalised his rejection of the Kyoto treaty on climate change on the grounds that consuming as much energy as they like is the right of every American and part of the American way of life, to which one European protestor responded, "The earth is our mother, not your supermarket." Current polls also show most Americans favouring energy conservation over the development of new fossil fuel supplies (Berke and Elder, 2001).

3 By the same token, this chapter does not purport to make arguments a propos the thesis' conclusions.

4 Accordingly, identifying the inquirer's social location, that is, her perspective, strengthens the objectivity of the inquiry (Harding, 1991). Likewise, the methods used to examine a phenomenon have bearing on the framing of the research questions and the interpretation of the evidence (Alford, 1998).

5 This definition is adapted from one by the World Resources Institute (http://www.wri.org).

6 See, for example, the International Institute for Sustainable Development's (IISD) web site on business and sustainable development (http://iisd...ca/).

7 There are but a handful of books and articles that explicitly address the evolution in computerised production technologies in relation to changing consumption patterns. Even among these, the AMT/consumption nexus is not a primary focus, with the exception of Yoshikawa's (1995) and Kidd's (1997) papers. The other works include those by Piore and Sabel (1984), Harvey (1990), Freeman (1992), SustainAbility (1995); and Hitomi (1996, 1997). In addition, the Factor Four/Ten literature (see, for example, Weizächer et al., 1998) makes the linkage between sustainable production and consumption. However, the thrust in this literature is doing "more with less", that is, resource efficiency. As I shall argue further on, the danger in the current scale of resource consumption cannot be addressed through resource efficiency alone.

8 A brief note on terminology is warranted here. I chose to use the expression "highly industrialised countries" over "advanced industrialised countries" because of the presumption of superiority suggested by the word advanced. Another way to describe these countries is "the North and West". This phrase, however, carries historical and political implications that are not covered in the thesis.

9 One of the key questions in this regard is the possibility of substituting manufactured for natural capital. Another is the possibility of dematerialization through technological progress. Both of these questions are discussed in detail in Chapter 6.

10 The normative implications of the model for competitiveness and sustainability are taken up in Chapters 5 and 6. The model itself is described in Chapter 3 and a description of the direction of AMT development in the model's terms is provided in Chapter 4. The middle section of the thesis, Chapters 7 through 9, is concerned primarily with the validation of model (the hypotheses are drawn from the exposition in Chapters 3 and 4) but also touch on the model's implications.

11 It also implies that the analysis will include a substantial number of variables.

12 From 1988 to 1997, the focus of my professional work was industrial modernisation, first as a student researching technology policy, then as a practitioner responsible for the design and implementation of technology extension services.

13 The phrase I have heard used by my industrial modernisation colleagues, "growing to compete", signals the emergence of this new understanding of what is essential to competitiveness.

14 In addition to her path-breaking research, Meadows was one of the rare few who practise their ideals. She taught systems theory at Dartmouth College, wrote for both the academic and popular presses, was an organic farmer, and lived in communal housing. She founded the Sustainability Institute, a think-do tank, to carry out systems research and experimentation in more sustainable ways to work, 
produce, and live. She died quite unexpectedly in 2001 from a chance illness. Her life and work was commemorated in 2001 Earth Day celebrations around the world.

15 Japan's current state of no growth results from weak demand in their domestic markets. Their situation constitutes a strong argument that the industrial system would not automatically adjust to reductions in consumer demand as some sustainable consumption advocates would have it.

16 Agenda 21, adopted in 1992 at the United Nations Conference on Environment and Development (UNCED, Rio de Janeiro, 1992), is commonly held to be the landmark policy document exemplifying this view. The document stressed governments' obligations to advance sustainable consumption and production. Since Rio, there has been a fair amount of activity by governments, business, environmental organisations and others to understand the scope of this challenge. Within the research community, unsustainable consumption patterns in the North have been accepted as one of the key problems in the transition to sustainability. However, in policy and business circles, "Reduction of consumption is resisted and is often seen to threaten lifestyles, competitiveness, and profitability." (United Nations Commission on Sustainable Development, p. 9). This has contributed to a tremendous "implementation gap" as reported at the World Summit on Sustainable Development, the ten year follow-up to Rio. Current approaches to addressing sustainable consumption are deemed, "too narrow and linear and system innovations are required that pursue changes and transformations that combine societal, institutional, and technological changes." (ibid., p. 10)

17 Interestingly, it is just this factor Kropotkin (1899) addressed in his work.

18 Helena Norberge-Hodge (1991) in her study of the Ladakh shows how tourism, Western media images, and development schemes led to disenchantment with their material situation among Ladahkis, especially the young. In exchange for the promise of a Western lifestyle, but without knowledge of its costs, and despite a strong communal culture, they traded happiness, satisfaction, resourcefulness, and the wealth of their traditional arts for the meanness and spiritual impoverishment that was the outcome of development.

19 Even conscious attempts at "living lightly" can be challenging. Recently, I tried to calculate when I should replace my water heater, taking into account its age and the associated loss in efficiency versus the energy consumption improvements I might get from a new water heater. A friend had told me that you used to be able to buy water heaters that lasted twenty years. Nowadays, the standard life is eight to twelve. Even if I had been able to find a heater that could last twenty years, I didn't have the information to be able to calculate what the material and energy savings would be from replacing it half as often.

20 Galbraith (1985), for one, has challenged this claim. "The great corporations ... sought the control, perhaps more precisely the predictability, not alone of prices but of all major factors bearing on their operations - of costs, labour supply, government action or intervention, and perhaps most important of all, consumer or other buyer response." (p. xvii-xviii) He continues, "Were it part of the producer design to ensure consumer acceptance of the product, it then followed that the consumer was less than sovereign. The consumer was, in some degree, the instrument of the producer." (pp. xviixviii). As consumer sovereignty is a necessary concept for economic equilibrium, in retrospect it is not surprising that other economists' rejection of Galbraith's thesis of a new industrial state was most vehement around this point.

21 We might also ask whether we should wait to address the problem of industrial growth until we all agree that there is a problem.

22 For four years in the mid-1990's, I had the privilege of working with a diverse mix of companies, small and large, learning to use recycled materials in product manufacture. The thrust of my work was to assist companies in validating product and process technologies that would increase the value of recycled materials. The programme for this effort, the Recycling Technology Assistance Partnership (ReTAP), was supported by the United States National Institute of Standards and Technology (NIST) and the Environmental Protection Agency (EPA). The programme, which I designed and implemented, offered customised, applied engineering services and disseminated information on recycling technology through a national network of technology sources and service providers. ReTAP issued over eighty technical reports, (more than all other programmes in the U.S. combined), including a se- 
ries of best practice manuals containing the technical know-how required to optimise the production and use of post-consumer glass, wood, plastic, and tyre materials.

23 This is highly symptomatic of the eco-efficiency proponents. See White (2000) for a critical examination of this position.

24 The core concepts of technological change and sustainability recur throughout the thesis but are discussed in detail in Chapters 3 and 6 respectively. 


\section{Chapter 2 The Theoretical Landscape}

Cash payment is not the sole nexus of man with man.

Thomas Carlyle: Past and Present

Nicholas Georgescu-Roegen (1970) claimed that the factory system deserved to be placed side by side with money as one of the two most fateful economic innovations due to a unique property - namely, the ability to arrange processes for the purpose of eliminating idleness in production. This assertion seems more acute than ever considering that the substantial economic growth of recent decades stems from the application of information technologies (ITs) to intensifying productive resource use.

This thesis argues that the organisation of production is equally fateful for our ability to realise sustainability and thus deserves our utmost attention. Beginning with a survey of current theory on the organisation of production, we arrive, over the course of the thesis, at a position corresponding to this argument. In this effort, it is useful to remember that socio-economic changes resulting from the diffusion of ITs have not yet made their full imprint on theory. Not surprisingly, this influence tends to work its way up the chain of abstraction. Those disciplines that deal most closely with the substantive content of these changes, e.g. engineering and production economics, have most fully incorporated their explanation into the disciplines' respective models. Those farther removed from the source of these changes - if not their impacts - more often use mass production as their reference point. Perhaps the most neglected aspect of recent changes in the organisation of production is their impact on consumption. In response, this thesis offers a theory of technological change that explains the interdependency of market demand and the strategic use of advanced manufacturing technologies (AMTs).

Figure 2.1, The Theoretical Landscape, gives a sense of the relative importance of various theoretical discourses to this analysis. The "view" of the valley's central landscape feature, the organisation of production, is from the "vantage point" of an evolutionary economics framework, but its source is found in management science theory, particularly the manufacturing strategy models based on operations and engineering management research. Adding to the picture is the resource-based view of the firm, in the "foothills" of neo-classical economics. Neo-classical economics constructs, as a whole, are more distant to the development of the thesis, but production economics is a main feature of the analysis. In the later stages of the analysis, ecological economics and systems theory contribute to our observation. 


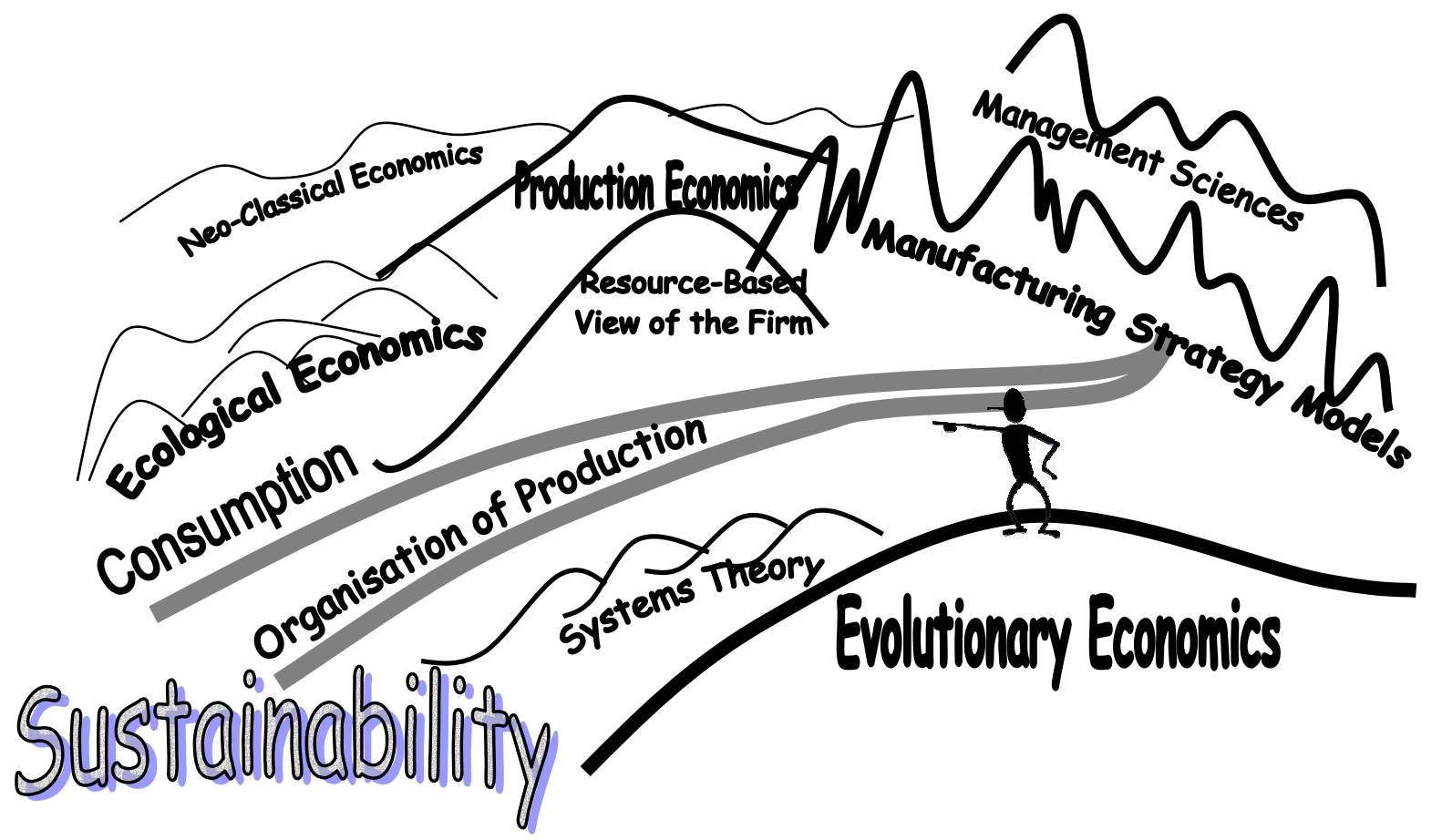

\subsection{Production System Models}

Explanations of the organisation of production are scattered throughout the engineering, economics and operations management literature, yet no central theory can be said to prevail by which to measure progress towards sustainability. This is not to say that there haven't been substantial writings on the relationship of sustainability to different socioeconomic organisational models (e.g., mass production and post-industrial production). Rather, these works often lack detailed and systematic observation of the production system itself, in the tradition of, say, Kropotkin (1899) or Marx (1939).

The approach to theory development within this thesis is grounded in such observation with good reason. The thesis maintains that there is a reciprocal influence between the socio-economic systems we call markets and the organisation of production. We are interested in how technological change shapes the organisation of production and hence market development. To construct such a theory we need a factual representation of the production system itself.

The term "production system" is used variously throughout the thesis to describe several different levels of organisation, from the ordering of processes in the plant to the supply of goods and services in the economy as a whole. In referring to the firm's production system, either the context of the discussion is explicit or the term is prefaced by a possessive indicating the firm. At the meso-level, the term denotes the dominant mode of process organization within an industry or sector. ${ }^{1}$ Finally, the conjunction, "the production and consumption system", refers to the socio-economic organisation of production and consumption at the macro level. Alternatively, "manufacturing system" always refers to plant-level processes. 
These multiple uses of the term production system reflect the concepts of system functional hierarchy and systems within systems. To take one example, Morroni's (1992) analytical scheme is nested with four levels. By "method of production" he is concerned with:

1. Technical conditions within a specific system;

2. A specific way of organising the production elements (e.g., Taylorism, neo-Fordism, project organisation, lean production);

3. A specific industrial organisational model (e.g., mass production, large-scale flexible production, small-scale flexible production, traditional artisan production); and

4. A specific socio-juridical form called mode of production (e.g., fuedal, capitalist, collectivist production).

This functional ordering suggests a relationship between the physical and spaciotemporal properties of manufacturing systems and the socio-economic reckoning of these properties. The degree to which this dependence is observed plays an important part in the application of an economic model.

We start with models describing the real-time organisational aspects of the manufacturing process as the point of departure for examining the economic models. From the economic models we turn to the theory on manufacturing strategy. Because strategy models focus on the allocation of productive resources for competitive purposes, they forge a link between the firm's internal organisation of production and the industry-level organisational models.

While the models described in this chapter are generic as to their technical description of the production system, frequent references are made to the current computer-assisted production technologies. Appendix A gives a technical summary of these technologies.

\section{System Organisation Models}

The standard approach to the factory organisation of manufacturing divides the firm's techniques for turning orders into delivered products into four principal processes: product design, process design, production, and manufacturing-related business processes. Specifically the four processes include the following responsibilities:

- Product design involves specifying a product's qualitative (functional) performance (e.g., provide instant communication with distant computer) together with determining some quantitative criteria (e.g., must weigh less than ..., must transmit information at rate of ...).

- Process design involves the development of a spatial and temporal sequence for the individual fabrication and assembly steps in converting materials (inputs) to finished product.

- Production involves the implementation of the process design (which may include changes to the capital stock) and the subsequent execution of materials/ energy/information conversions.

- Business-related manufacturing practices involve the production-related activities that are not directly part of the materials/energy conversions (beyond the shop floor), e.g. marketing, order taking, materials and resource management, and financial accounting. 
This particular model, which has a counterpart in the typical firm's organisational structure, is fast becoming obsolete. In it, each process is under the management of a different department, although in small plants two or more of the functions may be carried out by the same department or person. The logic of this organisational scheme is that of the linear sequential process in which each task, once completed, is handed off to the next unit in line with no further involvement of the first party to subsequent tasks, that is, the scheme reflects task specialisation.

What is happening now to change this is the increasing integration of all processes. In turn, there has been some modification in the thinking about how the processes are related to each other. ${ }^{2}$ For example, product specification is conventionally considered to drive process development, that is, product design precedes process design. By contrast, in a concurrent environment, product and process design proceed in tandem. In brief, viewed from a horizontal-process as opposed to vertical-functional-discipline perspective, the organisation of production becomes a systems engineering problem.

Taking this approach, a variant of the standard manufacturing organisation model streamlines the four processes into three: product flow (physical sourcing, product distribution, marketing); innovation flow (development of products and processes); and information flow. A second more contemporary view of manufacturing describes it in terms of planning, control, and execution (Montgomery and Levine, 1996). ${ }^{3}$ The divisions in this model reflect different time scales for the three activities as follows:

- Manufacturing planning involves matching the requirements of the product to the technical capabilities of the available manufacturing sub-systems, (see Table 2.1 for a list of generic capabilities and examples of associated processes). The planning horizon spans the lifetimes of both product and process.

- Production control involves management of shop floor activities. The pertinent time frame is usually a weekly schedule but the standard is fast approaching what is termed "intelligent control", that is, control in real time.

- Execution involves the real-time conversion processes.

Table 2.1 Machine Tool Capabilities/Technical Requirements

\begin{tabular}{ll}
\hline Machine Capabilities & Associated Processes (Examples) \\
\hline Shape and size producing & Casting, extruding, crushing, bending \\
Feature dimension producing & Drilling, turning, milling, sawing, laser machining \\
Surface quality & Polishing, grinding, electroplating, coating \\
Material property modification & Refining, extracting, hot working, heat treating \\
Joining & Welding, soldering, sintering, pressing, riveting \\
\hline
\end{tabular}

A yet more radical approach is to organise manufacturing in terms of obtaining a dynamic balance among the different system elements. Examples of emerging models of the production system include several used to guide technology development/deployment initiatives. Figure 2.2 depicts one such example, the product realisation model of the Technologies Enabling Agile Manufacturing project (TEAM, 1997, 1999). This approach to manufacturing organisation involves a series of trade-offs among critical parameters in the firm's product, process, and resource domains. ${ }^{4}$ The conceptual focus in the model is the management of concurrent processes. Notably, this 
Figure 2.2 The TEAM Product Realisation Model

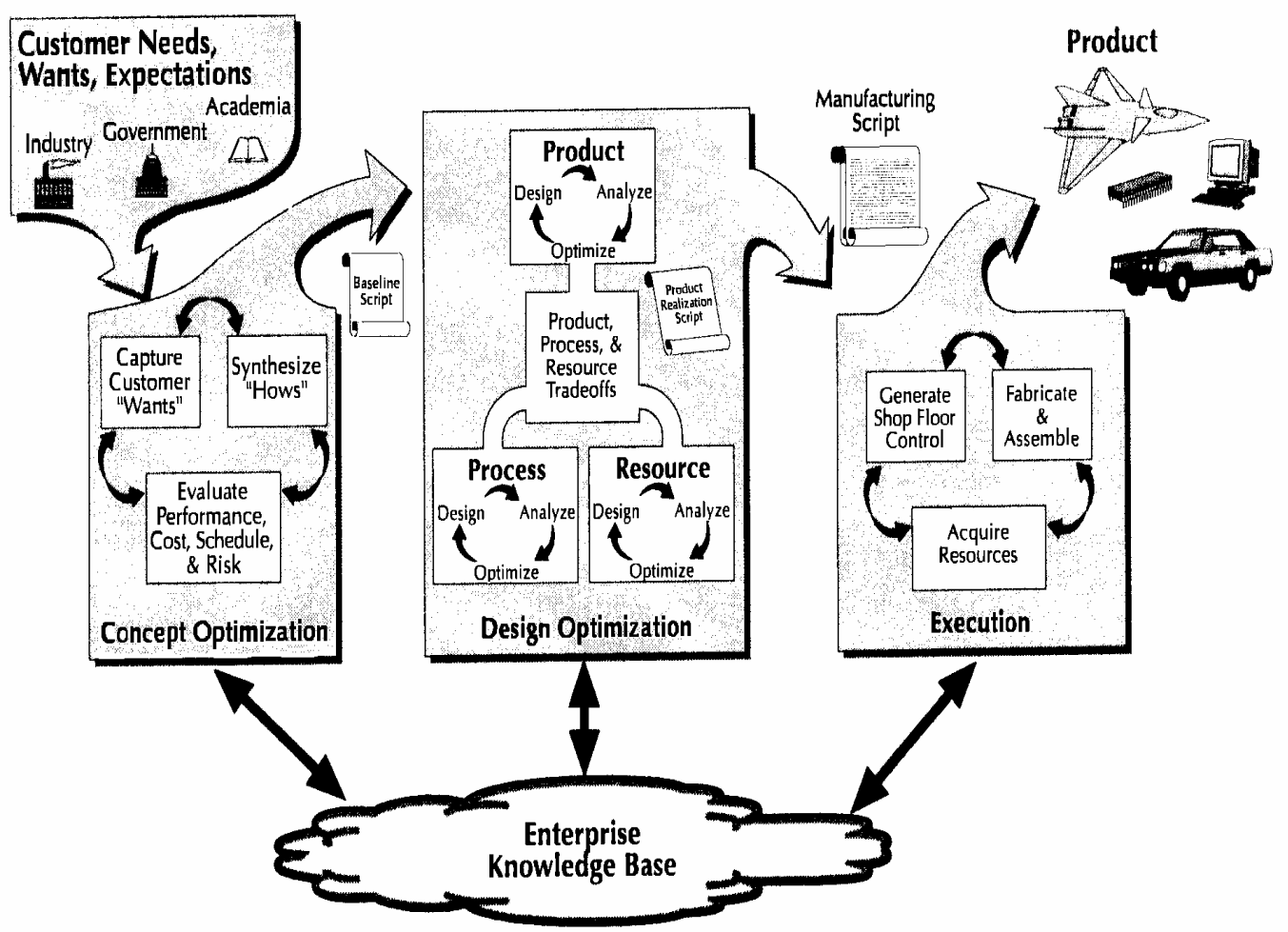

Source: Technologies Enabling Agile Manufacturing (TEAM), 1997, 1999.

approach introduces resource management as a separate deliberation from product and process design, a distinction we shall return to later.

The models discussed so far tend to focus on how manufacturing is organised. One technical factor that has a great deal of significance in characterising the forms production takes, at both the firm and industry levels, is production system type. Basically, industrial plants can be divided into two types: continuous process industries and discrete parts manufacturing. In the continuous process industries material flow is continuous and the portioning of output into product is not inherently related to the principle conversion processes. Examples include the high volume chemical plants, petroleum refining, and some food processing operations such as flour mills. By contrast, discrete parts production involves the manufacture of individual items that take form as a direct result of the conversion process. Differences in technology development according to the type of production system in use have led to quite different organisational practices and industry structures (Hayes and Wheelwright, 1984). In consequence, industry classifications based on the type of production system have more explanatory power regarding technology use than product/sector-based classification systems (Luria, 1997).

These engineering/operations management explanations of the organisation of production primarily concern the technical conditions within a specific system and the specific techniques for organising the production elements, that is, the first two elements in Morroni's classification scheme. The system boundary, for all intensive purposes, is the firm's in that we are dealing with manufacturing decisions inside the firm.

The models also emphasise a vision of manufacturing in which the production system is the centre of the organisation with other functions (e.g., marketing, human resources) 
providing support and service roles (Montgomery and Levine, 1996). At the same time, however, these models clearly suggest the significance of product development in the evolution of individual manufacturing systems. The point to be made here is that the models under discussion hold product innovations as exogenously supplied, or at least triggered by customer needs, as in the TEAM product realisation model. ${ }^{5}$ This seems consistent with the actual organisation of product research and development (R\&D) in most manufacturing industries. Many small manufacturing firms, in fact, do not perform product $\mathrm{R} \& \mathrm{D}$, and in many larger firms, $\mathrm{R} \& \mathrm{D}$ is carried out at the corporate level and not in close conjunction with plant manufacturing activities.

It is worth remarking at this time that the idea that product innovation drives manufacturing system development is widely accepted. One of the most influential theories in this regard is product life cycle theory. The theory contends that a product's life cycle, which describes the product's evolution and the kind of market segments the product is likely to occupy over time, can be used to summarise the customer and product requirements that must be satisfied by the manufacturing function. ${ }^{6}$

While product life cycle provides a useful framework for thinking about manufacturing priorities for the individual plant (Hayes and Wheelwright, 1984), the concept as applied to the evolution of process technologies seems problematical. For one thing, the products of different plants will be at various stages in their life cycles and thus are unlikely to exert a congruous influence on the general direction of production technology development. However, a wide-spread change in production technologies can influence product life cycles as happened when the diffusion of flexible production technologies led to shorter product life cycles. While in no way discounting the importance of the pattern of product innovations on industry development, there is a very strong case to be made for analysing the reciprocal influence of product and process development as a function of system organisation.

\section{Production System Terms}

Up to this point of our survey, we have looked at models of how manufacturing is organised. Here we turn our attention to what it is that is changing in the organisation of production. The particular aim is to add clarity to the subsequent analysis by defining several key concepts - process, practice, resource, and capability - as they are used in the engineering and production management literature. ${ }^{7}$

The management science models described above use what is loosely termed "process" as their organising principle. Process, as used in these models, invokes qualitative as well as quantitative transformation, and hence irreversibility (as will be discussed later in the chapter). While the notion of process is also central to the economics of production, it has been used there, for lack of definition, with less success (Georgescu-Roegen,1970). The difficulty, presumably, is that underlying the idea of process is change of a qualitative nature, while economics models reduce process to the more static notion of sequential tasks, that is, a set of discrete activities. Whereas it is easy to conceptualise the organisation of tasks, it is much more daunting to think in terms of the organisation of process.

Generally, engineers use the term process to refer to the operations for converting materials and/or information (inputs) into a desired product (output) using people, information, equipment and energy (resources). Often it is also used in the particular to refer to the equipment or technique for making a specified material conversion. In the models described above, it is applied in the more general sense to designate design and 
support functions as well as the materials conversion operations. This use is consistent with the definition of production system as consisting of processes for planning and controlling what happens on the shop floor in addition to the shop floor processes. In sum, the use of the term covers the hierarchy of manufacturing-related information and materials conversion operations. Table 2.2 gives examples of outputs associated with the four major manufacturing processes described earlier.

\section{Table 2.2 Process Outputs}

\begin{tabular}{ll}
\hline Processes & Outputs (Examples) \\
\hline Product Design & Blueprints, prototypes \\
Process Design & Process flow charts, routing sheets, shop floor layout, schedules \\
Production & Physical plant, parts, products \\
Business-Related Practices & Market forecasts, supplier certification system, employee incentive \\
& program \\
\hline
\end{tabular}

The common use of process in engineering then does not necessarily restrict the number or sequence of operations for a given conversion. In these models, measurement of the performance of a process in terms of its process goal(s) requires a representation of the process flow and data. However, a more technical definition of process is needed to determine the economic efficiency of a particular organisational arrangement. For this purpose, we define process as the unit operation (or sequence of operations) by which an "economically indivisible unit" of output is obtained (Morroni, 1992). By economically indivisible, we mean the minimum exchangeable unit which cannot be reduced for subsequent exchange on the markets.

In recent years, there has been a surge in the use of the term practice. In its common usage, practice refers to a company's approach to the organisation of its processes or some set of them. ${ }^{8}$ More specific uses of the term convey the notion of rules and routines. For example, the term "best practice" is used to denote the particular procedures which lead to process optimisation.

In engineering management terms, a practice consists of related rules and techniques for accomplishing a given manufacturing function. ${ }^{2}$ For example, the practice of crossfunctional teams refers to the use of teams, comprised of people from a number of functional areas, in planning and design activities and to the methods for engaging their participation. Table 2.3 on page 25 provides further examples of product and process design practices and rules.

The rapid diffusion of new practices in recent years (e.g. benchmarking, kanbans, total quality management) signals a shift in understanding of the manufacturing function. Practices, in this new sense, are guidelines which act as heuristic devices. They involve continuous reapplication of their component principles, rules, and techniques, and movement towards optimisation, underscoring the dynamic aspects of the manufacturing process. In this sense, practices evolve over time.

Engineers and management scientists define capabilities as the technological and organisational means of achieving the company's competitive priorities. Thus, the firm's capabilities encompass its practices, but capabilities more generally signify the synthesis of technology, practices, and structure. They refer to the firm's capacity to deploy resources (Winter, 1995). 
Table 2.3 Agile Practices and Design Rules

\begin{tabular}{|c|c|c|}
\hline Domain & Practices (Examples) & Design Rules (Examples) \\
\hline Product Design & $\begin{array}{l}\text { Review business plan to determine } \\
\text { the importance of developing new } \\
\text { products with regard to profitability; } \\
\text { review existing products to identify } \\
\text { changes needed to maintain market } \\
\text { niche and/or avoid obsolescence. } \\
\text { Design for manufacture and design } \\
\text { for assembly. }\end{array}$ & $\begin{array}{l}\text { - Design for a minimum number of } \\
\text { parts. } \\
\text { - Standardise part types. } \\
\text { - Design parts/modules for multiple } \\
\text { uses. }\end{array}$ \\
\hline Process Design & $\begin{array}{l}\text { - Implement visual methods of control. } \\
\text { - Group similar parts or products to- } \\
\text { gether (group technology) to support } \\
\text { flow production. }\end{array}$ & $\begin{array}{l}\text { - Design manufacturing operations for } \\
\text { processing in more than one se- } \\
\text { quence. } \\
\text { - Form machine cells according to the } \\
\text { value of the reliability of the ma- } \\
\text { chines. } \\
\text { - Form machine cells to minimise the } \\
\text { impact of mean repair time on manu- } \\
\text { facturing completion time. }\end{array}$ \\
\hline
\end{tabular}

Bespeaking their normative perspective, strategic management researchers define resources as "the assets, capabilities, organisational processes, firm attributes, information, knowledge, etc. controlled by a firm that enable the firm to conceive of and implement strategies that improve its efficiency and effectiveness" (Barney, 1991, p.101). More formally, resources have been defined as assets tied semi-permanently to the firm (Wernerfelt, 1984). The term resource also carries dynamic connotations in this literature and, perhaps, as a result, has largely replaced the use of the term assets in the discussion of strategy. Resource connotes the available means for system development, that is, the potential of the firm's investments, whereas asset connotes the current value of past investments. The term resources again reflects an emphasis on managing processes rather than a focus on the monetary valuation of process outcomes. One effect of this shift in emphasis is that firms view a wider range of practices as worthy of investment.

What emerges from the review of the production management models above is the convergence of focus on what is changing in the organisation of production with how these changes are taking place. This dynamic representation of the production system replaces a concept of change as the substitution of fixed elements.

\section{The Economic Models}

Morroni (1992) identifies three dimensions in the economic analysis of factory production pertaining to its organisational and temporal elements:

1. The relationship between physical quantities of input and output (productivity) and, at given prices, between input costs and output proceeds (profitability),

2. Relationship between times and modes of execution (organisation of inputs and size of productive units), and

3. Changes creating new inputs and/or new outputs according to technological opportunities and demand conditions. 
These dimensions figure to varying degrees in economic representations of production. The congruence of any given model with findings on actual production challenges would seem to indicate its usefulness to the task of analysing the effects of system change. However, we maintain (as before) that different tools have different purposes. The need then becomes one of applying the right tool at the right time.

The neo-classical production function serves as the baseline model in this analysis. We then consider derivations of the fund-flow model as conceptual means for analysing economic efficiency in terms of the technical parameters of the process. In this section, we also take a look at an emerging economic theory - the resource-based view of the firm for its analytical perspective on the firm's use of resources to build competitive advantage. Though not strictly a theory of the organisation of production, its conceptual focus closely parallels that of the manufacturing strategy models.

\section{Production Functions}

Production functions, in that they relate input quantities (and ultimately costs) to output quantities for a given state of technological development, tell us a number of things about the economics of the conversion process. ${ }^{10}$ Of particular interest to this study is the use of production functions to explain economies of scale and scope since these economies characterise the transition from mass production to mass customisation.

Economies of scale refers to the technical conditions of production which raise productivity in proportion to an increasing scale of operation. Production theory says that producers will choose those techniques which minimise total expenditures given the relative scarcity of the inputs. The locus of cost-minimisation in Figure 2.3 is the firm's expansion path.

Figure 2.3 The Production Function

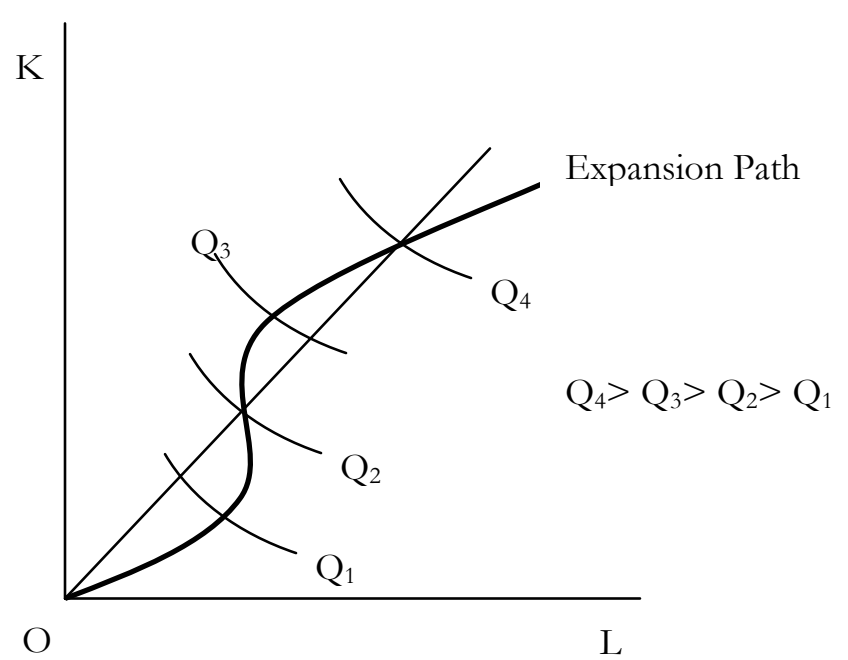

Most production functions, as with the one shown in the figure, are non-homogeneous, that is, the scale-up of production techniques does not occur along a linear expansion path, indicating a qualitative change in the organisation of production relative to the proportion of inputs. It is worth noting that this may not necessarily be for technical reasons but according to a technology's availability. For example, because of spillovers, equipment suppliers experience difficulties in appropriating returns on the sale of disembodied 
technology to small firms in fragmented industries, with the result that these markets are not well served (Guile, 1987).

As measures of productivity, production functions also can capture the economics of process innovation. By definition, existing technological know-how determines the shapes and positions of the isoquants. A process improvement is then represented by shifting the relevant isoquant, or portion thereof, towards the origin $\mathrm{O}$ in Figure 2.3.

When input prices are known, the firm's cost curves can be summarily derived from the production function, as shown in Figure 2.4. The effect of technological advance is generally to shift the cost curves down as a reflection of cost savings made available at each scale of operation. However, with regard to long-run average costs, this problematically assumes that new technology is qualitatively equivalent to the old (that is, all capital input units are identical). Nor should we assume that technological change in production is always the result of a search for improvements in technical efficiency. For example, change might be an attempt to acquire a stronger position in a certain market segment or to increase flexibility where market conditions are turbulent (Morroni, 1992). This raises the question whether a single long run average cost curve can incorporate different generations of technology.

Figure 2.4 Scale Economies

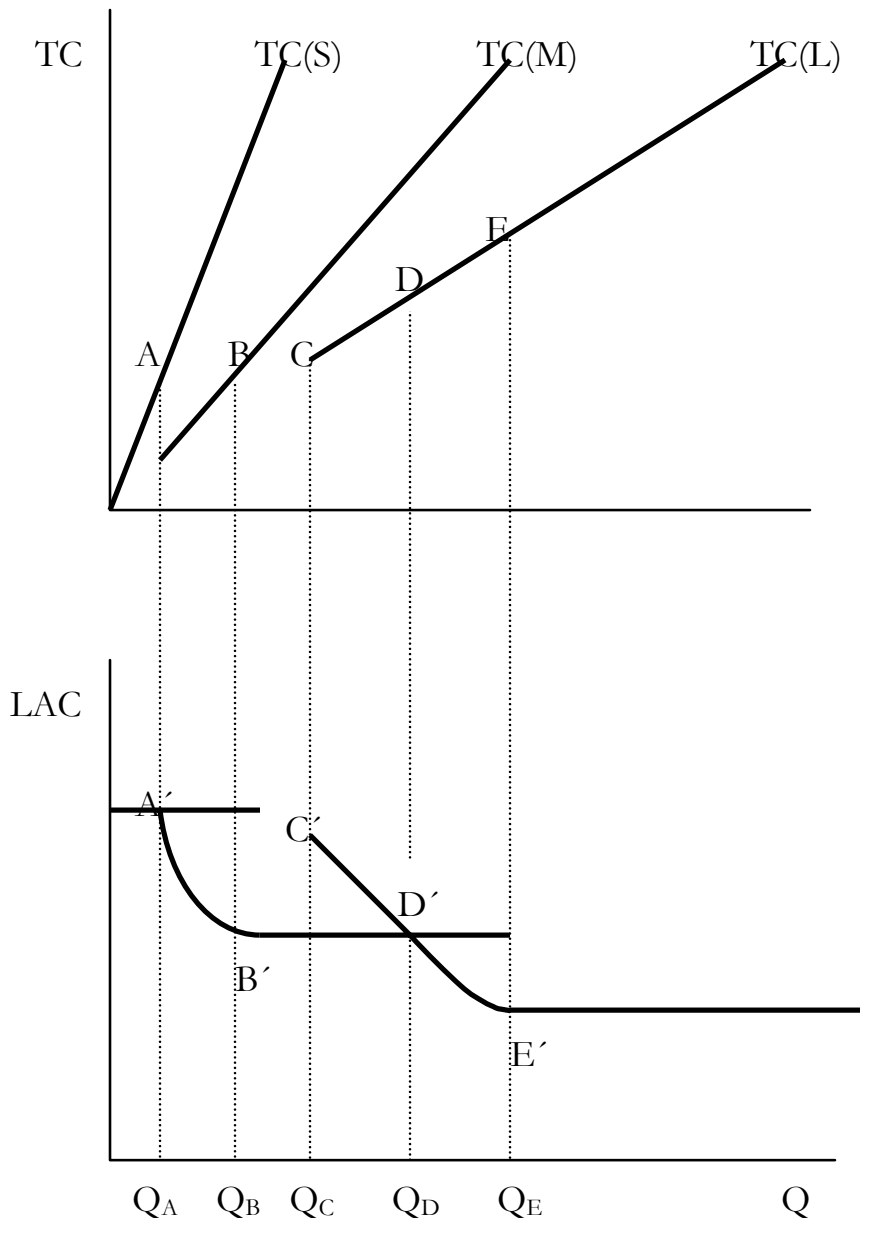

Figure 2.4 shows the costs curves associated with three different technologies, each of which operates over a different range of output quantities, from small scale (S) to medium (M) and large (L) scales. The figure implies that the technologies have different 
levels of productivity, which suggests that input units are not strictly identical, i.e. the homogeneity assumption has been relaxed.

Yet, since most production functions do not follow a linear expansion path, there is reason to redefine economies of scale in terms of an aggregate cost structure. In this case, scale economies are said to exist in a given output range if average costs exceed marginal costs in that range, that is, when average unit costs fall due to increases in the scale of output (Pratten, 1971). ${ }^{11}$ The point at which scale economies are exhausted is the minimum efficient scale (MES) of operation, points $\mathrm{B}^{\prime}$ and $\mathrm{E}^{\prime}$ for the medium and large scale technologies respectively in Figure 2.4. Movement down the curve towards MES is reaping scale economies.

We note in Figure 2.4 that the small and medium scale techniques are at a cost disadvantage to the large scale technique at any quantity less than QD. In point of fact, it is generally the case that smaller scale machines are less efficient if we are comparing costs on the basis of manufacturing a single product. The higher productivity of the larger scale techniques can be attributed to equipment specialisation and product standardisation in general, which, in turn, dictate a minimum scale of operation of some significance, ( $Q_{C}$ in the case of the large scale technology in Figure 2.4). Few plants, however, make a single product, nor are all products commodities. Historically, this explains the persistent use of small scale, general purpose machines suitable for the manufacture of a variety of parts.

Economies of scope are defined as the cost savings that arise from manufacturing two or more products together (Panzar and Willig, 1981; Baumol et al., 1982). ${ }^{12}$ The conditions for which economies of scope pertain are varied and changing, (as is the case for economies of scale), but we can summarise some essential points of interest here. Where economies of scope arise from the use of a shared piece of equipment, then the equipment cannot have been used to full capacity in producing a single product. In some cases, this may be because the capacity of the equipment exceeds market demand (Hall, 1994). But it could also be that market demand for a variety of products is growing at a higher rate than the size of the overall market, in which case a less efficient, but more flexible piece of equipment would prove more economical. These latter conditions are depicted in Figure 2.5.

The figure shows a two product market. The scale economies for manufacturing the two products independently are the curves $\mathrm{M}$ and $\mathrm{N}$ respectively. We assume that the cost of producing either $\mathrm{M}$ or $\mathrm{N}$ on flexible equipment approaches that of producing it on dedicated equipment, but to produce some mix of products $\mathrm{M}$ and $\mathrm{N}$ with the flexible equipment raises the unit costs because of an increase in, for example, set-up time, (the time required to change the equipment settings from the manufacture of one product to the other). Thus, the cost surface in Figure 2.5 is transray concave, that is, it is always cheaper to dedicate the equipment to producing either $\mathrm{M}$ or $\mathrm{N}$ than to producing a combination of $\mathrm{M}$ and $\mathrm{N}$ for any given quantity, say $\mathrm{A}$. But suppose that the market demand for $\mathrm{M}$ and $\mathrm{N}$ are $\mathrm{Q}_{\mathrm{b} 1}$ and $\mathrm{Q}_{\mathrm{b} 2}$ respectively. ${ }^{13}$ Then, $\mathrm{M}$ and $\mathrm{N}$ could be jointly produced at least cost at a quantity of $\mathrm{B}$, as the cost of producing the two goods separately, the sum of $\mathrm{Q}_{\mathrm{b} 1} \mathrm{~b}^{\prime}$ and $\mathrm{Q}_{\mathrm{b} 2} \mathrm{~b}^{\prime \prime}$, exceeds the cost $\mathrm{BB}^{\prime}$. However, we note that the equipment needed to produce these economies of scope is of a larger size than what be used in manufacturing either product separately. This is a highly significant condition that we shall return to later in analysing the effects of AMT use. 
Figure 2.5 Economies of Scope

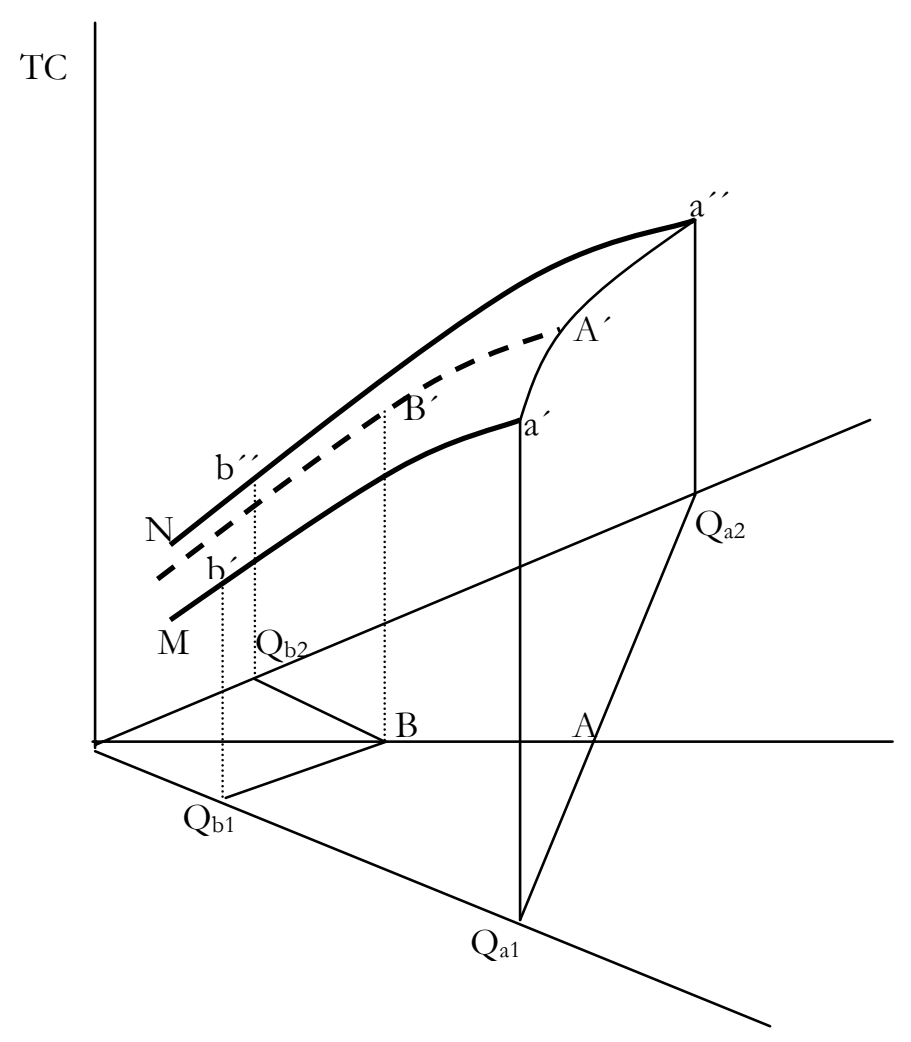

In discussing economies of scale and scope, I have made a number of remarks about market size and market demand. The production function and cost curves indicate the productivity loss from operating below a given capacity, but they are limited as tools in determining the appropriate scale of operation in that they cannot be used to derive actual market demand. ${ }^{14}$

Moreover, production functions tell us nothing about the organisation of the production elements. The assumption is that a given production function represents the optimal organisation of elements within the firm. But in addition to the quantity of inputs and outputs, organisation affects the amount of time the machine is in use, the number of machines involved in a process, the sizes of the various productive units, and the labour skill requirements, among other factors. New technology can effect changes in all of these as well. Particularly, technical and managerial innovations in the organisation of production are targeting time-saving as a source of cost reduction distinct from other factor-saving innovations (Piacentini, 1997).

Recalling that there are three economic dimensions of production, we can now see that production functions are almost exclusively focussed on the first of these, the relationship between physical quantities of input and output (productivity). We also can infer some economic effects of technological change as it affects the quantities of inputs and outputs, but it is not possible to track qualitative changes in either product or process.

Most significantly, however, production functions and the derivative cost curves cannot handle the relationship between process times and modes of execution as affected by the organisation of production. Foss (1997) has commented that the trouble with the reduced form mode of analysis that typifies the standard production function approach is that the "structural aspects" are lost from consideration. It omits the sequentiality of the 
production tasks. As a result, he writes "Both agency and co-ordination costs are hard to align naturally with the production function view. ... [A] problem of equal size is that endogeneity of knowledge is suppressed. ... The endogeneity of learning - the formation of capabilities - is not brought directly into the story." (p.313). To analyse the effects of production time and operational modes for their economic significance we need additional models.

\section{The Fund/Flow Model}

Nicholas Georgescu-Roegen, a near canonical reference for more than a few environmentalists, gave his own profession, economics, pause to think about the wisdom of ignoring the second law of thermodynamics, the inexorable grinding of matter and energy from low entropy/high energy-value (resources) to high entropy/low energy-value (waste). ${ }^{15}$ His genius was to apply this law in the development of an economic representation of the production process, the fund-flow model $(1970,1976)$.

The model's exposition here relies principally on its development by Morroni (1992) in which he incorporates the insights of evolutionary economists on the dynamics of technological change. ${ }^{16}$

In the model, flows represent the matter and energy entering and exiting the production system, while funds, (principally equipment, human resources, and knowledge), represent elements performing a service within the system. This departs from the orthodox economics representation in which stock (plant, equipment, knowledge or blueprints) can be accumulated, or de-cumulated, in an instant of time. In the fund/flow model, the expenditure of funds requires duration.

Defining the use of flows and funds within a given production process are the system properties of indivisibility, complementarity, and process irreversibility. ${ }^{17}$

- The indivisibility of integral system elements precludes their proportional distribution, and, for that reason, replication of the production process at a smaller output scale or in a shorter period of time. The use of each fund is marked by a specific time profile.

- Complementarities among fund elements specify their combinatorial performance. If a production fund is indivisible, relationships of complementarity, not substitutability, determine system organisation. Combining the productive capacities of indivisible funds according to specific relations of complementarity is a factor in determining scale, that is, scale increases are necessarily integral in occurrence. Sahal (1985) makes a similar point: the parts and the whole of a system do not grow at the same rate, which generally necessitates a change in system form.

- Irreversibility pertains to qualitative transformations in the production process, that is, entropy consumption, as every process entails some increase in entropy. The degree of reversibility concerning technical and economic choices influences the level of flexibility in the system.

Owing to these system properties, "The main economic problem in production," becomes, in Morroni's words, "no longer a simple problem of optimal inputs combination, but involves choosing a combination of processes, or single phases, largely characterised by indivisibility of inputs." (p. 30) 
What is striking about the fund/flow model is its use of time to measure productive capacity. This is highly consistent with how engineers model the production process. To quote, as one example, Dr. Dan Krupka, head of the manufacturing system engineering department at AT\&T Bell Laboratories, "Time- the interval from the start of manufacturing activity to its completion-is the single most useful and powerful metric any firm can use. [It is] a more useful and universal metric than cost and quality because it can be used to drive improvements in both." The Consortium for Advanced Manufacturing International (CAM-I), an influential international professional association, regards time metrics as the foremost tools for managing capacity (Klammer, 1996). This is Georgescu-Roegen's essential point. In Morroni's words, "Industrial production, whatever its organisational form, and technical changes ... reflect the economic necessity to reduce to a minimum any periods of fund idleness." (p.25).

The fund-flow model represents a much different concept of production than the minimisation of cost inputs as expressed in the production function. It stresses organisational improvement as a process, precisely because any specific organisation of the production elements involves fixed coefficient production and irreversibility. Moreover, in the fundflow model, the level of market demand and the specific characteristics of inputs and outputs (indivisibility and specialisation) play an essential part in determining the kind of organisation and the size of production units. By contrast, the production function assumes a de facto organisational optimisation whatever the output quantities. Choice, too, is an essential feature of the fund-flow model. The model suggests that the system's evolution over time is a function of its flexibility and the ability to incorporate technological change, that is, adaptability. These features of the model make it a powerful tool for interpreting the effects of change in production technologies, especially as regards system organisation. Such will be the direction of inquiry in Chapter 5.

\section{The Resource-Based View of the Firm}

In conventional economics, resources exhibit decreasing returns to scale. Implicit in the notion of economies of scope, however, is the idea that multi-product firms (at least) benefit from non-financial linkages. If so, firms can then generate rents through the management of their resources. Starting from this premise, the resource-based view of the firm was developed as a tool for analysing a firm's resource position and the strategic options suggested by this analysis (Wernerfelt, 1984).

As originally developed, the resource-based view of the firm was an alternative take on the classic economics question of why firms exist, hence its name. Popular theories of the firm (e.g., transaction cost analysis) tend to stress firms' competitive positions vis-àvis market transactions. By contrast, the resource-based view of the firm focuses on understanding the internal capabilities that enable some firms to secure competitive positions (Montgomery, 1995). Differences in performance between firms, that is, their manifest heterogeneity (Wernerfelt, 1984; Winter, 1995), suggest productivity advantages related to the organisation of the firm's activities (St. John et al., 2001). Further, the how of manufacturing a product is more difficult to copy than the product itself since it is easier to keep manufacturing-related knowledge proprietary (St. John and Harrison, 1999; St. John et al., 2001).

Recent theorising on knowledge and learning is contributing extensively to the further development of resource-based analysis. The essential notion is that competitive advantage stems from the firm's knowledge and the routines it has to generate this knowledge 
(Foss, 1997; Ghosh, 2001). Connor and Prahalad (1996) offer a unique interpretation of this. Their contention is that "the mode of organisation through which individuals cooperate affects the knowledge they apply to business activity" (p. 477). In other words, the difference in practices brought to bear under two different modes of organisation impacts the choice of the mode itself. This argument supports a dynamic interpretation of the firm's development: organisational mode affects how the firm learns and thus how it responds to new developments.

As an economic model that explains performance differences, the resource-based view of the firm fits well with strategic management theory. A focus on capabilities is also pivotal in manufacturing strategy models. The melding of the resource-based analytic with manufacturing strategy process models has produced what is called the "dynamic capabilities model", which we shall investigate in the next section of the chapter.

What is of interest in the context of our review of economic models of production is the resource-based view's emphasis on the organisation of the firm's resources as the source of competitive advantage. What the resource-based view lacks is an explanation of technological change and the influence of technological change on the development of capabilities (Foss et al., 1995).

\subsection{Manufacturing Strategy Models}

Product competition has changed dramatically as the result of the diffusion of computer and microprocessor-based manufacturing technologies, noticeably in the last two decades. A strict focus on cost leadership has given way to more varied means of competition. Effectively, advanced manufacturing technologies (AMTs) have opened the way for firms to exploit market opportunities in new ways, changing the terms of competition in the process. These changes have led researchers to rethink what it is that makes firms competitive.

This section covers the first of two research streams with complementary perspectives on this issue. A substantial literature exists in the management sciences on manufacturing strategy. The emphasis in this work is on the need for a "strategic fit" between operational strategies and business objectives. Recently, researchers have begun to integrate the conceptual apparatus of paradigms and dynamic change into strategic fit models to explain industrial transformation in the wake of AMTs. These theoretical advances have considerably extended the models' informative power, yet some important questions go unanswered. Chapter 3 introduces evolutionary economics as the necessary complement to operations management theory in understanding the role manufacturing strategy plays in helping firms adapt to technological change.

The production management models presented above speak to the first two levels of Morroni's production system hierarchy, namely, the technical conditions within a specific system and the specific way of organising the production elements, with an emphasis on the latter. The strategy models discussed here extend these representations to examining the organisation of production at the industry level.

Because technological change occurs in long waves, it is often difficult to judge its immediate effects. We begin this section with an overview of the historical shifts in the organisation of production to provide a sense of the magnitude of the changes involved in making the transition from mass production to mass customisation. 


\section{The Bases of Competitive Advantage}

The history of production technologies can be traced through the associated progression of competitive means. ${ }^{18}$ Prior to the industrial revolution, articles were crafted by hand and competitiveness was dependent on artisan skill and reputation. With the advent of steam power, competitiveness shifted to raw resource availability and low transportation costs. The next major system innovation, techniques for machining interchangeable parts, issued in the age of mass production at the beginning of the 1800's. The advancing specialisation of machinery under mass production shifted competitive advantage to plant capital itself, specifically to economies of scale. Industrial productivity is estimated to have increased by a factor of three from the time of craft production through the institution of mass production (National Research Council, 1995).

After World War II, markets were characterised by high demand and low productive capacity. Price was the dominant factor in competition. These conditions led to massive investments in automation. Extended backlogs served as the basis for material planning (Yusuf et al., 1999). The mass production mind-set viewed the factory as a productivity machine in which the core manufacturing operations needed to be buffered from external changes, including customer demands, for maximum efficiency and stability (Tu et al., 2001). The next major change of direction in competition came with the introduction of quality control techniques, first in Japan and then later in Europe and North America. While product quality certainly constituted a revolution in the marketplace, in terms of the organisation of production, it represented a refinement of mass production techniques. Improvements focussed on the ability to execute more complex tasks and make more complex products, which required better asset control and utilisation.

It was also in Japan that the production system that became mass customisation got its start. This change began in parallel with the quality revolution, but for a number of conjectural reasons - it took longer to institute, it was a more radical change in organisational thinking, it needed the application of computers to fully enable its realisation, and, to start with, it effected less noticeable changes in product market competition - mass customisation, or as it was then commonly called, flexible production, did not receive the attention that quality control did. It is worth recounting the beginnings of flexible manufacturing/mass customisation in detail as an illustration of how technological change unfolds.

Following World War II, the Toyota company of Japan, then a small craft-methods producer of trucks, laid out a strategy for entering the world car markets with a full-range product line. Having studied Ford's mass manufacturing methods in detail, Toyota's genius production manager, Taichi Ohno, determined that Toyota would not be able to copy them successfully. By the 1950's, when Ohno began experimenting with new techniques, mass manufacturing had reached its prime. Manufacturing strategy focussed almost exclusively on process mechanisation and economies of scale (Tu et al., 2001). ${ }^{19}$

Toyota, for all its ambitions of challenging the American hegemony in automobiles, did not have the capital, or the access to capital, to finance a mass production facility. Only through reordering the production processes to allow for greater equipment utilisation, thereby substantially reducing the amount of equipment needed, could Toyota hope to achieve the necessary economies.

Ohno began with developing quick-change tooling that could be used to produce a greater variety of products in smaller lot sizes. The key was reducing the set-up time 
which gave the equipment much greater flexibility. Greater flexibility meant less equipment could be used to manufacture a greater number of parts. With these tooling innovations, (and subsequent decades of refinement), the cost for Toyota to produce a small-lot part approached that of a mass-produced part.

This new production scheme challenged one of the central tenets of mass manufacturing, namely, the need for dedicated equipment. In essence, Ohno had substituted economies of scope for economies of scale. The significance of Toyota's advance is that economies of scope were being reaped for the first time in a discrete parts industry.

The conception of the Toyota system signalled a radical shift in the organisation of production and the "seeding" of a new technological paradigm. But it was through the application of computerised information technologies that the market significance of this change fully began to be realised. The first numerical control (NC) machine tools were introduced in the 1950's, but it wasn't until the 1970s before the use of computerised production technologies took off. The strict focus on cost leadership, anchored in long production runs, few product variants, few machine set-ups, and standardised equipment, that is, the advantages achieved through economies of scale and operating efficiencies, has been replaced with more varied means of product competition.

The story of the Toyota System which I have told here draws heavily on Womack , Jones and Roos' 1991 best seller, The Machine that Changed the World, but takes a different slant. Their story of the Toyota System emphasises the manufacturing philosophy that later came to be known as lean manufacturing. In relation to this inquiry, it is important to understand that lean production techniques, which focus on the elimination of waste in manufacturing, are part of a continuum of computerised technologies. The philosophies - or strategies - these technologies embody dovetail with each other (Spina et al., 1996). The particular angle adopted in this thesis is to stress production technology development in relation to changes in the structure of product markets, that is, the lines of development that culminate in mass customisation.

In retrospect, the Toyota System story strikingly exemplifies the interdependency of product market changes and the strategic use of manufacturing technologies. As Ohno remarked, the Toyota system was "born of the need to make many types of automobiles in small quantities with the same manufacturing process." (cited in Stalk, 1988) Ohno effectively had envisioned the development of a new production system based on economies of scope that would change the basis of competitive advantage, but the continuing development of this new system was tied to the emergence of market conditions, specifically, the demand for greater product variety, that favoured the system's development. This relationship has not always been remarked, perhaps because of the very remarkableness of these changes.

\section{Choices, Capabilities, Competitive Priorities and the Terms of Competition}

Basic to nearly every manufacturing strategy is the identification of the technological means of achieving the organisation's competitive priorities. In the marketplace, these priorities are described in terms of product and service attributes. How a firm makes products with specific attributes can be traced to its production technology choices, but it is more than technology alone that determines the firm's competitive success. 
That the linkages between a firm's technology choices and its competitive priorities and between its competitive priorities and overall business strategy are complex (Spina, 1998; Swink and Hegarty, 1998) can be readily appreciated. Table 2.4 summarises the key manufacturing decisions a firm makes in putting together a manufacturing strategy. ${ }^{20}$ These decisions need to be co-ordinated with the firm's other functional strategies, in particular the plans by the financial, marketing, and product development (design) departments. They also need to agree with the firm's business goals.

The use of AMTs touches virtually every one of the decision areas listed in Table 2.4. To take the decision category "external linkages" as one example: interest in supply chain/vendor management has mushroomed with the introduction of such technologies as just-in-time (JIT) production control systems and electronic data interchange (EDI). ${ }^{21}$ JIT is used to govern material flows through production in such a way as to reduce inventory and work-in-progress, thereby cutting costs, whereas EDI assists information flows via wide-area networks connecting firms with their sub-contractors, suppliers, and customers. The effective use of these technologies creates a need to realign customer/supplier relations to facilitate the resulting time-dependent flows of materials and information among firms. This often calls for "strategic sourcing", that is, designing the supply chain to engineer an appropriate mix of supplier capabilities complementary to the firm's own capabilities. That these decisions are not the sole province of manufacturing adds to their complexity.

\section{Table 2.4 Manufacturing Decisions}

\begin{tabular}{ll}
\hline Manufacturing Decision Areas & Types of Decisions \\
\hline Facilities & Size, location, focus \\
Capacity & Amount, timing \\
Span of Process & Extent of vertical integration, capacity balance \\
Processes and Process Systems & $\begin{array}{l}\text { Equipment, layout, degree of automation, process reliability } \\
\text { and precision }\end{array}$ \\
Resource Organisation & $\begin{array}{l}\text { Degrees of specialisation and integration, scope of author- } \\
\text { ity/responsibility }\end{array}$ \\
Human Resources & Skill level and development, incentive structure \\
Quality & Definition, techniques, program scope \\
Planning and Control & Degree of centralisation, process/product focus, source and \\
& direction of information flows \\
Internal Linkages & Information system applications, process/product devel- \\
& opment sequence (“life cycle fit”), investment criteria, \\
performance measurement systems & Sourcing, supplier responsibilities, co-operative ventures \\
\hline
\end{tabular}

Sources: Adapted from Hayes and Wheelwright, 1984; Hayes, Wheelwright, And Clark, 1988; Leong et al., 1990; Platts et al., 1998.

As a second example, consider the effect of technology choices on decisions in the "resource organisation" and "internal linkages" categories. AMTs which integrate design and machine control, e.g. computer-aided manufacturing (CAM) tools, have enabled changes in product design practices, such as the move to concurrent engineering, which is the parallel design of a product and its attendant manufacturing processes. These 
changes impact the degree of job specialisation and the scope of authority that define organisational structure.

The above examples show how closely woven technology choices are with decisions concerning manufacturing system organisation and practices. It is their synergy that gives rise to the firm's manufacturing capabilities (Yusuf et al., 1999). As synergy implies that the whole is more than the sum of the parts, capability implies a special advantage, or proficiency, adhering to the firm (Leonard, 1995; Swink and Hegarty, 1998). With regard to manufacturing capability, the relationships among the production system elements are as strategically significant, or more so, than the value of the elements separably (Porter, 1996). When their synthesis is unique to the firm, manufacturing capability is hard to copy (Hayes and Pisano, 1996; Teece et al., 1997; Swink and Hegarty, 1998).

Emerging models of the production system, discussed above, also accent the significance of capabilities building. In conventional treatments of manufacturing, the primary resources consist of organisational structure, technology (capital), and people (labour), where structure represents a particular set of functional (usually management) relationships. The elements used in the preceding paragraph to describe the firm's production system - technology, practices, and organisational structure - convey a different emphasis. Practices and structure refer to the organisation of processes and people respectively. This scheme gives more weight to process elements and suggests a choice of organisational arrangements, but organisation is still taken as a static input, the historical reasons for which are discussed below.

The most recent production system models identify people, technology, and processes as the bedrock resources. Knowledge also begins to make its appearance as a distinct element of import. In character, these models are systemic. Organisational practices are seen as operational modes rather than fixed inputs. The models' conceptual thrust is to tie the integration of the firm's resources to its manufacturing capability. ${ }^{22}$ Competitive advantage, as theorised in an influential article by Abernathy and Clark (1984), depends on the acquisition or development of particular skills, relationships, and resources. The models support a vision of the firm that is process-focused in lieu of the traditional functional organisation and management by numbers (see, for example, the recommendations of the Technology Foresight Programme (1995) and Schonberger (1996)). The new found emphasis on system integration is seminal - these models have outgrown Adam Smith's pin factory where all things economic flow from the division of labour.

But, for all the current interest in capabilities as the new foundation of competition (Montgomery, 1995), capabilities do not encompass strategy (Porter, 1996). The aim of strategy is to further link the firm's capabilities to opportunities present in the environment to achieve long-term objectives (Saren, 1990; Clark, 1996). Strategy, then, involves targeting the means to the ends as well as choosing the ends. Specifically, manufacturing strategy is the "pattern of decisions ... which determine the capability of a manufacturing system and specify how it will operate in order to meet a set of manufacturing objectives which are consistent with the overall business objectives." (Platts et al., 199823

A firm's achieving its business objectives - growth, increase in market share, profitability, and so forth - rests on its competitive success. The consensus view, by industry and researchers alike, is that the product attributes that matter most in today's markets are cost, quality, time-to-market, product differentiation, and increasingly service. ${ }^{24}$ Table 2.5 outlines the principal means of manufacturing products with these attributes. 
Table 2.5 Manufacturing System Capabilities

\begin{tabular}{|c|c|c|}
\hline $\begin{array}{l}\text { Competitive Priorities/ } \\
\text { Terms of Competition }\end{array}$ & Technoeconomic Means & System Capabilities \\
\hline Cost & Economies of scale; Automation & $\begin{array}{l}\text { Ability to produce large volumes } \\
\text { of low cost products }\end{array}$ \\
\hline Quality & $\begin{array}{l}\text { Product inspection; Process } \\
\text { standardisation; Process integra- } \\
\text { tion }\end{array}$ & $\begin{array}{l}\text { Ability to make products of con- } \\
\text { sistently high quality }\end{array}$ \\
\hline Time-to-market (Delivery Speed) & $\begin{array}{l}\text { Faster processes; Process and en- } \\
\text { terprise integration; Information } \\
\text { management; Process modulari- } \\
\text { zation }\end{array}$ & $\begin{array}{l}\text { Ability to introduce new prod- } \\
\text { ucts quickly; Ability to change } \\
\text { product mix rapidly; Ability to } \\
\text { make rapid deliveries }\end{array}$ \\
\hline Product Differentiation & $\begin{array}{l}\text { Economies of scope (flexibility); } \\
\text { Product and process modulariza- } \\
\text { tion }\end{array}$ & $\begin{array}{l}\text { Ability to introduce new prod- } \\
\text { ucts rapidly; Ability to } \\
\text { customise product }\end{array}$ \\
\hline
\end{tabular}

Note: Computer/microprocessor-enabled capabilities are marked in bold.

Said attributes define the "terms of competition" in an industry context, while a firm's "competitive priorities" are the attributes on which it concentrates. Through investing in equipment with particular functionality, firms can build specific manufacturing capabilities and shape their strategy.

Very few manufacturing researchers would dispute that AMTs have changed the face of market competition. Beginning with the quality revolution and followed by the rise of lean manufacturing and flexible automation, new production system functionality found its way into many industries. In particular, four system capabilities - the ability to introduce new products quickly, the ability to change product mix rapidly, the ability to make rapid deliveries, and the ability to customise product - are associated with the new terms of product competition. As suggested in Table 2.5, the application of techniques and practices in varying combinations leads to the emphasis of one capability over another as the basis for differentiating strategy (Spina, 1998).

Given the potential to leverage product competitiveness through the choice of production technology systems, for firms not to do so would seem short-sighted. Yet, the view that the manufacturing function can provide a competitive advantage is surprisingly recent. ${ }^{25}$ In the heyday of mass manufacturing, a firm's manufacturing system was typically considered a constraint on new opportunities (Hayes and Wheelwright, 1984; Wheelwright, 1984). The ideal was a manufacturing system based on long runs and, at best, there was one right way to do things (Clark, 1996; Hayes and Pisano, 1996). Organisational structure was predetermined by the ideal. The idea that manufacturers could compete through the way they elected to organise production took a wake-up call from the Japanese and even then the immediate response by Westerners was to attribute Japan's success to low wages and government assistance.

Another factor in the disregard for manufacturing's strategic role is the idea that product development and marketing are the primary sources of market advantage, an idea which tends to exclude consideration of how production technology choices also determine product attributes and the terms of competition. This is particularly symptomatic of the research on innovation, if less so in competitiveness research. ${ }^{26}$ Yet, without minimising the importance of product innovations as the source of new product functionality, supe- 
rior market positions are frequently obtained through process advantages. ${ }^{27}$ Abernathy and Clark (1985), after examining the pattern of technological development and competitive rivalry over time in the U.S. auto industry, concluded that it is a firm's capabilities, not its products' features, that are the source of its competitive advantage.

Not to attend to the influence of the "pattern" of manufacturing decisions is to present a lop-sided view of economic history. Chandler (1990), for one, contends that choices concerning the organisation of production were more critical to the rise of the modern industrial state and twentieth century economic growth than the introduction of new products. In Chandler's view, the organisational capabilities associated with economies of scale and scope played the central role in industrial development (Teece, 1993). ${ }^{28}$

\section{Strategic Fit Models}

The elements of strategy described in the preceding section - technology choices, manufacturing capabilities, and competitive priorities - are basic to most models of manufacturing strategy (Leong et al., 1990). Different models, however, place varying emphasis on what decisions are made versus how decisions are made. These two representations of manufacturing strategy are designated "content" and "process" models respectively, although most models are not strictly one or the other type. The distinction, however, is useful because the two model types tend to reflect real orientations in strategy development and implementation.

A number of manufacturing strategy practitioners have also observed that there often appear to be two manufacturing strategies within a given firm - the one evident in the plan and the one that has actually been implemented (Hayes and Wheelwright, 1984; Gupta and Lonial, 1998; Platts et al., 1998). "Planned strategy" is the outcome of an intentional (rational) decision-making process, whereas "implemented strategy" is the pattern of decisions embodied in daily operational practices. ${ }^{29}$ Moreover, the foci of planned and implemented strategies tend to correspond to the external and internal functions of manufacturing strategy respectively. Planned strategy is concerned with linking the firms' capabilities to opportunities present in the market; implemented strategy governs the daily internal flow of resources. Correspondingly, the intent of planned strategy is the principle subject of the frequently normative process models, and analysis of implemented strategy plays a bigger part in the more positive-oriented content models.

Content models, in the main, describe decision areas and competitive priorities (refer to Tables 2.4 and 2.5 above). The most recent give critical attention to the interaction between operational decisions and the setting of competitive priorities. Usually in these models, the discussion of technology choice is subordinate to deliberation of decision areas and competitive priorities as a whole or an examination of the "soft" elements in strategy, the human resource issues, but this is changing as researchers have become more observant of the effects of technological change.

In the process models, the influence of production technology choices on the terms of market competition is usually cast in terms of how the manufacturing function supports the firm's market objectives (Kotha and Orne, 1989; Kim and Lee, 1993). This view emphasises the firms' response to the external environment: What do customers want? And: What should we do to satisfy these wants and survive the competition? (Joseph, 1999). Most process models hold that business objectives drive the selection of competi- 
tive priorities, and, in turn, competitive priorities set the choice of technologies and practices (Leong et al., 1990; Platts et al., 1998; Spina, 1998).

In short, the standard process model describes a hierarchical decision-making process (Leong et al., 1990; Platts et al., 1998). Whether this process in fact results in a better performance lacks sufficient confirmation. In their review of strategy models, Leong et al. (1990) guessed that the standard process model "may be comforting because of its resemblance to familiar organisation charts," and suggested that more research needs to be done on bottom-up, or middle-up and down, processes. In a rare empirical study of the manufacturing strategy process, it was found that manufacturers were following a topdown approach to strategy development, but that the opportunities and competitive advantages they were seeking emerged from the bottom-up implementation process (Marucheck et al., 1990).

Nor do all theorists agree categorically with a top-down approach to strategy. Hayes (1985), for one, has taken a contrary position on "end-ways-means" models, arguing that these models, though appropriate in some situations, primarily those in which the results of strategy are fairly predictable, are not as effective as models stressing capabilitiesbuilding strategies, when what is wanted is a compass instead of a roadmap.

But, regardless of how the manufacturing strategy is arrived at, it is generally agreed that for a company to succeed, its manufacturing strategy must align with its business objectives. This concept of "strategic fit" is central to manufacturing strategy theory (Kim and Lee, 1993; Swink and Hegarty, 1998) and has been elaborated by a number of researchers (Skinner, 1969; Hayes and Wheelwright, 1984; Gupta and Lonial, 1998). Hayes, Wheelwright, and Clark (1988) observe that the root cause of most manufacturing crises is that firms' production systems have become incompatible with their competitive needs. However, something more than the right match of production system to management objectives appears to govern success, otherwise firms with identical technologies and similar business goals should perform more-or-less equally (Hayes and Pisano, 1996). ${ }^{30}$

In a more refined view of strategic fit, contingency theory maintains that firm performance is the outcome of fit among several factors: environment, organisational structure, people, technology, strategy, and culture (Kim and Lee, 1993). Proponents of this theory emphasise the influence of "contingency factors", such as industry type and product life cycles, on which strategic options are open to a company (Kotha and Orne, 1989). Porter's influential 1980 model, which drew on industrial organisation theory, argued that firms could gain competitive advantage from how they positioned themselves in relation to key industry-level forces. ${ }^{31}$ To succeed, firms should form their strategy in light of their industry's competitive conditions.

Hayes and Pisano (1996) have commented that Porter's model and its many derivatives hardened the division between decisions about where to compete and how to compete. Without an understanding of what connects a company's manufacturing capabilities to its scope of operations, managers lack sufficient knowledge to develop a manufacturing strategy that supports business objectives.

Business strategy is said to define the scope of the business unit, that is, which product, geographic locales, and service segments will be served, as well as how the business will achieve and maintain a competitive advantage (Hayes and Wheelwright, 1984). Business strategy then limits operations in three ways: it defines the geographic markets in which the business will compete, the breadth of its product line, and the expected source of its 
competitive advantage (Garvin, 1993). While the significance of manufacturing capabilities for how a firm chooses to compete is amply understood, the link between capabilities and scope is much more tenuously drawn in the literature. ${ }^{32}$ But to ignore this relationship then begs the question of how the two aims of business strategy - defining scope and the basis of competitive advantage - might be interrelated.

In a further criticism of Porter's model, Hayes and Pisano claim that it is essentially static in character. Garvin (1993) has similarly critiqued the standard process model, saying that the model neglects incentives for improvement once manufacturing decision-making is aligned with the firm's objectives. The dynamic capabilities process models, discussed below, take a different tack. Rather than focus on product market positioning, these models highlight the critical role capabilities play in firms' adaptation to changes in their competitive environments (Warnerfelt, 1984, 1995; Montgomery, 1995; Hayes and Pisano, 1996).

Yet another shortcoming of strategic fit models deserves explanation. Despite the stress put on the need for consistency between manufacturing strategy and business objectives, in many firms there appears to be a want of it. This lack of alignment is a common problem that has received significant attention in the literature (Porter, 1996; Millen and Sohal, 1998; Swink and Hegarty, 1998; Tracey et al., 1999). Much of this failure has been pinned on the actual practices of firms. Frequently, such practice differs from strategic intention. As noted earlier, often there appear to be two strategies at work - the one that identifies the plan and the one that has been implemented (Hayes and Wheelwright, 1984; Gupta and Lonial, 1998; Platts et al., 1998).

Moreover, many firms do not have mechanisms, that is, strategy formulation and implementation processes, to bring about the desired alignment. Operational decisions are carried out by reference to the firm's "way of doing things" - rules built on past experience - which may not be suited to the new technology. Further, the oft alluded-to pace of technological change and market volatility tends to exacerbate misalignment.

Yet, strategic fit theories say very little about the factors underlying actual practice, which makes poor practices difficult to correct. What researchers have observed (rather than predicted) is this: Production system development is an incremental process, driven primarily by operational necessity, and sometimes by technical opportunities (Hayes and Wheelwright, 1984; Kotha and Orne, 1989). AMT implementations frequently end in failure because firms do not take the necessary organisational and structural changes into account (Montgomery and Levine, 1996). ${ }^{33}$ Further, researchers have found that AMT investment strategy is frequently based on narrow technical assessments rather than a determination of how AMTs might serve the businesses' goals (Millen and Sohal, 1998). Still others have deduced that the gap between actual and expected performance gains from the adoption of AMTs is because manufacturers are not fully using the strategic capabilities of AMTs (Kakati, 1997).

In fact, many manufacturers appear not to be knowledgeable about the competitive advantages of AMTs. In one study of the impact of AMT use on competitive performance, Tracey et al. (1999) found that AMT use had no significant relationship to product quality, (whereas, AMT use did impact product line breadth and delivery capabilities), yet, in recent surveys of AMT use, manufacturers continue to cite product quality along with cost reduction, as one of the most important reasons for adopting AMTs (Small, 1998). In a 1985 Canadian survey, manufacturers more often thought the strategic advantage of 
AMTs was related to "labor shedding" than to increased productivity and quality (Britton, 1991). These findings suggest a drift in industry's evaluation of the strategic advantages of AMTs since their introduction.

Nevertheless, the foundation premise of strategic fit theories is remarkably solid and has provided many useful insights. Going back to Skinner (1969), strategic fit theories maintain that different production systems have different operating characteristics and, therefore, the task of management is to institute a production system which matches the company's competitive priorities. Implicit in the theory is that there are trade-offs to be made, and further, that these trade-offs are particular to the organisation, reflecting the specifics of the company's competitive situation. ${ }^{34}$ Summarily, firms cannot expect to optimise performance in all directions (Clark, 1996). They must necessarily choose how to compete.

To this end, the many content models of manufacturing strategy offer decision-making rules. For example, substantial effort has gone into devising production system typologies as guides to evaluating manufacturing technologies in terms of their fit with competitive priorities and their effects on organisational design. ${ }^{35}$ Hayes and Wheelwright's (1984) highly influential product-process matrix, deriving from product life cycle theory, matched production system capabilities to product/market requirements. Kotha and Orne (1989) integrated a third dimension representing organisational scope into the product-process framework to describe the content of fit between structure, strategy, technology, and performance. Both models embody a variant of the classic trade-off Porter (1980) immortalised: cost leadership versus product differentiation. Firms could produce low cost good at high volumes using complex production processes or they could use simple general purpose equipment to make a variety of products in small lots but at relatively high costs. (Of course, most models recognise this trade-off as two ends of a continuum.)

But the diffusion of AMTs has also undermined content models. Suddenly, fit was being reinvented as new strategic options came into play. Flexible equipment was touted as reducing the cost of low volume production to equal that obtained through economies of scale (see, for example, Goldhar and Jelinek, 1983). Many researchers maintained that the new production technologies changed the rules of the game and focused their research on establishing the parameters of the new manufacturing paradigm (for example, Kim and Lee, 1993).

This newer class of models hold that strategy must be compatible with the current technological paradigm. This suggests the strong influence of technology choice - as the basis of manufacturing capabilities - on a firm's competitive priorities. To some extent, this argument reverses the causality assumed in the earlier strategic fit models, in which business objectives drive technology selection.

A progression of researchers has deduced the existence of a bi-causal relationship between a firm's technology choices and its market objectives. Starting from the premise that manufacturing's assigned role is to support the company, Wheelwright and Hayes (1985) argued that manufacturing functions also "have authority to redefine [their assigned] mission". Hayes (1985) maintained that manufacturers should build capabilities and then encourage the development of plans to exploit them. Kim and Lee (1993) asserted that manufacturing technologies have an important influence on strategy choices and, hence, performance. Kotha and Orne (1989) proposed that three "manufacturing 
structure dimensions", (process structure complexity, product line complexity, and organisational scope), determine performance. Gupta and Lonial (1998) found in empirical tests that manufacturing strategy and business strategy independently, as well as conjointly, affect performance. Interestingly, the emergence of bi-causality echoes the conclusions of debates in the economics literature on the dominance of technology push versus market pull - that both matter. ${ }^{36}$

But paradigm theory also suggests that the degree of autonomy firms exercise in forming their manufacturing objectives is subject to debate (Foss et al., 1995; Hayes and Pisano, 1996; Spina, 1998). This raises an important question: If firms are limited in their strategic options for reasons of compatibility with the prevailing paradigm, what is the role of manufacturing strategy? Spina (1998) has made an effort to reconcile the assumptions of paradigm and strategic fit/contingency models by empirically demonstrating that the new AMT paradigm allows for different process configurations, thereby leaving firms a "strategic space". Because adaptation reflects a firm's specificities and competitive priorities, its results are not identical practices among firms.

What seems certain is that technological change and its effect on the organisation of the production system has shaken the foundations of established theory and has itself become a promising direction for research in manufacturing strategy. Yet, in many respects, the new paradigm models resemble contingency models, excepting that the trade-offs are different. Paradigm models invariably cite the litany of change drivers global competition, the rapid pace of technological change, changing customer requirements - but the change factors are still exogenously supplied.

Alternatively, contingency theorists are working to incorporate change into their models. Dynamic capabilities are the subset of capabilities by which the firm responds to changing market conditions. Montgomery (1995) identifies dynamic capabilities as those that "renew a firm's distinctive competencies by generating new routines and resources." (p.263) The key success factor in dynamic capabilities-based strategies (and the resourcebased view of the firm from which it derives) is identifying and cultivating potential firmspecific capabilities that would be difficult to replicate (Prahalad and Hamel, 1990; Teece et al., 1997) and valuable and non-substitutable from the point of view of the customer (St. John et al., 2001)

Hayes and Pisano (1996) have made the case that the trade-offs that count for firms are changing and dynamic, rather than given and static. In the manufacturing strategy process, as new opportunities develop, a company exploits those that are suited to its specific capabilities. In turn, these initiatives stimulate the company to develop additional capabilities. They conclude that firms should invest in building capabilities that require continuous adaptation and improvement of the organisation's skill base. For example, make-buy decisions should include consideration of the potential for organisational learning. This model begins to answer the question Hayes and Pisano themselves posed, "What should guide the selection of capabilities to pursue?" (p.32) Or to put the question another way, "If accompanied by high levels of uncertainty, shifts in technology confront firms with difficult investment choices. ... How, ex ante, are those choices made?” (Foss et al., 1995, p. 12)

Yet, to assume that all dynamic capabilities are equally relevant tomorrow is begging the question. Montgomery (1995) has noted that dynamic capabilities have the ring of "happily ever-after". Should we assume that building dynamic capabilities results in 
competitive advantage? Perhaps the challenge is greater. Determining the direction of change is crucial as well. As Teece, Pisano, and Shuen (1997) have remarked, "Deciding, under significant uncertainty about future states of the world, which long-term paths to commit to and when to change paths is the central strategic problem confronting the firm.” (p. 281)

\section{Puzzles in Strategy Models}

Empirical studies have shown that firms which organise production in a way that reinforces fit with their environments are more successful than those that do not. A recent bout of research indicates that this also proves true for firms using AMTs (Gupta and Lonial, 1998; Swamidass and Kotha, 1998; Tracey et al., 1999). From this and the research cited above on the actual practices of firms, it is reasonable to conclude that the function of manufacturing strategy should be to inform daily operational decisions and to establish a process for making good decisions (Platts et al., 1998). ${ }^{37}$ What is more, this function should be embedded in management practices since firms rely on rules/practices to conduct efficient operations.

To make this approach work, it seems necessary to construct a theory which could ground such practices. Such a theory would engage head-on the issue of how strategy can help firms adapt to technological change, especially if firms are to make "dynamic" trade-offs. In this regard, within the bounds the preceding construction of current theory, three puzzles stand out in need of solution.

Puzzle 1: What is the link between the company's scope of operations and its manufacturing capabilities?

The contingency and manufacturing paradigm models that have addressed this link present the problem as concerning the content of suitable fit. Current theory lacks an explanation for why this correspondence does or does not occur by way of describing an underlying mechanism.

Puzzle 2: What explains the misalignment between a preponderant number of firms' manufacturing practices and their business objectives?

AMT researchers have identified factors which describe fit between the component elements of an organisation and its environment. But, from the empirical evidence, it is clear that a number of forces are at work in manufacturing strategy development and implementation that can derail the process of achieving and maintaining fit. Theory should aim to identify these sources of misalignment.

Puzzle 3: Is it possible for firms to plan their adaptation to technological change?

Adaptation to change is at the heart of strategy. Contingency theorists have pointed out the need to consider how technological change might affect changes in future competitive priorities. Investing in dynamic capabilities that will increase future adaptability makes sense depending on the opportunities and risks involved. The questions remains, however, of how firms make good choices in the face of uncertain outcomes, that is, in times of change, what should guide the decision-making process regarding the choice and use of new technologies? Understanding the processes of technological change can help to enlarge the opportunities and reduce the risks. At present, manufacturing strategy theory pays insufficient attention to this prospect. 
Thinking about how firms initiate and respond to change in their environments through strategic manoeuvres meant to improve their competitive odds naturally suggests an evolutionary framework for explaining economic change. The model introduced in the next chapter says that firms learn new ways to achieve their business goals as an effect of the integration of new technology into the production system. This is not to say that other factors besides technology are secondary to the firm's competitiveness. But the model does imply that a firm's choices regarding the strategic use of production technologies are instrumental in shaping its future. This understanding, in turn, can be used to develop competitive advantage. 


\section{Chapter 2 End Notes}

1 See Hayes and Wheelwright (1984) on process life cycles for a discussion of process organisation at the industry level.

2 As shall be shown later in Chapter 4, AMTs enable this integration.

3 This model forms the basis for an examination of time-based strategies in Chapter 5.

4 In Chapter 5, the notion of irreversibility in the design processes is used to modify the fund-flow model.

5 Product research and development (R\&D) is not then included as one of the aforementioned support functions.

6 The concept of product life cycle has overlapping, but different meanings for management scientists, economists and ecologists. In market terms, product life cycle refers to the evolution of unit sales over the lifetime of the product (Bayus, 1994). The classical product life cycle goes through four stages: introduction, growth, maturity, and decline. The term is now more commonly used as an indicator of the rate of product introduction, that is, the term is used to refer to the lapse of time between the introduction of products, although technically the length of the product life cycle is the time from the product's introduction to its withdrawal from the marketplace. Shorter product life cycles are then an effect of a greater number of products being introduced and a shortening of the time between innovations. In ecological economics, product life cycle refers to all material transformations that occur in the manufacture and use of the product, starting with resource extraction and continuing until the product's discard.

7 Ghosh (2001) notes the often confusing and contradictory meanings of the terms "resources, capabilities, practices, processes and performance" (p. 133) found in the literature. My intent here is not to arrive at conclusive definitions so much as to give a sense of the evolving usage of these terms.

8 Practice deployed at the company-wide level are often referred to as philosophies. For example, computer-integrated manufacturing (CIM) which involves the integration of the functional areas of manufacturing enterprises with the factory floor functions through computers is considered a "a strategic thrust, an operating philosophy and methodology." (Zhou and Chauh, 1999).

9 As discussed in Chapter 3, the use of the term practices in the engineering management literature closely parallels the concept of rules and routines found the evolutionary economics literature (Nelson and Winter, 1982; Dosi, 1988; Winter, 1995; Metcalfe, 1997a).

10 The discussion on production functions in this section follows Peter Hall's summary (1994).

11 Pratten $(1971,1991)$ is the usual reference on the sources of economies of scale. The increasing ratio of equipment surface area to volume (and thus decreasing material costs) with increases in scale is often given as the textbook example for technical economies of scale. However, the material conditions for which this holds are almost exclusive to the continuous process industries. This partially explains why there have been different directions of technological development in the continuous process and discrete parts industries.

12 Panzar and Willig (1981) coined the term "economies of scope" to describe that property of production where it is less costly to combine two or more product lines in one firm than to produce them separately. This concept was then elaborated and applied in the analysis of industry structure by Baumol, Panzar and Willig (1982), particularly with respect to the analysis of monopoly conditions. Consequently, their work gives minimal attention to the case of economies of scope in which the weighted average of the costs of product-specific production is less than the cost of the firm producing a weighted average of the outputs of the product-specific firms, which is the focus of this study.

13 In most discussions of economies of scope, it is assumed that the cost surface is transray convex, in which case it would be cheaper to produce a combination of goods at any quantity than to producing the same quantity of either good separately. While such economies might be obtained through the application of ITs, it is more likely that the cost of production will rise for joint production at any given quantity at least in the early stages of AMT use. In Chapter Five we will discuss how the assumption of a transray convex cost surface could lead to some erroneous conclusions about optimal plant size. 
14 Instead, it is likely that the use of cost curves as a decision tool is instrumental in overproduction by masking diseconomies of scale, for example, inventory and work-in-progress costs.

15 A student of Joseph Schumpeter and Herman Daly's teacher, Georgescu-Roegen believed strongly that policy must deal with the real world. The formative experience underlying his theories was his first hand attempts to restore the Hungarian economy between the World Wars. His work is a cornerstone for ecological economics theory.

16 That Morroni's work is not more well-known among evolutionary and ecological economists is perhaps owing to its focus on production economics, a subject in large part relegated to the technical specialists.

17 In Chapter 5, I extend the model to include variance as a system property.

18 For more detailed histories of production technologies, the reader is referred to Hounshell (1984); Jaikumar (1988); and Ayres et al. (1992).

19 During the mass production era, when faced with shifts in product markets, firms also engaged in product innovation, or what was then more commonly referred to as invention. Invention strategies, however, typically presumed the manufacture of small volumes at high costs (Tu et al., 2001).

20 Leong et al. (1990) have shown that there is a high level of agreement among manufacturing researchers on what are the key decision categories.

21 JIT is the materials processing component of lean manufacturing.

22 In a parallel development in evolutionary economics, Winter (1995) defines a routine as "a web of co-ordinating relationships connecting specific resources." (p. 149)

23 The decisions referred to in this definition are the ones given in Table 1.

24 This list is remarkably consistent though different researchers tend to emphasise one or the other attribute by splitting an attribute up into its component characteristics. Additional characteristics, such as delivery reliability, are cited less frequently. For a comprehensive lists of competitive attributes see Swink and Hegarty (1998).

25 Wickham Skinner's seminal call to arms, "Manufacturing - Missing Link in Corporate Strategy" was published in 1969.

26 To take, as one example, the chapter on implementation in Leonard-Barton's informative study of the sources of innovation (1995). Leonard-Barton examines the influence of user know-how on the success of process technology development. However, the effect of process technology choices on product success are not similarly considered.

27 Of course, process improvements are also manufacturing technology product innovations. Here we are concerned with the advantage that comes from the deployment of a given process technology.

28 What Chandler does not remark on is that economies of scope were limited to the continuous process industries for technological reasons up until the introduction of computerised manufacturing technologies.

29 Platts et al. (1998) refer to implemented strategy as "realised strategy".

30 As explained later in this section, a determination of "fit" is based on the match between the firm's capabilities and the competitive requirements of the markets in which it operates.

31 In industrial organisation economics, Porter's model is alternately cast as a structure-conductperformance model (St. John et al., 2001).

32 One exception to this observation is Kotha and Orne's (19988) generic strategies model.

33 For example, a 1991 Chew, Leonard-Barton, and Bohn study cited in Montgomery and Levine found that 50 percent to 75 percent of U.S. companies failed in their attempts to implement AMTs.

34 The term "trade-off" assumes different meanings according to the organisational context, similar to the way the term "production system" does. Here we refer to choices at the firm level. Also, in manufacturing, the term is commonly used to denote design choices involving coupled product features, for example, the choice between cost and a performance dimension such as reliability, power consumption, or speed. The next chapter presents an explanation of trajectory trade-offs. 
35 For a survey of production system typologies, see Kim and Lee (1993). More recently, these typologies have expanded their scope to address capabilities in relation to competitive priorities. See, for example, Kathuria and Igbaria (1997) and Swink and Hegarty (1998).

36 Mowery and Rosenberg (1982), for example, argue that the dichotomy between supply-push and demand-pull is suppositional and that technological change is both push and pull.

37 As shall be discussed in later chapters, the approach described here rejects the hierarchical view of strategy in which decisions can be imposed. 


\section{Chapter 3 The Strategic Use Model}

Society does not consist of individuals but expresses the sum of interrelations, the relations within which these individuals stand.

Karl Marx: Grundrisse

The application of computer and electronics-based technologies in production has fundamentally changed the ways firms compete. While cost and quality remain important terms of product competition, other factors, such as speed of delivery, time-to-market, and service are critical market drivers or are gaining in importance. And more change is likely to come. New technology applications are being tried in response to the market's transformation and these, in turn, affect industry and market conditions.

The ability to adapt in a rapidly changing and complex environment has thus become increasing important to a firm's success. A well thought-out manufacturing strategy can help a firm to make production technology choices that support its overall business objectives. It can also determine whether a firm is able to respond to new opportunities and challenges as they arise. The focus in this chapter is to examine this second aspect of manufacturing strategy, that is, its role in firms' adaptation to change. Of particular interest are the changes associated with the use of new production technologies relative to their impacts on the organisation of production.

In Chapter 2, we looked at current manufacturing strategy models for their insights. The model developed below incorporates many of these and, as such, should be considered an extension of this work. Yet, current manufacturing strategy models insufficiently account for the influence of technology use. In contrast, the model developed here holds that technologically embodied trade-offs change the practices of technology users, creating momentum along predefined trajectories. This insight derives from evolutionary economics.

\subsection{The Evolutionary Economics Framework}

Since the ground-breaking work of Nelson and Winter in the field of evolutionary economics $(1977,1982)$, the study of technological change has developed into a fertile area of research. The contribution of evolutionary economics may be particularly regarded for its real world insights into the causes of economic change. Rooted in an understanding of firm behaviour as a set of routines for making technological and organisational 
choices, evolutionary models have proved very useful in understanding the effects of industry-level forces on populations of firms (Foss et al., 1995).

As a framework for analysing economic change, the scope of evolutionary economics is necessarily broad and inclusive of many avenues of investigation. The object here is to present its most salient theoretical elements as a context for the development of the thesis' core model. These points are as follows:

First, technological change is systemic in nature. ${ }^{1}$ In evolutionary theory, as a population adapts to its environment, it changes the nature of the environment in the process. Change in the environment, in turn, affects the direction of evolution. Sahal (1985) describes technological change in like manner: "[T]echnology both shapes its socioeconomic environment and is in turn shaped by it. Neither is a sole determinant of the other; rather, the two codetermine each other." (p. 62)

Second, technological change is a temporal process (Nelson, 1995). Three types of mechanisms govern this process: heredity mechanisms for transmitting technologically related knowledge; generation mechanisms for creating technological diversity; and selective mechanisms for differentiating among competing firms (or technologies) (Nelson, 1995; McKelvey, 1997). These mechanisms operate to change, in parallel, the composition and structure of knowledge, technologies, and firms over time.

Third, technological change is marked by uncertainty (Nelson and Winter, 1977; Dosi, 1988). Firms are not able to predict the outcomes of their innovative efforts. Technological change, then, is an open-ended process with no long-term equilibria, that is, it is a dynamic process. Accordingly, the economy is always evolving and, with it, the competitive environments of individual firms.

Fourth, the evolutionary mechanisms underlying technological change create "system coherence" - relatively ordered patterns of change (Metcalfe, 1997a). The inherence of this idea to the larger theory is that, while the outcomes of technological developments are unpredictable, there must also be the perception of opportunity for firms to pursue change (Dosi, 1988). Such perceptions are grounded in some ordered pattern of change. As Metcalfe (1997b) puts it, the question is not whether firms optimise - they do so in the sense that they make rational choices with the objective of maximising their gains but how do firms construct meaningful choice sets.

Fifth, technological change is cumulative (Dosi, 1982, 1988). The choice of a technology is determined by the firm's knowledge and practices, ${ }^{2}$ which are the product of past experience and the steps it takes to learn new practices. Learning is a key adaptive skill that lowers the cost of technological change. Learning-by-doing (Arrow, 1962) and learningby-using (Rosenberg, 1994) are key sources of experiential knowledge.

Sixth, technological change is not autonomous. The "direction" of technological innovation is linked to the accumulation of knowledge and capabilities at the firm level. Firms are constrained by the nature of technological knowledge, much of which is tacit (learned through experience) and specific to the firm. Additionally, the search for new technological opportunities is governed by heuristics, also learned. These constraints do not determine the outcomes of the change process, but improvements in one direction are made easier, cheaper, and more probable (Rosenberg, 1994). This tendency for technological change to advance in a direction prefigured by cumulative, experiential knowledge has been termed "path dependence". 
Seventh, technological change is embedded in structured environments. It occurs as an adaptive response by firms to changes in their environments - the socio-economic configurations we call markets. Markets are coextensive with what evolutionary economists term "technological paradigms" or "technological regimes", but regimes are also more than markets. A technological regime is a semi-coherent complex of knowledge, practices, institutions, and infrastructure which are the source of the rules for conducting change processes. Their configurations are defined by local, historical context conditions in addition to the economic signals of classical markets (Dosi, 1988).

Evolutionary economics, as composed of the elements above, provides a conceptually rich framework for developing an applied model of firms' strategic behaviour. But, some ontological caveats are in order.

Since Nelson and Winter's (1977) initial thesis, much discussion has been given to the appropriateness of evolutionary theory for analysing technological and economic change (Mokyr, 1990). Most evolutionary economists would agree that technological change is not sufficiently similar to biological evolution as to be able to make reliable conclusions about economic behaviour based simply on the theories of evolutionary biology. This is especially so with regard to the intentional (Lamarkian) transmission of characteristics. In biology, it demonstrably does not exist; in ecological economics, there is a strong case to be made for its impact on firm behaviour (Mokyr, 1990; Nelson, 1995; Metcalfe, 1997a).

As an analogy for technological change, however, evolution is a powerful heuristic device for understanding dynamic processes. Nelson (1995) suggests starting with a general theory of evolution and then examining its application in specific areas as special cases.

A second issue in applying evolutionary theory to the analysis of technological change regards what it is that is said to be evolving. In the model developed below, I take the firm to be the adaptive organism and industries to be the analogues of species. This is consistent with Nelson and Winter's original model, although other evolutionary economics models consider (often implicitly) that it is techniques or technologies that are evolving (see, for example, Mokyr (1990)). My objection to this construction is the inference that technologies actively compete for resources. Still, technologies clearly are changing. One way to resolve this issue is to consider a firm's set of technologies as its genotype, whereas its phenotype is the expression of technology use, that is, the firm's observable characteristics, or what we call its behaviour. In common with evolutionary models in general, the firm's phenotype is partly determined by its genotype and partly by its environment. I will extend this interpretation in developing the model later in the chapter.

Concerning the particular application of evolutionary theory, we remark that the thesis model describes the interaction between firms and their market environments that occurs as a result of production technology use. Technology use is a complex set of activities involving the operation and organisation of technologies for purposeful ends. In the case of manufacturing technologies, this is most often for producing competitive products. The model, then, is not intended as a universal model of technological change, and, while it is complementary to technology innovation and diffusion models, the model's focus on production technology use results in several shifts in emphasis. ${ }^{3}$ For example, the means of transmitting knowledge - the heredity mechanism - assumes more significance in this model than in other evolutionary models.

Evolutionary economics offers a distinctive view of the firm that contrasts with, yet complements, the more explicitly normative approach found in the management sciences 
(Montgomery, 1995). The focus on technological change bears emphasis as this element distinguishes evolutionary economics from other theories of firm behaviour. It is also inherently dynamic in its perspective, whereas other economics approaches, including the resource-based view of the firm, use equilibrium frameworks (Foss et al., 1995). Yet another important characteristic of evolutionary economics is that the analysis tends to converge on industry- and sector-level effects. At the firm level, the management sciences provide a much richer likeness of competitive behaviour in relation to material conditions. Yet, as discovered next, firm behaviour in light of an evolutionary reading of resource needs closely parallels that described in the dynamic capabilities models and the resource-based view of the firm.

\subsection{The Need for Resources}

It is competition for resources that drives evolutionary processes (Mokyr, 1990; Eldredge, 1998). ${ }^{4}$ In the case of economic evolution, competition motivates firms to seek better methods of positioning themselves in the marketplace. The success of such efforts determines their share of the resources that provide for future growth and stability. This evolutionary drive for resources sets in motion internal changes in firms that lead, in time, to large-scale socio-economic transformation. Such pervasive change prompts further adaptive responses in firms. Thus, economic change propels itself. This dialectic draws attention to a critical issue in comprehending technological change, namely, that it is firms that actively seek a "selective fit" with their environment (Metcalfe, 1997a).

This is not, of course, the way economists tend to think about firm's behaviour, which they conventionally regard as profit-seeking. However, the ostensible idiosyncrasy of the above interpretation hinges on the definition of resources. By taking as the point of departure the production management view of resources as the available means for system development, profits are understood to have value as a resource but a resource's value is not limited to monetary profits. This view accords with Winter's (1995) description of resources as stocks of available factors that are strategically related to decision options.

Technologies are embodied at three levels - knowledge, organisational capabilities, and artefacts (Layton, 1974) - and technological change occurs over all three. But it is within the firm that intentionality is involved. Through performing technological activities and constructing organisational capabilities, firms build resources that are not readily duplicated. Metcalfe (1997a) asserts that the inclusion of firm agency in the study of economic evolution more directly relates evolutionary theory to the competitive process. It is firms' differential behaviour, their differing ability to adapt, that generates the economic variety over which selection takes place and it is the drive for resources that engenders competitive behaviour. To this end, firms link their technology choices to market objectives.

The analysis of firms' need for resources sheds light on some fundamental aspects of their economic behaviour in the context of evolutionary models. When seen from this angle, the micro-level behaviour of the firm comes into view.

One essential aspect is the need to expend resources in order to gain resources. ${ }^{5}$ Adaptation always involves some cost. Moreover, experimentation, by which adaptation proceeds, is resource-intensive. A firm's adaptive success thus depends critically on its initial resource base and its ability to use this resource base effectively, (the latter being dependent on the former in many firms). Yet, firms call on different resources to effect 
their goals, which indicates variation in adaptive behaviour - and something more involved than the static combination of inputs.

Connor and Prahalad (1996) have identified two ways in which the firm's organisational mode affects its performance: how the elements in the firm's resource base, (in their terms, its starting knowledge), are combined and used and how the firm learns. In their analysis, these respectively configure the static and dynamic aspects of resource use. This division may be a little too neat. Because what the firm learns concerns the effective organisation of production. Moreover, this learning involves direct experience of different ways of organising production, the static elements in the resource-based view models.

As Rosenberg (1994) has pointed out, learning-by-using is of increasing significance as a change process because we are dealing with technologies with a high degree of systemic complexity. He stresses that the interaction of a technology with a given use environment cannot be understood until after prolonged experience of the technology's use. Such experience leads to new practices that increase the technology's productivity.

Whereas operational efficiency, the ability to make effective use of the firm's resources, is learned, this ability can also be considered a resource. Winter (1995) makes this point thusly, "Routines are the building blocks of organisational capabilities", (p. 148), and later, "The routine per se - the abstract activity pattern - is itself a resource." (p. 150)6 This concept of routines - or practices (to take into account their dynamical aspects) as resources supports the new emphasis being given to organisational learning and the development of capabilities in both the management and evolutionary economics literature. It suggests that firms will profit from investing in capabilities (resources) that enhance their ability to adapt to their environments.

Adaptive ability goes beyond acquiring a specific knowledge competency, training in an individual technology, or the adoption of a particular practice. New technology introduces new functionality into the firm's production system, where its effective use requires the ability to reconfigure the system. It is widely recognised that firms must undergo extensive changes in their organisational structures and practices to successfully integrate AMTs into their operations (Montgomery and Levine, 1996; Millen and Sohal, 1998). Imitative costs vary by firm according to whether a firm has already invested in the capacity to absorb new technology (Papaconstantinou et al., 1996). The adaptive challenge is to break with the past - to overturn the well-developed rules that reflect fixed investments and the institutional character of the firm.

This challenge is distinct from that of technology adoption and diffusion. What is involved is the particular organisation of the firm's resources in the context of changing market conditions. ${ }^{7}$ This synthesis is invariably unique to the firm, reflecting differences in past decisions, and explains the large degree of variation in firm behaviour. The synergy that results from the successful integration of resources gives rise to the firm's capabilities (Leonard, 1995; Hayes and Pisano, 1996; Swink and Hegarty, 1998; Teece at al., 1997; Yusuf et al., 1999). Such capabilities are not readily duplicated by other firms converting their profits to inputs.

Capabilities, then, provide a distinctive basis for the firm's competitive success in the marketplace. It is the "fusion" of manufacturing technology, operational practices, and organisational structure that determines the competitive potential of a firm's production system. To succeed requires far more than adopting the latest techniques, be they technologies or practices. Instead, a firm must be able to build unique capabilities - this is 
the inherent challenge of developing and implementing a manufacturing strategy. In evolutionary terms, capabilities building is identifiable as a mechanism for generating the technologically based organisational diversity over which selection takes place. The differential adaptation of firms to their environments is then another aspect of firm behaviour emphasised by a consideration of resource needs.

Among the most persistent of economic mysteries is the question of why firms fail to adopt proven, cost-effective technologies. But such an apparently non-profit-maximising decision might be explained by firms trying to create firm-specific resources that bolster their future competitiveness. Empirical research indicates that the lack of resources slows adoption (Mansfield, 1993; Swamidass and Kotha, 1998), but the slow diffusion of new technologies is more than an effect of underestimating the returns on investment in new technology. Resource considerations cut more deeply than the issues of budget constraints or access to financing - the relational value of a given technology to a firm's long term goals must be considered. Capabilities growing out of the firm's particular experience are difficult to copy (Hayes and Pisano, 1996; Swink and Hegarty, 1998). New technologies can add to or enhance the firm's unique capabilities. Thus, given a limited capital budget, a firm may choose to invest in what it considers a more "strategic" technology, even at a greater investment cost, than in building technological capabilities that are more easily replicated. This perspective on firm behaviour differs from that of neoclassical profit maximising models. Transaction cost analysis, for one, does not take firm-specific capabilities into account (Foss, 1997). Yet, it is the organisational specificity of a firm's resources that give them a strategic value. They are the door to opportunity.

The dynamic aspects of leveraging resource use include the firm's perception of opportunities to deploy its resources, that is, their perception of the resources' value; the ability to deploy those resources effectively in a constantly changing environment; and the ability to use resources for new ends (Winter, 1995). This conception of firm performance complements that of the resource-based view of the firm.

Environment is also a factor in differential behaviour. Adaptation presupposes a difference in environmental conditions. Levinthal (1998) has analysed technological speciation as the application of existing technical know-how to niche markets (domains) in which the abundance of resources and the particular needs of the domain set the pace of technological development. Entrenchment of established technologies in their primary domains of application is due to their refinement through adaptation within those domains. This is to reason that the product needs of any given market are a determinant of the resources required by manufacturers to meet those needs. In other words, manufacturing resource needs form an important nexus in the macro-production/consumption system.

From the preceding discussion, it can be seen that resource needs explain several key aspects of firms' adaptive behaviour. On the one hand, there is a drive to exploit new opportunities in order to gain additional resources. On the other, there is a need to make effective use of available resources in pursuing these opportunities. The firm's competitive advantage will depend on its ability to balance these two objectives (Wernerfelt, 1984), that is, the ability to use its resources strategically. Particularly, we are concerned with firms' use of new production technologies. What opportunities do they provide? But, equally important, how do firms make good choices in putting these technologies to use? 


\subsection{Technology Use, Trade-offs, and Path Dependence}

The tendency for technological innovation to occur along defined trajectories is described in the evolutionary economics literature as path dependence (Dosi, 1982; Rosenberg, 1994). A path, or trajectory, denotes the trade-offs firms make relative to the available opportunities for technological advance. Such trade-offs characterise a technology's functionality or performance, that is, the attributes that define the technology's effective use. In evolutionary terms, a technology's performance characteristics convey its selective advantage.

The envelope of available technological opportunities corresponds to the degree of technical challenge in realising proposed innovations; the prospects for appropriating returns on innovation; the degree of technological "cumulativeness" represented in past innovation and firms' capabilities; and the nature of the knowledge base (Dosi, 1988; Malerba and Orsenigo, 1993). But demand also determines which opportunities are available. Critical environmental pull factors in a technology's development include the distinctiveness of the selection environment - the domain of application - and the amount of resources available to foster development within that domain (Lee, 1996; Levinthal, 1998). What is more, which opportunities firms pursue depends on their perception of what is going on in the market.

These opportunity determining factors are embedded elements of technological paradigms or regimes. Mowery and Rosenberg (1982), among others, have argued that the dichotomy between supply-push and demand-pull is suppositional and that technological change is both push and pull, a position adopted here. Likewise, technological regimes provide the virtual context for selection - of technologies, firms, and industries - and the pattern for technological advance. This is to say that market needs both define and are defined by new technologies.

In effect, existent technology trajectories define the regime "space" by demarcating the span and depth of its configuration and structuring its relationships. In turn, each trajectory is defined by a series of trade-offs, which derive from the state of the regime at the time the trade-offs are made. In a trade-off, a gain in an advantage of one kind is exchanged for progress in another direction. Trade-offs then denote the regime's selectiveness. For example, in the case of mass production, the trade-off between economies of scale and economies of scope tends to promote low-cost product homogeneity as the basis of competition.

It is necessary to remark that while we speak of a series of trade-offs, trajectories, by definition, are characterised by a dominant direction of technology development, that is, a dominant trade-off. Yet, a dominant trade-off - the "tension" in the direction of development - reflects a multitude of decisions taken by individual firms. In assessing an individual firm's choices of technologies, the overall direction of technological development must then be taken into account, just as the technology choices individual firms currently face figure in the future direction of development.

Given relatively stable trends in environmental conditions, technological change will, more than likely, lengthen the trajectories inscribed by past innovations. The propensity is to refine existing technology; to build on previous investments; to copy success. Rosenberg (1994) calls this, "soft determinism", where the outcomes of the innovation 
process are not prescribed, but technological advance in one direction is made more probable.

By the same token, the trade-offs which characterise given trajectories do not arise independently - they are set in motion by preceding choices. Also, the resolution of a dominant trade-off either changes the course of the trajectory or is embodied in a new trajectory. These arguments are critical to the construction of a model of technological change because they signify that trade-offs are endogenous to the process of technological change. Specifically, we are concerned with path dependence as a consequence of technology use and the replication of trade-offs.

Consider that technologies function to mediate the interaction of users with their environments (Vanderburg, 1985; Latour, 1995). Through technology use, firms learn, by necessity, conformance with the effective use of the given technology, or else their performance suffers. To begin with, there is the intention of each firm to achieve certain ends (business objectives) through the use of a technology, but there is also the uncertainty that precedes learning the effective use of that technology. Firms cannot fully predict the nature of the technology's mediation, particularly with regard to its effects on the outcomes of the firms' business processes. (The material/physical transformations and knowledge manipulations performed by production technologies are much more exact and amenable to specification). With a new technology this uncertainty is greater than with an established technology.

Through technology use, firms can, however, learn how to effect the desired outcomes. They accumulate the experiential knowledge critical to the technology's functioning. Yet, to a large degree, form follows content. Recall that the firm's behaviour, its phenotype, is circumscribed by its genotype, the set of technologies it uses. By way of extending the evolutionary analogy, technologies are then the genetic code, so to speak, of technological change. To wit, technologies transmit knowledge of their own use.

In real world terms, technologies condition the knowledge and practices of their users. ${ }^{8}$ This is the inference in Winter's (1985) observation that, "The knowledge underlying a routine is embodied or embedded to a large extent in its associated human, physical and organisational capital." (p. 148). It is also similar in argument to Connor and Prahald's (1996) view that organisational mode affects the knowledge that firms apply to business activity.

The implication for strategy is that firms learn new ways to achieve their business goals as an effect of the process reorganisation brought on by the integration of new functionality into the production system. Performance depends on achieving effective use of the adopted technologies by reconfiguring the production system to conform with the new functionality. In such manner, new production technology initiatives provide the impetus to create new capabilities (Hayes and Pisano, 1996). As each firm operates from a different resource base, a firm's capabilities are unique, hence, the variety over which selection takes place. But also, as firms learn the use of new technologies, they replicate the tradeoffs embedded in those technologies.

In the case of production technologies, the technologies' functionality, that is, their functional purpose in the system, (e.g. flexibility, reliability, speed), pattern firm capabilities, which, in turn, set the terms of competition in the technology users' product markets. Technology use, then, has a corresponding path-dependent effect on product markets, that is, on firms' competitive environments. Ceteris paribus, market structures are func- 
tions of firms' strategies. We might then predict, for example, that an increase in the speed of product introduction will result in shorter product cycles and a consequent change in consumption patterns, say faster product replacement, in the same way that the rise in mass production technologies increased materials consumption as cheaper goods became available through economies of scale.

Figure 3.1, Manufacturing Strategy Linkages, shows the strong influence of technology choices - as the basis of manufacturing capabilities - on the terms of competition. The figure offers a structural alternative to the standard manufacturing strategy process models which argue that business objectives drive the selection of competitive priorities and, thereby, the choice of technologies and practices. Yet, the figure's lighter arrows do indicate that market conditions influence the selection of a firm's competitive priorities, which, in turn, affect decisions about manufacturing capabilities and technologies. Figure 3.1 , then, backs the prevailing view of the role of strategy, although it stresses the reverse causality, to wit: firms' technology choices shape product market formation and growth.

Figure 3.1 Manufacturing Strategy Linkages

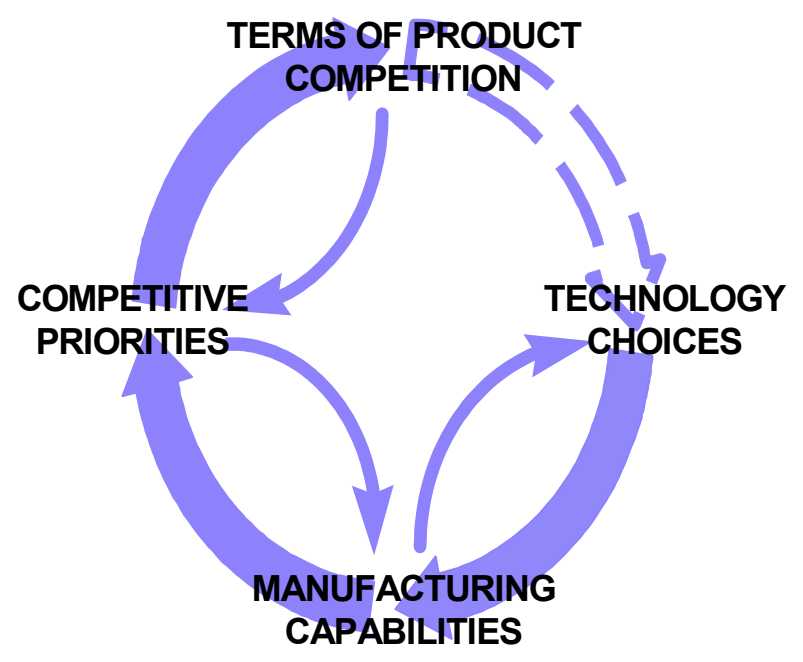

The dashed arrow in Figure 3.1 implies the direct influence of the firm's product market conditions on its technology choices. It signifies the influence of trajectories on technology choice.

As technology selection agents, firms do shape their futures, but their choice sets are not unlimited - they derive from the paradigm (Spina, 1998). Further, we might question the extent to which firms proactively construct their choice sets. Firms build on their past success in adapting to market needs, but their current resource needs are shaped by change in their competitive environments - the product markets. If some firms succeed in deploying a new production technology, thereby changing the bases of product competition, equipment suppliers are wont to provide more of the same manufacturing technology innovations, only better. Moreover, in the normal course of technological change, the trade-offs being made along production technology trajectories are not the outcome of unrelated choices by individual firms as much as a system response, consequently, the choice sets of individual firms contract to the trade-offs represented in current trajectories. This outcome recounts that adaptation occurs in two ways: change in the internal behaviour of firms, but also change in the structure of the population. 
By way of this analysis, the significance of the larger environmental context to the role of manufacturing strategy in the firm's adaptation to technological change begins to emerge. Shifts in the social, economic, or technical conditions of a market can affect the firm's ability to respond to change as well as any given technology's competitiveness.

These interdependencies between production technology use and product market conditions are summarised in the thesis' core model, the Strategic Use Model.

\section{The Core Model}

Strategy's role is to inform the choices firms make on how to deploy resources in response to changing industry and market conditions. As the framework for firm decisionmaking, strategy is embodied in structure and practices for translating the firm's cumulative knowledge into selective advantage. Increasingly, operational choices concerning technology use are understood to affect the firm's adaptive ability, that is, its ability to organise production in response to a highly variable environment (Morroni, 1992; Hayes and Pisano, 1996). As the past success of particular strategies for appropriating and managing resources in large part decides current strategy, (in as much as current strategy is the outcome of both cumulative learning and investment processes), and, since firms' past success in adapting to market needs is the result of their cumulative experience with its technologies, an industry's dominant strategy will mirror the course of its dominant production technology trajectories. ${ }^{9}$ Practically, firms copy their past successes and select technologies from the governing trajectory. Technology use is then, first and foremost, a heredity mechanism. ${ }^{10}$

The pattern of manufacturing decisions reciprocally figures in the rise of dominant technological regimes. The object of strategy is to couple the organisation's capabilities to opportunities present in the environment to achieve long-term objectives. Since technologies condition the knowledge and practices of their users, firms' technology choices determine their capabilities. New ways of organising production, configured around new process technology capabilities, set off changes in product markets which alter the terms of competition and affect the direction of current trajectories. ${ }^{11}$ In effect, technology choices set the terms of competition, thereby shaping product market formation and growth. It then follows that strategy is instrumental in determining the consumption patterns, that is, the level and composition of market demand, necessary to efficient operation.

Figure 3.2 elaborates the core model. The linkages, shown by arrows, convey a strong sense of contingency and path dependence, specifically, that technology use creates technological momentum through a process of replicating the socio-economic trade-offs embedded in trajectories.

The figure shows the industry level view of the technology use change process. In the model, the prevailing technological regime is represented by overlapping systems of consumption and production, defined respectively by product trajectories and a dominant production technology trajectory. ${ }^{12}$ At the heart of the figure, manufacturing strategy is depicted as a set of curved arrows, signifying the synthesis of the production system elements. The evolutionary mechanisms of generation, selection, and heredity underlie manufacturing strategy, driving technology choices and process organisation. Through technology use, strategy sets the terms of market competition with consequent effect on consumption patterns, as represented by the product trajectories. In turn, product trajec- 
tories determine manufacturing resource needs, which impinge on the production technology trajectory, maintaining its direction. Thus, the production technology trajectory embodies the sequence of trade-offs made through the aggregate of firms' technology choices.

Figure 3.2 Strategic Use Model

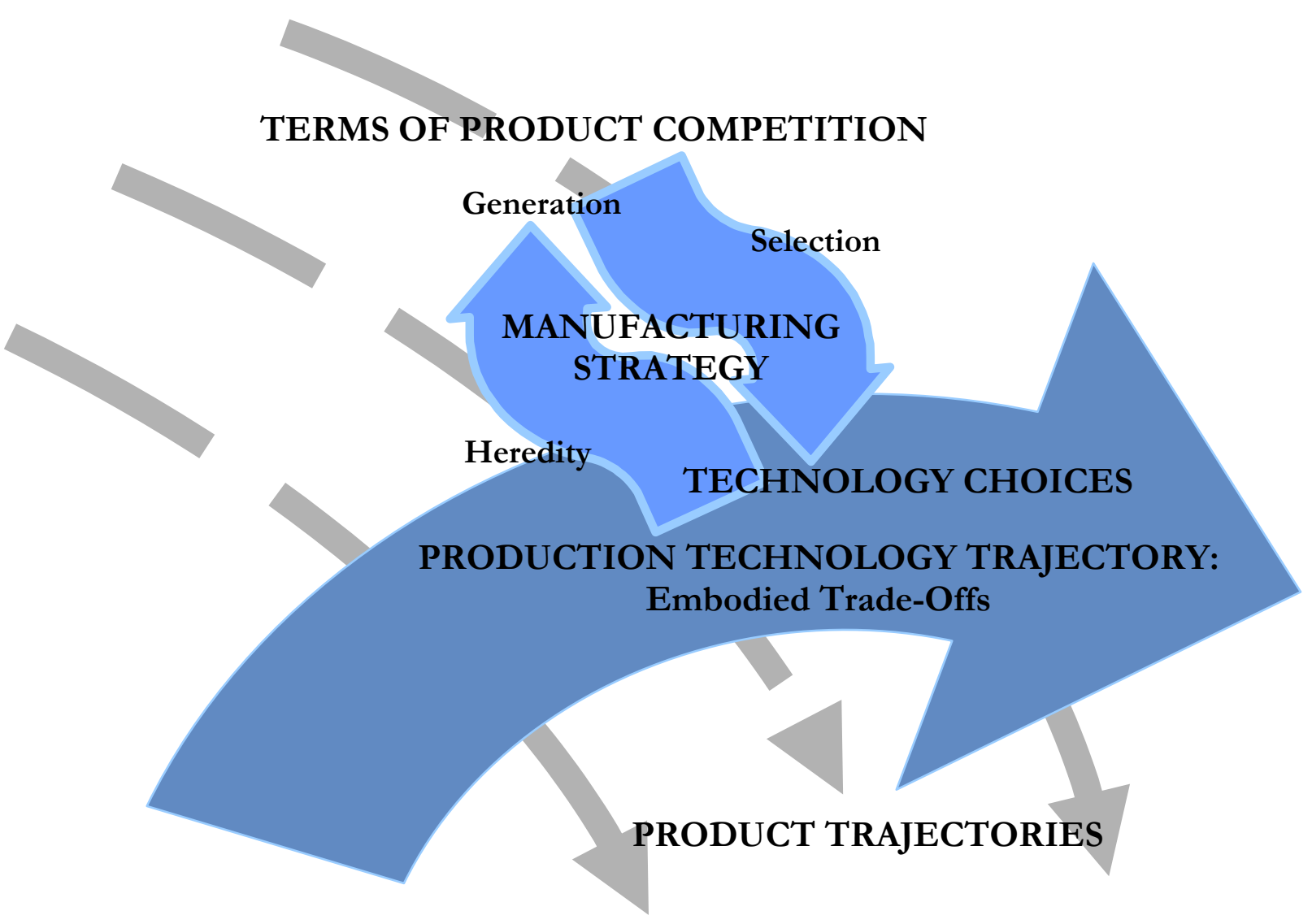

In sum, the evolutionary process works to channel technological change along developed pathways according to firms' past success in adapting to market needs, even as markets are shaped by technological change - that is, product markets and production technology systems co-evolve. Firms' operational strategies cause changes in their product markets that rebound to affect decisions on how current generation production technologies should further be developed to meet changing market demands. As experience in the use of advanced manufacturing technologies has accumulated, distinctive patterns in market organisation have emerged, which, in turn, have caused more firms to adopt these technologies. This interdependency of market needs and the strategic use of advanced manufacturing technologies creates a powerful technological momentum with consequence for producers and consumers alike. 


\subsection{The Model's Implications}

The significance of technological momentum in production technology use to the possibility of realising sustainability has largely been unexplored in both the technical and social literatures. This chapter concludes with some preliminary reflection on the implications of the Strategic Use Model for this possibility, but first we compare the different models.

The Strategic Use Model has several points of theoretical emphasis in common with the manufacturing strategy models surveyed in Chapter 2: both model types rely on decisionmaking rules; they point to the systemic nature of technological change by reference to the necessary structural and organisational change that accompanies successful AMT adoption; and they are based on the organisational specificity of firms' production systems.

Similar theoretical challenges also confront researchers in manufacturing strategy and evolutionary economics. Manufacturing strategy theorists are seeking to incorporate a dynamic perspective into their models and while evolutionary models are inherently dynamic, the Strategic Use Model is the first detailed evolutionary model to focus on the dynamics of technology use and the organisation of production. The model suggests that during the transition to new production systems, there will be two opposing forces on firm practices, including strategy formation and implementation: there is the hangover of old practices associated with the former production technologies, but also the use of newly adopted technologies exerts a force as firms adjust their practices in efforts to achieve the optimal use of the new technologies. This indicates constraints on the firm's behaviour within any particular technological regime.

One of the central issues driving research on strategy in general is how firms make good choices in the face of uncertainty. Hayes and Pisano (1996), two of the key researchers in the development of the dynamic capabilities models, ask what should guide the firm's decisions on which capabilities to pursue. Metcalfe (1997b), an evolutionary economist who has written extensively on technology strategy, phrases the question as one of how firms make meaningful technology choice sets.

Missing from the earlier models is the explicit proposition that technology use conditions firm behaviour. Interestingly, Hayes and Pisano (1996) and Teece, Pisano, and Schuen (1996), in their most recent models, refer to path dependence, but only at the firm level. Hayes and Pisano counsel that "a company should consider how [a change in one of its structural or infrastructural elements] might affect its ability to make future changes in its competitive priorities." (p. 39) Which is to imply that technology use influences the ability to adapt. Nevertheless, how firms might go about determining what future changes in competitive priorities might be desirable is left vague.

In evolutionary models, path dependence plays a central role. Understanding the processes of technological change can help to enlarge the opportunities and reduce the risks involved in capabilities building. The Strategic Use Model suggests that firms can gain a better understanding of the impact of their technology choices on their future by examining the trade-offs in current production technology trajectories. This claim is elaborated in the coming chapter on AMT trajectory analysis.

The different levels of contextual development - the focus on firm-level behaviour in strategy models and industry effects in evolutionary economics models - has further im- 
plications in the Strategic Use Model. The model provides a link between the micro-level behaviour of firms and the meso-conditions in an industry and helps to explain the technological dominion that occurs at the intersection of product and manufacturing technology trajectories.

The model reveals the gradualism of industrial transitions, which proceed slowly, firm by firm. Thus, the development of distinct patterns of technology use and the consequent change in the technological regime are often the work of decades that may not appear transformative until the changes are well under way. Also, from the perspective of industrial transformation, each firm's adaptation to the effective use of a new technology is an incremental improvement. Yet, adaptation is often a radical transformation at the level of the individual firm. The firm's ability to control this process, to balance the old and the new, incremental and radical change, may be the key to its success.

Finally, we remark that earlier evolutionary models in the Nelson-Winter $(1977,1982)$ tradition have focused almost exclusively on firms' behaviour with regard to the supply of product innovations. By comparison, the Strategic Use Model integrates both the evolution of supply and demand into one model, appreciably extending our understanding of what is involved in technology use. Whereas, Rosenberg $(1982,1994)$ and subsequent authors (Leonard, 1988; von Hippel and Tyre, 1995) have stressed in their research the incremental product innovations consequent to a product's adoption and use, the Strategic Use Model investigates the organisational adaptation that occurs with the integration of new technology into the production system. Further, the model is unique in the evolutionary tradition in examining technology use as a principle source of path dependence. In the coming chapter, we examine the impact of AMT use on the ways firms compete based on the proposition that the effective use of AMTs dictates changes in practices and process organisation. The transformation in the organisation of production consequent to AMT use signifies a powerful technological momentum that describes not only the way we work, but also the way we consume.

Recall that we have defined technological regimes as socio-economic configurations, implying specificity of the elements' interrelations. In point of fact, technological regimes are restricted spaces. But, while regimes are bounded, their influence is not confined to economic relationships. The processes comprising technological change are characteristically social as well as economic. ${ }^{13}$

How the complexity of regime conditions bears on firms' strategic behaviour is illustrated by the declining fortunes of apple farmers (Egan, 2000). In the U.S., the red delicious apple is the icon of apples, but in perfecting the red delicious, growers were responding to the dictates of big buyers, the major supermarket chains, who wanted a uniform product to entice the eye of the harried shopper. Apples were bred for size and colour, which counted for more than taste in pricing. Only where producers maintain a direct link to consumers are the non-standardised varieties competitive. But the volume producers are in trouble with apple sales flat, which many attribute to the perfect apple's bland taste. On top of this, the apple growers, most of which are family farms, are tradition bound once a red delicious grower, always a red delicious grower. At the same time, they maintain a fierce independence from government assistance that is common elsewhere in agriculture. Yet, in the face of mounting losses, (three-quarters of a billion dollars in three years), farmers cannot afford to refuse subsidies. As a result, there will probably be more red delicious apples produced than people are willing to eat. 
Freeman, with regard to technological possibilities, says this: "[T] he realm of the scientifically conceivable is infinitely greater than the realm of the technologically feasible and the realm of the technologically feasible is far greater than the realm of the economically profitable and the socially acceptable." (1992, p. 202). Moreover, the social character of each of the change mechanisms uniquely contributes to the direction of change.

While Arrow (1962) and Rosenberg (1982) have described the economic effects of learning-by-doing and learning-by-using respectively, we are also concerned here with changes in social behaviour that are a consequence of technology use. For what is being transmitted through technology use is the embodied trade-offs which characterise the technology's performance or functionality.

As firms use technologies, they replicate these embodied trade-offs, begetting the inculcation of socio-economic values. As such, the large-scale transition to use of a new production technology reveals a social character. There is a selection of technologies and the firms that use them according to competitive, though not strictly economic, performance. As firms succeed with these new technologies, the technologies' particular socioeconomic functionalities gain currency. Subsequently, there is an aggregation of behaviour brought on through the new technology's use.

With respect to the replication of AMT trade-offs, the dynamics of path dependence in technology use are revealed in the increasing speed and complexity of everyday life. The next chapter explores these linkages. 


\section{Chapter 3 End Notes}

1 Systemic properties arise from a configuration of ordered relationships (Capra, 1996).

2 Nelson and Winter in their original paper (1977) used the term "heuristics" to describe the firm's search process, later gravitating to the term "routines". Instead, I have purposefully chosen the term "practices" because of its common use in industry where it has the sufficiently broad connotation intended in the evolutionary literature that the term "routines" does not. For further discussion of industry's use of the term practices, see Section 2.1.

3 Further, the model is circumscribed in the extent of its examination of the prevailing production/consumption regime. It does not actively address the intersection of manufacturing operations with research and development, regulatory, or consumer product use activities. It is useful to consider these separate activity domains as sub-regimes, although for the purposes of exposition we use the convention of "markets" and "product markets" to refer to the sub-regimes of interest. Note also that we use the term "market" here in its vernacular sense as to signify the environment firms operate in and their perception of that environment as more than just economic transactions.

4 More explicitly, Eldredge (1998) links evolution to the twin forces of cooperation and competition.

5 By gaining resources, we mean either their internal development or external acquisition, the latter of which includes profit-making.

6 Here we adopt the definition of routine as that which is "regular and predictable about business behaviour ...includ[ing] the relatively constant dispositions and strategic heuristics that shape the approach of the firm to the non-routine problems it faces." (Nelson and Winter, 1982, p. 15) This dynamical representation of routine is what we called a practice in Chapter 2.

7 Technological adaptation as described here is then contiguous with the fund-flow model's view of organisational improvement as a process of reorganising the system's elements.

8 Langdon Winner (1986) eloquently makes this case in his treatises "Technologies as Forms of Life" and "Do Artifacts Have Politics?".

9 The cumulative learning process affects the strategic choices of both equipment suppliers and users since articulated market needs reflect experience with existing technologies.

10 There has been much speculation on what provides for the heredity mechanism in economic evolution. The common suggestion is that heredity is transmitted via the individuals working in firms.

11 Path dependence in consumption patterns also pertains in the construction of regimes.

12 Only one production technology trajectory is shown in the figure for purposes of simplification.

13 There is a large literature on the social shaping of technology (among others, MacKenzie and Wajcman (1985) and Bijker et al. (1987)) that examines the socio-economic patterns embedded in both the content of technology and the processes of innovation and that claims that technology is a social product, patterned by the conditions of its creation and use. 


\section{Chapter 4 AMT Trajectories Analysis}

Every salient technology raises ethical questions.

Edward Wenk, Jr.: Tradeoffs

The implementation of production technologies with specific performance characteristics forms the core of a firm's manufacturing strategy. What is more, technology use plays a critical role in firms' adaptation to changes in their competitive environments, changing the nature of those environments in the process. The growing use of AMTs thus raises important questions concerning the influence of current production technology trajectories on the organisation of production and consumption. Namely: What are the current strategic uses of AMTs? Are they sustainable? And are there other, more sustainable choices? The answers to these questions depend on our ability to analyse patterns in AMT use and to redirect use on the basis of that analysis.

Given relatively stable trends in environmental conditions, technological change is more than likely to continue in the same direction. In times of industrial transition, the direction of technological advance is less certain. Yet we know that technologies embodying new performance characteristics succeed in the marketplace because they fill unmet needs. ${ }^{1}$ These needs run parallel to the trade-offs embedded in current trajectories. This suggests that the study of current technological trajectories can provide clues to the direction of near term technological developments, both during periods of stability and during regime transitions.

In the last two decades, the diffusion of computer and microprocessor-assisted manufacturing technologies has dramatically changed the face of product competition. The strict focus on cost leadership, based on long production runs, few product variants, few machine set-ups, and standardised equipment, no longer holds. Beginning with the quality revolution and followed by the rise of lean manufacturing and flexible automation, new production system capabilities have found their way into many industries. In particular, three directions in AMT use - product differentiation, system optimisation, and knowledge systematisation - are associated with the new terms of product competition, and a fourth, adaptability, is beginning to take effect.

In presenting these four trajectories, this chapter applies the Strategic Use Model to the analysis of AMT use. The approach used is to describe changes in the direction of a trajectory as the result of a process wherein product markets and the strategic use of production technologies co-evolve. 


\subsection{Researching Trajectories}

While many evolutionary economists cite the evidence for specific trajectories in their work, few studies have the specific purpose of trajectory analysis. As a result, there is no generally accepted analytical approach to researching trajectories. Even the subject content of trajectory analysis might be considered open to interpretation. Problematically, the boundaries of technologies, trajectories, and regimes can be difficult to discern in the absence of shared definitions. ${ }^{2}$

Conventional product classification places product technologies in hierarchical orderings as shown in Figure 4.1 in the column labelled "Levels of Product Markets". However, there is no one-to-one correspondence between the traditional product categorisations and the evolutionary hierarchy (the left-hand column in Figure 4.1), except perhaps for that between technology, as used in the evolutionary literature, and product category, as used in industry publications. Instead, technological regimes and trajectories cross cut the traditional categorisations of industries and product categories. This is particularly the case for information or process technology trajectories, given the many applications of these technologies.

Figure 4.1 Correspondence between Technology and Product Hierarchies

Levels of Technological Regimes

Levels of Product Markets
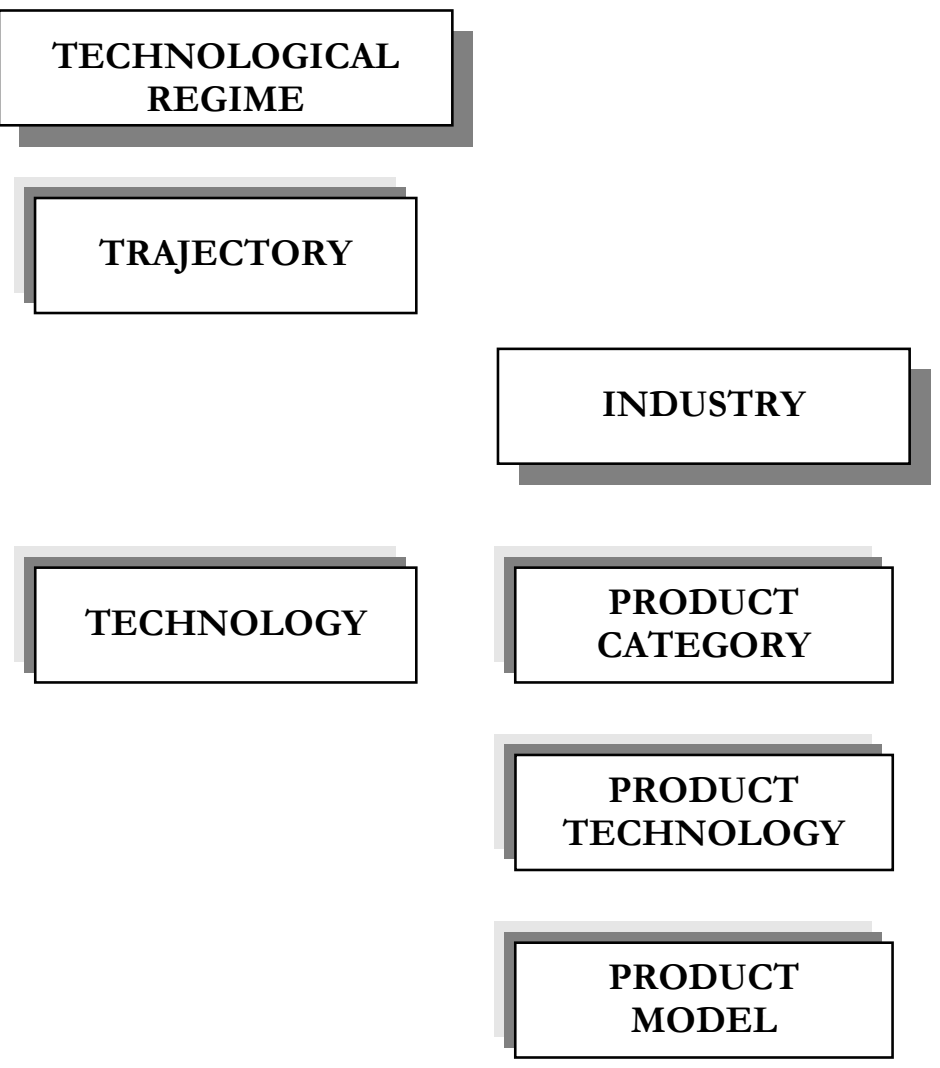

Source: Product markets hierarchy adapted from Bayus (1994).

\section{Examples}

Agile Production

Product Differentiation

Machine Tools

Household

Appliances

$\begin{array}{ll}\text { Multi-axis } & \text { Vacuum } \\ \text { Machining } & \text { Cleaner } \\ \text { Centre } & \end{array}$

High-Speed

Cyclonic

(Bagless)

Vacuum

Machining

Centre 
This study's approach to trajectory analysis is necessarily inclusive of a range of technologies since the intent is to observe the pattern of socio-economic change related to AMT use. As such, the subject focus is broader than usual for trajectory studies. The analysis also differs somewhat in that it focuses less on changes in specific technologies and more so on the direction of change in related technologies. To better understand this distinction, we first discuss previous research on production technology trajectories.

\section{Previous Research in Production Technology Trajectories}

According to Layton (1974), technologies are embodied at three levels - knowledge, organisational capabilities, and artefacts. Most previous studies of trajectories by economists have focused on artefacts, tracing the genealogy of a particular technology or technologies. Nevertheless, an examination of one level of technological embodiment is inextricably linked with reflection on the other levels. For example, Sahal (1985), chose technologies at the product category level to illustrate the ordered advance of design templates, but each template is characterised by design rules. His study of artefacts thus segues to an examination of the structure of the associated knowledge base.

Production technologies have been the subject of several studies. Mazzoleni's (1997) investigation of numerically controlled (NC) machine tools confirmed that organisational learning processes affect the direction of trajectory development. Hagedoorn (1988) examined control technologies in the continuous process industries, focussing on the interrelation of innovative behaviour and technological change. This study is something of an exception in that it looks at not just the individual technologies but the evolution of what Hagedoorn terms "basic designs", that is, the configuration of the control systems, an approach similar to that used in this thesis. Rosenberg's $(1963,1982,1994)$ analyses of the history of different techniques span industries. In his 1963 study of the machine tool industry, he showed that the adaptation of varied processes across industries occurred in response to demand for new skills and techniques, highlighting the knowledge and organisational dimensions of change. Freeman and Perez (1988) examined transitions between successive techno-economic paradigms and the effects of production technology shifts on industrial organisation.

These studies illustrate that while trajectory analyses tend to focus on artefact as subject, the interactions among all three levels of technological embodiment are important to understanding the development of trajectories and regimes. ${ }^{3}$

More immediate to this inquiry, a substantial number of AMT studies have been carried out by operations and production management researchers. These studies typically yield fairly broad analysis of AMTs' techno-economic attributes, but they are rarely performed within a temporal framework. Consequently, this line of research does not project a sense of technological change as a dynamic response to market forces, a perspective that tends to foreclose understanding of its socio-economic consequence. An exception is The Machine that Changed the World (Womack et al., 1991), which may owe its popularity to providing a historically-grounded, contextual reasoning for advocating lean production techniques, thus providing deeper social insights than are usual for these studies.

An incisive source of intelligence on AMTs has its roots in the need to build a common understanding on the direction of technological change in order to co-ordinate publicprivate investment. Industry roadmaps are documents that depict desirable futures according to stakeholders' interests and outline steps for getting there. As a rule, they are 
heavily influenced by industry's participation, which can lead to trenchant analysis. Because the production of roadmaps entails the empanelling of experts, both from the public and private sectors, they represent consensus on the broader outlines of current technological developments. Industry foresight analyses have a similar purpose.

Roadmaps and foresight analyses serve as the main source of information for the study of AMT trajectories in the thesis. They are especially useful for both their similarities and dissimilarities to the analytical approach taken in this study. On the one hand, since they are concerned with the future use of technologies and the rationale for change, they lend themselves easily to trajectory analysis. On the other, since their analytical frameworks complement but are distinct from trajectory analysis, they serve to show the utility of trajectory analysis by comparison.

\section{Industry Roadmaps and Foresight Analyses}

The principal source materials for the analysis in this chapter are nine industry roadmaps and foresight analyses focusing on manufacturing and the information technologies used in manufacturing. Three of the nine documents used in this study are from Europe, five from the U.S, and one is international. ${ }^{4}$ Table 4.1 gives a list of the nine documents.

\section{Table 4.1 Source Materials for the AMT Trajectories Analysis}

1. Agility Forum, Leaders for Manufacturing, and Technologies Enabling Agile Manufacturing. 1997. Next Generation Manufacturing: A Framework for Action. CD-ROM Project Report. Agility Forum.

2. Defence Science Board (DSB), Office of the Under-secretary of Defence for Acquisition, U.S. Department of Defence. 1993. Engineering in the Manufacturing Process. Report. Defence Science Board Task Force.

3. Eureka. 1995. Factory of the Future, Final Report. Report. Eureka 1005.

4. The Institution of Electrical Engineers (IEE). 1998. Next Generation Manufacturing Enterprise Framework. Internet. Available:www.iee.org.uk/PG/I7/framew.htm. Accessed: February 2000.

5. Intelligent Manufacturing System (IMS). 1994. Knowledge Systematisation: Configuration Systems for Design and Manufacturing. Final Report of Technical Work Package 5, Post Mass Production Paradigm, Gnossis Project.

6. National Centre for Manufacturing Sciences (NCMS). 1996. NCMS Collaborative Manufacturing Agenda. Report. CMS, Ann Arbor, Michigan.

7. National Research Council (NRC). 1995. Information Technology for Manufacturing: A Research Agenda. Report for National Science Foundation. NTIS, U.S. Department of Commerce.

8. Technologies Enabling Agile Manufacturing (TEAM). 1997. Areas of Research Needed for TEAM. Internet. Accessed: October 1998.

Technologies Enabling Agile Manufacturing (TEAM). 1999. TEAM Final Report. Internet. Available: www.llnl.gov/eng/eetd/ise_TEAM/. Accessed: January 2000.

9. Technology Foresight Programme, Office of Science and Technology, United Kingdom. 1995. Progress through Partnership 9: Manufacturing, Production, and Business Processes. HMSO.

Technology Foresight Programme, Office of Science and Technology, United Kingdom. 1997. Winning through Foresight: Action for Manufacturing, Production and Business Processes. Department of Trade and Industry. 
The key words and acronyms in bold font, identifying the reports' authors, are used subsequently throughout the chapter to reference the particular roadmaps. (The dates of publication have been eliminated in the citations to facilitate their repeated presentation.) In content the nine documents are similar, but they vary as to the depth of analysis and in their formats. Commonly, the starting point of analysis is to identify the drivers shaping the competitive environment, that is, the contextual factors which influence the direction of industrial development. (In this study's analytical framework, these drivers correspond to the dominant forces of the prevailing technological regime.) Typically, a roadmap/foresight analysis then turns to an assessment of what companies must do in order to be competitive in response to these forces. In some studies, the goal is to then identify specific opportunities to meet social and economic needs based on the subject industry's competitive strengths and technical potential. In others, the object is to layout a direction for future technical research.

A number of the roadmaps draw on theoretical models of the production enterprise in their analyses. The Next Generation Manufacturing Enterprise and IMS roadmaps (IEE, IMS) use the notion of the post mass production paradigm, whereas the U.S. Next Generation Manufacturing (Agility Forum) uses a structured hierarchical framework to elaborate drivers, the attributes a company must possess in response, the dilemmas in the way of achieving the attributes, and the enablers/imperatives needed to resolve the dilemmas. As for policy issues, while all nine studies focus on competitiveness, only two explicitly address sustainability as a major component in their analyses (IEE, IMS). ${ }^{5}$

\section{Identifying Trajectories}

Trajectories comprise an array of performance characteristics founded on technical and organisational rules/practices for realising technological advantages. Consistent with this construction, this study's fundamental units of analysis are the trade-offs embodied in the signature performance characteristics of a trajectory's constituent technologies. These characteristics are termed "functionalities" to place emphasis on their adaptive purpose. The definition of functionality that pertains is "design or adaptation to a particular use". 6 The concept is similar to that of a basic design or key element used in Hagedoorn (1988) to delineate trajectories. He describes trajectories as "a succession of generations of a basic design or a key-element." (p. 149)

One way of identifying a trajectory is then the dominant functionality of its constituent technologies. In that trajectory analysis concerns the study of technological change, a functionality must be grounded in a clear technical source or sources of competitive advantage. $^{7}$ But functionalities also assume a socio-economic dimension related to their respective competitive purposes and, in turn, each trajectory is itself situated within a particular socio-economic context, namely, a technological regime. Trajectories also stand out against the background flux of technological change by way of the operationalisation of their functionalities and the operational resource requirements of their constituent technologies. For example, the current level of product differentiation is enabled through the application of flexible production techniques in work settings that support crossfunctional teams.

The four trajectory markers - functionality, operational means, resource requirements, and socio-economic context - correspond to constructs used in systems analysis. Specifically, resources are the required system inputs; operationalisation, the operating 
mechanism; functionality, the desired system output; and the context is the system environment. Trajectory analysis thus stands to benefit from methods for formulating descriptions of system elements and their interactions. One such concept is that a change in a system parameter triggers changes in other parameters. Another is that system efficiency is a function of integration (Schütz, 1999) or "fit" between the individual system elements. Conversely, sub-optimisation - making a single process as effective as possible without attending to system interactions - results in inefficiency.

The system constructs used in trajectory analysis are also distinct at the firm level. Specifically, strategy involves the application of new operational functionality within a firm. The firm's practices are the methodologies it uses to implement strategies and achieve specific goals, that is, to operationalise system functionality. And the specific and detailed engineering methods, technical know-how, techniques and technologies used to support various practices are resources. In keeping with the principles of system operation, new technology introductions require changes in other production system complements - the firm's practices and strategy.

\section{Examining Trade-Offs}

Trade-offs are commonly referred to in the manufacturing strategy literature as the substance of design choices, and increasingly as the core of strategy (see, for example, Porter, 1996). But while a number of studies have probed specific trade-offs, few have examined their dynamics. More attention may be due as researchers begin to consider what should guide the selection of capabilities. Clark (1996), for one, points to the study of trade-offs as an important avenue for research, "Trade-offs are at the heart of manufacturing strategy, but we know little about their underlying sources.” (p.57)

Drawing on the evolutionary economics framework, this thesis posits that trade-offs result from path dependence in technology use. ${ }^{8}$ To wit, trade-offs emerge from the pursuit of performance benefits associated with technologies of like functionality. In a trade-off, a gain in an advantage of one kind is exchanged for progress in another direction. The classic example is the trade-off between low-cost, standardised goods production, based on economies of scale, and high-cost, small-lot manufacturing, that characterises the mass production regime.

A shift from one trajectory to another signifies a major technological adaptation corresponding to the "resolution" of a trade-off embedded in the earlier trajectory." By resolution, we mean a technical solution that enables firms to reduce the tension in the earlier direction of development. Yet, as observed in the preceding chapter, firms are wont to pursue opportunities along current trajectories until the costs begin to outweigh the gains to be made through continued efforts in the prescribed direction. At some point, diminishing returns will force a reconsideration of carrying on as usual. Sahal (1985) concluded from his studies of trajectories that "the origin of a wide variety of innovations lies in attempts to overcome the limitations of a technology's betterment." ( $p$. 80) At the macro level, Freeman and Perez (1988) have argued that the limits to development under the old paradigm act as a spur to investment in innovations that circumvent those limits through the begetting of a new type of productive organisation.

Progress along the new trajectory, however, comes at some new cost - and attendant need - in the organisation of the system. In addition, for the system to operate, new rules must be put into effect. As these rules derive from the regime, the onset of a new 
trajectory is governed by existent contextual factors at the same time the trajectory opens a new direction of development.

Often, a trade-off is calculated in terms of the "cost" of the chosen performance benefit, although such costs may not always be apparent. For example, a trade-off might involve the loss of an ability which would make future adaptation to as yet unknown conditions easier. A case in point is when increased economies of scale are achieved at the expense of greater process rigidity. Under the relatively stable market conditions of mass production, a loss of production flexibility was not seen as a potential weakness - in a volatile market, production flexibility is a competitive requisite. Yet, even these hidden trade-offs might be detected through an analysis of the current direction of technological advance by assessing firms' performance across a variety of measures. While the outcome of innovative activity is unknown for individual firms, the overall direction of technological advance is discernible. We can see, in general, which strategies succeed under current conditions.

While a new trajectory stems from the resolution of a previously existing trade-off, it would be a mistake to assume that the dominant functionality of the preceding trajectory no longer applies. Consider our earlier example of increasing economies of scale versus the loss of production flexibility. The ability to cost effectively reprogram machine tools to make a variety of parts opened the way for firms to offer differentiated product at costs near those of standardised product. However, flexibility comes at the cost of increasing equipment complexity which strongly tends to increase capital costs. ${ }^{10}$ Firms, as a consequence, still need to produce large volumes of product to make a return on their investments, that is, quantitative output continues to matter even though the trade-off between volume production and flexibility is resolved. Likewise, it is an oversimplification to reduce a regime to its dominant trajectory. In point of fact, several different modes of production commonly make-up regimes. For example, batch production exists alongside the continuous flow lines of mass production.

The extent to which a new direction of technology development extends or disrupts previously established dominant functionalities in the regime may be an indicator of how easy it is for one generation of technologies to supplant the next. A similar logic informs Abernathy and Clarke's (1985) innovation typology in which innovations are categorised according to the extent which they conserve or disrupt existing firm capabilities and/or market relations. A trajectory's strength is also probably related to its age, its influence growing with market penetration of the constituent technologies. More importantly, as the technologies mature, firms wield the new technologies with greater purpose as experience in their use accumulates. Consequently, the trade-offs may become strongly embedded in the trajectory through conscious efforts at optimisation.

It also seems fair to say that the subsequent effect on product markets of a change from one generation of production technologies to the next will vary according to the proportional balance between the successive generations of technologies over time and the strength of the respective trajectories. We are then likely to witness a mix of strategies and types of markets at any one time as technologies spread across industries according to different regime conditions.

All of these factors come into play in analysing the direction of AMT development, reflecting the complex dynamics of technology use, yet, as we see next, definite patterns emerge. 


\subsection{AMT Trajectories}

A fundamental issue in the rise of AMTs, both for competitiveness and sustainability, is their impact on product markets. It is clear that the transition to AMT use is not just in response to exogenous changes in competitive conditions but that AMTs themselves gave rise to those conditions. The dominant terms of product competition in today's markets are cost, quality, time-to-market, and performance based on distinctive product features. These attributes of competitive products have correlates in manufacturing competitive priorities and AMT functionality. The surge in such strategies as mass customisation provide evidence of the link between manufacturing strategy and the dominant production technology trajectories. ${ }^{11}$ This chapter uses trajectory analysis as a tool for tracing the effects of AMT evolution to conditions in the marketplace.

The analysis follows the line of argument that technology use creates technological momentum through a process of replicating the socio-economic trade-offs embedded in trajectories. New uses of production technologies, configured around new functionalities resolving old trade-offs, set off changes in product markets which alter the terms of competition. Given the success of the adaptation, more and more firms will follow the new direction of strategic advantage, strengthening its effects. By looking at emerging trade-offs, we can get a handle on the future direction of technological change and the opportunities for redirecting that advance.

\section{Drivers of the New Regime}

The emergence of a new industrial order that replaces mass production is close to universally acknowledged both in industry and in academia, although some manufacturers cling to a mass production world view, claiming that advanced manufacturing technologies and practices are not applicable to their industries. Still, merely granting the existence of a new paradigm leaves a wide margin by which to interpret its nature.

Regime transitions are distinguished by periods of turbulence resulting from social and institutional structural adjustments to pervasive technological change (Freeman and Perez, 1988). Nevertheless, from a research perspective, transitions proceed slowly. While the introduction of computer and microprocessor-based technologies into manufacturing dates to the 1950's, large scale adoption of the new technologies only started in the 1970s. Hence, the regime's mature character has only lately been revealed.

Researchers have affixed various names to the new production paradigm, including postFordism, flexible automation, lean production, flexible production, mass customisation, and, most recently, agile production. The succession of names is a sign of the continuous evolution in the technologies, as well as in the thinking about their socio-economic significance. In the beginning stages of the regime transition, it was common to characterise the new regime in contrast to mass production: where mass production meant high volumes, the new paradigm entailed low volume production. This led to some conclusions on the viability and economic potential of small-scale firms as the key enterprise in the new paradigm (see, for example, Piore and Sabel, 1984) that in retrospect appear to have had limited scope of applicability. Rather than small firms being able to compete headon with larger firms because flexibility lowered the cost of small production runs, it now seems that added flexibility in large firms allowed them to profitably enter niche markets that were formerly conceded to smaller firms (Booth, 1995). ${ }^{12,13}$ 
The objective of the roadmap initiatives under study in this thesis is to come to an understanding of the recent changes in manufacturing and what they mean for future competitiveness. The roadmap analyses converge on several elemental drivers that are observably related - the accelerating pace of change (Agility Forum, NCMS, Foresight), shorter times to market (DSB, IMS, NCMS, NRC), greater market volatility and dynamism (Eureka, IMS, NCMS), and increasing product, process, and system complexity (DSB, Eureka, IEE, NRC). These conditions are seen to directly affect firms' adaptive success, that is, to decide the requirements of successful competition. The most commented on social factor is changing customer requirements in the form of greater demand for product customisation and increasing customer expectations (Agility Forum, IEE, NRC, Foresight). Increasing consumer choice foretells market fragmentation and shrinking market segments (NCMS). At the same time, companies participating in the Factory of the Future study (Eureka), saw market drift, the tendency for today's product to become tomorrow's commodity, driving product differentiation strategies. Increasing product variety is regarded as the viable alternative to trying to become the low cost producer, a strategy deemed self-defeating in the long run because of low wage competition. This observation is allied to another frequently cited driver, the globalisation of markets, information, and competition (Agility Forum, IEE, NCMS, Foresight). Lastly, several roadmaps point to the increasing resource value of information and knowledge as a critical driver (Agility Forum, IEE, IMS, NCMS).

These conditions have superseded those characterising mass production, namely: homogenous markets, limited competition, regulated markets, and limited customer expectations (IEE). By contrast, rapid change and market unpredictability appear to have a commanding edge as the dominant features in the current regime (Katayama and Bennett, 1999; Sharp et al., 1999; Yusuf et al., 1999). The symptoms of market instability include shorter product cycles, the increasing number of product variants, an increase in demand for customised product, and the increasing pace of product introductions. Volatile markets, in turn, have led to the promotion of competitive strategies that emphasise flexibility, adaptability, and responsiveness to customer demands. Agility is gaining increasing attention as an umbrella manufacturing philosophy that harnesses flexible production techniques to the objective of meeting diverse customer requirements (Katayama and Bennett, 1999; Yusuf et al., 1999). Notably, speed is critical to the implementation of all of the envisioned competitive approaches.

In contrast to competitiveness drivers, sustainability issues receive only passing attention in most of the roadmaps and foresight analyses. There is note of resource limitations, the need to meet environmental regulations, and the increasing conflict between growth and the environment (Agility Forum, NCMS, NRC). Companies support public organisations taking the lead in developing clean manufacturing techniques (Eureka). But the diffuse nature of environmental challenges rarely convinces firms, on their own, of the need to modify their practices, as do competitiveness drivers. For example, one foresight report comments that, at present, there is little pressure to develop products with substantially longer lives (Foresight). Two of the roadmaps, however - the IEE Next Generation Manufacturing Enterprise Report (IEE) and the IMS Gnossis Project Report (IMS) place a critique of the mass production paradigm at the centre of their analyses. Increasing customer demand is linked to the "artificial stimulation of growth through the proliferation of trivial goods that people may want to buy, but which they do not really need." (IEE) Citing the problems of growing natural resource scarcity, environmental 
destruction, and the unsustainability of a mass consumption economy, they articulate a basis for the development of a post mass production paradigm.

\section{Current AMT Trajectories}

Three trajectories anchor the new regime and a fourth is beginning to take effect. In the analysis that follows, two primary descriptors are used for each trajectory. The first encapsulates the dominant performance characteristic of the trajectory's constituent technologies. The second descriptor defines the basis of the operationalisation of that functionality. Each trajectory is then described both in terms of the embodied technological opportunity (the functionality) and by the technical rules/practices for achieving this opportunity (the means of implementation).

The four trajectories are described in the approximate order of their historical appearance and thus delineate successive generations of AMTs, although there is also overlap and concurrence in trajectory development. This order appears to correlate with the strength of the trajectories in terms of their current influence on firm strategy.

The four trajectories are:

- Product differentiation/flexibility

- System optimisation/integration

- Knowledge systematisation/information management

- Adaptability/reconfigurability

The three current trajectories are profiled in Table 4.2 and all four are described in further detail in the text below.

The trajectories were arrived at through a process of comprehensively listing AMTs, their attributes, and their strategic uses as referenced in the nine roadmap/foresight documents. ${ }^{14}$ These data were then fused into the trajectories' descriptions. In addition to the dominant functionality and operationalisation for each trajectory, the resulting typology identifies the significant adaptation which resolves a given trade-off. The analysis is consistent with the approach to trajectory analysis developed in Section 4.1 and to standard content analysis methodology. ${ }^{15}$ Data from the roadmaps used to construct the four trajectories are summarised in Appendix B, AMT Trajectory Descriptions. The descriptions elaborate aspects of each trajectory's dominant functionality and its operational features.

It should be noted that the problem is not to establish definitive AMT trajectories but to understand the forces guiding AMT development so as to discover the elemental tradeoffs embedded in the trajectories. Even with this latitude in specifying trajectories, there is general concurrence in the roadmaps and in the operations and production management literature on what are the primary features of the new production paradigm. For example, Kim and Lee (1993) argue that "the new manufacturing technologies increase flexibility, integration, speed and information of manufacturing systems" (p. 4). The Next Generation Manufacturing Enterprise Report casts three features of the post massproduction paradigm as enterprise types (IEE). These three enterprise types associate compare neatly with the four trajectories in this paper: the "adaptive enterprise" corresponding to the adaptability/reconfigurability trajectory, the "niche production enterprise" to the product differentiation/flexibility trajectory, and the "knowledge-based enterprise" to two trajectories, the integration/communication and knowledge systematisation/information management trajectories. 
Table 4.2 PROFILES OF CURRENT AMT TRAJECTORIES

\section{Product Differentiation/ Flexibility}

Functionality: Product differentiation

Aspects of Functionality: Increased customisation; faster product delivery; ability to accommodate greater product or throughput variation

Operationalisation: Increased flexibility and faster cycle times

Operational Features: Rapid changeover of manufacturing processes; faster machining/processing times

Representative Technologies and Practices: High-speed multi-axis machining centres; cellular manufacturing; flexible manufacturing cells; rapid set, quick change tooling and fixturing

Adaptation: The automation of flexible manufacturing techniques in discrete parts manufacturing lowers the cost of product variety, making it possible to pursue low cost and product differentiation goals simultaneously.

\section{System Optimisation/ Integration}

Functionality: System optimisation

Aspects of Functionality: Improved process design tied to extended product variation; process, production, and business variable trade-off optimisation

Operationalisation: Integration of product, process, and business controls; expanded information exchange

Operational Features: Tighter process control; improved communication of goals and constraints

Representative Technologies and Practices: Computerised planning systems; intelligent processing; networked customers and suppliers; concurrent engineering

Adaptation: Through enhancing system interactions, the integration of manufacturing and business processes overcomes system inefficiencies characteristic of the fragmented, linear processes found in mass production.

\section{Knowledge Systematisation/} Information Management

Functionality: Knowledge systematisation

Aspects of Functionality: Systematisation of design and manufacturing knowledge; complexity management

Operationalisation: Knowledge capture, conversion, codification, and translation.

Operational Features: Improved capture of nominal and variant product and process behaviour; improved performance specification and mapping of specifications onto assemblies

Representative Technologies and Practices: Modelling and simulation; data mining and warehousing; in-process control metrology; knowledge-based systems

Adaptation: New processes for managing knowledge enhance firms' abilities to exploit opportunities in the unpredictable, rapidly changing markets which have superseded the homogeneous, stable markets of mass production. 


\section{Product Differentiation/Flexibility}

Under a mass production regime, plants with highly specialised equipment designed for long production runs co-exist with shops having more flexible production means. Using general-purpose, traditional machine tools, the latter, usually smaller-scale operations, make product in small batch lots or contract as job shops (Alcorta, 1998). These smaller comprise the supplier base that make goods to industrial customers' specifications. The two types of operations, mass production and traditional low volume manufacture, typify the fundamental trade-off in strategy under mass production - the choice between manufacturing low cost or differentiated product.

The development of flexible automation resolved this trade-off, (see Helms et al., 1997, and McDermott et al., 1997 for empirical evidence). Altogether, flexible techniques substantially lower the cost of product variety. Manufacturing a mix of products, however, depends critically on speed, which generally has meant increasing equipment and operational complexity.

The first advances in flexibility came with reducing set-up times through the development of quick change tooling. ${ }^{16}$ Later, the ability to reprogram machine tools stepped up the pace of production changeovers. Faster machine speeds, in turn, cut the work time of manufacturing product families and multiple product variants. In point of fact, higher speeds can also be used to increase economies of scale, but it was the application of speed to the opportunity of increasing flexibility through process reorganisation that reduced the costs of manufacturing multiple products, thereby stimulating demand for high speed equipment. Likewise, information technology (IT) provides more performance data at faster rates. By enhancing equipment accuracy, IT-enabled process control adds to equipment flexibility. A major breakthrough in flexibility came with cell technology, that is, grouping equipment to accommodate the manufacture of product families. This organisational innovation marked the transition to flexible systems thinking.

Increasing flexibility also requires a shift in operational focus from organisational structure to manufacturing practices. In mass production, because the tasks and the sequence of tasks are relatively fixed, organisational structure presents the greatest opportunity for further optimisation. In flexible production, the combining of various processes demands sustained attention, hence the need for a process focus. This shift in focus has consequences for the hierarchy of the system elements, with lateral communication among elements assuming greater importance.

\section{System Optimisation/Integration}

The axiom that efficiency results from the division of labour into specialised tasks dates back to Adam Smith. Under mass production, this principle led to dedicated machinery for a growing number of tasks and increasing levels of automation. But, the effort to optimise each process independently tends to preclude the consideration of systemic benefits, such that while individual tasks gain in efficiency, the firm's production system loses its ability to respond effectively to changes in the environment (Vonderembse et al., 1997). The result is local optimisation but global inconsistencies (IMS).

The one-way communication and linear equipment arrangements found in mass production lack the capacity needed to handle a mix of products. Under mass production, as long as plants focused on a few products and kept to linear production sequences, process co-ordination was manageable with simple relay controls. However, local decisions 
made sequentially over a period of time are liable to generate conflicts (Greaseley, 1999). Moreover, once the number of products made at a single facility starts to climb, a large number of process interfaces can disrupt material and information flows (NCMS).

Application of information technology to production and process control functions advances the integration of complex production processes. Interactive communication overcomes fragmentation (Foresight) and the limits to "command and control" operations. Operational focus shifts from organisational structure, who is doing an activity, to what is happening, process functionality (Ang and Gay, 1996). Intelligent machines perform a range of functions in various degrees through control feedback loops. Rapid transmission of detailed and accurate information on the status of individual equipment and quick feedback of instructions enables co-ordinated functioning as a systemic whole. Again, speed is a critical operational element.

Beyond the shop floor, integration pays more systemic dividends. The organisational complement to process integration is the team. Whereas, in mass production, a hierarchical structure facilitated command and control techniques, the shift from a product to process focus has meant dissolving the functional organisation. This, in turn, allows for fuller use of the knowledge and skill bases of workers and the cultivation of a sense of responsibility and process ownership.

In engineering, parallel product and process design reduces system uncertainties and speeds up implementation. Product modelling and simulation technologies are replacing the trial-and-error design approach, minimising the number of design iterations and reducing product development costs. Computerised production and process planning systems support multiple production pathways and trade-off management. The current wave of integration is to electronically link customers and suppliers to the shop floor in the virtual enterprise.

The intent of functional integration is to satisfy overall system objectives (Milne, 1995). This resolution of the efficiency versus inter-operability trade-off diminishes the problem of sub-optimisation of individual production tasks. ${ }^{17}$ Gone are the "islands of automation", the wall between design and manufacturing, and the information-short transaction. In their place stands the computer-integrated factory and the networked enterprise.

\section{Knowledge Systematisation/Information Management}

Mass production thrives in a static environment: scale requires predictability (Swink and Hegarty, 1998) and predictability greatly simplifies process data requirements. Consequently, knowledge resources under mass production are apt to be underdeveloped as the expense of monitoring change and controlling variability in a narrow range of processes is not warranted. In contrast, the desire to exploit rapidly changing and unpredictable market opportunities intensifies the need for access to information and knowledge (NCMS). Whereas, under mass production, competitive advantage was embodied in the scale of the physical plant, the ability to manipulate knowledge has become a primary competitive force in the new regime.

Information processing has customarily involved data collection, analysis, and information-based decisions. But, in addition, the accelerating pace of change has spurred the development of new processes to capture, manage, and store knowledge. The challenge of converting tacit into explicit knowledge has yielded the development of modelling and 
simulation technologies and knowledge-based systems (KBS) which feature artificial intelligence, neural networking, and fuzzy logic techniques.

Knowledge of nominal and variant product and process behaviour provides a foundation for the development of agile manufacturing capabilities. Similarly, IT-based data collection and processing technologies are used to recognise patterns in customer behaviour (St. John et al., 2001). At the same time, process flexibility coupled to integration creates a demand for rule-based controllers. Moreover, the scale and complexity of product data contributes to the need for codification.

The socio-economic dimensions of knowledge management have also raised challenges. Knowledge is reusable, non-exclusive, and in unlimited supply, but paradoxically, embodied knowledge has a shorter half-life. Companies might invest in training to enhance workers knowledge, but they risk losing that investment if the worker takes a job elsewhere. ${ }^{18}$ Sharing increases the value of knowledge, but sharing also goes against the competitive grain. New processes are needed for collective learning. And, not least, there is the question of how to value intangible assets.

\section{AMT-Enabled Adaptations}

As described above, the shift to AMTs resolves three trade-offs inherent to the mass production regime: economies of scale versus economies of scope; linear efficiency versus system inter-operability; and process predictability versus agility. The respective AMT-enabled adaptations are as follows:

Product Differentiation/Flexibility: Through economies of scope, flexible manufacturing technologies reduce the costs of producing a mix of products, making it possible to pursue low cost and product differentiation strategies simultaneously.

System Optimisation/Integration: The integration of process, product, and business functions overcomes the inefficiencies associated with linear specialisation by enhancing system interactions through the exchange of information.

Knowledge Systematisation/Information Management: The development of new processes to capture, manage, and store knowledge promotes the ability to exploit opportunities in the rapidly changing, unpredictable markets that have superseded the homogenous, stable markets of mass production.

New trajectories begin with adaptations that resolve trade-offs embedded in the existing regime. As the consequent system reorganisation proceeds, the seeds of emerging tradeoffs begin to take hold and the pattern of change becomes increasingly visible. The pattern of AMT-enabled change has led to the emergence of a fourth trajectory as observed in the roadmaps and foresight analyses. The adaptability/reconfigurability trajectory resolves trade-offs arising from the earlier three, as follows.

\section{Adaptability/Reconfigurability}

As customers require more, the demands on process performance grow in tandem. The rise in demand for differentiated product and faster product introductions has seriously stretched production capability. Frequent and rapid changes in process configuration present new challenges in the design and management of manufacturing systems, pushing system complexity (Greaseley, 1999). Manufacturers, on the other hand, have an affinity for process rationalisation and standardisation. Modularization has emerged as a key 
technical concept in resolving the trade-off between increasing responsiveness to customer needs and keeping process complexity manageable.

Modularity addresses the need for rationalising variety through the formation of autonomous sub-systems that permit flexibility in application (Marshall et al., 1999). It gives structure to complex manufacturing operations by virtue of its system-level framework for product realisation. Reconfiguration, based on intelligent autonomous modules that interact dynamically, replaces hard-wired interconnections (Leeuwen and Norrie, 1997). Critically, modularity forms a viable technical and managerial approach to continuous product innovation and process reorganisation. These latter capabilities provide the essential means of adaptability.

The emergence of this trajectory reflects a general evolutionary bent towards greater complexity and the organisation of systems around means of dealing with that complexity. While modularization may provide the definitive technical means of system rationalisation, other approaches to managing complexity have been envisioned. These include process simplification, streamlining operations, and concentrating on a small set of core activities. Katayama and Bennett (1999) have argued that Japanese companies seek to increase their cost sensitivity by shifting their fixed cost base towards variable costs. This allows them to modify their cost performance according to demand. Issues of complexity also underlie the move towards forming alliances to gain technology or market access (Foresight).

\subsection{The New Regime}

We have argued that coincident to the appearance of volatile and unpredictable markets, there has been the materialisation of a new industrial order - a production regime - primarily defined by the four trajectories described above. These trajectories embody tradeoffs realised through applying rules and practices found in the regime, of which probably the most common is to exploit speed. All four trajectories share this means of operationalisation, but speed is also a crucial aspect of each trajectory's functionality. In effect, speed is both a means and an end. Substantively, the emergence of the new industrial order marks a shift from scale-based to time-based manufacturing strategies.

Faster machine speeds and reduced set-up times enable the low-cost production of product mixes, permitting rapid turnover of product in the market. Integration of product, process and business controls provides the ability to react quickly and effectively to changes in part configurations, lot size orders, and delivery schedules, while the ability to quickly process large amounts of information provides for seamless operations. Higher levels of knowledge use, supported by rapid-fire information processing, increase the speed and quality of decision-making, an essential capability in volatile markets. The lightening speeds of information processing also enable continuous process reconfiguration, that is, the strategic capacity to respond dynamically to demand fluctuations.

While speed may be the dominant characteristic of the new regime, this does not entirely displace the influence of other functionalities. As noted before, a mix of strategies and types of markets exist concurrently as technologies are adopted according to the varying regime conditions found in different industries. Efforts to improve quality and lower prices are still competitive imperatives (NCMS) and IT has also enabled the continued 
development of high-precision equipment. However, these advances do not dominate the evolution of advanced production technologies to the extent speed has and does.

All four trajectories thus demonstrate the centrality of speed to the new regime. They figure predominantly in the development of time-based strategies, the subject of the next chapter. The ultimate goal is strategic agility - the ability to quickly change focus whenever the market moves (Eureka). Speed enables dynamic responsiveness to customer needs and requirements. But just as with any regime, mass customisation portends the de facto development of trade-offs.

The most recent AMT trajectory of adaptability/reconfigurability addresses a trade-off emerging out of early AMT use: increasing responsiveness to customer demands versus process manageability. Modularisation addresses the need for rationalising variety and keeping process complexity manageable through the formation and configuration of autonomous sub-systems that permit flexibility in application. The emergence of this trajectory tends to confirm the existence of new trade-offs specific to AMT use, in this instance, increasing flexibility and process integration have come at the cost of increasing complexity. But AMTs may pose other, more fundamental, trade-offs. As Swamidass and Kotha (1998) have succinctly put it, strategic initiatives provide new opportunities for making money, while strategic technologies seldom save money. When AMTs add to system complexity and increase resource requirements, this indeed appears to be the case. The four trajectories then signal new needs related to AMT use. Moreover, trade-offs manifest at all levels of the regime given its systemic nature. The consequence of AMTrelated trade-offs for firms' ability to compete is the subject of the next chapter. There we look at the costs of product variety and faster product introductions. Then, in Chapter 6 , we turn to examining the implications of AMT-related changes in the organisation of production for sustainability. 


\section{Chapter 4 Endnotes}

1 "Needs" in this chapter assumes a similar sense to that of trade-offs noted in Chapter 3. A need points to a dominant direction in technology development that presents manufacturers a challenge, It is not meant to refer to the immediate capital needs of individual firms.

2 As with any theory that becomes popular, many of the commonly used terms in evolutionary economics have taken on a life of their own. Definitions proliferate and exact meaning is lost. For example, it is difficult to tell where previous theorists have drawn the dividing lines between paradigms and trajectories or between trajectories and technologies, as definitions tend to change from model to model. When possible, I try to add clarity by giving definitions to give the model internal consistency and points of reference for comparison with other models.

3 An empirical study of trajectories based on Pavitt's (1984) taxonomy of industrial sectors found no significant relationships to confirm the model (De Marchi et al., 1994). As Pavitt's classification relies primarily on industry characteristics (sources of technology, e.g. R\&D versus outside suppliers, requirements of users, e.g. low cost versus performance, and means of appropriation) rather than the production technology's characteristics to define trajectories, it is difficult to find points of comparison to the model put forward in this thesis. However, Pavitt's taxonomy seems to stress sectoral differences that pre-date the influence of AMTs, specifically, the trade-off between cost and performance.

4 The greater number of U.S. documents used in the study reflects the higher incidence of U.S. roadmap initiatives.

5 In addition to the in-depth study of the roadmaps and foresight documents, articles from Manufacturing Engineer, a journal published in the United Kingdom from the years 1995, 1997 and 1999 were analysed. Articles in this magazine are an important vehicle for communicating research findings on operations and technology management to manufacturing professionals. A final source of information were several reports prepared under the auspices of the Institute for Prospective Technologies (IPTS). These included a 1999 roadmap-like document focussing on information and communication technologies (Ducatel et al., 1999). However, the scope of this document is much broader than the nine roadmaps chosen for detailed analysis.

6 Functionality is the commonly used term in the operations and engineering management literature to refer to a technology's purpose within its users' systems.

7 This point, to which we return later in the thesis, is significant in considering the viability of different solutions for realizing sustainability.

8 Chapter 9 elaborates this premise in greater detail.

9 In the roadmap/foresight models, the genesis of change drivers is invariably exogenous to the change process, resulting in numerous tautologies describing the purpose of new technologies and their market causes. In contrast, this study's analytical approach describes change in the direction of a trajectory as the result of a process wherein markets and the strategic use of technologies co-evolve.

10 The evidence for this assertion is presented in Chapters 5, 7 and 8.

11 The definition of mass customisation that applies here is given in Chapter 1 as "the manufacture of highly individualized product on a volume basis".

12 Chapter 6 elaborates the consequences of this development.

13 Similarly, in the retail sector, we see specialty shops in supermarkets displacing delicatessens.

14 As noted above, articles from Manufacturing Engineer were also used in this analysis.

15 See Chapters 1 and 7 for further elaboration of content analysis.

16 More precisely, quick-change tooling is the term used today to refer to the latest generation of these techniques, which are of course many time faster than those devised originally by Taichi Ohno. But it was Ohno's innovations in tooling set-up that became the foundation for the Toyota revolution described in Chapter 2. 
17 Inter-operability is the ability to directly accept, process, and share information without degradation in the quality of the information. Sub-optimization refers to the optimization of single parameters or processes without considering how this effects the total process.

18 This may be more of a dilemma for small companies in the U.S. than in Europe, where stricter labour laws discourage mobility between companies. On the other hand, managers in small European companies often will not hire someone whose education surpasses their own since they may not be able to get rid of them if they prove disruptive to the hierarchy. 


\section{Chapter 5 Economies of Speed}

In the great struggle for life - for the greatest possible fullness and intensity of life with the least waste of energy - natural selection continually seeks out the ways precisely for avoiding competition as much as possible.

Peter Kropotkin: Mutual Aid

In the name of competitiveness, numerous initiatives in the past few decades, both public and private, have aimed to accelerate industry's transition from mass production to what we now call mass customisation. They are largely succeeding. At the very least, the technical means of achieving this transformation are well in hand. AMTs have enabled the relatively low cost production of a wide variety of goods and industry has embraced AMT use.

Yet, being competitive does not guarantee well-being. To the contrary, there is cause for concern that many current practices in the strategic use of AMTs are unsustainable since they lead to increasing resource consumption in the aggregate. In particular, faster product introductions and increased product variety have serious implications for sustainability for the reason that firms with time-based strategies must 'grow to compete', resulting in the need for an ever larger effective demand.

Proposed solutions to intensive resource consumption and the more general problem of how to decouple industrial activity from negative environmental impacts have largely focused on producing "more with less" and integrating sustainability criteria into economic decision-making. While effective in limiting the environmental impact per unit of production activity, this approach essentially overlooks the issue of how growth in consumption is allied to increasing competition. The analysis offered in this thesis differs by examining the interdependency between market demand and the competitive uses of AMTs.

In this chapter, we trace the economic significance of shortened product cycles and greater product differentiation to its technological sources, by way of examining why firms, driven to stay competitive, are adopting operational strategies based on reducing the time it takes to develop and manufacture products. 


\subsection{Time-Based Strategies}

The increasing prevalence of time-based manufacturing strategies is linked, on the one hand, to the wide-spread use of AMTs and, on the other, to the emergence of a mass customisation regime. This dynamic sustains itself with new forms of strategy coming into effect as new technology and market conditions emerge. Additionally, every regime is marked by distinctive goals. Faster product cycles and low-cost product variety effectively define the emerging regime, just as economies of scale and low-cost standardised product commanded mass production.

In Chapter 4, we saw that speed is an essential characteristic of the four production technology trajectories comprising the new regime. In this chapter, we focus on two market effects of time-based strategies - faster product introductions and increased product variety - in developing a more explicit economic rationale for the pursuit of these strategies and examining their effects on demand.

Faster product introductions are made possible by cutting product cycle times, that is, the time it takes to bring new products to market. Historically, depending on the industry, the average product's life cycle has been five to ten years; now the average is one to five years (National Centre for Manufacturing Sciences, 1996). Toyota, to take one example, has the capability to introduce a new car model every ten months (Lau, 1995). Correspondingly, product markets reach maturity much faster (St. John et al., 2001). Telephones took 35 years to reach one-quarter of the U.S. population, television 26 years, personal computers 16 years, and mobile phones 13 years (United Nations Development Programme, 1998).

Increased product variety derives from low-cost production flexibility. The less time it takes to re-order production to make a product variant, (holding capital costs constant), the lower the cost of the variant. Reducing the costs of variants has dramatically increased their supply. Matsushita, for example, at one point offered 220 types of televisions and 62 types of VCRs (Lau, 1995).

These two phenomena, faster product introductions and increased product variety, definitively characterise the new regime's consumption domain. ${ }^{1}$ We associate their impact on the extent of consumer product choices with mass customisation. But although customisation implies that the products are made to order, in point of fact, very few household consumption products are presently made to end users' specifications. Thus, in assessing the impact of AMT use on product market structure, it is important to examine closely what mass customisation means in practice.

\section{Competing on Time}

The competitive benefits of time-based strategies are said to include: price premiums for rapid response to customer demands; increased market share as a result of greater customer satisfaction tied to the rapid delivery of customised product; improved product quality; better market coverage via expanded product lines; stimulus for product innovation; a quicker reaction to changes in market conditions; and increased operational productivity (Schmenner, 1988; Stalk, 1988; Stalk and Hout, 1990; Bozarth and Chapman, 1996; Kumar and Motwani, 1995; Lau, 1995; Tu et al., 2001). 
Whether these benefits are specifically the result of time reductions, or of systematic efforts to reorganise production with the intent to reduce process time, is not the issue here. $^{2}$ What is of interest is the extent to which speed has become a central focus of manufacturing strategy (Stalk, 1988; Bartezzaghi et al., 1994; Bozarth and Chapman, 1996; Yusuf et al., 1999; Tu et al., 2001). ${ }^{3}$

The impetus for time-based strategies has its roots in two earlier developments: just-intime (JIT) production and the ascent of product innovation as a common business strategy (Bozarth and Chapman, 1996). As manufacturing dictums, the two approaches, JIT and new product development (NPD), differ in their operational emphasis. JIT, or lean production, focuses on rationalisation of the production processes, particularly with regard to eliminating "waste" - waste of materials, plant capacity, product (in inventory), space, human effort (in unnecessary and duplicative steps), and time (Womack et al., 1990; Katayama and Bennett, 1999). NPD strategies, on the other hand, call for increasing responsiveness to customers' needs, which generally means developing additional capabilities. There is a seeming tension between the two approaches: one emphasises elimination, the other addition. And, while both JIT and NPD lead to shorter manufacturing lead times, time reduction tends to occur in different operational processes according to the approach (Bartezzaghi et al., 1994). ${ }^{4}$ NPD stresses speed in the design functions, JIT in the shop floor processes.

Yet, the emergence of time-based competition as a strategy with its own influence suggests that JIT and NPD are not incompatible. Instead, over time, each approach tends to activate time reductions throughout the production system since shrinking the time it takes to perform key activities requires substantial reorganisation of all of the production processes. ${ }^{5}$ We can thus see the effect of time changes in one part of the system on the whole, that is, in the organisation of execution, control, and planning operations. ${ }^{6,7}$

Speed in execution involves higher machine speeds, eliminating equipment set-ups, and reducing the time it takes to reset equipment and move product or parts from one manufacturing stage to the next. In discrete parts manufacturing, two AMT-related advances are particularly associated with these reductions: the reprogrammable, multi-purpose machine tools, known as machining centres, and cellular manufacturing. Machining centres can be programmed to switch machining axes and between machine tool operations (e.g. milling, drilling) previously embodied in separate equipment. ${ }^{8}$ Cutting set-up time increases equipment availability, thus increasing its effective capacity, (assuming variety is held constant). In cellular manufacturing, the equipment needed to make a family of parts is grouped together as opposed to the earlier practice of locating functionally alike pieces of equipment (e.g. lathes) in process technology centres. Since similar parts need similar set-ups and parts travel shorter distances, a cellular equipment set-up works to shorten throughput time and streamline processes. ${ }^{9}$

In terms of bringing down the costs of product variety, these advances either increase volume capacity, holding product variety constant, or increase operational flexibility (mix capacity), holding volume constant. But to make use of these advantages requires the efficient allocation of machine time and cutting tool time, that is, reducing manufacturing lead times also depends on the speed of control operations.

Speed in control is a function of the rate of transmission of information on the availability of different resources and the location of workpieces. Each product variant has a specific combination of routing and tooling requirements. The control system resets the 
production system according to these product-specific requirements. As Ranta (1997) describes it, there is one production system but several logical or virtual production lines. Efficient routing of orders through the plant facilitates the equipment's utilisation. To this end, JIT pull systems reverse the usual programming of control signals. In pull production, demand at the succeeding workstation signals start of a part's production, whereas in conventional production, parts are pushed through the system, that is, production at one stage only starts once all the preceding production steps have been completed. As a result, previous to AMTs, long lead times were needed to resolve resource conflicts (Stalk, 1988). Management efforts to increase machine utilisation would lead to excess inventory building up in front of machines (Schmenner, 1988). Products were in actual production only 0.05 to 2.5 percent of the time (Stalk, 1988). By contrast, shop floor activities based on real-time information processing proceed more quickly by eliminating the need for centralised decision-making. The use of real-time information also prevents the development of bottlenecks due to unscheduled equipment downtime. In addition, when scheduling is moved to the basis of current orders, as in a JIT pull system, the effect is to free machines for use in the manufacture of needed parts, reducing idleness in downstream equipment. Work-in-process (WIP) inventory is dramatically reduced and product flows swiftly through the plant as the piling and re-piling of parts is eliminated. ${ }^{10}$

Reorganising the control function to reduce manufacturing lead times changes the way process information is used. Rather than use dated information and demand forecasts, information on the current status of equipment and WIP is used to control operations. In turn, this shift in information use triggers a corresponding need for additional planning information. As product mix evolves over time and demand fluctuates, effective control depends on timely information on when different manufacturing capabilities will be needed.

Speed in planning involves the ability to deploy resources rapidly. Firms have traditionally used sales forecasts to offset long manufacturing lead times, but the accuracy of forecasts declines as lead times increase. ${ }^{11}$ Planning by forecast tends to result in higher levels of inventory (and thus longer lead times) and unsold product, plus a higher frequency of expedited jobs disrupts the flow of product through the plant. Computerassisted planning technologies, such as the currently popular Enterprise Resource Planning (ERP) programmes, provide a tool for handling complex resource management transactions. Long lead times are also associated with the use of sequential design practices. New product generations call for the development and implementation of additional manufacturing capabilities, plus there is the time to design the products themselves. The difficulty of managing this process sequentially often leads to revised product introduction dates. Rapid product introductions then require not only superior design capabilities but also their integration with the engineering, marketing, and manufacturing functions (Hardaker et al., 1998). Key design technologies include computer-aideddrafting (CAD), especially programmes with 3-D solid modelling, and rapid prototyping.

The development of resource management and concurrent engineering practices thus support the continuous reconfiguration of the physical system. Effectively, they represent the emergence of time-based capabilities in the externally oriented planning level of system organisation. The ultimate time-based capability is real time response to customers' demands (Yusuf et al., 1999). If design and manufacturing lead times can be reduced to zero, then plants would only have to forecast for the next day (Stalk, 1988). 
The above composite view of time-related system changes suggests that we are witnessing a convergence of the execution, control, and planning processes. Moreover, as these processes converge, the entire production system approaches a real-time operational basis. In Stalk's (1988) view, companies are systems in which time connects all the parts. As companies move towards faster response times, the convergence of processes becomes more marked, but how customised the product is also a factor in response time.

\section{Customising Product}

Mass customisation is widely held to be replacing mass production as the future of manufacturing (Blanchard, 1995; The Economist, 2001). The intent is to quickly design, produce, and deliver products that serve individual customer preferences at prices close to that of mass production (Tu et al., 2001). ${ }^{12}$ Renault's dream is to build and deliver cars to the customers' specifications within fifteen days. Currently customers wait an average of 50 to 60 days for a customised car. In other markets, the transition has already occurred. It takes Dell less than two hours to customise a personal computer (PC) per a customer's order: four minutes to assemble the PC and 90 minutes to load the software.

Table 5.1, Customisation Strategies, presents a manufacturing strategy classification based on the range of capabilities firms have for making customer-specific product. These encompass the abilities to design, engineer, manufacture, and/or assemble a product to a customer's specifications. The strategies vary according to when, during the production process, the customer's individual preferences are taken into consideration, which then determines the extent of product customisation (Bozarth and Chapman, 1996).

\section{Table 5.1 Customisation Strategies}

\begin{tabular}{|c|c|c|c|}
\hline Strategy & $\begin{array}{l}\text { Customisation } \\
\text { Capabilities }\end{array}$ & $\begin{array}{l}\text { Degree of Product } \\
\text { Customisation }\end{array}$ & $\begin{array}{l}\text { Representative } \\
\text { Products }\end{array}$ \\
\hline Design-to-order & $\begin{array}{l}\text { Design and engineer } \\
\text { product to customer's } \\
\text { specifications }\end{array}$ & $\begin{array}{l}\text { High: Each product is } \\
\text { unique (one-off) and } \\
\text { customer-specific }\end{array}$ & $\begin{array}{l}\text { Commercial buildings; } \\
\text { major plant equipment }\end{array}$ \\
\hline Engineer-to-order & $\begin{array}{l}\text { Engineer product to } \\
\text { customer's specifica- } \\
\text { tions using standardised } \\
\text { design elements }\end{array}$ & $\begin{array}{l}\text { High: At least some } \\
\text { portion of product is } \\
\text { specially designed ac- } \\
\text { cording to customer's } \\
\text { engineering input }\end{array}$ & $\begin{array}{l}\text { Machine dies; main } \\
\text { frame computers }\end{array}$ \\
\hline $\begin{array}{l}\text { Manufacture- (or make) } \\
\text { to-order }\end{array}$ & $\begin{array}{l}\text { Make product to cus- } \\
\text { tomer's order using } \\
\text { standard designs }\end{array}$ & $\begin{array}{l}\text { Moderate: Final pro- } \\
\text { duct configuration is } \\
\text { customer-specific }\end{array}$ & $\begin{array}{l}\text { Custom bicycles; cus- } \\
\text { tom doors; custom } \\
\text { jeans }\end{array}$ \\
\hline $\begin{array}{l}\text { Assemble- (or finish) } \\
\text { to-order }\end{array}$ & $\begin{array}{l}\text { Assemble to customer's } \\
\text { order from standardised } \\
\text { parts }\end{array}$ & $\begin{array}{l}\text { Moderate: Product is } \\
\text { available in standard } \\
\text { major options with } \\
\text { choice of features }\end{array}$ & $\begin{array}{l}\text { Automobiles; commod- } \\
\text { ity chemicals; custom } \\
\text { computers (e.g., Dell) }\end{array}$ \\
\hline Manufacture-to-stock & $\begin{array}{l}\text { Make product to replen- } \\
\text { ish stock; orders filled } \\
\text { from inventory }\end{array}$ & $\begin{array}{l}\text { Low: Product is stan- } \\
\text { dardised; purchases are } \\
\text { off-the-shelf }\end{array}$ & $\begin{array}{l}\text { Non-power hand tools; } \\
\text { consumer goods sold } \\
\text { through retail stores }\end{array}$ \\
\hline Manufacture-to-forecast & $\begin{array}{l}\text { Make product to set } \\
\text { forecast; orders filled } \\
\text { from inventory }\end{array}$ & $\begin{array}{l}\text { Low: Product is stan- } \\
\text { dardised }\end{array}$ & Light bulbs; clothes \\
\hline
\end{tabular}


As one would expect, the greater the customer's involvement in determining the final product design, the greater the degree of product customisation, and the greater the requisite capabilities. These capabilities, however, need not be time-based. In a mass production regime, many supplier companies have design-to-order or engineer-to-order capabilities as required by the nature of their product markets. Instead, the development of time-based capabilities means that design- and engineer-to-order products are no longer limited to small volume production (Tu et al., 2001).

The last two strategies listed in the table, manufacture-to-stock and manufacture-toforecast, do not allow for direct input by the customer into the production process. These two strategies are typical of, but not limited to, mass production facilities. Neither strategy, however, precludes product variety or faster product introductions. The classification in Table 5.1 then makes a distinction, not generally recognised in the literature, between product customisation and product variety. One implication of this difference is that shorter lead times are necessary to, but not dependent on, faster response times.

Table 5.1 also points to some crucial differences between cost-based and time-based strategies. Cost-based strategies drive manufacturers to reduce costs at the expense of responsiveness (Stalk, 1988). This dictates a manufacture-to-stock or manufacture-toforecast strategy. By contrast, time-based strategies increase responsiveness to the customer as a result of cost effectively extending the firm's capabilities.

But then again, the two approaches are not mutually exclusive. Low cost product variety and faster product cycles are features of commodity markets where there is no individual consumer input in the production process, for example, mobile phones. As it happens, in consumer markets, a first-to-market strategy, in which companies aim to be the first to offer product, may be the most common approach to "satisfying" customer needs. Product variety and new product variants are then available from the retailer who replaces inventory as needed. From the point of view of the manufacturer, this is a maketo-order environment since production is only initiated once the order is received from the retailer. However, from the end users' perspective, this might be considered a maketo-stock strategy as consumers are selecting product from inventory, albeit a continuously changing inventory.

The choice to increase customisation or not then appears to pose a trade-off between keeping product variety costs low and the cost of increasing responsiveness to the customer. A customisation strategy reduces the risk of unsold product, assuming that customers are willing to pay a premium. On the other hand, although customers care about when the product is available, they are not really interested in how long it took to make. What matters is how suited the product is to an individual's particular needs. Customers appear to be willing to pay premium prices for customised product - as long as they do not have to wait too long for that product.

In choosing a strategy manufacturers must balance these considerations according to the dictates of their markets. At the same time, the overall evolution of market demand appears to be headed in the direction of increased individual customer requirements, (as illustrated in the following company profile). This may represent the increasing significance of customer-related knowledge as a production input, which, over time, might develop as a separate competitive advantage apart from the speed of production. Meanwhile, time-based capabilities are supremely evident in today's markets in the form of 
increased product variety and faster product introductions, whether or not there is a customisation strategy involved.

\section{Mass Customisation - A Company Profile}

Stoves plc makes mass-produced goods for individual customers' tastes (Kellock, 1999). Rather than market a range of stoves from which the customers choose, the company asks the customers what they want. With no products made for stock, they produce around 2500 types of cooking appliances weekly in small lots, typically in batches of three. 20 per cent of their product goes directly to the end customer. For repeat customers, Stoves plc offers a seven-day lead time.

The company's key production elements include modular product designs, flexible equipment, and a responsive workforce. Tool changeover on their oven cavity forming line is just 10 to 15 minutes. Integrated programming has replaced the programming of individual machines, resulting in reduced programming time and higher machine and material utilisation rates. The company also stresses hands-on independence and the continual search for new manufacturing methods. Stoves plc's production engineers, not the equipment suppliers, are responsible for installing, commissioning, maintaining and servicing new equipment.

The mass customisation strategy has turned Stoves plc into a profit maker with a 5.8 million pounds profit on a turnover of 90 million pounds in 1998 from a company with a 4 million pounds loss on a volume of 17 million pounds in 1989.

\subsection{Speed and the Organisation of Production}

A full understanding of the competitive advantages of time-based strategies requires an understanding of the organisation of production. In the section above, we saw that the reorganisation of the production process has both spatial (e.g., cellular manufacturing) and temporal (e.g., rapid prototyping) dimensions, as well as effecting changes in the pattern of relationships among the processes (e.g., JIT techniques). In this section, we apply the fund-flow model to the analysis of the development of AMT-based capabilities and the concomitant reorganisation of production to construct a typology of speed-related sources of competitive advantage. The analysis owes considerably to Morroni's (1992) development of the fund-flow model as explained in Chapter 2. It also draws on the analysis of the industry roadmaps described in Chapter 4.

\section{Time in the Production Process}

Time appears in two guises as an element in the production process. Time is the measure of the use of funds in the manufacture of specific product, but also time marks the progression in development of specific product/process/resource systems. Economic gains from time reduction occur when average unit costs fall as a function of reduction in the time a given microeconomic unit (for our purposes, the firm) takes to produce a given evolving mix of specified product.

Reducing time in the manufacture of product is achieved through technical innovations in speeding up the execution of production. ${ }^{13}$ The effect is to manufacture the same mix of products faster. The material transformations taking place in converting inputs to 
product remain the same, but occur at greater speeds. By increasing speed we increase productive capacity (the range of output levels over which a technically optimised unit produces), holding organisational structure and environmental (institutional) conditions constant.

Reducing time in the implementation of product/process/resource systems is a matter of increasing the speed of production system planning and realisation. The effect is to manufacture an evolving mix of products faster. The resource transformations are the same, but occur at greater speeds. By increasing speed we increase productive capacity, holding organisational structure and environmental (institutional) conditions constant, but within wider parameters, that is, by increasing strategic flexibility. ${ }^{14}$

It is the second aspect of time, regarding the speed of adaptation of production systems to changes in market and industry conditions, that veers from the standard economics notion of measuring productive capacity. Morroni's exposition of the fund-flow model introduces production flexibility, the capacity of the organisation to respond to changes in its environment, and, in particular, the capacity to change the mix of products according to market evolution, as a central concept relating time to the modes of execution (the organisation of inputs and size of the productive units). The implication is that, since market conditions are not static, there can be no single fixed technically optimal combination of system elements. Instead, there is the possibility of continuous reorganisation of the production processes in response to a highly variable environment.

The object of reorganisation is to cost effectively adjust production to serve different customer's needs. The fund-flow model maintains that the indivisibility of integral system elements and their complementarities define the use of flows and funds. Recall that funds are those system elements which provide productive service (e.g. land, capital, workers, knowledge base), while flows correspond to process inputs or outputs. ${ }^{15}$ Changes to system properties, that is, in the relations among the production system elements, thus provide for increasing productivity and cost savings. When funds are indivisible, they combine with each other in relations of complementarity, not substitutability, that is, fixed coefficient production is the general case. ${ }^{16}$ Indivisibility prevents payment for production funds in exact correspondence with the capacity used and the time strictly necessary for their use. This results in fixed costs which lead to an increase in unit cost under conditions of insufficient demand. ${ }^{17}$ Complementarity is expressed by limitational flows, that is, inputs that are transformed in proportion to some particular combination of funds. Because of complementary relationships, the main economic problem in production is choosing a combination of processes that minimises fund idleness under changing conditions.

But processes are also characterised by variability, (here we extend the model), as well as by the indivisibility of inputs. Variability is that property limiting the predictability of the performance of the system or of individual elements within the system. Variability results from the inherent randomness of processes (Klammer, 1996). Classical treatments of the production process, for example, Smith's pin factory, have presumed deterministic processes. In contrast, historical exegesis of production systems have shown the constitutive need to control variability in the improvement of the production process. For example, establishing interchangeability of parts was essential in the transition from craft to mass production. In mass production, worker and equipment specialisation limits process 
variability. In multi-product production, knowledge-based production planning systems, such as ERP, are key to managing process variability (Kræmmergaard, 2001).

Variability is the primary cause of non-productive capacity (Klammer, 1996) or, in the model's terms, fund idleness. Process variability constitutes a principal barrier to improving response times (DSB, 1993; Agility Forum et al., 1997). As a matter of production system operability, the analysis of variability focuses on characterising and assessing process stability (Deleryd, 1997). It involves the analysis of component, subsystem, system and process interactions, dependencies and constraints. The greater the system variability, the higher the "technical transaction costs" occurring at the system/element interfaces. Any process that produces a higher system order, that is, reduces system variability, will not occur without the addition of resources (usually energy or information), in which case it is an open system. ${ }^{18}$

Variability can then also be seen as a measure of entropy or process irreversibility (Guilmet, 1982; Capra, 1996). Irreversibility in system organisation comes into play because, by the nature of the cumulativeness of technological advance as encoded in the knowledge base a given system draws from, including the knowledge embodied in equipment and products, only certain complementary relationships among the production elements will find use. Perception of "the way things work" and what is possible are predicated on user knowledge of the variability and relationships of complementarity associated with present outcomes. ${ }^{19}$ These outcomes are cumulative, irreversible, and specific to the production unit; they are qualitative in nature. Because improvements are based on unwritten tacit knowledge of the machines in use and the problems to be solved in a given production unit, the perceived determinacy of system processes tends to restrict the search for more productive relations of complementarity, magnifying the "economic problem of production". As Morroni concludes, "[T] he degree of irreversibility of economic choices about production processes influences the level of strategic flexibility."

In its entirety, this derivation of the fund-flow model links the relationship between times and modes of execution and planning processes to the processes underlying technological change. We can thus use the four system properties (indivisibility, complementarity, irreversibility, and variability) to identify the impact of increasing the speed of different processes on system organisation.

\section{The Sources of Speed}

An analysis of the economies of speed centres on what are its sources with respect to particular technological paradigms and how specific reductions in time drive reorganisation of the system elements. The analysis here addresses the change in system relationships for each source, drawing on data from the roadmaps and foresight analyses for substantiation, (see Section 4.1 for a list of these documents). The results of this analysis are presented in Table 5.2 and discussed below in relation to the trajectory analysis presented in Chapter 4. Effectively, this classification of the sources of speed reprises the trajectory analysis within the framework of the fund-flow model.

The analysis here focuses on technical and managerial factors related to AMT use. Comparing the sources of economies of speed to those of scale shows that increases in speed affects the organisation of production in a different manner than do scale increases. The technical factors in economies of scale are usually placed in two categories. The economies of increased dimension derive from the geometrical relationship between volume 
Table 5.2 Sources of Economies of Speed

\begin{tabular}{|c|c|c|c|c|c|}
\hline Source & $\begin{array}{l}\text { Time Reduction } \\
\text { In: }\end{array}$ & $\begin{array}{l}\text { Change in Organisation } \\
\text { of System Elements }\end{array}$ & $\begin{array}{l}\text { Representative Tech- } \\
\text { nologies \& Practices }\end{array}$ & $\begin{array}{l}\text { Productivity Improve- } \\
\text { ments \& Cost Savings }\end{array}$ & $\begin{array}{l}\text { Competitive Advantage - } \\
\text { Operational Strategy }\end{array}$ \\
\hline $\begin{array}{l}\text { Equipment } \\
\text { Speed In- } \\
\text { creases }\end{array}$ & $\begin{array}{l}\text { Machining or as- } \\
\text { sembling a unit; } \\
\text { information process- } \\
\text { ing }\end{array}$ & $\begin{array}{l}\text { Changes proportions of } \\
\text { flows to funds, re-ordering } \\
\text { specific relations of com- } \\
\text { plementarity }\end{array}$ & $\begin{array}{l}\text { High-speed machining } \\
\text { technologies; faster spindles }\end{array}$ & $\begin{array}{l}\text { Increased manufacturing } \\
\text { throughput and utilisation } \\
\text { of funds }\end{array}$ & $\begin{array}{l}\text { Faster product delivery } \\
\text { (shorter manufacturing lead } \\
\text { times) }\end{array}$ \\
\hline $\begin{array}{l}\text { Equipment } \\
\text { Flexibility }\end{array}$ & Resetting a process & $\begin{array}{l}\text { Increases complementarity } \\
\text { among elements through } \\
\text { reducing specificity of } \\
\text { equipment purpose }\end{array}$ & $\begin{array}{l}\text { Cell technology; FMS; } \\
\text { CAM; rapid set tooling; } \\
\text { open-architecture control- } \\
\text { lers }\end{array}$ & $\begin{array}{l}\text { Increased economies of } \\
\text { scope }\end{array}$ & $\begin{array}{l}\text { Rapid execution of orders } \\
\text { (shorter time-to-customer) }\end{array}$ \\
\hline $\begin{array}{l}\text { Integrated } \\
\text { Processing }\end{array}$ & $\begin{array}{l}\text { Processing system } \\
\text { requirements and } \\
\text { trade-offs }\end{array}$ & $\begin{array}{l}\text { Reduces and controls for } \\
\text { process variability through } \\
\text { the addition of information } \\
\text { in execution }\end{array}$ & $\begin{array}{l}\text { Concurrent engineering; } \\
\text { JIT; CIM; EDI; intelligent } \\
\text { machining (intelligent } \\
\text { closed loop processing); } \\
\text { process planning software }\end{array}$ & $\begin{array}{l}\text { Tighter process control (re- } \\
\text { ductions in processing } \\
\text { delays, non-value-adding } \\
\text { activities, scrap, WIP and } \\
\text { inventory); reductions in } \\
\text { process time scales }\end{array}$ & $\begin{array}{l}\text { Faster product realisation } \\
\text { (shorter product cycle } \\
\text { times) }\end{array}$ \\
\hline $\begin{array}{l}\text { Information } \\
\text { Generation }\end{array}$ & $\begin{array}{l}\text { Developing process } \\
\text { capability }\end{array}$ & $\begin{array}{l}\text { Facilitates system develop- } \\
\text { ment through the addition } \\
\text { of information in design } \\
\text { (order creation) }\end{array}$ & $\begin{array}{l}\text { Computer modelling and } \\
\text { simulation; rapid prototyp- } \\
\text { ing; process modelling }\end{array}$ & $\begin{array}{l}\text { Improved utilisation of } \\
\text { funds in implementing } \\
\text { product/process/resource } \\
\text { systems }\end{array}$ & $\begin{array}{l}\text { Faster implementation of } \\
\text { new concepts in products } \\
\text { (shorter time-to-market) }\end{array}$ \\
\hline $\begin{array}{l}\text { Knowledge } \\
\text { Codification }\end{array}$ & $\begin{array}{l}\text { Organising proc- } \\
\text { esses }\end{array}$ & $\begin{array}{l}\text { Decreases variance in } \\
\text { knowledge utilisation }\end{array}$ & $\begin{array}{l}\text { SPC; CAE; KBS; PDM; } \\
\text { configuration management } \\
\text { systems; data mining and } \\
\text { warehousing; in-process } \\
\text { control metrology }\end{array}$ & $\begin{array}{l}\text { Increased efficiency in } \\
\text { knowledge utilisation }\end{array}$ & $\begin{array}{l}\text { Faster response to evolving } \\
\text { customer needs }\end{array}$ \\
\hline $\begin{array}{l}\text { Equipment } \\
\text { Modularity }\end{array}$ & $\begin{array}{l}\text { Implementing new } \\
\text { shop floor processes }\end{array}$ & $\begin{array}{l}\text { Facilitates system reorgani- } \\
\text { sation through increased } \\
\text { divisibility of funds }\end{array}$ & $\begin{array}{l}\text { Modular, "plug and play" } \\
\text { machine tools and controls; } \\
\text { rapid prototyping of tools } \\
\text { and dies; micro- and nano- } \\
\text { technologies }\end{array}$ & $\begin{array}{l}\text { Longer life spans for capital } \\
\text { funds; economies of scale } \\
\text { in factory implementation }\end{array}$ & $\begin{array}{l}\text { Dynamic response to evolv- } \\
\text { ing customer needs }\end{array}$ \\
\hline
\end{tabular}


and surface area. As scale increases, there is a declining surface to volume ratio that allows for both capital and operating cost savings. The second technical factor, economies of the threshold dimension, refers to the reduction in total unit costs that obtains from the presence of indivisible intermediate stages which remain constant for all output levels above a certain threshold. The managerial/organisational counterpart of the technical threshold dimension factor is the systems organisation of certain productive services, such as R\&D and marketing, for which indivisible system-related costs are non-scale dependent above a given level of output.

We discuss six sources of speed in turn.

\section{Equipment Speed Increases}

Reducing the duration of a process increases the ratio of flows to funds, enabling companies to increase manufacturing throughput and equipment utilisation. This effect applies to information as well as material processes. Increasing the flow of information, often referred to as increasing the response time, also extends the range of possible operations within a given period of time, as noted in one roadmap, "Because information technology can provide more accurate performance data about production processes (and at higher speeds than with manual methods of data collection and analysis), the machines used in the processes can become more flexible and more accurate." (NCMS, 1996) Depending on the equipment's use, increasing speed may or may not affect the equipment's indivisibility, and thus be scale related. Often increases in speed amplify economies of scale and, as such, are applicable to mass production as well as flexible production systems, but increased speed might also be used to lower the minimum efficient scale of equipment in multi-product production.

\section{Equipment Flexibility}

Reducing process set-up time, effectively increasing the potential uses for a piece of equipment in a given period of time, reduces the cost of manufacturing a mix of products. In the terms of the fund-flow model, multi-use equipment increases the possible number of relations of complementarity among different system elements. According to one roadmap, "Flexible manufacturing equipment/processes are characterised by both speed and an ability to handle a variety of manufacturing processes, thus increasing the ability of a firm to anticipate and meet changing needs and customer requirements. It has its roots in the need to improve capital utilisation rates and to support just-in-time (JIT) inventory objectives by reducing changeover time and expense.” (Agility Forum, 1997)

\section{Integrated Processing}

Integrated processing eliminates delays and non-value-adding activities and optimises lead time and resource use as an effect of reducing and controlling for process variance through the addition of information. The object is to balance process performance requirements with process capabilities and resource development, cutting waste as a result (DSB, 1993). The customary serial techniques for developing and managing systems introduce constraints on system development and take more time than does concurrent processing of system requirements (Foresight, 1995). The import of integrated processing to faster product introductions follows: "A fast-to-market strategy is among the most important success factors for manufacturing companies. Past strategies have separated design from manufacturing, causing long lead times and costly product and process itera- 
tions ... A key enabler is the creation of interoperable business, engineering, and manufacturing hardware and information systems to enable rapid trade-off decisions to be made among performance, design features, and manufacturing costs." (Agility Forum, 1997) Substituting parallel for sequential processing reduces irreversibility in the linking of system elements, which lowers costs and enhances the possibility of realising optimal system organisation. Development programme costs decline as trade-offs are resolved early in the design process, preventing costly design changes later. Reducing uncertainty through early definition of variability permits narrower design margins and tighter process control.

\section{Information Generation}

Modelling and simulation technologies facilitate the rapid realisation of possible system complementarities, thereby effecting changes in the ratio of various funds (design blueprints to equipment) to quality of output. ${ }^{20}$ It capitalises on the "opportunities for understanding the relative costs of evolving alternative designs, minimising development iterations, enhancing first-pass quality performance, shortening time-to-market, and reducing product development costs." (TEAM, 1997) For example, information-based processes for predicting system performance, such as computer models of manufacturing queues to identify manufacturing bottlenecks, provide means for identifying subsystem variability during the design phase. Simulated technology validation leads to better definition of process conditions and overall reduction in the technical transaction costs occurring at process interfaces. Substantial time savings in the realisation of the product/process/resource system result from the elimination of trial-and-error procedures.

\section{Knowledge Codification}

The need to continuously reorganise the production process to respond to a highly variable market conditions dictates the systematisation of, and ready access to, information on system processes. This requires "robust methods of handling the bulk complexity and uncertainty of information." (Foresight, 1995) Further, the new manufacturing paradigm "require[s] communication and knowledge sharing across the boundaries of individual companies, technical domains, and time. To realise this, the knowledge must be systematised to ensure that it is generally available and reusable throughout the life cycle." (IMS, 1994) Moreover, efficiency in manufacturing operations increasingly depends on the capture of nominal and variant product and process behaviour for use in real-time control. Reducing the per-piece cost of small lot production orders to that of higher order volumes will require "first-pass accuracy and repeatability resulting from extraordinarily close monitoring and sensing of acquisition, analysis, and process correction techniques." (NCMS, 1996) Information technologies support a higher level of data processing and the appropriate reuse of knowledge, increasing the speed and quality of decision making (NRC, 1995). Economies of scale pertain in standardising processes for managing large systems of variables. Practically, these changes represent a shift in the locus of the knowledge base in the science of manufacturing to include shop floor processes.

\section{Product and Process Modularisation}

In the time frame of product/process/resource implementation, scale- and timedependent indivisibility in system elements exhibit diseconomies: "For many manufacturing jobs, manufacturing capability is needed for a period of time that is short in comparison to the life of the process equipment. In addition, manufacturing equipment 
is often sized and purchased, not for the current part being manufactured, but for the worst-case part that one can envision in the life of the process. Both of these practices tie up valuable capital in equipment that is not fully used." (Agility Forum, 1997) In the reconfigurable plant, modular, "plug and play" equipment will radically increase the divisibility of funds, thereby increasing system complementarity, and, resultantly, equipment utilisation. Large threshold costs for designing equipment will be averaged over multiple units triggering economies of scale in equipment production. Under these conditions, plants could be mass produced and plant economics will evolve from a fixed to a variable capital input basis.

\subsection{The Economies of Speed}

Schmenner (1988), one of the management scientists cited in Section 5.1, claims that "the potential of any new investment or technology is fully realised only when it can speed up the flow of materials through the process." (p. 15). Nevertheless, the way in which AMT-based production relies extensively on time-saving to boost productivity is not a subject receiving wide consideration from economists. Both Pratten (1971, 1991), the standard reference on economies of scale, and Morroni (1992) recognise increases in speed as a source of economies of scale, although both subordinate economies of speed to other derivations of advantage in scale.

The question arises whether there are economies resulting specifically from the speed of a firm's operations. ${ }^{21}$ While it is beyond the scope of this treatise to formally define such economies, it is an important question to ask in relation to distinguishing the economic effects associated with increases in speed from those of economies of scale and scope. The answer appears to be yes, there is an economies of speed in that increasing the speed of production increases marginal productivity. In other words, economies of speed can be said to exist if total costs rise proportionately less than does total output under the application of greater speed. Also, we note the case in which economies of speed exist if the marginal cost of producing any one product decreases with increases in the quantities of all products under conditions of increasing the speed of production. However, these definitions may also be construed as special cases of economies of scale and scope.

Yet, there is a strong case to be made for using the term "economies of speed" if we take a historical perspective. In Chapter 4, we have shown an explicit connection between speed and the direction of current AMT trajectories. The section above discusses the perception in the managerial literature of speed as the foundation of the current regime. Moreover, in today's volatile market environment, productive capacity includes the ability to respond quickly to changes in industry and market conditions. Then, as a historical phenomena, the economies of speed are distinct from the mass production modes of economies of scale and scope.

Further, Piacentini (1997) shows that time-saving activities play an autonomous role in production. Consider that we can express the cost of production per process cycle of given duration as follows:

$$
\mathrm{C}=(\mathrm{R} / \mathrm{H}+\lambda \mathrm{w}) \mathrm{t}_{\mathrm{c}}
$$

where $\mathrm{R}$ is the rental cost of the process, that is, $\mathrm{R} / \mathrm{H}$ is the cost per machine-hour, $\lambda$ is the units of labour, $w$ is the cost per worker hour., and $t_{c}$ is the duration of the process. Then $R, \lambda$, and $t_{c}$ "identify three distinct sources of cost reduction ... If any of these pa- 
rameters is lowered as a consequence of innovation, while the other two remain constant, we shall have, respectively, pure cases of capital saving, labour saving, and time-saving." (pp. 171-172) He goes on to investigate time-saving in relation to both technical processes and organisational practices, such as learning-by-doing.

Still, the question remains of how the economies of speed are linked with the economies of scale and scope. This linkage has important implications for the possibility of seeding a sustainable regime based on qualitative economic development, as we discuss later in this chapter.

\section{The Impact of Speed on Economies of Scale and Scope}

While the analysis of time as a production input remains largely to be explored, many economists have given their attention to the economic implications of flexibility in production. Quite a few have weighed in with predictions as to whether large or small enterprises will dominate with the maturation of AMTs (see, for example, Piori and Sable, 1984; Dosi, 1988; Alcorta, 1998). ${ }^{22}$ The pitch of this debate has been over whether economies of scale or economies of scope predominate with the ascendancy of the new IT-related production technologies. In this, I side with Morroni (1992), who argues that technical forces favour both increases and decreases in minimum efficient scales and whether innovations are centripetal or centrifugal, (to or away from the dominant technical paradigm), depends on the economic conditions under which the innovations are applied. Clearly, however, the economies of speed are directly linked to those of scale and scope.

The main point of agreement in the debate about the effects of production flexibility on industrial structure is that AMTs lead to economies of scope. However, the contention, initially put forward by a number of researchers (Goldhar and Jelinek, 1983; Piore and Sabel, 1984, among others), that flexible production techniques increase the cost viability of small scale operations confounds small-scale production with flexibility. ${ }^{23}$ The historical tendency has instead been towards increasing plant sizes (Alcorta, 1998).

Stalk (1988) argues that manufacturing costs fall into two categories: those that respond to volume or scale and those that are driven by variety. Variety-related costs reflect complexity (van Asseldonk, 1998). In Stalk's studies of conventional manufacturing, cutting variety by half led to decreases in costs of $17 \%$, increases in productivity of $30 \%$, and substantial reductions in the break-even point. As variety increases, costs typically increase at the rate of 20 to $35 \%$ per unit each time the variety doubles. In the flexible factory, production is organised so as to reduce the costs of variety to near those of mass production. Figure 5.1 illustrates Stalk's analysis. Total operational costs decrease as a result of time reductions which lower the cost of variety. But variety-related cost savings are only available at higher variety and break-even points, that is, at greater minimum efficient scales, as scale costs dominate at lower volumes. In sum, AMT use leads to higher break-even sales volumes and greater throughputs.

Stalk's analysis is supported by a number of observations. Recall from Chapter 2 that quick-change tooling was key to the development of Toyota's revolutionary production system. Nowadays, reduced set-up times continue to be a major category of time savings (Piacentini, 1997). Tu et al. (1999) found that of the time-based capabilities, reducing setup times has the highest correlation with the firm's level of mass customisation. But, 
Figure 5.1 Volume and Variety Costs
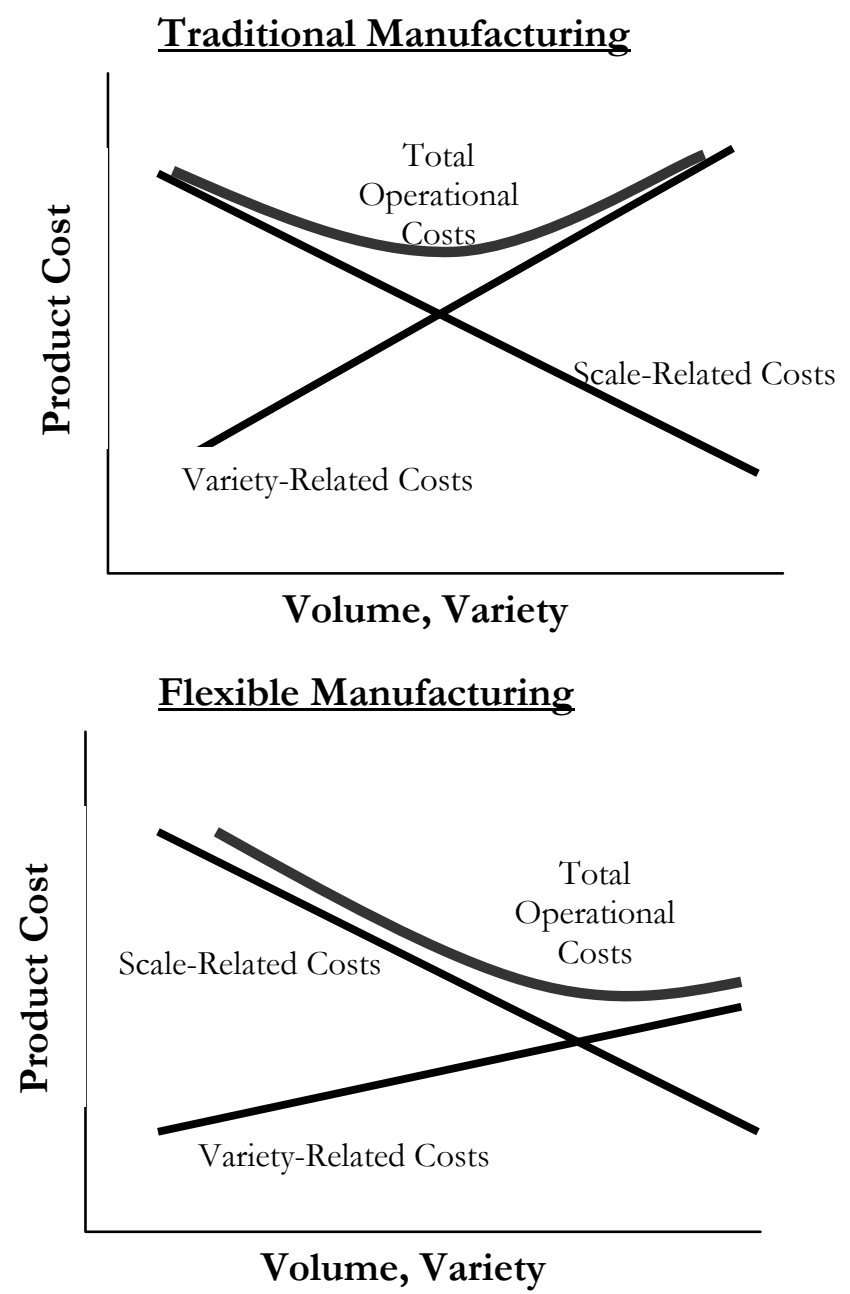

while individual set-up times are being reduced, there are more set-ups as product variety increases. Inevitably, a cause-and-effect cycle is set into motion, to wit: reductions in setup times increase process flexibility, lowering the cost of product variety, which then stimulates the demand for more product differentiation, leading to further attempts to reduce set-up times and keep costs low, thereby starting off another cycle. ${ }^{24,25}$

Another consequential time-based capability is cutting product cycle times and thereby the costs of implementing the product/process/resource system. This is the case of economies of scope arising from the joint utilisation of inputs, identified by Baumol et al. (1982), specifically the capability to introduce new products rapidly. But again we note an incremental additional cost to using this capability. As Morroni (1992) points out, greater adaptability increases efficiency over a larger range of output but reduces efficiency at specific optimum technical output levels.

Figure 5.2 reproduces the economies of scope graph first discussed in Section 2.1. Economies of scope are present when firms with diversified product mixes have lower total costs than the total costs of firms independently producing the same mix for the same level of total output. A trans-ray cross section of the graph, (for example, the surface $a^{\prime}-A^{\prime}-a^{\prime \prime}-Q_{a 2}-A-Q_{a 1}$ ), shows the costs of product-specific firms in comparison with the costs of firms producing a weighted average of the outputs on the axes. The cost situation described in this figure is said to be trans-ray concave since the weighted aver- 
age of the costs of product-specific production is less than the costs for the firm producing a weighted average of outputs. ${ }^{26}$ We can now see that because of the incremental costs of additional set-ups and/or cutting product cycle times, essentially the product variety costs Stalk (1988) refers to, AMT use exhibits trans-ray concavity. Further, in a situation of trans-ray concavity, to reap economies of scope firms must increase their output relative to single product production. For example, $\mathrm{M}$ and $\mathrm{N}$ can be jointly produced at least cost at a quantity of $\mathrm{B}$ as the cost of producing the two goods separately, the sum of $\mathrm{Q}_{\mathrm{b} 1} \mathrm{~b}^{\prime}$ and $\mathrm{Q}_{\mathrm{b} 2} \mathrm{~b}^{\prime \prime}$, exceeds the cost $\mathrm{BB}^{\prime}$. Assuming product substitutability between standardised and differentiated product, it is not enough for firms to keep output as before because of the lower costs of the standardised product.

\section{Figure 5.2 Economies of Scope}

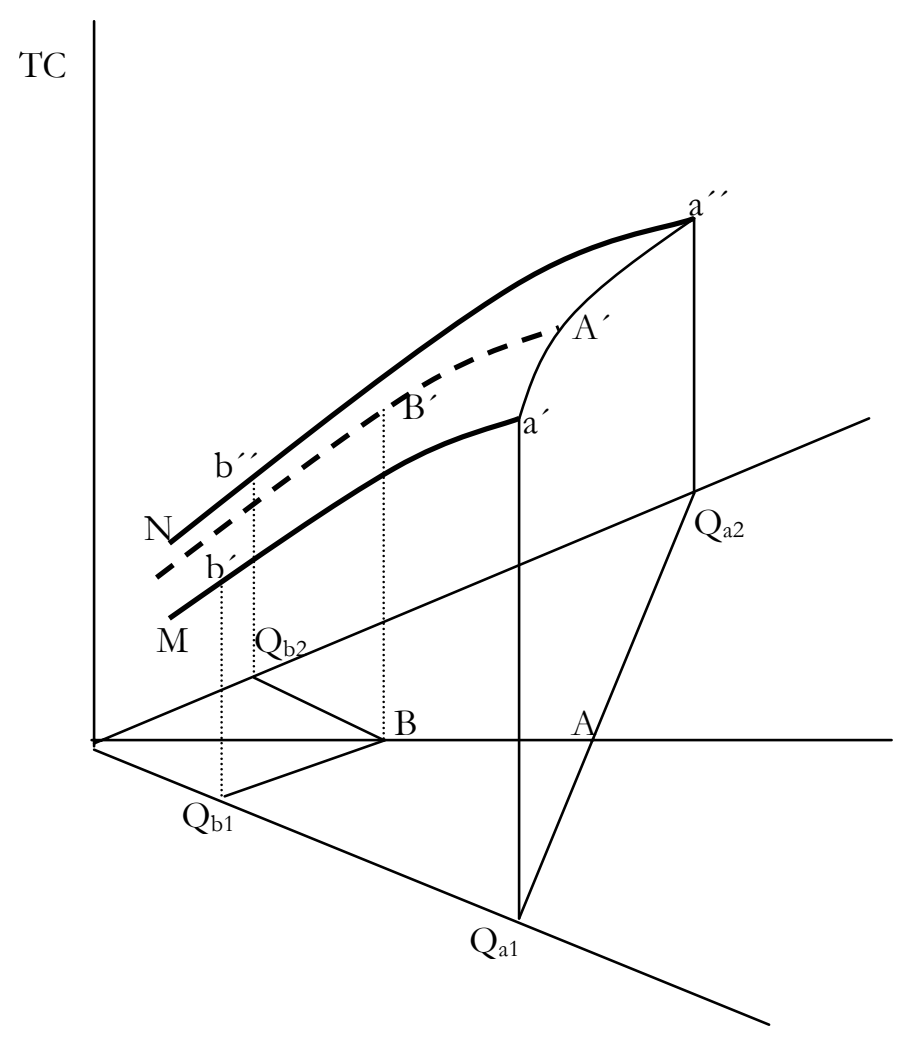

Yet another reason exists for increases in plant scale - the higher capital costs of AMTs. The additional functionality of automated flexibility and integration comes at the expense of increasing equipment complexity (refer to chapter 4, section 4.2). Alcorta (1998) notes that the divisibility effects of flexible equipment, which some argued would result in descaling, are not in the machine tool itself. Generally, this has meant that flexible technologies are more capital intensive than conventional equipment, and hence, the need for volume production (Katayama and Bennett, 1999).

In practice, then, volume production is needed for obtaining economies of scope in the current regime. The study by Alcorta (1998) and colleagues of 62 firms adopting flexible technologies provides empirical confirmation of the tendency of firm size to increase upon AMT adoption, but as Alcorta points out this is not necessarily conclusive that optimum plant size also increased. The first order effects of AMT adoption included a decrease in set-up times and an increase in the scope of products, and therefore an in- 
crease in set-up times. In the $60 \%$ of the firms where unit costs fell, scale also increased. Firms that had high unit costs after adoption, also had low capacity utilisation rates. In a more detailed study of the Indian firms, it was found that in nine out of eleven cases, the lower unit costs were dependent on achieving higher levels of output.

In sum, flexible production/mass customisation, as actualised in the current regime, lowers the cost of manufacturing a mix of products of large aggregate volume, not of manufacturing small lots individually. This is because speed acts as a multiplier on the economies of scope and scale. Speed reduces the operational costs of product variety providing for economies of scope, but at greater volumes than in product-specific production. In addition, owing to their greater complexity, AMTs tend to cost more than conventional equipment, thereby amplifying multi-product economies of scale.

We can then conclude with Morroni (1992) that, "[T] he very common assertion that with information technology economies of scope tend to prevail over economies of scale is not accurate. If anything the contrary is true: information technology tends to link economies of scope with economies of scale." (p. 184) This promotes the development of a "new model of industrial organisation", large-scale flexible production, that is, mass customisation.

\section{The Market Impetus of Speed}

From time reductions in specific operations it is conceptually a short distance to specific cost savings, keeping in mind that the deployment of AMTs for a given mix of product will reflect the trade-off between achieving operational cost savings and the investment required to realise this state of operations. But, as the diffusion of new technology hinges on opportunities for appropriating returns, the strategic use of advanced manufacturing equipment dictates more than just productivity gains (Kakati, 1997). Going back to the requirements of today's markets, cost is no longer the only, or even the principal driver in market evolution. While speed in production supports cost reduction strategies, it is the strategic advantage of faster product introductions and expanded product variety that has propelled firms along the trajectories of time reduction.

Recall that product cycle times can be decomposed roughly into design and physical production turnover rates corresponding respectively to the planning and execution phases of the production process. Firm strategies can emphasise one or the other depending on their external conditions. A manufacture-to-order operational strategy requires the process capability to rapidly execute customers' orders, which has as its effect solidifying customers' goodwill and bringing repeat business. Moreover, manufacture-to-order capability works to eliminate over- and under-production, the bane of fluctuating markets. In comparison, the crux of a first-to-market strategy is the ability to anticipate and respond rapidly to customers' evolving needs, which takes superior design capabilities. Success, measured in terms of market share, belongs to first entrants (Boulton, 1995; VanderWerf and Mahone, 1997). One estimate puts 50\% of U.S. profits deriving from products less than 5 years old (Hardaker et al., 1998). Further, as appropriation means, lead time and learning curve advantages, coupled to marketing efforts, dominate in most industries.

However, aside from their competitive advantages, strategies that emphasise faster cycle times create their own vulnerabilities, a major dilemma being how to recover plant and equipment costs over abbreviated product and process lifetimes. ${ }^{27}$ The challenge is evi- 
dent, as voiced in the Next Generation Project report: "Immediate sales growth is required for companies to justify the significant investments needed to sustain economic growth and future earnings." (Agility Forum et al., 1997) In substance, fast-to-market strategies assume strong market growth.

And market growth coupled to faster product cycles presages new product variants and faster product obsolescence linked to intensified customers' needs. To wit, mass customisation strategies play to escalating customer demands. The economic rationale underlying growing product diversification and market fragmentation suggests itself: evolving customer needs, expressed through faster product replacement or product use particularised to individual consumers, and even to differentiated "needs" of single consumers, counteracts problems of market saturation and over-capacity.

What's more, economies of speed do have a cost impetus, as discussed above While cost may not be the deciding factor shaping market demand, it is a logic that impels growth in output. The search for the optimal combination of production elements has as its motivation the necessity of competing on cost. The firm that produces less than at optimal productive capacity, at less than the most efficient scale and rate of production, pays a penalty. Consider that, in the case of an established, non-growth market, a strategy that halves manufacturing lead times will need a market size twice as big, ceteris paribus. Enhanced speed of production, through its cost advantages stemming from increased productive capacity, and through its multiplier effects on economies of scope and scale, puts pressure on firms to grow through boosting output. In effect, firms must grow in order to compete.

Ayres (1996) has alerted us to the "deeper structural problem" of materials goods production underlying environmental degradation: increased demand drives up production scales; larger scales drive down costs; lower prices up demand. ${ }^{28}$ Still, under mass production, consumption grows only until the market is saturated. The effect of faster product cycles and more product variety also appears to cause demand to spiral upward, but in a different manner. Consumers demand more, but not just more of the same. With mass customisation, the pace of product replacement speeds up and people purchase more product variants. Needs grow as more products are available to satisfy their creation. Effectively, these strategies have the power to raise the ceiling on market saturation.

\section{The Economic Trade-offs}

Since the introduction of AMTs in the 1950's and the acceleration of their adoption in the 70's, there has been a considerable shift in the discussion of the economic significance of AMT use. One major thread of this discussion has been the impact of AMTs on industry structure. It is now clear that the prediction that flexible production would lead to smaller scale production has not borne out. Instead, a consensus appears to be developing that AMT use is not in contradiction to mass production but rather an extension of it (Schonberger, 1996; Sharp et al., 1999).

$\mathrm{Tu}$ and colleagues (2001) have described mass customisation as a strategy that aims for achieving customer responsiveness, cost efficiency and volume production simultaneously. By volume effectiveness, they mean the ability to increase product variety without diminishing production volume. However, this conception of the challenges to adopting a mass customisation strategy takes for granted the focus of a large company. In fact, AMT use has had different results depending on whether companies start off as a small 
scale, job shop, or large scale producer (Ranta, 1997). For small firms, AMT use leads to capacity increases, while they maintain flexibility; for mass production firms the biggest benefit of AMT use is the ability to cope with market changes and new product demand.

Yet, in interpreting the economic effects of AMT use, it is wise to be careful not to let near-term economic analysis at the micro level mask effects at the meso-level. Katayama and Bennett's (1999) accounting of Japan's strategic initiatives in the 80's and 90's is instructive in this regard. Strategies emphasising shorter delivery times and a wider choice of products won market share, but they also resulted in higher fixed costs, increasing break-even points, and lower profits, which led to further attempts to expand market share. The essence of these strategies was to couple fewer resource inputs to higher output performance. This approach could only be sustained with large investments in resource-reducing technologies. Japanese companies had to commit more and more human and financial capital to keep pace with market demands (Stalk and Webber, 1993). But under conditions of increasing market volatility, a large fixed cost base is a point of vulnerability.

This outcome raises the important question of how closely allied faster product cycles and increasing differentiation are to market volatility. As new products enter the market, premiums shift from established products to the latest offering. Stalk and colleagues, among the foremost proponents of competing on time, have repeatedly stressed that strategies to capture market share through product variety have reduced everything to a commodity (Stalk, 1988; Stalk and Hout, 1990; Stalk and Webber, 1993). Stalk, with Hout, advocated that companies compress product cycles to keep prices and margins from eroding. But in his later work with Webber, he added that it was not enough to launch products faster and faster and produce more and more product variety. This was squandering resources. Instead, speed must be connected to the strategic purpose of satisfying customer needs by developing superior customer knowledge (Stalk and Webber, 1993).

This argument is echoed in several of the roadmap documents. The future is in agility as: "[Consumers] will require customised products with colour, size, shape, and configuration tailored to specific wants and needs, delivered quickly, wherever they happen to be, with no reduction in quality or premium for customisation." (Agility Forum et al., 1997) But here we must ask if this new market condition, "for today's highly differentiated product to become tomorrow's commodity," represents an opportunity for the agile manufacturer (Eureka, 1995) - or whether some new direction in the organisation of production is needed. It is not clear that more mass customisation technologies will work to overcome the problem of the "drift towards commoditisation" or to exacerbate it. In the aggregate, changes in technologies mean greater uncertainty as an effect of greater complexity, even though individual technologies may reduce uncertainty (St. John et al., 2001).

Recently, market volatility is also being cited as the reason to conclude that the only chance not to be driven out of competition is to achieve growth (Bullinger, 1999). This logic may be implied when the analysis is limited to orthodox economic considerations. In the next chapter, we examine the current directions in the strategic uses of AMTs from a sustainability standpoint for a broader perspective. 


\section{Chapter 5 Endnotes}

1 These characteristics have their mirror images in the production domain. For instance, Ranta (1997) claims that the two significant features of the IT production paradigm are production flexibility in terms of product variety and time management, specifically, time-to-customer and time-to-market.

2 For example, improved quality may be the result of process integration, but not an effect of time reduction itself, and in other cases there may be a trade-off between quality and time reductions, such as when faster throughput rates compromise safety in food processing.

3 The current spotlight on agility in the manufacturing research community chiefly concerns this focus. The term agility was coined in 1991 by a group of U.S. university researchers to designate the ability to respond quickly to changes in the marketplace. Since then, it has gained considerable prominence in the literature. My research indicates, however, that the practical considerations of what constitutes agility, as distinct from current practices, is not yet clear to manufacturers, (see chapter 9). Also, many researchers use the terms agility and time-based competition synonymously, (see, for example, Kumar and Motwani (1995)). An emerging emphasis is to characterise the agile company as a very fast and efficient learning organisation (Kotha, 1996; Sharp et al., 1999). It is possible that learning as an organisational characteristic figures in a new trajectory, as considered in chapter 9. However, for the purposes of this chapter's exposition, agility is best considered as the continuing development of time-based capabilities in the direction of operational reconfigurability.

4 Lead time refers to the time it takes to design, make, and deliver the product to market. Manufacturing lead time is the elapsed time from start of an item's physical production to product delivery. Another term for manufacturing lead time is time-to-customer as opposed to time-to-market, which refers to time to carry out both design and manufacturing activities. Lead time is alternately defined as the time from receipt of all inputs for the first activity to when the product is ready to ship (Schmenner, 1988; Bartezzaghi et al, 1994). It is important to note that the time from the placement of an order to delivery, referred to as delivery time, is not necessarily an indicator of time-based capabilities as a company can use inventory to fill an order. Lead time then refers to operating conditions, whereas delivery time is a measure of external performance.

5 The discussion here concentrates on AMT-related time reductions and the consequent reorganisation of the firm's production system. There are also important managerial and organisational practices associated with time reductions, such as cross-functional teams, supply chain management practices, and virtual partnerships, that are not covered here for reason of the need to focus the analysis.

6 See section 2.1 for a description of the execution/control/planning system organisation model. Interestingly, Piacentini's (1997) economic analysis of time-saving, discussed later in this chapter, echoes the execution-control-planning model in his categorisation of time-saving innovations.

7 In terms of the fund-flow model, this is an expression of the complementarity of fund elements, as discussed below in section 5.2.

8 Commonly, conventional machine tools were constructed with one or two axes. Machining centres contain multiple axes allowing co-ordination of machining along the various axes.

9 Further, it allows a single worker or team of workers to attend to machines at higher ratios of machines to workers than is possible when the equipment is located in different parts of the plant.

10 Reductions in WIP and inventory increase cash flow relative to capital investment, a cost advantage invisible from a production function approach.

11 For example, demand forecast errors for electronic goods over a three month planning horizon are around $\pm 50 \%$ (Mason-Jones and Towell, 1999).

12 Some researchers suggest that mass customisation is an externally focussed strategy, while time-based competition is internally focussed (see, for example, Tu et al., 2001). In our framework, mass customisation and time-based competition are two aspects of the same general strategy having to do with functionality and operationalisation respectively.

13 In this section, the execution phase of production includes the control processes. 
14 We can distinguish between operational flexibility, the capacity to vary the quantities of a product mix using a given production structure, and strategic flexibility, the capacity to reorganise the product/process/resource system.

15 Refer to section 2.1 for the model's introduction. The point of Georgescu-Roegen's (1970) division of production system elements into funds and flows was to denote their faulty representation in the standard production function models. Funds, for example, are characterised by specific time profiles that are neglected in the standard representation.

16 To illustrate the significance of fixed versus flexible coefficients, Morroni (1992) uses Robertson's example of ten shovels for eleven workers - to discover the marginal productivity of the workers the ten shovels must be transmuted into eleven.

17 We rule out the option of leasing equipment because of implementation costs.

18 The increase in order does not negate the second law of thermodynamics, rather total entropy of the system keeps increasing, but this increase does not occur as a uniform increase in disorder (Capra, 1996).

19 This is in essence the same point made by Connor and Prahalad (1996).

20 Information generation and integration proceed through the development of feedback loops, a standard system operational feature.

21 I am indebted to Robin Cowan for raising this issue. While many economists use a less formal definition of "economies" to signify particular sources of increasing productivity, (e.g., the "economies of standardisation"), a rigorous approach to defining terms facilitates their use.

22 See Alcorta $(1995,1998)$ for an intensive review of this literature.

23 One possible source of this confusion is that under mass production the basic trade-off is between economies of scope and economies of scale. The knowledge that AMTs supersede this trade-off came later.

24 Alcorta (1998) cites a simulation study by Mody et al. that showed AMT use leads to increases in the efficiency of producing small lot sizes because of reductions in set-up times but that annual throughput rates must increase.

25 The same argument regarding reducing equipment set-up times can be easily extended to time reductions associated with the speed of control.

26 To put it another way, differentiated production is more costly than standardised production when the loss of economies of scale is greater than the gain in economies of scope (Morroni, 1992).

27 This problem is complicated by the use of equipment over different stages of different products' life cycles.

28 Ayres' analysis is an application of the Salter cycle. 


\section{Chapter 6 Speed, Scale and Sustainability}

Consumer wants can have bizarre, frivolous, or even immoral origins, and an admirable case can be made for a society that seeks to satisfy them. But the case cannot stand if it is the process of satisfying wants that creates wants.

John Kenneth Galbraith: The Affluent Society

Until recently, policy discussions on the significance of AMT diffusion with respect to industrial transformation have focussed almost exclusively on the competitive implications of AMT use. In these discussions, the expanding use of AMTs is mainly treated as a matter of individual firms' decisions on how to compete and the consequence for competitiveness. Currently, however, there is increasing interest in how AMTs might help to solve the sustainability challenges in front of us. This approach tends to stress the potential for designing more environmentally-friendly, less resource-intensive products with AMTs and the benefits of replacing older, less environmentally-friendly production technologies with AMTs. Considerable attention is being given to how AMTs, and information technology in general, might support expansion in services which offset materials consumption (Cahill and Scapolo, 1999).

While this turn of policy is most welcome, it fails to address fundamental concerns regarding the direction of AMT development. This chapter tackles the broader issue of how the diffusion of AMTs affects the overall pattern of consumption and production. It offers particular insights on how emerging AMT-related trade-offs might affect the sustainability balance. There are two focal points to the discussion: the influence of AMT-related trade-offs, both positive and negative, on sustainability, and the possibilities for strategically using AMTs to achieve a transition to sustainability.

What has been called the "evolutionary paradigm" (Hwang, 1998) and the "coevolutionary perspective" (van der Leeuw, 2001) forms a background for the discussion in this chapter. Presently, the sustainability discourse involves the exploration of several new intellectual paradigms that belong to an evolving post-modernist view of society and human development. The development of a dynamic systems framework that perceives the co-evolution of socio-economic systems and the natural environment has emerged as an important focus. Because this framework provides a means for interpreting complex system interactions, it is finding increasing use in sustainability research. We draw on this framework to develop an understanding of the interdependencies between consumption and production activities and the consumption/production system in relation to societal 
development and the natural environment. This discussion closely parallels the evolutionary economics framework described in Chapter 3 but involves additional systems concepts that are evoked in the course of the chapter.

The analysis here also shifts to a more complex interpretation of consumption than attempted in previous chapters. From a competitiveness perspective, changes in consumption patterns are, for practical purposes, synonymous with changes in the terms of competition. From a sustainability perspective, we are interested in the scale and composition of consumption, but also in the production/consumption system's ability to satisfy socio-economic needs. The chapter begins with an overview of the current discourse on sustainable consumption.

\subsection{The Pattern of Consumption}

The analysis presented in this thesis implies that the interdependency of market needs and the strategic use of AMTs will influence the success of any policy to reduce consumption and promote sustainability. Notwithstanding the potential of AMTs to contribute to dematerialization of products and processes, we need to consider the effects of their use on the organisation of production as a whole. Preceding chapters have described firms' micro behaviour in selecting and using technologies. In this chapter, we situate this behaviour in a socio-economic context, focusing on how AMT use is linked to the macro problem of growing resource consumption and how current policy views this problem.

\section{The Speed and Scale of Consumption}

Despite considerable advances in reducing resource intensity (the quantity of resources per unit of economic activity), consumption of materials and energy continues to grow or hold steady in the highly industrialised countries (World Resources Institute, 1997, 2000). As the rate of population growth in these same countries has levelled or even decreased, the implication of these trends is that the rate of personal consumption is speeding up, and with it, the amount of resources we consume individually.

Of what does this growth consist? With respect to the highly industrialised economies, three possibilities suggest themselves.

1. More individual product consumption: A number of studies have documented increases in personal consumption. For example, in 1960, Norwegians, on average, bought 2 pairs of shoes and 7 outer garments; in 1996, those numbers were 4 and 17 respectively (Røpke, 2001a). Similar increases have been recorded for cars, meat, paper, plastics, televisions, vacuum cleaners, and other household appliances (OECD, 1997; Reisch and Scherhorn, 1999; Myers, 2000; Røpke, 2001b). Perhaps most significantly, the average dwelling size in Europe and North America has more than doubled since the 1950's, even as family size shrank and the number of independent households multiplied (Reisch and Scherhorn, 1999; Røpke, 2001a). Demand for household goods has thus risen significantly as more items are needed to fill the expanding space and to provision the increasing number of homes.

2. More individual product use: Not only are there more products, we make use of them more often. Gains in a product's resource efficiency are commonly off-set by 
increases in product use - cars and washing machines being prominent examples - a phenomenon known as the "rebound effect". For example, the aggregate energy consumption by televisions rose by a factor of two from 1970 to 1995 , even as their energy efficiency increased by a factor of 3.5 (Hirschl, 1998). Paper consumption has tripled in the last three decades partly as a result of the computer's enabling of high-speed text reproduction. Moreover, product efficiency improvements tend to stimulate demand for the products themselves, such that efficiency gains at the micro level are overtaken by growth in consumption volume at the macro level (Sachs, 1999).

3. Embedded consumption in higher value products: Many of the products we use today are made with fewer materials than the products they replaced, but when waste and upstream materials consumption are taken into account, this may no longer be the case. ${ }^{1}$ Consider that manufacturing a silicon computer chip uses 4500 times the chip's weight in materials, 8\% of which is hazardous (Ryan and Durning, 1997). And chips are not just for computers - they are increasingly being placed in items as mundane as toasters. Or take food as an example: the greater diversity we enjoy today contributes to growing indirect energy consumption. While Europeans eat only slightly more than they did 30 years ago, the transport of food (tons $/ \mathrm{km}$ per capita) has almost doubled (Resich and Scherhorn, 1999).

The aggregate effect of these developments is to reverse the impact of individual products' dematerialisation on resource consumption. ${ }^{2}$ The World Resources Institute (2000), based on their detailed study of material flows in five highly industrialised countries, concludes that "materials efficiency has improved in recent decades, relative to economic growth, but that resource use and overall waste quantities have remained approximately steady on a per capita basis and have continued to grow in absolute terms. This is a finding of critical importance to economic and environmental decision-making in the years ahead. We have learned that efficiency gains brought by technology and new management practices have been offset by the scale of economic growth and consumer choices that favor energy- and material-intensive lifestyles." ${ }^{, 4}$ (p. 35)

But what are the less material-intensive choices? A chorus of growth proponents suggest that knowledge-intensive products and services can substitute for materials consumption such that increases in the scale of global output will not harm the environment. ${ }^{5} \mathrm{~A}$ similar contention is that the knowledge revolution means that growth is no longer bound by the availability of materials inputs. There are several reasons to question these views.

First, there must be a material base to support knowledge and service consumption. For example, travel and transportation, which are the biggest growing category of services, depend on a highly developed physical infrastructure. The highway system, for example, grows with the number of vehicles.

Second, while the service sector continues to grow relative to manufacturing, this shift is measured in terms of employment or share of GDP, not output. As such, changes in employment or GDP are misleading indicators of materials resource consumption. Moreover, services which provide industrial support functions, such as engineering and business financial services, are among the fastest growing service industries (Røpke, 2001a). This trend does not attest to the substitution of services for manufacturing as implied when it is cited as an indicator of the dematerialisation of the economy. Outsourcing of manufacturing to the newly industrialising countries also conceals the material goods basis of the highly industrialised world in the national accounts. 
Third, many services have been converted to material products - automatic teller machines, medical diagnostic equipment, and answering machines, to name a few. With the advance of knowledge-based systems, this trend is likely to continue.

Finally, it is highly questionable, given a choice, whether consumers will opt for less materials intensive services over products. The historical trend has been in the opposite direction with products displacing personal services, paid and unpaid (Kidd, 1997). Thus, we have our own personal transportation vehicles, household entertainment centres, a multitude of household cleaning appliances, frozen dinner entrees to heat in the microwave, electronic security systems, and computers that substitute for teachers. While the size of some personal service industries, such as health services, has grown as a percent of the economy, the current move to substitute services for products is mainly occurring in the industrial sector. At least for the present, the incentives to switch to services are weaker for households because the time such services are offered coincides with when people work.

But what can be said of specific possibilities for ITs to reduce resource consumption? Say, for example, the substitution of electronic communication (the use of computers) for physical transportation (the use of cars). Obviously, there is an energy savings in using the computer versus the car for the same period of time, but the overall materials/energy impact depends on the products' uses. Computers are used for much longer periods of time than cars and as the number of features grow, they take more and more energy to run. Both are factors in the dramatic increase in the share of U.S. power consumed by personal computers (PCs) from 1 percent in 1992 to 13 percent in 1999 (Nadeau, 2000). As for materials, between 8 and 18 tons are used to manufacture one computer, compared to around 25 tons used in the average automobile (Sachs, 1999). ${ }^{6}$ In the case of telecommuting, we might reasonably expect that the substitution rate of computers to cars to be two computers, one for home and one for office use, to one car. So while computers entail less energy use than cars, total materials consumption also depends on the ratio of computers to cars per capita and their respective rates of replacement. Then again, it is likely that more and more cars will contain computers to provide various new functions, which may or may not reduce car use. The use of integrated computers is becoming complementary to the use of cars and many other products as well - hot tubs, washing machines, and home lighting systems, to name a few. Not all are involved in energy saving applications. While this is but one example, it illustrates that the choices on what products to buy and how to use them are complex.

Whether then sustainable lifestyle choices are readily available for the majority within the current production/consumption system is open to debate. The interconnectedness of our lives with our support systems makes the ownership of certain items almost compulsory, for example, clean clothes. Moreover, the social conception of what is clean has changed to become more clean as the energy efficiency of washing machines has risen. Whereas consumption patterns are the effect of many converging forces, product choices reflect trade-offs made by both individuals and societies.

To take, as one more example, Japanese air conditioning practices (Ger et al., 1999). In 1967 there were 3 air conditioners per 100 households in Japan; by 1993, that number had risen to 150 per 100 households - a fifty fold increase in less than thirty years. One reason for this dramatic rise is that modern buildings are not designed for natural cooling, but also air conditioners are retrofitted into older buildings as well. This takes place de- 
spite the fact that many Japanese do not like the feel of artificially cooled air. Housewives only turn on the air conditioning just before their husbands arrive home from work. Why then do these households use air conditioning, especially when people say they are more comfortable without it? What researchers found was that air conditioners symbolically represent what it is to be a modern Japanese family.

Leaving aside the question of consumer choice (for the moment), the implications of growing product consumption are fundamental to the realisation of sustainability. Consumption cannot increase indefinitely in a finite world. However, the problem is not so much a lack of resources - although the rate of consumption often leads to severe environmental degradation as resources become harder to extract - rather the problem appears to be that we have become too efficient at converting natural and social resources into material goods for consumption (Sachs, 1999; Hinterberger et al., 2000; Wackernagel, 2000).

\section{The Problem of Over-Consumption}

While economic growth portends many positive trends in social development, such as rising life expectancy and higher levels of education, higher levels of consumption do not inevitably mean greater social welfare or individual happiness (Schor, 1998; Vlek et al., 2000). Instead, there is reason to believe that non-essential consumption gives rise to personal discontent as well as causing serious social and ecological imbalances.

The proposition undergirding mainstream economics that more consumption raises utility and, by inference, satisfaction, does not bear out on closer examination within the frameworks of the other social sciences (Sanne, 1997; Røpke, 1999; Reisch and Scherhorn, 1999; Brown and Cameron, 2000). Even when consumption growth is predicated on an increasing number and variety of goods and services, this proposition does not seem to hold.

One body of evidence to suggest this are the studies examining the association between income and measures of personal well-being (Schor, 1998; Brown and Cameron, 2000). ${ }^{7}$ These show a weak link within countries between income and how satisfied people are with their lives. However, this association does not persist over time or across countries. Even when income levels have quadrupled, there have been no appreciable gains in happiness. Comparisons among countries show that after a certain level of income is reached, around $\$ 10,000$, there is no relation between income and subjective well-being (Inglehart, 2000). Although the Germans are twice as wealthy as the Irish, the Irish are happier. And the Taiwanese are as happy as the Japanese even though Japan's GDP per capita is three times greater than Taiwan's. These comparisons argue that having the means to meet basic material needs (adequate housing, enough food to eat, transport) is a necessary condition of happiness, but having the income to buy more is incidental.

What is dubious then is the simplistic notion that having more means greater well-being or that we can fulfil all needs through consuming more. This is not to imply that acquiring material goods categorically leads to unhappiness, but it would seem that happiness is also conditioned on other, more intangible needs, such as financial security or having time for family and friends. Moreover, people regret when market values - which they perceive as materialism and selfishness - begin to displace the more meaningful presence of family and community in their lives (The Harwood Group, 1995). Increasingly, people 
are also examining whether too much work and stress are worth having more money to spend (Schor, 1998).

In short, happiness appears to be a question of balancing needs. The problem of overconsumption emerges when we become locked into a system that dictates increasing levels of consumption. On the demand side, this may be the result of misguided attempts to buy happiness - the illusion that having such and such a product will add to our sexiness, intelligence, power, or whatever. When one product fails to deliver, we try the next. But also, the ascending spiral of needs seems related to the complexity of modern social structures. Røpke $(1999,2001 \mathrm{~b})$ points to how consumption is embedded in our everyday lives. For example, one reason people give for buying mobile phones is to keep track of their family's whereabouts. Thus, consumption bears on the quality of life.

This said, a great deal of product consumption seems to be in the category of satisfying manufactured, or artificial, needs (Yoshikawa, 1995). We buy items that are unnecessary to our well-being and ones that we already have. The power of advertising to stimulate needs is well known. Simply put, if advertising didn't work, there would be a whole lot less of it. Its pervasive and often intrusive presence undercuts the idea that companies are only responding to consumer demand for more products. Rather, it appears that the economy is structured in such a way that its success is dependent on the continued consumption of nonessential goods and experiences and marketing serves to ensure that success. Echoing Galbraith's $(1958,1967)$ challenge to the notion of consumer sovereignty, one marketing theoretician concedes, "If wants cannot always be specified, if specific goods and services are not always necessary to the satisfaction of wants, and buyers are easily manipulated, perhaps production need not simply respond to demand. It might be more efficient to mass produce goods and services and manipulate demand to match the assortment produced," (as quoted in Kilbourne et al., 1997).

Increasing consumption has also been linked to the process of individualisation and competition in modern society. Consumption signals status. But as status is always relative (we can never be the most powerful, the most sexy, the best bowler), we always end up needing more. However, competitive consumption is not strictly in quantitative terms. Rather most of us select categories of goods for high consumption that reflect our identity and "lifestyle" choices. This explains why people who agree that materialism causes social and environmental problems tend to say the fault is with other people's consumption and not their own (The Harwood Group, 1995; Røpke, 1999). One of the aims of advertising is to get potential consumers to see a product in terms of their own values, even to the point of turning a value on its own head, as Frank (1997) argues in his study of counter-culture advertising: "In the counterculture, admen believed they had found both a perfect model for consumer subjectivity, intelligent and at war with the conformist past, and a cultural machine for turning disgust with consumerism into the very fuel by which consumerism might be accelerated.” (p. 119)

This predicament of wanting more is perhaps the most tangible form of dissatisfaction that comes of equating quality of life with having more. To have enough, according to survey research, generally means having an income twice what you currently have, whatever that is (Brown and Cameron, 2000). More immediately, the satisfaction that derives from having something new fades quickly. For some people, consumption evolves to the point where it is not the item itself that produces satisfaction, or a sense of self, but the act of consuming - the "I shop, therefore I am" life. Kilbourne and his colleagues (1997) 
assert that the transmogrification of consumption values from "consuming to live" to "living to consume" is the essential focus of marketing.

Beyond the question of whether consumption provides for happiness, the more is better ethic also discounts the aggregate environmental and social effects of our consumption behaviour. The most serious environmental challenges we face today - global warming, disruption of the global nitrogen cycle, loss of bio-diversity - concern the scope and intensity of human activities (Sacks, 1999; McKibben, 2000). These problems reflect the intrusion of humans into the natural cyclical processes by which the ecosystem sustains itself. Since the mid-1900s, we have consumed more resources and caused more pollution and waste than in all of previous history (Myers, 2000). According to a report by the World Wildlife Fund (2002), issued in cooperation with the United Nations Environmental Programme (UNEP) World Conservation Monitoring Centre and Redefining Progress, we will need 1.8 and 2.2 earth-sized planets in 2050 to sustain current consumption levels while holding $\mathrm{CO}_{2}$ levels constant. We are overwhelming the environment's ability to regenerate itself by making use of its services at an unprecedented speed (Hinterberger et al., 2000). ${ }^{8} \quad$ This problem is of a far greater magnitude than the technical challenge of curbing pollution because it requires system change.

The disparity in resource consumption between rich and poor countries also reflects present consumption practices (Reisch and Scherhorn, 1999; World Wildlife Fund, 2002), bringing into question the scale of economic activities in the North and the West in which $15 \%$ of the world's population consumes over 70 percent of its resources (Brown and Cameron, 2000). ${ }^{9}$ This imbalance in the pattern of consumption and production has grave environmental and social consequences.

According to United Nations Development Programme figures (Reisch and Scherhorn, 1999; Myers, 2000), since 1950, the countries making up the wealthiest $20 \%$ of the population have generated more than $75 \%$ of its industrial and municipal wastes and $80 \%$ of its $\mathrm{CO}_{2}$ emissions. A child born in one of these countries will consume, over the course of his or her lifetime, 30 to 50 times as much as a child born in the countries comprising the poorest $20 \%$ of the world's people. In fact, average household consumption in Africa has declined by $20 \%$ over the last 25 years. The gap between rich and poor widens. In 1970 the ratio of income between the richest quintile of the world's population and the poorest was 30:1, today it is 74:1. Given the astounding development taking place in the last quarter century, we must ask whether "the poor are poor in part because the rich are rich" (Myers, 2000, p.5).

Poverty and environmental degradation are closely interrelated, as the impoverished are forced to overuse scarce resources in order to survive. But the costs of poverty are not endured by the poor alone. In the words of Kofi Annan (2001), Secretary General of the United Nations, "Today, no walls can separate humanitarian or human rights crises in one part of the world from national security crises in another." All people must be granted the resources to increase their consumption to meet basic human needs - food, health care, shelter, and an education. Otherwise, we will continue to live in a world of extreme political violence.

The disparity in resource distribution also brings the issue of environmental justice into sharp focus, such as in the case of global climate change. On the release of the U.N.affiliated Intergovernmental Panel on Climate Change's report warning of the danger of global warming, the chief science advisor for the World Bank and chair of the panel, 
Robert Watson, predicted, "The poor in developing countries will be most affected." (The New York Times, 2001) The director of China's National Climate Centre added that China was already dealing with the consequences: grain production fell 10 percent in 2000 in the midst of the worst drought in decades.

Furthermore, growth does not guarantee greater environmental, social, or economic equity, as evidenced by income gaps that continue to widen in countries with the greatest share of resources. Nor can present consumption in the poor nations rise to the levels of the wealthy without unimaginable stress on the environment. In consequence, we must begin to imagine solutions which will equitably redistribute resources, bringing into balance the needs of all the world's people.

Cutting consumption in the highly industrialised countries, however, need not be the same thing as cutting needs. Through reflective consideration of what our choices mean for sustainability, we can hope to create relationships that provide for the needs of all. In the words of the OECD Task Force on Sustainable Development, "Defining a set of goals for sustainable consumption and production implies the construction of a wider vision of welfare in which the satisfaction of needs, rather than consumption per se, is the aim." (OECD, 1997, p. 59)

\section{Sustainable Consumption}

Awareness of the need to reduce consumption as an essential focus for realising sustainability is gaining momentum. The watershed event in this development was the United Nation's Earth Summit held in Rio de Janiero in 1992. At this conference, 178 governments adopted the Agenda 21 agreement that detailed environmental plans of action. Chapter 4 of Agenda 21 stated that "the major cause of the continued deterioration of the global environment is the unsustainable pattern of consumption and production, particularly in industrialised countries" ( UNCED, 1992).

What grew out of Agenda 21, Chapter 4 is commonly referred to as sustainable consumption policy. Both the United Nations Environmental Programme (UNEP) and the Organisation for Economic and Co-operative Development (OECD) have developed sustainable consumption programmes. Several European countries, among them, the Netherlands, Sweden, Norway, and Austria, have also instituted sustainable consumption initiatives as integral elements of their environmental and economic development policies (Myers, 2000).

These programmes incorporate a number of approaches. The most accepted strategy is promoting resource efficient technological innovation as this avoids the sacrifice of reducing consumption and (presumably) safeguards economic growth (Røpke, 1999). The issue framed in this way is then not how much we consume, but what we consume - not how many products we make, but how we make them. In fact, the suggestion has been put forward that there is no need to reduce goods consumption since consumption is becoming dematerialised through technological progress. ${ }^{10}$

That this does not seem to be the case so far is discussed above, but also there are solid theoretical critiques of this position turning on the question of whether manufactured capital can substitute for natural capital (Cleveland and Ruth, 1997; Hinterberger et al., 2000). Beginning with Georgescu-Roegen (1970, 1976), ecological economists have pointed out there are limits to such substitution. Capital can never be produced independent of "inputs" from the eco-sphere - the matter and energy embodied in natural 
resources and environmental services. ${ }^{11}$ No such dependency exists in the reverse direction, that is, the eco-sphere can function apart from the economy (Hinterberger et al., 2000). Thus, we derive a fundamental tenet of ecological economics: the economy is but a part of the eco-system, dependent on it for its growth (Daly, 1996).

In economic terms, this is to argue that elasticities of substitution for individual items do not account for the indirect natural capital costs of producing and maintaining manufactured capital (Cleveland and Ruth, 1997). That is, elasticities of substitution neglect the life cycle impacts of high value-added products, however dematerialised the products themselves are. ${ }^{12}$ Further, the expectation that we might substitute high-entropy waste for low-entropy resources without a net loss in efficiency is also questionable, which is to recognise the biophysical limits to recycling. ${ }^{13}$

Still, critiques of the assumption of limitless growth should not be read as arguments against dematerialisation. To the contrary, the call for the dematerialisation of the economy has provided the most powerful economic principle yet to stimulate consideration of alternative technologies. ${ }^{14}$ The work of Amory and Hunter Lovins in developing energy efficient technologies in preference to increasing energy supplies is a powerful example of this approach. Further, the argument that we must radically reduce the scale of economic activity, as a whole, by factors of four to ten (SustainAbility, 1995; Hinterberger and Meyer-Stamer, 1997; Hinterberger and Schmidt-Bleek, 1999; Myers, 2000) forces an examination of the need for system innovation in addition to incremental development along current trajectories.

A second important emphasis in sustainable consumption policy is advocating less resource-intensive lifestyles. The issue is often framed in terms of sufficiency: how much is enough? The success of this approach is premised on the assumption that individuals' behaviour is the root cause of increasing consumption. Schor (1998), for example, argues that when people begin to consume responsibly, production will follow suit. Programmatically, the goal is to counteract the role of consumption in identity formation through a shift in personal values. People in Denmark, for example, are inclined to use bicycles, (40\% of the trips in central Copenhagen are by bicycle), because they represent independence and socially responsibility, which for Danes is the modern outlook (Ger et al., 1999). ${ }^{15}$ However, such a shift in individuals' behaviour, at least with regard to curtailing consumption, is only likely to occur if there is a corresponding shift in the predominant worldview (Kilbourne et al., 1997; Brown and Cameron, 2000). Currently, for most of the highly industrialised countries that social paradigm is informed by consumerist values embedded in the market structure. This may explain why sustainable consumption policy more often focuses on consuming differently, rather than less (Michaelis, 2000).

Current policy thus contains more than a few assumptions about what drives harmful consumption (Heap and Kent, 2000). Some analysts stress the production side - for example, industrialisation and the cheap availability of fossil fuels - others, human behaviour - for instance, consumption as a means of positioning within social groups.

This interdependency of consumption with so many aspects of our lives suggests the need for a more comprehensive, integrated framework based on a systems view of production and consumption (Vlek et al., 2000). A systems model presumes that consumption practices are formed by the socio-economic regime, while over time the regime is shaped by the practices. This view gives added weight to the idea that while consumption is often discussed as a matter of choice, these choices are bounded by the 
existing socio-techno-economic framework (Røpke, 1999; Resich and Scherhorn, 1999; Wackernagel, 2000). And since consumer behaviour is strongly embedded economically and socially, making the transition to sustainable consumption cannot depend on lifestyle decisions alone (Vlek et al., 2000).

\subsection{Assessing the Impact of AMTs on Sustainability}

The urgency of the socio-economic and ecological dilemmas surrounding increasing resource consumption compels the search for solutions. Given the balance of the evidence, we reach the conclusion that making the transition to sustainability requires that the prosperous countries cut quantitative consumption. This leaves us to consider qualitative economic development, that is, socio-economic progress resulting from the more effective use of a constant or decreasing level of resources, as the viable alternative for maintaining economic stability (Daly, 1996). Yet, a shift to qualitative development will require a substantial change in how we make products and organise production, in effect, a transformation of the production regime.

As presented next, the impact of the organisation of production on market structure and thus consumption - presents considerations apart from, but interrelated with, those included in current sustainable consumption and production policy. The analysis aims, in particular, for a better understanding of the sustainability of current directions in AMT development.

\section{The Present Production/Consumption Regime}

In product terms, increases in consumption in the highly industrialised countries are driven by cheaper products, faster product obsolescence, increasing product specialisation, and new categories of products. This demand regime has developed in tandem with the use of information technologies in production.

The market shift towards faster product cycles and increased product customisation reflects the adoption of AMT-based manufacturing strategies. To compete in today's markets, firms must develop the capability to manufacture a large mix of products quickly. Speed figures critically in fast-to-market and product differentiation strategies by keeping the costs of manufacturing a wider variety of products relatively low. This increase in speed is paid for by increasing throughput rates. Consequently, the use of speed pushes firms in the direction of expanding output.

Currently, production is organised to facilitate the throughput of low-cost differentiated product as the primary means of satisfying needs. Consumers are presented with a profusion of already manufactured goods from which they make choices. The absorptive capacity of consumer markets to accept a huge volume of manufactured goods thus figures critically in productive efficiency.

AMTs have also contributed substantially to the rise in resource productivity in manufacturing. It is probable that AMT-enabled lean production techniques have been a major factor in decreasing resource intensity, leading to the much remarked-on gains in dematerialization. New applications of AMTs will likely result in even more waste reduction, with significant gains in dematerialization to be made as AMT use moves back up the supply chain to the materials processing industries, where resource waste is rampant. 
Yet, increasing resource efficiency in manufacturing also serves to lower product costs and spur demand.

In sum, the effective use of AMTs appears to strengthen production system dependence on quantitative growth because of trade-offs inherent to AMT use. Faster product introductions and greater product variety are achieved at the expense of increasing system complexity, capital intensity, break even sales volumes, and market volatility. On the demand side, product consumption spirals upwards as a result of faster product obsolescence and more individuated consumption.

This spiral of increasing needs has not been lost on industry. Manufacturers cite changing customer requirements in the form of greater demand for product customisation and increasing customer expectations as the principle market conditions shaping the future of competition. ${ }^{16}$ At the same time, the use of AMTs is promoted as the solution to increasing market volatility.

Considerable sums of public money go to manufacturing research and modernisation programmes aiming to increase industry's use of AMTs for competitive purposes. A small percentage of these funds now supports research on eco-efficient product manufacturing. ${ }^{17}$ There are no on-going manufacturing research programmes that take the organisation of production for reducing private goods consumption as their objective. ${ }^{18}$ Instead, mass customisation is now being promoted as the future of manufacturing.

Until recently, the expanding use of AMTs has almost exclusively been seen as a matter of individual firms' choices about how to compete. The mirror image of this position occurs in policy discussions concerning sustainability in which achieving the goal of sustainable consumption is presented as a function of individual consumers' choices on what to consume. In a co-evolutionary world, the truth must lie somewhere in between.

\section{The Direction of AMT Development}

Necessarily, the strategic uses of AMTs aim at enhancing the firm's competitive position. This goal, however, does not necessarily take into account how such uses might impinge on sustainability. To the contrary, the path dependent nature of technological change gives us reason to believe that techno-economic optimisation occurs at the expense of social and ecological considerations. Historically, the consequences of change have often been an imbalance favouring industrial efficiency over environmental welfare and socioeconomic equity. The rationale for continued economic growth tends to ignore growth's biophysical and socio-ethical limits (Daly, 1996). ${ }^{19}$

The assessment offered here is necessarily preliminary since not all the tools yet exist to carry out a full calculation of sustainability. The current bias in evaluating the impact of technological change runs towards techno-economic measures. The effort is focussed on measuring environmental progress in terms of efficiency. This invites a certain circularity of reasoning where solutions tend to look a lot like the original problem (Sachs, 1999). By contrast, the assessment below points to a need for examining technological developments from an ecological and social standpoint.

What, then, is the relation between sustainability and the current direction of production technology development? A primary concern is whether current changes in the terms of product competition parallel unsustainable consumption patterns characterised by faster product replacement, faster throughput, and more individuated consumption. But the 
approach we adopt here is to employ three measures of sustainability in order not to conflate a definition of the problem with a description of current conditions. The three assessment criteria are: resource efficiency, throughput (speed and scale), and resiliency (diversity and flexibility).

\section{Resource Efficiency}

The amount of use (or service) derived from a given amount of energy and material determines its resource productivity (or efficiency). The inverse of resource productivity, the material intensity per unit service, or MIPS, has been devised as an indicator of the "life-cycle wide environmental impact intensity" of a product, service, industry, or economy, depending on its level of application (Hinterberger and Schmidt-Bleek, 1999, p. 53). Because MIPS subsumes all of the material and energy inputs that are used in the production of a product/service, it provides a reasonable assessment of competing practices. ${ }^{20}$ Longer-life and higher use-intensity products will have lower MIPS values.

At the level of an industry or an economy, MIPS provides an indication of progress towards sustainability with respect to consumption (Hinterberger and Schmidt-Bleek, 1999). But it is important to remember that resource efficiency by itself does not tell us what is sustainable in terms of the scale of economic activity. This is especially true of claims for dematerialisation at the product/service level, as it is the sum of our energy/matter throughputs that matters. Dematerialisation "does not rein in the spiral of need." (SustainAbility, 1995, p.21) However resource-efficient products are, we are on an unsustainable path if aggregate consumption is greater than the ability of society and the environment to adjust for this level of throughput.

Existing policy initiatives give priority to increasing resource efficiency in the transition to sustainability. This priority dovetails with the competitive aim of cost-effective product differentiation strategies. In point of fact, it is probable that AMT-enabled lean production techniques have been a major factor in decreasing resource intensity, accounting for much of the to-date gains in dematerialization.

The further implications of AMT-related trajectories for resource efficiency are:

- More waste reduction as a result of higher production system efficiencies from system optimisation/integration: This could well be a particularly important effect as the use of AMTs moves back up the supply chain to the materials processing and extraction industries, where the bulk of waste occurs. ${ }^{21}$ For example, wood products companies have effectively addressed supply shortages with yield optimisers which maximise the cuts from a given work piece. However, in many of the high value-added industries, there may not be much to gain in resource efficiency. A study of the electronics industry found that the manufacturing processes generate very low levels of byproduct, e.g. waste (Cascadia Consulting Group, 1995). Many individual companies have also targeted six sigma and zero waste goals. ${ }^{22}$ Yet, scrap reduction and quality programmes could result in much greater yields in more industries, including some that make high value-added products, such as composite products manufacturers. ${ }^{23}$

- Higher capacity utilisation rates enabled by increased information flows: AMT-based process controls support the rapid set-ups characteristic of multi-product plants, leading to higher equipment utilisation rates. As a result, companies are able to increase their productive capacity without purchasing new plant. 
- Increasing use intensity as products and processes are reconfigured to serve new functions: This involves the design of modular products and processes that can be continuously re-assembled to fill needs as they arise. In effect, materials use is averaged over a greater amount of service. Modular processes and "plug and play" machine tools hold substantial promise for orders-of-magnitude dematerialization by increasing capital utilisation. However, modularization is likely to have a greater effect in industry, where there is an incentive to conserve resources, than in consumer markets, where consumption is tied to life style and social status.

- Increasing complexity leading to inefficient resource use: As processes become more complicated many companies have experienced difficulties with maintaining productivity. Data requirements can exceed the system's capacity (Efstathiou et al., 1998) and equipment is often sized for a hypothetical maximum expected demand resulting in unused capacity. However, these outcomes may be more the result of unskilful management of AMT processes than an inherent AMT trade-off.

- Increases in unused capacity as an effect of resource building: In order to respond to changing market and industry conditions, companies must develop capabilities in advance of their possible use. Firms run the risk of not being able to put these resources to full use. At the same time, investment in adaptive capability may prolong the effective lives of resources. Also, firms duplicate each others' resource development efforts.

\section{Throughput: Speed and Scale}

Material flows, or throughput, are a primary measure of the scale of an economy (Daly, 1996; Hinterberger and Meyer-Stamer, 1997). Likewise, speed is inextricably bound with scale as it is a primary determinant of throughput, that is, the amount of materials consumed in a given period of time. In ecological (biophysical) terms, throughput is understood as the process whereby low-entropy raw materials are converted to highentropy wastes. Order in the production system is maintained at the expense of increasing entropy in the environment. When the speed and scale at which the economy grows exceed the planet's capacity to regenerate resources and absorb wastes without irreversible damage, we have breached the limits of sustainability (Boulding, 1966; Meadows et al., 1992; Daly, 1996). There are serious doubts as to whether the natural environment, over the long term, can accommodate the ever-increasing pace of change in economic activities (Hinterberger et al., 2000; Wackernagel, 2000). Natural systems are slow to adapt relative to the speed of change we now impose on the environment and feedback signalling environmental stress often occurs too late for us to reverse the effects of our actions.

Consider the burning of fossil fuels. Under natural conditions, the amount of $\mathrm{CO}_{2}$ being released to the atmosphere is roughly in balance with that being absorbed by vegetation. But each year we burn the equivalent of a million year's production of fossil fuels (Sachs, 1999). Further, consumption is projected to meet $95 \%$ of additional energy demand through the year 2020 (Myers, 2000). Therefore, unless new policies are adopted triggering a shift to other energy sources, we can expect a corresponding $70 \%$ rise in $\mathrm{CO}_{2}$ emissions over this same period. In sum, we are risking an abrupt change in climate conditions from the cumulative impact of fossil fuel consumption. In this regard, as Sachs (1999) succinctly puts it, "100 efficient Indian Maruti cars are not better than 30 old and wasteful Ambassador cars." (p. 184) Further, the control of oil sources has resulted in 
tremendous political and social unrest, bringing into doubt the ability of our political systems to cope with our fossil fuel dependence.

Throughput, by comparison with resource-efficiency, provides a measure for assessing where we are at relative to a steady state economy (Cleveland and Ruth, 1997). A steady state economy is one in biophysical balance where throughput is maintained at a rate of resource use sufficient for a good life now and the foreseeable future (OECD, 1997). According to Daly (1996), the steady state economy is realised when aggregate throughput is constant. Various indicators that measure the scale of consumption include carrying capacity, environmental space, ecological footprints, ecological rucksacks and total material requirement (SustainAbility, 1995; OECD, 1997; Hinterberger et al., 2000). These serve to demonstrate the limits of consumption relative to future, intergenerational needs and social equity and ecological considerations.

Considering the enduring rise in per capita materials resource consumption, the issue of scale merits concerted attention in policy discussions on how to achieve sustainability. It is well known that gains in resource efficiency are off-set by attendant increases in product use and increased consumption associated with rising affluence in general (Ehrlich et al., 1999; Reisch and Scherhorn, 1999). However, AMT use portends other effects which increase the scale and speed of production and consumption that have received scant attention in policy discussions.

Potential effects of AMT use on throughput include:

- The rise of time-based competition leading to faster product obsolescence and more individuated products: The highest market share for a product usually goes to the firm that first produces it. This provides a significant market incentive for firms to accelerate product life cycles. Likewise, many firms look to increasing demand for customised product for future revenue growth. ${ }^{24}$ AMTs' operational speeds are critical to both mass customisation and first-to-market competitive strategies, but higher speeds correspond to higher throughput rates.

- Production output increases driven by higher optimal process/plant scales: As product variety increases, operating costs per unit go up. Capital costs also rise in step with increasing flexibility and capital intensity. In consequence, the optimum scale for a flexible factory is even greater than for the conventional plant based solely on economies of scale (Stalk, 1988; Katayama and Bennett, 1999). As reported in Chapter 5, detailed studies of AMT adopters show that lower unit costs are dependent on achieving higher levels of output (Alcorta,1998).

- Changes in product requirements that date equipment: Simultaneous to faster product cycles, the pace of production system development mounts. Specific capabilities are needed for times that are short in comparison to the potential lives of the process equipment. Machinery is replaced more often and capital costs must be recovered over shorter and shorter periods. The Agility Forum roadmap (1997) identifies recovering rising plant and equipment costs over shorter product and process lifetimes as a major dilemma for the agile company. They conclude that, under these conditions, growth in sales is needed to justify investments. Shorter product life times also can result in the premature closing of plants relative to their useful lives. This results not only in environmental waste but also involves a social cost when people's livelihoods are involved. 
- Decreasing occurrence of over-production associated with reductions in uncertainty: The ability to organise production to manufacture what, in effect, is already sold could eliminate the product waste associated with manufacturing-to-forecast. Manufacturing-to-order strategies based on AMT-facilitated customer-producer interaction use knowledge of customer needs to produce only that amount of product that will find use.

- Increasing needs satisfaction/creation as an effect of product customisation: AMTs could play a unique part in reducing the level of consumption if needs can be satisfied through more accurate means of specifying and developing the product according to needs. Under this scenario, people would buy fewer products because what they did buy would more closely fit their needs. A particularly intriguing suggestion is "virtual consumption" - where customers use interactive design tools such as simulation and virtual reality technologies to shape needs in non-material directions. However, as with gains in resource efficiency, customisation and virtual consumption capabilities may lead to rising levels of demand.

\section{Resiliency: Diversity and Flexibility}

Diverse, flexible systems are resilient, able to reorganise themselves to adapt to change. ${ }^{25}$ Under constantly changing conditions, such as pertain to the production/consumption system, adaptability is important to realising social and environmental balance as well as economic stability (Hwang, 1998). As Hinterberger and colleagues (2000) argue, sustainability cannot mean the perpetuation of the system's present state, as the throughput of energy and matter that production/consumption depends on is never constant.

In this regard, a healthy diversity is essential to sustainability (SustainAbility 1995; Capra, 1996). Diversity allows for the system to adapt through the formation of new relationships among varying sets of system elements (Leydesdorff, 1997). The rate of increase or decrease in the "different viable patterns of self-organisation with distinct co-ordinated sub-systems of knowledge" is a measure of integrated functional diversity, which reflects a higher order of system interaction than efficiency (Schütz, 1999, p. 25). Flexibility, the ability to vary process parameters as a function of knowledge of the environment, approximates reflexivity. Flexibility is a measure of the organisation's ability to respond to disturbances (both internal and external) and to vary behaviour in consideration of the relationship that the firm holds with its environment in ways that balance the interests of the firm and those of the sustaining environment. Diversity and flexibility together encode system complexity, defined as the number of different system elements and their possible interrelations (Leydesdorff, 1997; Hinterberger et al. 2000).

The differences between first and higher order system functioning is pivotal to understanding the significance of the adaptability criteria. Efficiency measures (sub)system performance in terms of input and output flows, which is a first-order system description, whereas adaptation is a reflexive process (Leydesdorff, 1997; Hukkinen, 2001). Succinctly put, efficiency describes quantitative relationships, whereas resiliency is a description of a system's qualitative relationships. Efforts to maximise sub-system efficiencies result in a decrease in adaptability in the overall system, (a condition referred to as sub-optimisation), be this in a plant, an economy, or an ecosystem (Stacey, 1993; Schütz, 1999). Efficiency gains pertain to increasing standardisation and homogenisation, whereas resiliency is effected through increasing flexibility and diversity. ${ }^{26}$ Sustainability then refers to the conditions for maintaining self-organising processes. 
The concept of resiliency has not been operationalised to the same extent as ecoefficiency and throughput. Composite indicators of well-being, such as the Genuine Progress Indicator (GPI), attempt to capture the complex interactions of system components through description of qualitative relationships (Cobb et al., 1995). But forwardlooking policy development requires indicators that can track the interactions of technologies, the environment, and society in terms of complex, dynamic informationprocessing systems (van der Leeuw, 2001). The understanding of production and consumption as co-evolutionary developments is a start in this direction.

The implications of the strategic uses of AMTs for resiliency include:

- Increasing adaptability as an effect of process reconfigurability: Expanding the number of possible interactions among system elements is the basis of reconfigurable design, which in turn is the basis for experimentation and the development of experiential knowledge. Process simulations can be used to speed up the learning process. Enhanced adaptability reduces firms' vulnerability to demand volatility (Katayama and Bennett, 1999). Moreover, dynamic capabilities and capabilities building enhance the firm's ability to respond to changes in environmental and social conditions in addition to market signals.

- Potential loss of worker and small firm capabilities and decision-making autonomy in the transition from experience- to knowledge-based production: AMTs play a key role in supporting the information needs of the adaptive organisation, but there are also limits to the deterministic structure of current knowledge systems. The rise of supply chain management practices is leading to a new form of vertical integration. Scale requires predictability and so integration demands that system actors follow the same rules. Knowledge systematisation often results in the development of conditions where workers and small firms have less say in system operation. Further, the use of codified knowledge can decrease the opportunity for experiential learning, leading to a loss of creativity (see, for example, the study of ERP implementation by Kræmmergaard et al., 2001). Likewise, the focus on increasing supply chain efficiency has resulted in the loss of innovative capabilities in small firms (Luria, 1997).

- Increasing privatisation of knowledge in response to the risk of not being able to appropriate a return on its development: As knowledge becomes a resource (and economic good) in its own right, the issue of its ownership becomes increasingly problematical.

- Fewer small-scale, local firms, but more local subsidiary plants, due to system rationalisation: An open question is whether expanding system systematisation and rationalisation works to reduce functional diversity among firms so as to increase industrial homogeneity and endanger small-scale, local firms. Historically, small firms have been the major source of functional diversity in the industrial system. However, as AMT-based flexibility enables the take-over of niche markets by large firms, smaller firms are being crowded out (Booth, 1995), thereby increasing overall system vulnerability. At the same time, the development of modular, small-scale processes may create economies of scale in manufacturing and deploying plant systems, opening the possibilities for distributed plant sitings. For example, mini paper mills could be sited close to urban sources of recycled paper (Clean Washington Center, 1995). 


\subsection{New Directions in AMT Use}

On balance, given the present strategic thrust of AMT use, the potential is to substantially increase resource efficiency, while the risk is to reinforce growth of material goods consumption. The possible influence of AMT use on firms' adaptive capabilities raises concerns that need study. Table 6.1 presents the summary assessment of AMT effects on sustainability.

The conclusions in Table 6.1, however, largely concern the dynamics of the present regime. In the larger context of how we can realise a transition to sustainability, we face an additional set of questions regarding how to create technological momentum in the direction of sustainability. This final section of the chapter poses some considerations in this regard. In Chapter 10 we examine policies to effect industrial transformation.

\section{Technological Innovation in the Growth Context}

The idea that technological progress will serve to overcome the limits to growth has a long history of debate. ${ }^{27}$ Innovation vanquishes scarcity, according to one view. Clearly, the boundaries of human intervention in the physical world are continuously extended through scientific knowledge and technological know-how. Moreover, new technologies take less and less time to reach the marketplace. On the other side, there is the argument that there are no technological fixes. In this view, the human economy is but an open sub-system of the finite world ecosystem (Georgescu-Roegen, 1976; Daly, 1996). There are limits to technology's pushing back the limits of bio-physical constraint (Cleveland and Ruth, 1997). Rather than providing lasting solutions, new technologies are apt to displace "scarcity" problems from one part of the environment to another (Wackernagel, 2000). This debate is often carried out by the two sides framing the salient question to this inquiry - what is the relationship between well-being and growth? - in opposing terms.

For growth proponents, the question is: does environmental progress limit growth? Ekins and Jacobs (1995), for example, argue that it possible for GDP growth and sustainability to be compatible. The relationship between value-added and material throughput is variable and can be altered by structural economic change, substitution between factor inputs, and more efficient use of the same input. The technologies we use and how we use them bear on all these relationships. Summarily, in this view, largely based on the neo-classical economics paradigm, technological innovation provides the means to overcome environmental limits (Hwang, 1998).

For growth critics, what is important is the inverse question: does growth limit environmental progress? This conception of the problem tends to identify technological innovation with growth and, in fact, historically this has been the case, at least with regard to industrialisation, as claimed also by the growth proponents. More specifically, growth sceptics object to the de facto subordination of social and environmental needs to economic progress through the instrumentality of technological change. Taking this view to an extreme, the critics argue against new technology and even, in some cases, for a dismantling of the industrial infrastructure (see, for example, Macy and Brown, 1998). 


\section{Table 6.1 AMT Impacts by Sustainability Criteria}

\begin{tabular}{|c|c|c|c|c|c|}
\hline Resource Efficiency & & Throughput & & Resiliency & \\
\hline $\begin{array}{l}\text { More waste reduction as a result of } \\
\text { higher production system efficien- } \\
\text { cies from system optimisation/ } \\
\text { integration. }\end{array}$ & Increase & $\begin{array}{l}\text { The rise of time-based competition } \\
\text { leading to faster product obsoles- } \\
\text { cence and more individuated } \\
\text { products. }\end{array}$ & Increase & $\begin{array}{l}\text { Increasing adaptability as an effect of } \\
\text { reconfigurability. }\end{array}$ & Increase \\
\hline $\begin{array}{l}\text { Higher capacity utilisation rates } \\
\text { enabled by increased information } \\
\text { flows. }\end{array}$ & Increase & $\begin{array}{l}\text { Production output increases driven } \\
\text { by higher optimal process/plant } \\
\text { scales. }\end{array}$ & Increase & \multirow{2}{*}{$\begin{array}{l}\text { Potential loss of worker and small } \\
\text { firm capabilities and decision- } \\
\text { making autonomy in the transition } \\
\text { from experience- to knowledge- } \\
\text { based production. }\end{array}$} & \multirow[t]{2}{*}{$\begin{array}{l}\text { Decrease } \\
\text { and } \\
\text { Increase }\end{array}$} \\
\hline $\begin{array}{l}\text { Increasing use intensity as products and } \\
\text { processes are reconfigured to serve new } \\
\text { functions. }\end{array}$ & Increase & $\begin{array}{l}\text { Changes in product requirements } \\
\text { that date equipment. }\end{array}$ & Increase & & \\
\hline $\begin{array}{l}\text { Increasing complexity leading to ineffi- } \\
\text { cient resource use. }\end{array}$ & Decrease & $\begin{array}{l}\text { Decreasing occurrence of over- } \\
\text { production associated with } \\
\text { reductions in uncertainty. }\end{array}$ & Decrease & $\begin{array}{l}\text { Increasing privatisation of knowledge } \\
\text { in response to the risk of not being able } \\
\text { to appropriate a return on its develop- } \\
\text { ment. }\end{array}$ & Decrease \\
\hline $\begin{array}{l}\text { Increases in unused capacity as an effect } \\
\text { of resource building. }\end{array}$ & $\begin{array}{l}\text { Decrease } \\
\text { and } \\
\text { Increase }\end{array}$ & $\begin{array}{l}\text { Increasing needs satisfaction/creation } \\
\text { as an effect of product customisation. }\end{array}$ & $\begin{array}{l}\text { Increase } \\
\text { and } \\
\text { Decrease }\end{array}$ & $\begin{array}{l}\text { Fewer small-scale, local firms, but more } \\
\text { local subsidiary plants, due to system } \\
\text { rationalisation. }\end{array}$ & Decrease \\
\hline
\end{tabular}

Note: Impacts in bold are established dynamics in current production/consumption regime. 
Between these two standpoints, a middle view is emerging in which technological change is understood in terms of adaptability. Accordingly, technology is conceived as providing a means of reconfiguring the system in response to changes in the environment rather than a device for overcoming "environmental" problems. This view holds that our perceptions of the environment are the result of our interactions with it, including our technology choices.

When we identify the economy as different than nature, we tend to favour human intervention in the natural domain, the technical fix, as a way of solving environmental problems (van der Leeuw, 2001). If we assume that environmental problems are caused by humans instead of arising from social/environmental/economic interactions, we constrain our ability to respond to change (White, 2000). Both technological optimism and pessimism are deterministic in outlook. Both obscure the problematique of adaptability, which is to argue that guiding the direction - and extent - of technological change is critical to realising sustainability. From this standpoint, history matters, biophysical limits pertain in the use of technologies, and technological outcomes are unpredictable.

To what extent then is technological progress bound to growth and to what extent can it be put in the service of sustainability?

With regard to the organisation of production there are some important developments in the making. One is industrial ecology, which takes as its inspiration natural cycles in the ecosystem. (Náray-Szabó, 2000). The use, processing, transformation, and consumption of resources is based on replacing open linear systems with closed loop designs. ${ }^{28}$ Another is product-service systems (PSS), in which products and services are offered in combination with the express intent of re-orienting unsustainable production and consumption patterns (UNEP, 2000). ${ }^{29}$ Also, green design and design for environment (DfE), though less directly concerned with the organisation of production, are important tools in re-orienting the product realisation process. Yet, while these practices offer promising new directions, they do not account for the current strategic uses of production technology and their relation to market developments. A study of PSS in Swedish companies found that selling product-services was not seen by firms as a competitive advantage (Mont, 2000). It is also notable that the production technology roadmaps and foresight analyses contain no mention of these developments.

What has caught the attention of the business community is the opportunity to sell solutions to the world's environmental problems. In this twist on the view that innovation vanquishes the limits to growth, green products are the focus of strategy for winning new business (see, for example, Hart (1997) and World Business Council for Sustainable Development (2000)). To be sure, a small but growing number of companies are making sincere efforts to rethink their strategies according to sustainability principles. When these strategies translate into changes in practices, there is genuine progress toward sustainability. But to believe that information technology, or any other advanced technology, can be used to create greener products and processes is not enough to create system change (Fleming, 1996). From a systems perspective, one can argue that efficiency improvements are the driving force behind the continued expansion in output (Sachs, 1999). The very success of new technology is what makes it possible for societies to increase their ecological throughput (Wackernagel, 2000). In the end, developments increasing throughput describe a harmful path dependence. It is this contradiction that industry needs to confront to realise strong sustainability. 
Nicholas Ashford (1993) has proposed that, "Encouraging technological changes for production purposes (i.e., main business innovation) and for environmental compliance purposes must be seen as interrelated, rather than separable, activities that must be fully integrated. To bring about this integration, management must be committed to expanding the 'problem space' of the engineer/scientist/technologist to include environmental and safety concerns so that those concerns are reflected in both design and operational criteria of a firm's technology." (pp. 277-278) With regard to the organisation of production, the Strategic Use Model further suggests that for such practices to gain hold, they must involve the effective use of production technologies in resolving trade-offs embedded in current trajectories.

The distinction wrought here between innovation and adaptation refocuses our attention on the issue of technological choice and defuses the notion that innovation is inherently beneficial. Instead, adaptability suggests a balanced use of technology in synchronisation with nature and society, opening up new possibilities for the realisation of well-being that are not dependent on technological intervention.

\section{Creating Technological Momentum}

The growing use of AMTs marks a shift from scale-based to time-based manufacturing strategies. But the analysis in this thesis also shows that time-based strategies depend on growth in consumption to succeed. Thus, the goal of reducing consumption levels challenges many of our assumptions about the way things are, not least of the need for economic growth. We are also concerned that, in the process of technological change, firms replicate the trade-offs embedded in current technological trajectories. How then do we get on a more sustainable path?

The contribution of AMTs to resource efficiency is well established. But it is also becoming increasingly clear that resource efficiency measures are not enough. For one thing, they tend to stimulate higher levels of product use as well as more demand for the product itself. But it may well be that a greater problem is that efficiency gains in the organisation of production come at the expense of balance in the ecosystem.

There are indications of the potential for reductions in throughput if the strategic uses of AMTs were to take a new direction. Even now, AMTs are associated with decreasing occurrence of over-production by way of manufacturing-to-order. Manufacturing only what is already sold eliminates the product waste associated with sales forecasts. Another potentially more powerful development is the coming modularization of AMTs which puts the development of small-scale, cost-efficient plant within reach. ${ }^{30}$ Modular, flexible technologies can extend the range of output levels at which profitable operations are possible. This certainly, in part, underlies the demand for easy-to-use and smaller scale AMTs. But when and where the next generation of AMTs are used will in large part determine to what strategic purposes they will be put and hence the direction of their future development. For this reason, it is imperative that these technologies be made available for use in a variety of industrial contexts, particularly small, independent firms.

On a more conjectural note, AMT use may lead to the development of strategies based on higher product use values, including possibilities for increasing product use intensity and needs satisfaction. ${ }^{31}$ The potential is there for AMTs to be used in manufacturing products readily configurable to present and future use value (Kidd, 1997). This would involve the creation of "a new category of goods which are fabricated in greatly reduced 
volumes, but with each product having much greater individual value." (IMS, 1994, p.11) The characteristics of such products would be their long life coupled to a high use flexibility. A self-maintenance combination photocopier/fax/printer is one example. Such products are likely to require a long term relationship between the product supplier and user and have a high customisation quotient. Product ownership may devolve to the length of time only for which the product serves an immediate need, following which the product would be re-deployed to the next use (Kidd, 1997). In order to manage the continuous reconfiguration of products and processes requisite to such a strategy, organisations would have to be highly adaptable. This would require firms to invest in the development of dynamic manufacturing capabilities.

Moreover, a substantially different way of organising production is likely to grow out of the use of reconfigurable production technologies. Already, these technologies are being heralded as ushering in the coming age of "variable capital" (Agility Forum, 1997). Industry will not only continuously introduce new products, there will be continuous reorganisation of the production process to support this innovation. A second outcome, already taking place, is the development of production networks. Increasingly, customers are being brought into the production process through virtual linkages.

The question for us though, in our inquiry here, is what impact these developments might have on throughput. As the future of these technologies is currently envisioned by industry, they are likely to be put to use expanding output in the effort to "meet the growing demand for customised product". In one respect, then, these technologies are intended to boost the productivity of the current production/consumption system. Yet, at present, the operationalisation of mass customisation strategies involves manufacturing an over-abundant array of goods from which customers choose. The waste in this system is enormous. ${ }^{32}$ In the future, the idea is to manufacture only what is already ordered. This will undoubtedly result in a major increase in production system efficiencies. But, conceivably, it will also act as a further spur to demand as what were once luxury, madeto-customer-specification items are now put in reach of the average consumer. To some extent this has already happened in the development of lifestyle products.

Achieving sustainability is more likely to require the development of new relationships between consumers and producers, that is, through changing the system conditions. Sustainability is a question of balancing our consumption needs with the developmental needs of society and the environment, which are our needs too. These needs are currently articulated through the consumer-producer nexus. Expanding the consideration of needs to include social and environmental concerns regarding AMTs' influence on market and industry structure will be an extraordinarily complex undertaking. Whether we are able to create technological momentum in a more sustainable direction then depends on the development of our reflexive, adaptive capabilities.

We have argued that firms learn new ways to achieve their business goals as an effect of the process reorganisation brought on through the integration of new functionality into the production system. It stands to reason that firms with a developed understanding of the strategic range of AMTs could use them to experiment in new ways to "manage" consumption for competitive advantage.

It is perhaps this prospect which is most intriguing from the standpoint of sustainability. The next generation of AMTs could well provide the foundational experience for the sustainable use of production technologies. As argued above, adaptability, or resiliency, is an 
essential condition of sustainability. Adaptability is also the defining characteristic of the next generation of AMTs. Adaptive capabilities might also be developed through the experience of change enabled though the use of process simulation and reconfigurable production technologies. Substantively, adaptive capabilities are both the means and the end, both process and outcome.

This reciprocity of ends and means reflects the current direction in the co-evolution of production technologies with product markets. Such co-evolution is basic to creating technological momentum. I would argue that the current failure of alternative sustainability schemes for organising production, such as product-service systems, to become mainstream is because the ends are not embedded in the means. Since the proposed alternatives are not linked to the current strategic uses of AMTs, from a manufacturing standpoint, they present no strategic advantage - in other words, they do not resolve current trade-offs. ${ }^{33}$ By comparison, manufacturing strategies based on dynamic, adaptive capabilities open possibilities for dealing with the complexity and volatility that characterise today's markets. Further, they provide the basis for the development of unique capabilities grounded in experiential knowledge.

The adaptability trajectory thus represents the possibility of a convergence of the sustainability discourse with developments already happening in industry and in the manufacturing and engineering sciences. That path would explore how current developments in the strategic uses of AMTs might be used to restore balance in the ecosystem by supporting the practice of sustainability in production. However, taking this path will necessarily place the development of both technology and sustainability policy in a wider context.

These policy development needs are addressed in Chapter 10. But before advancing to that stage, we will form a more specific understanding of firms' adaptive behaviour through an empirical investigation of the model presented in Chapter 3. 


\section{Chapter 6 Endnotes}

1 Only $2 \%$ of the materials used in manufacturing goes into final product (Duncan, 1994).

2 Dematerialisation has been defined as the progressive minimisation of material and energy inputs as a ratio of output (Fleming, 1996). In discussing dematerialisation it is imperative to specify which level of aggregation is being referred to. At the individual product level there is an evident trend towards dematerialisation, (sports utility vehicles (SUVs) in the United States notwithstanding). However, the volume of material input for the entire economy is not declining.

3 The WRI report covers the period of 1975 to 1995.

4 What goes unexamined here is the extent to which technology and new management practices foster excessive lifestyles, a question we take up later in this chapter.

5 A summary of these claims is given in Ehrlich et al. (1999). This idea also appears in a number of European countries' IT development programmes (Cahill and Scapola, 1996).

6 The computer chip also contains a material called columbite-tantalite or col-tan., mined in the Congo. In processed form, col-tan is used in electronics products -- mobile phones, jet engines, and air bags - as well as for maintaining the chip's electric charge. Control of col-tan is now centre stage of the war for the Congo's resources.

7 Income is used as a proxy for consumption although it is understood that the two constructs are not synonymous.

8 The term "regenerative capacity" has been coined to refer to this ability.

9 This figure is based on World bank data.

10 This view is rarely explicitly stated, although it is heavily implicit in such opinions as that of Jacqueline Aloisi de Larderel, Director of UNEP's Division of Technology Industry and Economics (DTIE), "Sustainable consumption is not about consuming less, it is about consuming differently, consuming efficiently." (Quoted in the position paper of the European Brands Association on Sustainable Consumption, Association Des Industires De Marques (2001)).

11 Environmental, or eco-system, services is the term used by ecological economists to denote the natural processes which regulate the eco-system's balance, such as $\mathrm{CO}_{2}$ absorption by rain forests and vegetation in general.

12 For example, the current trend towards products made of light-weight composite materials makes many of these products practically unrecyclable because of their materials complexity.

13 This is of course hinges on what one considers waste. Aluminum recycling, for example, requires less energy than production from raw materials. But, in general, the properties of materials change during processing such that there is a limit to their reuse.

14 This principle is embodied in the design for environment and green design movements.

15 This finding comes from a study of the symbolic meanings of consumption practices that involved content (qualitative) analysis of interview data.

16 See Chapter 4, Section 4.2 for references.

17 Freeman (1992) reports that in the debate about the limits to growth, the "optimists" took the position that growth could and should continue on the condition that the world R\&D system was reoriented towards solving environmental priorities as a high priority.

18 The one example of a manufacturing research programme focussing on alternatives to mass production is the now completed Gnossis Project of the Intelligent Manufacturing Systems programme. This programme is discussed in Chapters 9 and 10.

19 We refer to quantitative growth based on increasing the physical scale of matter/energy throughput.

20 The calculation of MIPS is then closely allied with life cycle assessment (LCA)methodology. It then seems to present some the same challenges as do LCAs. Chiefly, the amount of service provided by a product is also influenced by its design and by use practices.

21 However, there is a trade-off between process efficiency and waste reduction in the extraction and processing industries that may be difficult to overcome. This is because current processes are designed to produce a large supply of homogenous product from what are highly variant raw materials at the lowest cost possible. At present, the internalised costs of discarding less homogeneous materi- 
als are low compared to the costs of processing these materials into a variety of usable industrial inputs. Further, it is less expensive for the downstream industries to design for and use homogeneous materials than it is small lots of materials of different grades.

22 Six sigma is a quality assurance methodology for eliminating defects during product manufacture. It takes its name from the goal of eliminating process variability within the six sigma range, i.e. manufacture produces no more than 3.4 defects per million opportunities for defects.

23 Although many composite materials are so costly that they are only used in very high-tech applications, such as military aircraft, the materials are produced in standard lengths and widths with the result that a great deal of material is wasted in cutting pieces.

24 See Chapter 8 for empirical evidence relating to this argument.

25 In this chapter I use the term resiliency as this is the common one in the ecological economics and systems theory literature (Hinterberger et al., 2000; Hukkinen, 2001). This term appears to be a general analogue for adaptability, which is more common in the management science literature. Another term of similar meaning used in the engineering sciences is robustness.

26 On this point, consider that specialisation is but another way to describe standardization and homogeneity.

27 This debate includes contributions by Brooks (1982), Freeman (1992) and a special issue of Ecological Economics (1997) commemorating Georgescu-Roegen's work that includes several commentaries on the Georgescu-Roegen/Solow/Stiglitz debate of the substitutability of funds and flows. For a recent analysis of the conflicts between technology and sustainability policy formulations, see MeyerKrahmer (1999).

28 Closed loop design refers to system models in which resources flow continuously in a loop with waste from one process serving as input to another process.

29 PSS is similar in intent to the Natural Capitalism principle of offering service (flow of value and performance) in lieu of product purchase.

30 For example, the design for each "Whirlpool World Washer" plant is modular and production capacity is added by country on an incremental basis.

31 It should be noted that use value is different from value added. Use value refers to the amount of services (or function) that can be obtained from a product, whereas value added is a measure of product input costs.

32 For example, the clothing industry has an estimated \$25billion loss annually due to clothing inventory markdowns and liquidation (NRC, 1995).

33 The Futures Project conducted by the Institute for Prospective Technological Studies notes that unlike other technology development, environmental technology is defined by its objective rather than the application of specific fields of scientific knowledge (Cahill and Scapolo, 1999). As another example of this gap, the PSS concept is virtually unknown in manufacturing circles. In several conversations with experienced manufacturing practitioners (i.e. consultants), I have not found anyone who seems to think PSS is feasible, or represents an opportunity, in consumer markets. 


\section{Chapter 7 The Role of Manufacturing Strategy: The Model's Validation}

The ability to adapt in a rapidly changing and complex environment has become an increasingly important aspect of firms' competitiveness. In consequence, manufacturers are thinking more intently about how to manage change and what tools are available to facilitate change. This chapter draws on their experiences in AMT use as related to strategy development and implementation to provide evidence for the Strategic Use Model.

The model advances a theory of technological change that explains the role of manufacturing strategy in the co-evolution of product markets and production technologies. It describes the influence of successive generations of production technologies on the development and implementation of manufacturing strategy and in turn on the structure of product markets. In effect, firms learn new ways to achieve their business goals through the integration of new technology into their production systems, thereby replicating the socio-economic trade-offs embedded in current technological trajectories.

The intent in this chapter is to validate and refine the model, leading to a more complete explanation of how firms adapt to technological change than that offered in the standard manufacturing models. The model is based on a conceptual ordering of the processes involved in firms' adaptation to technological change. Such an approach has been described in the economics literature as appreciative theorising (Nelson and Winter, 1982). Elsewhere, empirically oriented researchers, such as Leonard (1988) and von Hippel (1994), have used qualitative techniques to study contextual phenomena. Their studies on learning-by-using provide a platform for this chapter's analysis of firm's technology use behaviour, both in terms of methodology and the findings. The power of these approaches - appreciative theorising and grounded research - is to give meaning and substance to dynamic and non-linear processes.

\subsection{The Validation Framework}

Chapter 3 presents a co-evolutionary model of technological change that identifies technology use as a key change process. Further, this model is distinctive in relating technology use to path dependence such that the research on firms' behaviour presented in this thesis breaks new ground. Even so, traces of this work's conclusions can be found in earlier empirical studies in both the manufacturing strategy and evolutionary economics literatures. We refer to these findings here to present an empirical context for the model's validation. 


\section{Earlier Empirical Studies on Firms' Technology Use}

Technology use as a research subject has been very much "inside the black box", to use Rosenberg's $(1982,1994)$ now familiar phrase. Rosenberg plied the metaphor of the black box - a device that is described only in terms of its inputs and outputs - to challenge economists to analyse the influence of technological phenomena on the economy, that is, to look inside the black box. This chapter seeks to follow this tradition by examining what firms actually say about how they adapt to technological change.

We are also indebted to Rosenberg for the "discovery" of learning-by-using. He observed that the productivity increases which derive from using a product are distinct from those which attend making the product, what Arrow (1962) referred to as learning-bydoing. In singling out learning-by-using, Rosenberg shifted attention to the economic importance of the change process in which technologies adapt to their use environments.

In the evolutionary economics literature, research on production technology use has been largely framed in terms of learning-by-using. However, the focus of this research is on the incremental improvements in the technologies being used rather than the reorganisation of production which accompanies new technology use. This is not to say that systemic change goes unnoticed, but perhaps its significance is underplayed.

Rosenberg (1994), for example, in his key paper on learning-by-using, concludes, "Such learning by using - sometimes leading to modifications in product design, sometimes to alterations in maintenance practices or merely to alterations in operating procedures - appears to be characteristic of more and more high-technology industries." (p. 139, emphasis added) The "merely", in part, reflects Rosenberg's tendency, in this one paper, to confine the analysis to first-order technical effects of a technology's introduction into its use environment. Hence there is an involved discussion of maintenance practices and almost no mention of changes in managerial or organisational practices. While Rosenberg did the original research for this paper in the late 1970's, when the impact of AMT use on competitive strategies was not yet pronounced, the absence of an assessment of higher-order effects is still somewhat surprising in light of his extensive research on the early capital goods industry (Rosenberg, 1963). This research shows awareness of the influence of production technology developments on industry structure.

Much of the learning-by-using research on production technologies concerns technology validation, the phase of a technology's life when it is first tested in its use environment. Eric von Hippel and Marcie Tyre (1994) investigated unanticipated problems encountered in the early use of two novel process machines in electronics manufacturing. Their intent was to develop an appreciation of the micro-level processes involved in learningby-doing and -using, given their acknowledged economic significance. Their analysis attributes such advances to identifying "interference" problems between a technology and its use environment that in most cases can only be uncovered in the process of using the technology. ${ }^{1}$ This is because a technology's introduction frequently precipitates a change in operator routines in response.

In Hippel's and Tyre's study, the emphasis is on the technical rather than the organisational aspects of new technology introductions, but the study also brings to mind several interesting dialectics of relevance to this thesis. One is that, with regard to production technology use, the line between learning-by-doing and learning-by-using is fuzzy since the manufacture of products is coincident to production technology use. Even when the 
technology a company uses to make a product has a large effect on product features and thereby the product's saleability, companies also compete on capabilities having to do with the organisation of production, for example, the speed of delivery. These may be independent of the individual product's features but are more likely to be interdependent. Moreover, how a technology is deployed bears on the technology's performance. An incremental technical change could lead to a radical application of a technology.

All of this suggests that there is more to be learned from technology use than regards the technical fit of a technology with its use environment - and more to be economically gained than can be attributed to productivity increases that come from solving technical problems. In short, viewing the consequence of technology use only in terms of product improvements is a limited perspective. Instead, the economics of production technology use may be better understood in terms of interaction between the technology and the firm in which the rate of the firm's adaptation in the use of the new technology figures as much as the rate of technical innovation.

In this regard, Leonard (1988) has described the process of aligning the user organisation with the technology's performance as mutual adaptation, using as her point of departure the observation that: "Innovations not only adapt to existing organisational and industrial arrangements, but also transform the structure and practice of these environments." (citing Van de Ven, p. 252) In her study of twelve cases of new technology introductions, she examined several aspects of fit between the new technology and conditions in the user organisation, concluding that "implementation is innovation". (p. 265, her emphasis) Managers, she contends, cannot foresee all of the specific changes that need to occur in the user environment in order to exploit a new technology. However, her study stops short of exploring the economic implications of reorganising production. Instead, her analysis of organisational adaptations focuses on changes in job performance criteria. ${ }^{2}$

What is interesting about Leonard's study is that she does emphasise technology use in terms of how firms adapt to technological change, shedding light into a particular corner of the black box. She observes that the adaptation process is dynamic, reiterative (occurring in cycles), and interactive between the technology and its use environment.

Another study in the learning-by-using tradition worth mentioning uses statistical analysis of patent activity to show that supplier firms' innovating behaviour tends to lag user investment (Lee, 1994), suggesting to the author the effects of learning-by-using on the pace of technological change. ${ }^{3}$ The author next goes on to discount the inverse proposition, namely that machine tools innovation influences user investment because, as he argues, machine tools are for the most part customised. This argument neglects path dependence in the development of machine tools, no matter their customisation.

The body of research in the management sciences on the influence of AMTs on the firm's organisation of production is magnitudes greater than in evolutionary economics. One important source of evidence on why firms vary in their technology use are the survey studies on AMT adoption. ${ }^{4}$ The main objective of these surveys is to provide statistics gauging the manufacturing competitiveness of the country or region under study, but also there is an interest in determining the significant factors that influence technology adoption. Underlying these objectives is the implicit premise that AMT use leads to increasing competitiveness. However, empirical tests of the technology use/performance relationship based on survey data are not always conclusive (Beaumont and Schroeder, 1997; Rischel and Burns, 1997; Swamidass and Kotha, 1998). In fact, 
there can be a notable reduction in performance following AMT adoption as firms struggle to adapt their operational practices to the new technology (Millen and Sohal, 1998). Deducing a causal relationship between the prevalence of AMTs and competitive performance is problematical because of statistical limitations, such as the difficulty of finding appropriate variables that can trace the effects of AMT adoption over time.

In addition to the surveys, a number of empirical studies have examined some aspect or aspects of technology adoption in greater depth with the intent of operationalising a theoretical model. Many of the theories put forward have emphasised market failures, or more recently, system failures, in explaining the slow diffusion of AMTs (OECD, 1997b). Because the diffusion of new technologies proceeds through the exchange of information, information market failures figure predominantly in this research.

A second major class of models interprets adoption patterns in terms of management issues. These focus on the types of organisations that are most likely to adopt AMTs and the ability of manufacturers to respond to changes in their competitive environments through AMT use. Of the management factors influencing AMT adoption, the development of process-related capabilities appears to be the most significant. The most recent findings suggest that learning-by-using is crucial to developing such capabilities (Kelley and Helper, 1997). Previous experience with related technologies makes it easier to manage new technology implementation, thus lowering the costs and increasing the likelihood of adoption.

This result coupled to the lack of evidence for a significant adoption/performance relationship indicates that using AMTs to strategic advantage involves more than just adoption. A number of studies have found that, after adopting AMTs, firms failed to make use of their strategic advantages, only adapting their practices over time (Jaikumar, 1986; Millen and Sohal, 1998), where very few studies have found significant relationships indicating a linkage between AMT use and competitive priorities. ${ }^{5}$ One explanation for these findings is the frequent misalignment between corporate and manufacturing strategy (Millen and Sohal, 1998; Swink and Hegarty, 1998). There is also the difficulty of using quantitative approaches to study dynamic interactions and shifts in behaviour that are not well documented. Moreover, researchers do not always observe the necessary differences in approach to researching what decisions are taken (content models) versus how such decisions are reached (process models) (Leong et al., 1990).

As noted in Chapter 2, very few empirical studies have been carried out on manufacturing strategy implementation. The few that have seem to contradict the ends-drive-waysdrive-means logic. For example, a study by Maruchek at al. (1990) of the strategy process in six leading-edge firms found that strategy implementation is a behaviourally oriented process which provides the company its source of competitive advantage, but that the behaviours required for actualising the firms' competitive priorities differed from those that were being currently practised.

As a rule, however, manufacturing strategy research says little as such about the effects of technology use on firms' strategic behaviours. The two studies discussed next are exceptions to this rule. Each takes a unique methodological approach.

Spina and colleagues $(1996,1998)$ applied fuzzy logic to examine the effect of technological paradigms on firm's strategies. The problem in using traditional quantitative techniques, as they saw it, was that, "The concept of paradigm can hardly be measured directly in the reality, as it is complex and multidimensional in nature." (p.691) In re- 
sponse, they developed a "synthetic" measure of the firm's orientation to a paradigm by aggregating survey response data through fuzzy operators. What they determined was that the use of different AMTs and manufacturing practices influence the company's strategic orientation. ${ }^{6}$ Context factors (e.g. country, industry, company size) were found to influence a company's choice of competitive priorities and technologies but played a limited role in the development of capabilities. The study also concluded that superior business performance is the result of the development of an internally consistent program of mutually reinforcing elements.

Platts and colleagues at Cambridge University's Engineering Department (1998) developed a non-hierarchical (top-down/bottom-up) model of the manufacturing strategy formulation process that counters the "simplistic view" that "strategy formulation is a planned and rational activity" (p. 518). The model makes use of the difference between planned (coming from management) and realised (coming from the shop floor) strategies to drive the formulation process. To test the model, they applied it - with the intent of demonstrating that the model could be used to formulate strategy.

In their view, proving that companies bettered their performance as a result of the strategies they developed wasn't possible. Even if they were able to control for the effects of all confounding variables through statistical analysis, testing outcomes would only show correlation and not causation. They also decided against case studies since their object was to develop and refine the strategy process for practical application. The action research approach they adopted involved testing their model at multiple sites, the use of process facilitators not involved in the modelling, and outside observers. ${ }^{7}$ They concluded that the development of new manufacturing capabilities informs the company about new opportunities at the business level.

These two studies open a window on the idea that a firm's capabilities act to shape its strategy. Further, they suggest that the effective use of technologies evolves over time. Both of these ideas play a central role in the Strategic Use Model.

With respect to the system effects of technology use, perhaps the most illuminating of the model's forerunners is Abernathy and Clark's (1984) well-known paper on the competitive significance of different types of product innovations. This paper is something of a benchmark for evolutionary economists in the study of innovations. Interestingly, Abernathy and Clark's field of expertise was operations strategy. This suggests that the integration of strategy theory with evolutionary economics is fertile ground for research, as I also hope to show by the analysis that follows.

In the paper, Abernathy and Clark measure an innovation's significance along two axes: the degree to which it conserves or disrupts existing competencies and the degree to which it conserves or disrupts existing market linkages. From these measures, they define four classes of innovations: niche, incremental, revolutionary and architectural (what we now refer to as system innovations). Their conclusion was that different kinds of product innovations require different kinds of organisational and managerial skills. A similar conclusion can be drawn from the Strategic Use Model but the starting point is process rather than product innovations. As shall be shown later in the chapter, the innovation framework applied to process innovations proves useful to understanding the implications of the Strategic Use Model.

In turn, this survey of the empirical research suggests the utility of the Strategic Use Model in advancing our reading of technology use as a fundamental change process. 


\section{Hypotheses}

To test the Strategic Use Model, a set of hypotheses was framed describing the role of manufacturing strategy in firms' adaptation to change in production technologies and product markets. Figure 7.1, Manufacturing Strategy Linkages, lays out the hypotheses.

The set of hypotheses divides into two streams, A and B, corresponding to two questions posed at the start of the research. These two questions reflect the co-evolutionary nature of changes in production technology use and firms' market environments as evidenced in the role of manufacturing strategy plays in firms' adaptation to technological change. The two questions are:

A: In what ways do existing trajectories in the development of advanced manufacturing technologies influence manufacturing strategy formulation and implementation?

B: How do manufacturing strategy practices, as they pertain to the choice and use of production technologies, act to preserve the current direction of technological change or to activate new directions in technology development?

Several definitions help to establish the scope of this research. Manufacturing strategy is defined as the pattern of operating decisions which determine the capability of the manufacturing system. AMTs consist of computer-or microelectronicsbased production equipment and systems. A trade-off is defined as an exchange of a gain in advantage of one type, for a loss of advantage of another type. For example, a tradeoff occurs when automating processes to increase efficiency leads to reduced interoperability among the system components.

AMTs encompass a wide range of technologies as nearly all currently produced manufacturing equipment and systems incorporate some electronics element, (an assertion backed by the interviews). A list of generic AMTs was used for the purpose of the research, representing different generations of AMTS and different functionalities that have applicability in most industries. 8,9 Also, the research focussed on AMTs currently in use.

In the analysis of the interview findings related to the model's validation, it is useful to recall the distinction, initially raised in Chapter 2, between planned and implemented strategies. A planned manufacturing strategy is one developed through a planning process and is usually articulated in the firm's competitive priorities, that is, the product attributes by which the firm chooses to compete, for example, cost or order-to-delivery time. Implemented strategy, on the other hand, is the outcome of daily operational decisions. These decisions determine the firm's manufacturing objectives, e.g. increased flexibility or tighter process control. These objectives are realised in the firm's manufacturing (process) capabilities.

This distinction between planned and implemented strategies can be derived from the Strategic Use Model. As seen in Figure 7.1, different influences bear directly on the development of the firm's competitive priorities and its manufacturing capabilities. For example, in the discussion of why there is frequent misalignment of firms' manufacturing practices with their business objectives, we noted that conscious changes in competitive priorities - what firms say they will do - may not produce changes in implemented practice - what firms actually do. This critical distinction between intentions and actual behaviour is captured in the hypotheses statements by reference to strategy "as it is embodied in daily operational decisions", that is, real outcomes are used as the test of the influence of changes in product markets and production technologies on behaviour. 
Figure 7.1 MANUFACTURING STRATEGY LINKAGES

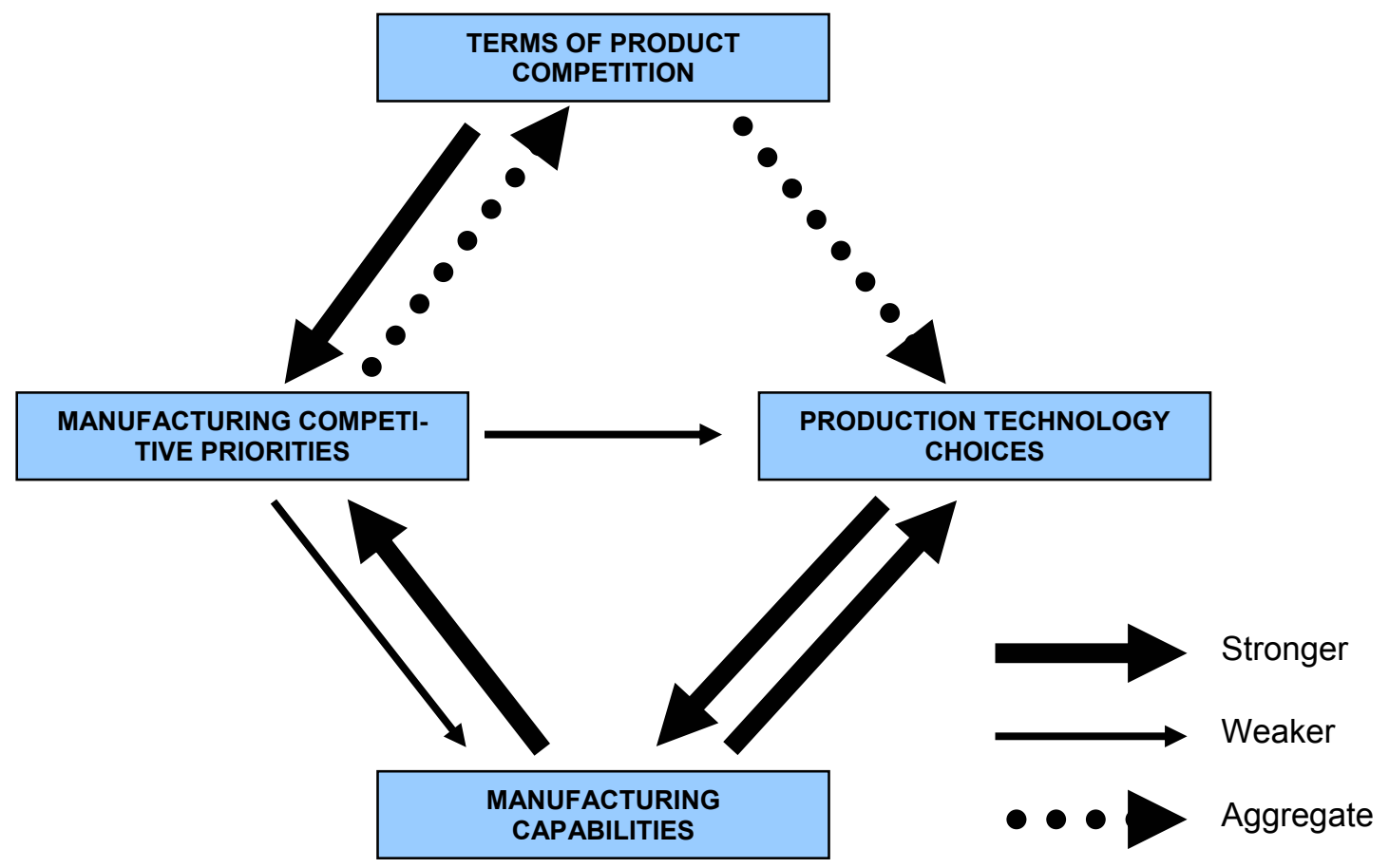

What is the role of manufacturing strategy in adapting to change?

Stream A: Trajectories $\rightarrow$ Strategy

In what ways do existing trajectories in the development of advanced manufacturing technologies influence manufacturing strategy formulation and implementation?

Hypothesis A1: A change in manufacturing strategy, as embodied in daily

operational decisions concerning the organisation of production, is more likely to occur as the result of a change in the firm's technology than as a direct result of a change in the firm's competitive priorities.

Corollary to Hypothesis A1: A change in manufacturing strategy, as embodied in daily operational decisions, is more likely to follow the adoption of new technologies than to precede adoption.

Hypothesis A2: Firms are more likely to select technologies in relation to the current terms of product competition than in relation to the need to develop new manufacturing capabilities for competitive advantage.
Stream B: Strategy $\rightarrow$ Trajectories

How do manufacturing strategy practices, as they pertain to the choice and use of production technologies, act to preserve the current direction of technological change or to activate new directions in technology development?

Hypothesis B1: Current manufacturing practices, as embedded in the firm's manufacturing capabilities, are more likely to influence the firm's technology choices and the use of new types of technology than is an intended change in competitive priorities.

Hypothesis B2: Firms are more likely to succeed in instituting a change in competitive priorities through manufacturing strategies focused on system capabilities than through strategies focused primarily on technology adoption.

Hypothesis B3: Firms with practices for identifying and assessing trade-offs have a wider range of technology choices than firms without such processes. 


\section{Methodology}

The research described below makes use of qualitative methods of analysis based on searching for patterns in the relationships under study (Neuman, 1997). The essence of these techniques, which is generally referred to as content analysis, is the development of a typology summarising a mass of narrative data, that is, the systematic identification of categories or themes in the data (Tashakkori and Teddlie, 1998; Mayring, 2000). These methods provide for a rich contextual understanding of the behaviour under study (Strauss, 1987), particularly, in the case of complex, non-linear systems, when the meaning of the part (individual firm behaviour) can only be understood in relation to the whole (the regime dynamics).

The data used in the model's validation was generated through a series of twenty-one interviews with technology users, suppliers, and service providers from European Union countries (Sonntag, 2000c). The interview protocol consists of open-ended questions concerning firms' use of AMTs and related practices in strategy development and implementation. The responses to these questions are then linked in the data analysis to the hypotheses deriving from the model. Appendix $\mathrm{C}$ includes the technology user variant of the interview protocol. The primary form of qualitative analysis used in the model's validation involves identifying the "themes" of the text's natural units (usually a quotation regarding a specific experience), and then linking these themes to the hypotheses to see if the evidence supports the theory (Steiner, 1996; Neuman, 1997). This method allows for testing of the model as well as its refinement. ${ }^{10}$ In addition, the interview data are also presented in quantified form to give an indication of the response range.

The interview protocol design serves several important research objectives. The intent is for the evidence to ground the theory, not for the theory to decide the evidence. To this end, the interviewees are not asked directly whether they agree or disagree with the hypotheses. Instead, the interview subjects are questioned with regard to their actual experiences. This design encourages the interview subjects to discover new relationships in those experiences and discourages them from interpreting those experiences on the basis of pre-formed ideas about how firms behave. ${ }^{11}$ Also, as the questions were not "prompts", (i.e., leading questions), regarding specific hypotheses, this methodology provides for unbiased responses. At the same time, the interview structure provided for consistency in the data and its interpretation.

An additional benefit of interview research is that it is possible to collect data from a wide range of subjects, strengthening the generalisability of the results. The aim in the selection of the interviewees was to build a representative cross-section by country, industry, type of market, and firm size or size of companies served. The interviews with technology service providers (e.g. trade associations, Innovation Relay Centres, strategic management consultants) and with technology system suppliers (e.g. machine tool builders) covered AMT use patterns by their customers, in effect multiplying the number of observed cases. Also, several of the interviews involved more than one interviewee. The transcription of the twenty-one interviews came to 145 pages. A breakout of the interviews is given in Appendix C.

The data from the interviews are presented in Appendices D and E, corresponding respectively to validation of the model and its application in the trajectory analysis (see Chapter 9). Appendix E contains lists of the specific AMTs, terms of competition, manufacturing capabilities, and trade-offs discussed during the interviews. 


\section{Some Considerations Regarding Data Interpretation}

The Strategic Use Model operates at several levels of analysis. It discusses the behaviour of individual firms in responding to technological change but it also surmises the direction of change and the effects of that change on markets and on industry AMT use patterns. Thus, it involves analysis at the meso (industry) level as well as at the micro level of firm behaviour.

In interviews it is possible to obtain data on individual firms with regard to their technology use behaviour. The hypotheses and the interview questions address these behaviours directly. However, conclusions regarding the production/consumption system as a whole can only be inferred because it is only at the system's level that system properties emerge. Firms can only relate their perception of these system conditions or properties, as these are not inherent in their own individual behaviour. This is the point Spina and colleagues $(1996,1998)$ address with their use of fuzzy logic to interpret survey data.

A second consideration with regard to data interpretation is to allow that system interactions are reciprocal, that is, a change in one element will cause a change in other elements that, in turn, cause changes in the first element. In practice, it is then difficult to show directions of causality. With this in mind, the hypotheses have been constructed to indicate that, given the system processes, one behaviour is more likely than another and not that given changes are deterministic of firm behaviour.

Finally, we note that in addition to the different levels of analysis, there are different modes of analysis. In the next chapter we apply the model in the analysis of AMT use, using statistical methods to explain industry patterns. In effect, the subject's form in the applied analysis is that of the content model, whereas the form in this chapter is that of the process model. As noted in reference to Platts et al's (1998) study above, the likely intent of a process model is practical application. In view of this intent, we draw some lessons from the model's exposition to conclude the analysis.

\subsection{Interview Findings}

The Strategic Use Model speaks to the need for a theory that informs the manufacturing strategy process. It offers a framework for analysing current trends in the development and use of production technologies in the context of the relationship of manufacturing strategy to changes in both product market needs and the use of AMTs. The aim of the interview research was to test the validity of this framework as mapped against the realworld observations of technology users, suppliers and service providers.

This section presents the empirical findings related to the model's validation. The model basis of each hypothesis is discussed in turn below along with supporting evidence from the interviews. We also consider the evidence for system level interactions as described by the model, specifically the influence of trajectories on technology choices and strategy and the influence of strategy on trajectory development. Appendix D gives a record of the interview data and its analysis. In addition to data relevant to the model's validation, the interviews provided observations relevant to several ancillary questions regarding firm behaviour, for example, the impact of supplier requirements on technology choices. These questions are presented in order of their bearing on the model's exposition. 


\section{Stream A Hypotheses: Trajectories $\rightarrow$ Strategies}

Hypothesis A1: A change in manufacturing strategy, as embodied in daily operational decisions concerning the organisation of production, is more likely to occur as the result of a change in the firm's technology than as a direct result of a change in the firm's competitive priorities.

Corollary to Hypothesis A1: A change in manufacturing strategy, as embodied in daily operational decisions concerning the organisation of production, is more likely to follow the adoption of new technologies than to proceed it.

\section{Model Exposition and Supporting Evidence:}

The Strategic Use Model holds that technologies condition the knowledge and practices of their users. Specifically, the model reasons that learning new ways to organise production takes place as an effect of technology use since the knowledge of how different technologies can be used for competitive advantage is embedded in the technologies themselves.

It then follows that as firms learn the effective use of new production technologies, their practices change to suit. ${ }^{12}$ As one interviewee confirmed, "When you have a new system, you are forced to use new ways." He backed this observation with an example: "A simple modification is to code every tool you are using because the computerised system handles this resource. Yet, the system cannot operate without the correct codes. So you are forced to code. If you don't anticipate this, you find all these problems about coding and giving information and naming things, and this changes completely the way you are using the system and even if you don't want to change, you are forced to change. [W] hen the same thing is called in different ways by different people inside the organisation, installing the AMT gives you the possibility that requires everyone agree on one name."

This example describes a "simple" change in practices that is but one part of a systems move towards integration in manufacturing, whereas the Strategic Use Model discusses trajectory level changes, of which integration is one (see Chapter 4). But the model also suggests that system change proceeds incrementally through learning-by-using. Since a firm's production technology forms an integral part of its production system, a change in technology leads to cumulative change in practices at all levels of the company, adding up to radical transformation. Such was the finding of Spina and colleagues $(1996,1998)$ that different AMTs and practices influence the company's strategic orientation. Kim and Arnold (1996) also found evidence to suggest that competitive priorities emerge as a cumulative effect of the firm's historic pattern of investment in specific shop floor improvements. The interviewees expressed a sense of this repeatedly. As remarked in one interview, "They don't just buy a machine - they have to change the whole philosophy of their company. They have to get into new markets, change what they did before they bought the machine, and orient themselves in a totally new way."

Such observations confirm that at least some firms learn new ways to achieve their business goals in consequence of technology use. But how strong of an influence is technology use on strategy, in particular, as found in the firm's organization of production? One indication of its strength is that a majority of the interview subjects explained changes in manufacturing objectives as an effect of technology use, as shown in the chart. 


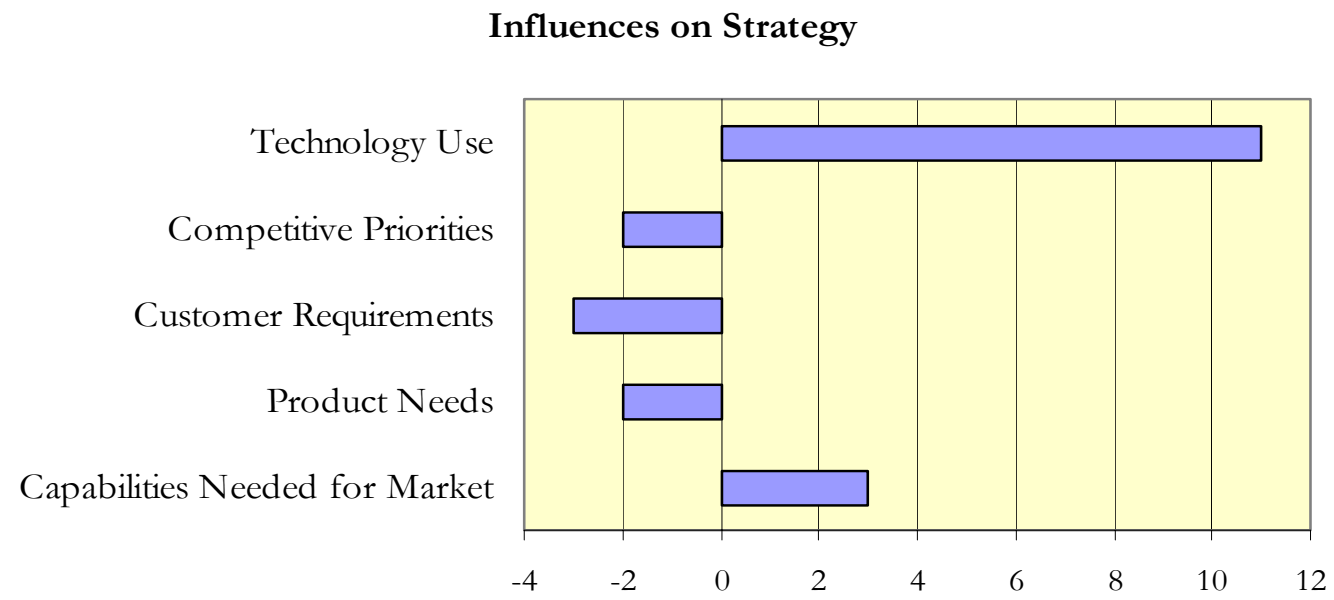

(The figure shows the number of interviewees citing a particular influence. A positive number indicates responses confirming the hypothesis, whereas a negative number indicates an alternative explanation of firms' behaviour. )

By comparison, only two subjects indicated that it was a change in competitive priorities that led to implemented changes in manufacturing objectives. ${ }^{13}$ Other influences that were cited included customer requirements, product requirements, and the need to develop new capabilities in response to changes in the market. These latter responses, although open to interpretation, are not inconsistent with the model, as discussed further below. Suffice it to say here that both changes in product and customer requirements are usually implemented through the application of new technologies. And, assuming that changes in the terms of competition are being driven by AMTs, the response that new capabilities are needed in the wake of market changes indicates a reciprocal influence between technology use and market conditions, as does the model.

That technology use is largely an experiential process explains why there are few instances of a change in competitive priorities leading to a change in how firms actually use their technology. Although such change is possible, intentions to respond to changes in the competitive environment through a change in planned strategy must generate a change in practices to take effect. But effective use of a technology in the context specificity of the firm is mostly learned through experience. As remarked by an interviewee, "[Companies] don't understand all of the possibilities of working with [new] equipment. They tend to think in very conventional ways and are not able to imagine how to use the equipment differently." This is Rosenberg's (1994) point that the interaction of a technology with a given use environment cannot be understand until after prolonged experience with the technology's use.

In this regard, failed implementations and the poor performance that follows new technology adoption are not just information problems or a problem of "fit" between manufacturing and business objectives. A better explanation is that performance lags adoption as firms learn the effective use of the new technology. For one thing, firms misjudge what it takes to get a technology up and running, not yet having gone through the experience. One interview subject commented that: "The real problem is that companies have lost most of the potential benefit of these technologies by the time they fully integrate them into their systems. They would have a greater competitive advantage by thinking ahead." 
Firms that do "think ahead" regard implementation as a critical part of the change process and plan accordingly. One interview subject remarked, "Changes in practices are perhaps after the introduction of the new technology, but we try to implement the technologies when they are so far developed that we know what changes will be necessary and how they will integrate with our systems." Yet changes to the company's way of doing things cannot always be anticipated, nor are they necessarily positive. The findings from a longitudinal case study of an enterprise resource planning (ERP) implementation indicated that that ERP systems impose a logic of their own and that change of this kind is often unforeseen: "What however seemed to come as a surprise for Beta was the powerful role the ERP system began to play in the organisation. Beta found it difficult to maintain the entrepreneurial spirit, the flexibility and creativity that had characterised the organisation previous to the implementation." (Kræmmergaard, 2001, p. 224)

The Strategic Use Model thus predicts that technology adoption frequently precedes a change in strategy as a lack of experiential knowledge hinders the informed development of strategy. Firms cannot fully predict the impact of new technology on their business objectives. As one interviewee remarked, "The order of change is first doing, then knowing - not knowing, then doing." This is particularly the case with smaller firms.

The chart below shows that a majority of the interviewees indicated that, in their experience, technology adoption usually comes before a strategy change than after it, a finding which supports the Hypothesis A1 corollary.

Timing of Technology Adoption in relation to Change in Strategy

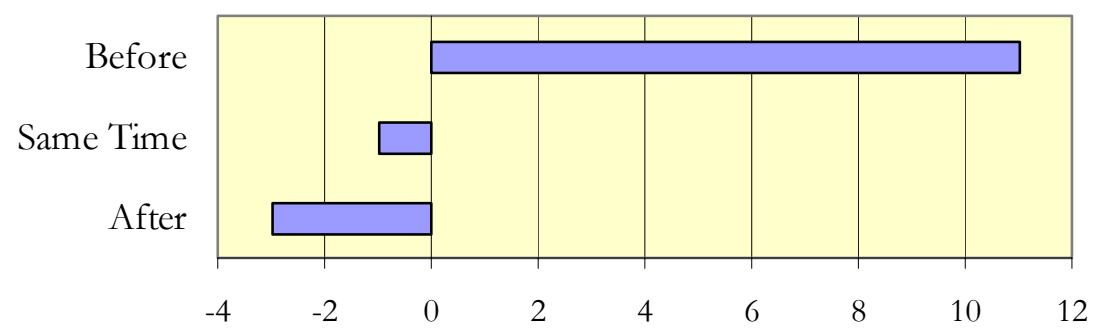

Regarding the impact of learning-by-using, the interview narratives paint a picture of broader significance than that previously considered in the literature. In this picture, new production systems emerge through an incremental process of firms' adaptation to the requirements of new technologies. This transformation reflects the cumulative effect of technology use on the knowledge and practices of the users and indicates the power of technology use to mould firms' practices and manufacturing capabilities, notwithstanding the agency of individual firms. As explained by one interviewee, "We, as users, might not understand the technology good enough to begin with, which means we can't utilise the advantages. Sometimes we tend to use the disadvantages also, since we keep on working in the same way with the new equipment. But you have to adapt your way of working, your way of organising, your routines, you have to adapt them to the new equipment, and that always takes some time." This observation signifies that adaptation is a learning process in which production technology trajectories, both old and new, shape firms' strategies. 
Summary of Evidence, Hypothesis A1 and Corollary: It is through the integration of new technology, and the consequent reorganisation of the production system, that firms learn new behaviour, resulting in actual changes in strategy. The interview findings clearly show that new strategies emerge as an effect of technology use and that changes in competitive priorities are difficult to carry out when firms lack experience of the associated technology uses. Changes in a firm's manufacturing capabilities are then more likely to be influenced by its technology choices than by its competitive priorities and to follow the adoption of the new technology than to precede it.

\section{Refinement to the Model regarding Customer Requirements}

Without question, one of the biggest change drivers in a supplier firm's manufacturing system development is a request - or requirement - by a customer for the firm to develop certain capabilities. We note, however, that this condition pertains predominantly, if not exclusively, to the relationship between industrial customers and their suppliers.

The Strategic Use Model, as a simplified representation of the production/consumption system, omits this relationship. Still, the model implies that supplier firms are subject to the influence of current directions in production technology development by way of their customers' requirements. In this light, responding to a customer requirement is not an effect of a change in the suppliers' competitive priorities. Rather, it represents an extension of the customer's technological capabilities to supplier firms as a result of the effective use of AMTs in the customer firm. A good example of this is the upstream development of JIT capabilities coupled to the recent interest in supply chain management. A number of the interview responses indicated the primacy of customer requirements in making technology choices, for example, "Many big companies are not completely free to select their own technology as they need to involve their customers in the decisions."

Hypothesis A2: Firms are more likely to select technologies in relation to the current terms of competition than in relation to the need to develop new manufacturing capabilities in anticipation of changes in the terms of product competition.

\section{Model Exposition and Supporting Evidence:}

According to the Strategic Use Model, a firm's competitive advantage depends on its ability to use its resources strategically. Firms stand to profit from investing in resources that enhance their ability to respond to new opportunities and challenges as they appear. But the model also maintains that in order to gain resources the firm must expend resources. The strategic use of production technologies thus involves the firm's choices on how to deploy its current resources in responding to changing industry and market conditions. The model then describes how path dependence affects these choices.

The model indicates that firms plan according to experience, favouring proven market solutions and investments that solve current problems. It is the past success of particular strategies for managing resources that in large part decides current strategy on which capabilities to develop and when. For example, an analysis of Japanese firms' manufacturing action programmes for instituting capabilities improvements showed that the programmes did not address identified future priorities (Katayama and Bennett, 1999). Instead, firms respond to changes in their markets after these changes have taken effect. As one interview subject commented, "Firms change their strategic priorities ... when they are not able to produce the quality the market requires." 
Moreover, orientation towards the present limits a firm's ability to respond in the future, as the experience of one manager shows, "So we have nice machines in our factory, but they are not fitting the need today. ... If they had projected [at the time the equipment was bought] the future with the growing product diversity and quantities, then some machines would not be as they are today." In effect, strategies based on current conditions often fall short of future needs. But it is current market conditions that most strongly influence decisions on which capabilities to develop, as shown in the accompanying chart. By contrast, few of the interview subjects named future needs as an influence.

\section{Influences on Capabilities Development}

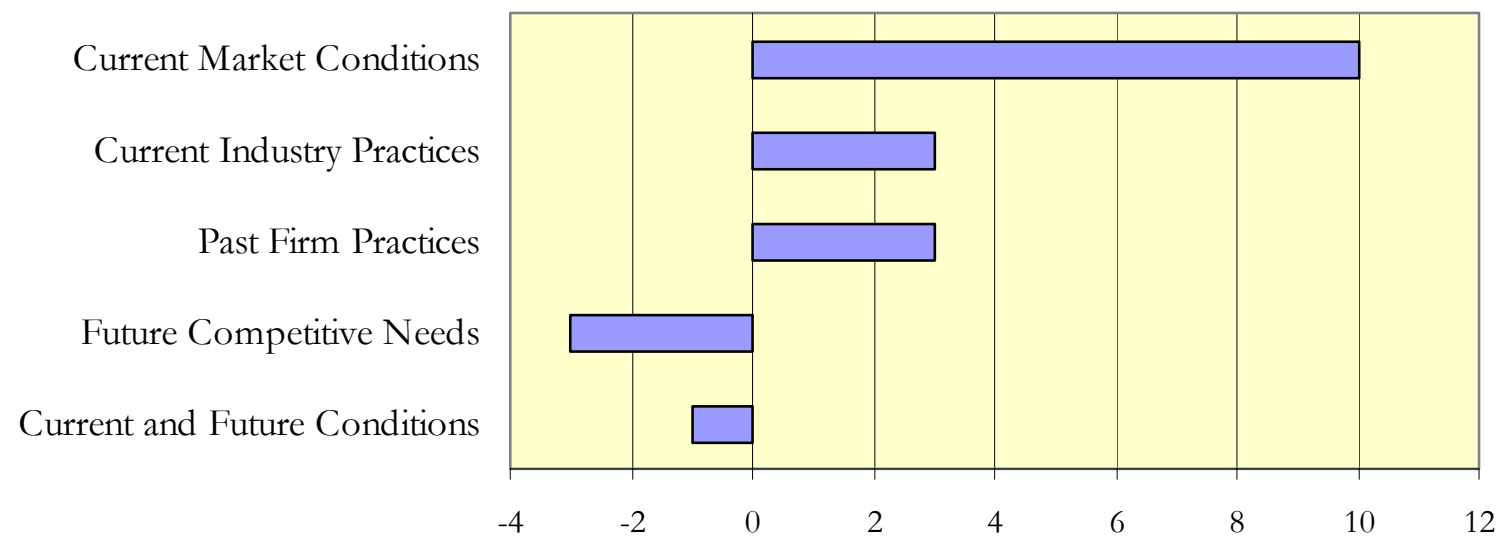

Why don't more firms plan the development of their capabilities for future needs? The model suggests that the uncertainty of future changes in the market affects firms' strategic behaviour. Knowledge of what specific capabilities will be needed is incomplete since firms have no direct experience of these needs (Leonard, 1988). In one consultant's estimation, this uncertainty presents a challenge to which many firms are not equal: "The markets are unpredictable and constantly changing. Firms do respond to market changes. However, they tend to concentrate on striking a new balance between the same [existing] elements, when there is a need to rethink what elements are needed. There is a lack of strategic vision. They seek compromises rather than innovations."

As remarked, firms do perceive and act on changes in their markets but the direction to take may not always be clear. Information on how new production technologies affect business performance is limited. Often there is a tenuous relationship between a firm's market scope, (the product market segments in which the firm competes), and its manufacturing capabilities. This lack of definition widens the gap between strategy based on a perception of market conditions and daily operational decisions.

Even when firms have an idea of future developments, they may still be reluctant to invest. Managers may choose not to spend limited capital resources on technology that they think will not give their companies a unique advantage. The results of a gap analysis study conducted with 56 Danish firms showed that although informed on the competitive benefits of new modelling and simulation technologies for meeting emerging market demands, the companies preferred to retain current practice (Conradsen and Lystlund, 2001). This gap between strategy based on current experience and strategy that would address future competitive requirements is likely related to the resource costs of developing new capabilities and the uncertainty of the outcomes of new technology use in the 
context specificity of the firm. But also, the model suggests that understanding the strategic implications of new technologies is a different order of understanding than grasping their technical advantages.

The question is then how firms can develop this higher-order understanding which leads to new opportunities. The model suggests that firms which invest in developing their manufacturing capabilities with an eye to strengthening their capacity to explore new opportunities will have the competitive advantage. Or so concluded one interview subject from a company that had succeeded in expanding its market share: "The only way, not just to survive, but to succeed is to explore new market opportunities. We anticipated what the market was asking and how the market was moving. Our competitors chose to keep with the same technology - not to react." In this light, dynamic capabilities are those which embody the firm's balanced use of resources for learning new ways to organise production for strategic effect.

Summary of Evidence, Hypothesis A2: Uncertainty around future market conditions constrains investment oriented towards the future, but also firms regard the future as an extension of current conditions. Interview questions regarding firms' abilities to effect a change in strategic orientation revealed a gap between strategy based on current experience and strategy based on future competitive requirements. This gap is related to the difficulty in understanding how new technical capabilities can be used for strategic advantage without such an experience in hand. As a result, firms are more likely to base planning on current conditions than to develop capabilities in anticipation of future market requirements.

\section{Refinement to the Model regarding Supplier Capabilities}

One question in the interviews concerned the role of system suppliers in providing their customers with the knowledge they need to evaluate the impact of new technology on their operations. We can surmise that suppliers' ability to provide this information depends on whether or not the technology is intended for a new application. In the case where technology is being used to develop future capabilities, the supplier may not have a pool of experience from which to draw. For example, a technology manager from one leading company remarked, "Equipment suppliers are not always able to provide the information that supports decision-making. The problem is that, in many cases, we [the users] are driving the changes and they don't always know what are market requirements are. ... In many cases there is a gap between their [the suppliers'] technical capabilities and their understanding of what we are trying to do in our markets." In effect, suppliers are not always able to bridge the experiential knowledge gap.

A related issue is the hype equipment users encounter in purchasing new technology. The problem is not solely a matter of technical optimism on the suppliers' part. One supplier explained, "[The challenge is] getting equipment suppliers to provide their future customers knowledge in this area of strategy before their customers buy the machines - to get their customers on a certain level of understanding of what they are really buying. That may be difficult because first the machine suppliers want to sell and they also don't want to give away the knowledge. We need to think about these processes. If you sell someone equipment and then they have problems, they will not be happy with it, and they will then influence other potential customers. This is a risk then in selling equipment without giving the buyers the knowledge on how to use it first." 


\section{The Influence of Trajectories on Technology Choices and Strategy}

The Strategic Use Model argues that while current changes in the terms of competition prompt firms to adopt new technologies, product market conditions affect technology choice through stimulating demand for those technologies which set the current terms of competition. As experience in the use of new technologies accumulates, distinctive patterns of market organisation emerge which prompt more firms to adopt these technologies. The evidence from the interviews on this is indirect.

The interviews provide ample support for the existence of trajectories or certain lines of development in production technologies and industry's awareness of these trajectories. Chapter 9 presents a summary of this evidence. In Abernathy and Clark's (1984) terminology, new trajectories constitute "architectural" changes, that is, they lead to the establishment of new capabilities in the firm and disrupt existing market linkages. One interview participant used the concept of system, or radical, change to describe the influence of computerised numerical control (CNC) machine tools, "Sometimes in introducing a radical change there is a strong impact on the users. For example, this was the case of CNC machines. CNC was developed in 1965 but the real development occurred in the eighties. CNC caused major changes for both the technology's users and developers. In the case of the suppliers, the change was the result of a transfer from manufacturing a pure mechanical to a mechatronics product. $\mathrm{CNC}$ resulted in change for the users as well, introducing the need for programming and the subsequent reorganisation of the firm."

However, the distinction between incremental and radical change may serve to obscure the influence of technology use on firms' behaviour. Instead, the model infers that there is a dialectical relationship between incremental and radical change. Incremental improvements are the effect of firms learning to use new technology for strategic purposes. It is the cumulative effect of these small changes in strategic behaviour that occasions major shifts in market relationships. In short, radical change proceeds through incremental adaptation, much as suggested by Leonard (1988), excepting that here we are concerned with the emergence of a new technological regime rather than the implementation of a single innovation. The length of time it takes to institute system changes is one indication of this dialectic between radical and incremental change.

The choice for individual firms then concerns how to manage their adaptation to market changes brought on by changes in technology use. As suggested by the interviews, firms tend to frame their choices in terms of available technologies and do not regard technologies from alternative trajectories to be part of their choice set, which is to say that technology choice is endogenous to the regime's development. Thus a question on whether firms are able to obtain the technologies they want usually prompts an affirmative answer, whereas a question on whether firms are able to achieve their market objectives with the available technologies may elicit a response on unmet technology needs. For example, one company president in commenting on a production planning system expressed his discontent with current choices: "The computers are telling you what the system should be, not the other way around. ... You need to have a system where you can make the changes."

This type of response argues that firms see their choices in the context of the existing paradigm and not system alternatives. The question of technology choice is moot when manufacturers see their choices as one of responding to customer demand or being 
forced to compete according to the current terms of market competition. Choice then is limited to those technologies shaping the current terms of competition. Further, technology use leads to improvements within the existing paradigm, that is, its continuance. The interview responses suggested that many firms advance the lines of development by imitating their competitors' strategies. As one supplier commented, "Many of these companies look and see what their neighbours have and buy what they have with maybe one feature more. They can say they have bought a machine with four axes, even if they don't use the fourth axis."

In sum, there is substantial, if indirect, evidence from the interviews to conclude that current industry use patterns strongly influence the individual firm's choice and use of technologies by setting the terms of market competition.

\section{Stream B Hypotheses: Strategy $\rightarrow$ Trajectories}

Hypothesis B1: Current manufacturing practices, as embedded in the firm's manufacturing capabilities, are more likely to influence the firm's technology choices and the use of new types of technology than is an intended change in competitive priorities.

\section{Model Exposition and Supporting Evidence:}

Strategy is embodied in the firm's structure and practices for turning its capabilities into selective advantage. The Strategic Use Model argues that a firm's choice of technologies is the product of its past experiences and the steps it takes to learn new practices. Moreover, strategy development is itself a practice that is embedded in the firm's organisation of production. The model thus implies that since routine behaviour guides decisionmaking, firms' technology choices tend to correspond to the current regime's governing trajectories.

The evidence from the interviews indicates that firms' practices are oriented towards solving current problems and improving existing capabilities. Many firms select new technologies primarily on the basis of technical criteria without assessing the equipment's strategic implications As one equipment supplier stated, "The decision to acquire a new manufacturing system is related usually to a specific production problem. There is a reason ... but the longer term vision is often not formalised." This is particularly the case for smaller firms. In the words of a service provider, "Companies evaluate their options starting from a technical point of view. 90\% of the SMEs we work with don't have any strategy - they don't think about strategy - they don't what strategy is. Mostly they are attempting to deal with daily problems."

Without an established approach to developing and implementing strategy, firms find it difficult to carry through an intended change in direction. As the experience of one company shows, a shift in competitive priorities can backfire without a program for changing manufacturing practices to suit, even when there is an apparent market success. "With growing diversity there is the danger of offering products that are too specialised, that you do not have enough standard products with turnover that give you the money. ... For example, we were asked by the wholesalers to develop a low cost product that looked like our high end product. It was developed with some cheaper features, but the technology to make it is exactly the same as for these high end products. So what did you see happening? Once the cheaper product was introduced, the sales of the high end product plummeted. The sales of this cheap product have gone up, but there's no profit margin on these products. That could have been predicted beforehand." 
Moreover, changes in competitive priorities and technologies present problems when firms rely on old practices in the absence of the necessary experience with new practices or the intentional learning thereof. A number of studies have found that after adopting AMTs firms failed to make use of their strategic advantages, only adapting their practices over time (Jaikumar, 1986; Millen and Sohal, 1998). Similarly, Spina and colleagues $(1996,1998)$ found that context factors influence competitive priorities and the choice of technologies but they are of limited significance in the development of capabilities. In point of fact, persistence with past practices likely explains the poor performance that often follows technology adoption. As remarked one consultant in the interviews, "The need is to reconsider the basic configuration of their processes, but they retract to their old process configuration, even when trying to institute their competitive strategies."

At the same time, the effective use of production technologies requires the development of complementary practices. A series of detailed implementation studies of manufacturing improvements at Hewlett Packard found that a stable environment and incremental changes in customer requirements favoured embedded routines, but when demands shifted, these practices became liabilities (Henderson et al., 1998). This finding is echoed in the observations of one interview subject concerning the challenges involved in changing competitive priorities, "If you really want to become good at manufacturing, then you follow procedures and you follow processes. Then you've got to train everyone in those processes. We really decided that we had to go back to square one [on changing priorities] and it isn't easy, if for no other reason than the wide range of decisions that have to be taken. ... I don't think people fully understand the vast range of things management needs to take decisions on."

In sum, practices based on the firm's current organization of production weigh heavily in its choice and use of technologies. As seen in the chart below, in the majority of the interviews, current practices, as opposed to intended changes in competitive priorities, were mentioned as a significant influence on technology choice and use.

\section{Influences on Technology Choices}

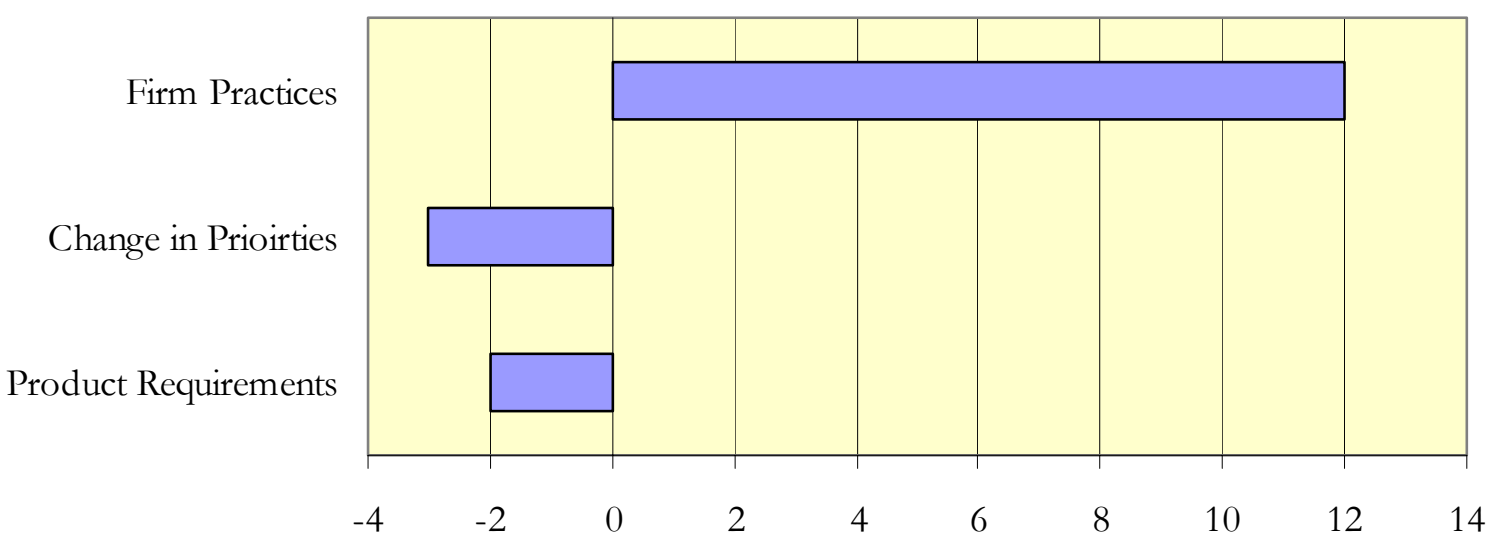

This influence contributes to the gap between planned and implemented (or realised) strategies that Platts et al. (1998) use as the driver in their manufacturing strategy process model. The finding is also consistent with the results from Gupta and Lonial's (1998) statistical investigation of the influence of competitive priorities on performance which 
showed that the firm's organisation of production as embodied in its practices had a larger effect on performance outcomes than did competitive priorities.

Likewise, an empirical study of the strategy process involving six leading-edge firms found that implementation of manufacturing strategy is a behaviourally oriented process which provides companies their source of competitive advantage, but that the behaviours required to realise firms' formulated strategies differed from those that were being currently practised (Maruchek et al., 1990). But what does this mean concerning the role of strategy in adapting to change?

The Strategic Use Model indicates that firms' response to new opportunities and challenges is linked to their ability to develop new capabilities. "Open" practices and a vision of the future can facilitate the firm's strategy development and implementation, and hence its adaptation. Such an approach to strategy recalls the definition of dynamic capabilities as those that "renew a firm's distinctive competencies by generating new routines and resources." (Montgomery, 1995 p.263) To this end, successful firms use their experience to support the implementation of new capabilities. In the words of one interviewee, "Experience is something that can help you to face new knowledge without a lot of problems. You need a good framework for absorbing the new information instead of just using information because it is new. The challenge is to be informed, but to build on experience and current capabilities." The ability to use resources strategically thus involves striking a balance between the pursuit of new opportunities and the practical use of existing resources for this end.

Summary of Evidence, Hypothesis B1: The interviews confirmed that current practices strongly influence firms' strategic choices regarding production technologies. Because practices are shaped by past experience, firms are more likely to try and duplicate past successes than to try new solutions. But firms can also use their experience to develop dynamic capabilities that open them to change.

\section{Refinement to the Model regarding Product Requirements}

As discussed in Chapter 2, product life cycle theory holds that the product's life cycle requirements drive the evolution of manufacturing capabilities. This understanding came up in a few of the interviews. For instance, one interviewee commented, "A change [in equipment] is always combined with the cycle of new products. Things would not change dramatically within one product cycle."

Undoubtedly, some companies take this approach to equipment selection. However, as a whole the interview responses indicated that the current relationship between product and process requirements is more complex than suggested by product life cycle theory and that, in general, equipment users are aware of this complexity. This is particularly the case in multi-product manufacturing. As one manufacturing manager described the situation in his factory, "We do not know the links. The problem is that for these three operations, we have machinery for them, but what this machine is doing is meant for another product line. ... Now the question comes up, what do you do? Are you putting more cells for everyone or are you investing in dedicated machine, perhaps not a 100\% occupied, [yet] specific for this product line? Question mark. ... The technical guys would like the very complex, nice machinery, but the production guys prefer the simple things and more than one. Then if I have a problem, I have some way out."

This observation suggests that another way to pose the question of product requirements is to ask what trade-offs, or choices, are involved in the development of specific prod- 
uct/process/resource systems. Earlier in this chapter, we remarked that the manufacture of products is coincident to production technology use such that the distinction between learning-by-doing and learning-by-using fades. Effective strategies then involve consideration of the company's current organisation of production and the direction of system development in addition to product requirements. since the organization of production will affect product market needs. ${ }^{14}$

Hypothesis B2: Firms are more likely to succeed in instituting a change in competitive priorities through manufacturing strategies focused on system capabilities than through strategies focused primarily on technology adoption.

\section{Model Exposition and Supporting Evidence:}

The Strategic Use Model states that firms learn new ways to organize production through the integration of new functionality into their systems. It further holds that performance is related to firms achieving effective use of new technology by reconfiguring their production systems to conform with the new functionality. This argues that strategies which facilitate the "mutual adaptation" of technologies and their user organisations (Leonard, 1988) will positively impact firm performance.

The model then differs from conventional thinking on technology adoption which regards the acquisition of new, more technically advanced technologies as the source of competitive advantage. Instead, the model contends that while technological functionality determines firms' capabilities, these capabilities are developed through technology use, that is, technologies, by themselves, do not embody capabilities. To take a simple example from the current regime: it is not equipment speed per se that provides a competitive advantage but how that speed is used. Speed can be used to improve either economies of scale or scope, as the experience of one company shows, "A lot of our competitors are looking at the equipment speed rather than the timing of production and then they have their product in stock for several months. We have come to conclusion that it is more economical to run the materials to produce what is immediately needed on the market, looking at the entire system."

Moreover, a given strategy's success depends on the firm's resource base and on conditions in the industry and markets in which the firm operates. In this case, the challenge is to develop a strategy that parlays technology use within the firm's particular environment into a performance advantage. One CEO defined the challenge this way: "Technology is important but almost all companies have access to these technologies and rather quickly. The competitive edge we can keep on a long term basis is not just by buying a new machine but by learning to use that equipment in a certain application."

The reflective consideration of particular experiences of technology use can provide the basis for a systems approach to strategy development and implementation. A systems focus helps to couple the firm's capabilities to opportunities present in the environment. As such, it involves more than the determination of which technologies to use. According to one consultant in the interviews, “[T] here isn't one solution: it's a combination of taking the benefits of working in teams and getting everyone cross-trained and making sure that people understand the aims of the module, then linking that with the new technology that enables things to be done in a fully process capable way. It's the combination that really gets it - it isn't just one thing." Thus, a systems focus drives consideration of the dynamic aspects of resource use. 
The power of a systems approach is supported by the number of interview subjects citing a systems approach as important or critical to changing strategic priorities, as seen in the chart below.

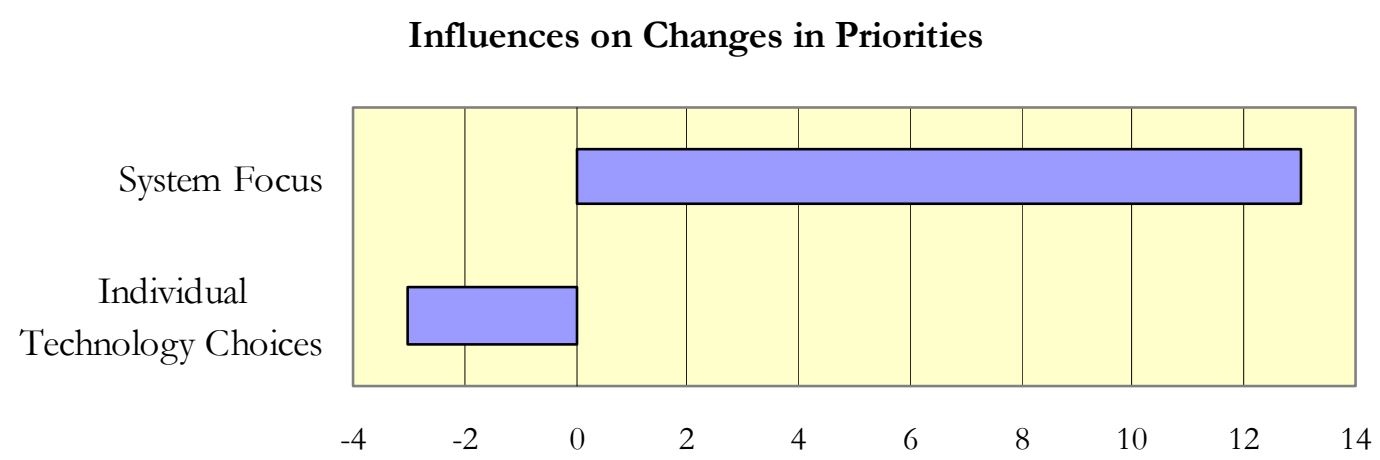

While it is the sum of technology, practices, and structure that determines how a firm organises production, the synthesis of these elements is greater than the sum of the individual resources. The capacity to perform this integration, that is, to create new system functionality, enables the firm to respond dynamically to changes in its environment and to engage new market opportunities. It is these dynamic aspects of resource use that provide a distinctive basis for competitive success. In the words of one manager, "In the market we operate in, we have distinctive, value-adding manufacturing capabilities. We use these to differentiate our product in the market from our competition."

Summary of Evidence, Hypothesis B2: The integration of new technology with organisational practices and structure plays a determining role in successful adaptations as a crucial step in aligning a firm's capabilities with its business objectives. To succeed, firms must develop a systems perspective of their capabilities. The strength of a systems approach to formulating and implementing strategy is clearly evidenced by the number of interviewees citing such an approach as a critical success factor.

Hypothesis B3: Firms with practices for identifying and assessing trade-offs have a wider range of technology choices than firms without such processes.

\section{Model Exposition and Supporting Evidence:}

From contingency theory research, we know that firms that align their operations and business goals have higher performance (Gupta and Lonial, 1998; Swamidass and Kotha, 1998; Tracey et al., 1999). Yet, business goals are customarily formed with reference to the existing regime. If so, is it then possible for firms to plan for change in industry and market conditions? The Strategic Use Model suggests that firms can successfully shape their futures through assessing the influence of technological change on their operations and by leveraging this knowledge to develop dynamic capabilities.

Knowledge of which dynamic capabilities offer a firm selective advantage is linked to the ability to identify trade-offs. A technology manager of a world-class company summed their approach as: "In looking at the technology's strategic impact, we try to understand what the technology might provide in terms of competitive advantage. Identifying tradeoffs is key to understanding the future. What is needed [in the future] will be different." This reflection argues that firms' ability to manage change grows with their understanding of how new technologies can be put to use to gain strategic advantage. But firms also need to understand how current technology choices might constrain future operations. 
By understanding the trade-offs involved in current technology choices, firms can guard against the establishment of practices that might limit their potential. The resultant balance permits greater choice in technology use. As explained by one CEO, "When we evaluate the technologies for purchase, starting at the planning phase, we are looking at what we need and to avoid problems in the latter stages. So it is a preventive approach, and we don't get the reaction." The experience of the UK Foresight Programme corroborates this approach. Highly successful companies knew how to examine the impact of change drivers on their long-term future (Foresight, 1995). Likewise, trade-offs point towards the regime's selectiveness.

Because practices influence the firms' strategic options, manufacturing strategy should inform daily operational decisions through a process for making good decisions. Leonard (1998) has further observed that the adaptation process between technologies and their users is interactive and iterative. Accordingly, companies need to structure learning the effective use of new technologies with the aim of balancing the trade-offs inherent to the technology's use. As described by one technology manager, this involves incremental adaptation to radical change: "Through this incremental substitution of new technologies, the people who are working with the machines follow the path that we designed for the correct use of the system. You can feel how you are changing the way they are working." In effect, learning-by-using creates technological momentum, while strategy guides the process.

Summary of Evidence, Hypothesis B3: The interview findings indicate that practices to identify trade-offs in technology use expand firms' strategic options by helping them manage their futures. On the other hand, firms that ignore the trade-offs embedded in new technologies compromise their ability to respond to future changes.

\section{Refinement to the Model regarding the Timing of Adoption}

The question of when to adopt a new technology is often posed in terms of the technology's costs and the risks involved at that stage of the technology's development. But the timing of adoption is also likely to affect a technology's strategic uses. An evaluation of trade-offs puts the timing decision in terms of the company's capabilities. For example, adoption may be forestalled until the company sees itself as ready. The benefits of this approach were remarked by one interviewee: "We try to implement the technologies when they are so far developed that we know what changes will be necessary and how they integrate with our systems." Whereas, premature adoptions and the experience of poor returns on investments can make a company technology adverse.

This suggests that the assessment of new technology must take into account the interaction of the company's specific development path with the trade-offs embodied in that technology. The assessment of cost and risk is then quite specific to the company and apart from the assessment of the technology's cost and risk as a whole. Not all new technologies are likely to be suitable for all companies - the company's strategic use of a technology makes a difference in performance. The technology's suitability for different users also then explains differential performance among users.

\section{The Influence of Strategy on the Direction of Technological Change}

The Strategic Use Model maintains that firms replicate the trade-offs embedded in current trajectories. Trajectories influence firms' choice and use of technologies - that is, their practices and the development of their capabilities - but also current practices and 
capabilities embody the prevailing trade-offs. Thus, industry practices and capabilities perpetuate the conditions that give rise to a given adaptive response.

The interview responses support the conclusion that strategy, as embodied in daily operational decisions concerning the organisation of production, determines the firm's response to its environment. These decisions concern not only the conversion of inputs to product, but also the development of the firms' capabilities, which are specific to the firm. One interview subject assessed the opportunity thusly: "The configuration aspect is very relevant [to the firm's vision]. There is the challenge of not only designing the system but configuring it for a specific demand." Thus, the current organisation of production, particularly as regards the firm's dynamic capabilities, embodies its future.

Firms that consciously guide the development of their capabilities, that engage both planning and implementation practices for effecting this, can thereby shape their futures and thus influence the regime's development and the overall direction of technological change. The practice of evaluating trade-offs associated with the use of current production technologies can provide guidance in the selection of which capabilities to develop. The evidence for this is indirect, but can be inferred from the ability of successful firms to support their goals through the strategic use of production technologies.

These findings call to mind Abernathy and Clark's (1984) conclusion that different kinds of organisational and managerial capabilities are needed according to the degree of change embodied in a given innovation. As regards process innovations, embodied trade-offs progressively change the fit between technologies and their user organizations and user organizations and their environment. The development of distinctive patterns of technology use is gradual because it is through technology implementation that these changes are realised. The role of strategy is to guide the inherently dynamical learningby-doing/using process in the development of specific product/process/resource sys-

tems. Strategy thus enables the firm to balance the old and the new, the specific and general, and the incremental and radical effects that mark the firm's adaptation to technological change.

\section{Evidence Supporting Other Interpretations}

In two of the interviews, the responses appeared to contradict the Strategic Use Model. For example, remarks included:

- "Formally planned manufacturing strategies are common. The product has to be oriented to the needs of the market, so a company's production strategy is one of its competitive aspects. Companies constantly review strategy to remain competitive."

- "Technology users understand the strategic implications of the technologies beforehand, because they are evaluating this during planning. Secondly, the machine tool producers have to describe the competitive advantages of their systems. Machine tool producers ... are able to help their clients understand the strategic implications of the new technology."

- "Customers have a deep knowledge of what they want."

These observations suggest a level of firm agency in effecting new strategies not evidenced in the other interviews. This discrepancy might in part be explained by a more limited view of the role of AMTs in setting the terms of product competition. The two interviewees appeared to have adopted particular frameworks for interpreting this role, in 
one case, product life cycle theory, and in the second, globalisation. For example, in one of these interviews, the firm's competitiveness is described as the result of product development: "Companies do not really look at the details [of strategic impact during technology evaluation]. What they have is a part they want to produce. Then they find the machine that can make that part. They put the part on the table and the machine tool manufacturer provides a bid on what it would cost for a machine to produce that part."

However, the responses given in these two interviews lacked internal consistency. On the one hand, there was the claim that suppliers gave their customers the information they needed to strategically apply the technologies, on the other, the view was that customers already knew what was needed and that technically specifying a machine is a sufficient determination of manufacturing capability.

It is worth noting that neither of these two interviewees were involved directly with manufacturing strategy implementation. As a description of what firms should do, their accounts are consistent with the prevailing manufacturing strategy models. There is no disagreement that to be competitive, firms require a knowledge of the impact of AMTs on their operations.

\subsection{Strategic Practices in AMT Use}

The Strategic Use Model brings to light the significance of the influence of technological trajectories on firms' strategic orientation and the role of manufacturing strategy in the co-evolution of product markets and advanced manufacturing technologies. Current theories on manufacturing strategy do not explain how strategy might help firms adapt to technological change and, more specifically, how firms make good operational decisions in the face of the uncertain outcomes associated with new technology use. Understanding the influence of a firm's past experience on making choices and what role current choices play in the future adds to the firm's ability to respond to change, that is, to its dynamic, adaptive capabilities.

\section{Strategic Change Practices}

The Strategic Use Model is a tool for firms and industries to critically examine the possibilities for orienting their technology use in a direction that supports their long term viability and movement towards a sustainable future. While it does not predict outcomes or prescribe specific measures, it does offer useful insights into what might be termed "strategic change practices" in production technology use.

The model's exposition and the supporting evidence drew out some fairly concrete aspects of firm behaviour, including: the dependence on old ways of doing things, the tendency to focus on technical solutions, the gap between planned and implemented strategies, and the effectiveness of experiential learning. Further, the model can be used to interpret many of the observations made by manufacturing strategy practitioners, among them: that strategy implementation is an incremental process driven by operational necessity; that frequently manufacturers do not make full use of the strategic advantages of AMTs; and that a change in competitive priorities is easier to talk about than accomplish. 
These accounts of the dynamics of technology use indicate the need for practical solutions from which companies can benefit while learning. Significant findings from the interviews pointing to strategic practices in resource development include:

- A firm's choices on how to deploy its resources in responding to changing industry and market conditions - in effect, its choices on how to organize production - lies at the heart of strategy.

- Firms stand to lose the potential benefits of new technology adoptions by failing to develop the strategy and capabilities to exploit these benefits in an opportune way.

- Companies have agency in how they put new strategy into practice but their substantive strategic choices are circumscribed by prevailing regime conditions and the direction of technological change.

- The strongest effects of technological path dependence are on practices not plans. Successful firms take into account the effect of new technology use on their practices and, by extension, their competitiveness. This goes beyond an evaluation of the company's technical strengths to an assessment of the trade-offs embedded in new technologies.

- Without an established approach to developing and implementing strategy, firms find it difficult to carry through an intended change in direction. In developing strategy, special attention needs to be focused on linking the company's business objectives to implemented strategy as embodied in the firm's manufacturing capabilities.

- A capacity to reorganise production, that is, to create new system functionality, enables the firm to respond dynamically to changes in its environment and to engage new market opportunities. It is these dynamic aspects of resource use that provide a distinctive basis for competitive success.

- Knowledge of which dynamic capabilities offer a firm competitive advantage is linked to their ability to identify trade-offs. An evaluation of trade-offs puts the decision of when to adopt a new technology in terms of the company's capabilities.

- The ability to use resources strategically involves striking a balance between the pursuit of new opportunities and the practical use of resources for this end.

- In many firms, planning does not include allowance for change. Firms select technologies in relation to the need to develop new capabilities but often without full consideration of what is involved in the development of those capabilities. Moreover, the extent of the necessary changes is only likely to become apparent in the process of using the new technology.

- Firms learn how to manage change through experience. The adaptation process is dynamic and interactive between the technology and its use environment. Poor adaptability appears to be less of an information problem than one of limited opportunities for learning new practices.

- New technology is not necessarily the best strategic choice for the individual firm, but adaptation requires the ability to respond to changes in the terms of competition brought on by new technology.

- An incremental, gradual approach to radical change and developing new capabilities supports learning and facilitates change. 
One of the most important conclusions that can be drawn from these findings is that firms' strategy formulation and implementation practices are critical to realising the benefits of new production technologies. For example, firms that focus on system development, that is, developing their capabilities, are far in advance in their ability to use AMTs for strategic advantage than those that adopt new technologies without thought to how they will need to adapt their practices. In short, manufacturing strategy matters, as do the specific practices used to develop and implement strategy.

Strategy involves firms learning new ways of organising production as an effect of using manufacturing technologies to new purposes. So too with strategic change practices adaptive capabilities develop out of firms learning how to configure the dynamic relationships involved in the firm's resource use. As technology use is embedded in local, sociohistorical contexts, this is an experiential process first and foremost. The uncertainty of technological outcomes, particularly with regard to the social and ecological effects of new technology use, suggests the need for wide-spread experimentation in a variety of contexts.

The model and research findings also imply that the interdependency of market needs and the strategic use of AMTs will influence the success of any policy to reduce consumption and promote sustainability. The limited agency of individual firms in affecting new directions of change suggests that there is a governmental role in catalysing cooperative initiatives to explore new directions in the use of production technologies. These issues are taken up in Chapter 10.

\section{A New Understanding of Manufacturing Strategy}

The Strategic Use Model holds that manufacturing strategy forms a critical link not only in firms' ability to adapt to change in their environments, but also in their ability to knowingly shape their futures. New ways of organising production, configured around new process technology capabilities, set off changes in product markets which alter the terms of competition and affect the direction of current trajectories.

The power of the analysis presented in this chapter is to link actual observations on firm's behaviour to a co-evolutionary model of technological change. While other researchers have taken similar approaches to studying technology use at the firm level, the research presented here explains the dynamics of resource use at the industry level.

This influence of technological trajectories on firms' behaviour and the corresponding influence of the strategic uses of manufacturing technologies on product markets provides an alternative explanation of how firms adapt to technological change from that of the standard manufacturing strategy models. In Chapter 2, we remarked on three puzzles uncovered in the current models that stand out in need of solution. The analysis undertaken in this chapter offers useful insights into these puzzles.

Puzzle 1: What is the link between a company's scope of operations and its manufacturing capabilities?

Manufacturing strategy models commonly cast strategy as a response to customer needs. The firm's scope is represented as a function of those needs, independent of the firm's capabilities. The Strategic Use Model, by contrast, clarifies the reciprocal nature of market needs and production technology use. It suggests that a systems' approach to planning helps to couple the firm's capabilities with opportunities pre- 
sent in the environment, which is the goal of strategy. Such an approach includes bottom-up as well as top-down perspectives. It views the integration of new technology with organisational practices and structure as a crucial step in aligning a firm's manufacturing capabilities with its business objectives.

Puzzle 2: What explains the misalignment between a preponderant number of firms' manufacturing practices and their business objectives?

The Strategic Use Model suggests that during the transition to new production systems, there will be two opposing forces on firm practices: there is the hangover of old practices associated with the former production technologies, but also the use of newly adopted technologies exerts a force as firms amend their practices in efforts to achieve their effective use. Such opposition between new and old practices could explain the lag in the emergence of new manufacturing and business strategies consistent with new AMT functionality. Thus, new production systems emerge through an incremental process of adaptation to the requirements of new technologies, in which old practices are often abandoned only once their excessive costs can no longer be ignored. This behaviour shows the cumulative effect of technology use, both old and new, on the knowledge and practices of their users. Misalignment between planned and implemented strategies is not primarily due so much to a lack of information as it is to a lack of experience. And a successful transition may not depend so much on learning new practices as unlearning old ones, which are deeply embedded in organisational structure and culture.

Puzzle 3: Is it possible for firms to plan their adaptation to technological change?

Contingency theorists have pointed to the need to consider how technological change might affect future competitive priorities. The question left open is how. The Strategic Use Model contends that the gap between strategies based on current experience and those based on future competitive requirements is related to the difficulty in understanding how new technological capabilities can be used for strategic advantage without such an experience in hand. Product market conditions also affect technology choices via the aggregation of market demand for proven technologies, those which set the current terms of competition. The technology choices of individual companies thus reflect the trade-offs represented in current trajectories. However, to generate new opportunities firms must invest in future-oriented capabilities. The model offers a framework for analysing current trends in the development and use of production technologies. Knowledge of which dynamic capabilities offer a firm selective advantage is linked to the firm's ability to identify trade-offs. Firms can successfully shape their futures through assessing the influence of technological change on the development of their manufacturing strategy and through leveraging this knowledge to develop dynamic capabilities.

These three puzzles draw out an essential aspect of technology use - its path dependence. While firms can make choices on when, and if, to adopt specific production technologies, they do not individually, determine the direction of technological advance. At some point, firms must replace their old technologies with new technologies of different capabilities and must reorganise production accordingly. Through technology use, firms learn, by necessity, the effective use of these new technologies. Therefore, firms must learn the uses embedded in currently available technologies. This aspect of technological change is neglected in most manufacturing strategy models. 
The significance of this conclusion is that operational choices cannot always be made to fit the firms' objectives, especially if those objectives are set without a sense of how the market will change as a result of new technology use. Instead, technologies exert a force on firm development that firms should take into account in setting their business goals. This suggests that, to succeed, not only must manufacturing strategy support the firm's business objectives, but also the firm's goals must align with the current strategic uses of production technologies.

With regard to AMTs, the interaction between the terms of market competition and the use of production technologies, as shown in the next chapter, contributes to the complexity and rapid change that characterise today's markets. Good manufacturing strategy practice must then involve the firm's understanding, to the best of its ability, the tradeoffs current technologies impose on its development. Such an understanding can be used to create technological momentum in new directions and guide the change process. 


\section{Chapter 7 End Notes}

1 This finding echoes the analysis in Chapter 5 concerning the effects of variability at process interfaces.

2 She suggests that successful implementation hinges on the technology's acceptance vis-à-vis what rewards its use provides different levels of the firm's hierarchy.

3 An alternate explanation, discussed in Chapter 3, is that it is the amount of resources available to foster development in the domain of application that is influencing the rate of innovation (Levinthal, 1998).

4 Among them, Whybark and Vastag (1993); Fortier, Y., L.M. Ducharme and F.Gault (1993); Northcott and Vickery, (1993); U.S. Bureau of the Census, Economics and Statistics Administration, U.S. Department of Commerce (1994); Baldwin and Diverty (1995); Baldwin and Sabourin. (1995); Baldwin, John R., David Sabourin, and Mohammed Rafiquzzaman (1996); Shapira and Rephann (1996); Gate, (1997); Youtie and Shapira (1997); Baldwin, John R. and Zhengxi Lin. (1999); and Sabourin and Beckstead (1999).

5 Two exceptions are Helms et al., 1997 and McDermott et al., 1997. Both of these studies examine the impact of AMT use on the low cost-differentiation trade-off.

6 The analysis was based on survey data from 443 companies in 20 countries. The overall survey response rate was 33.5 percent.

7 Action research is the term used to describe research in which the researcher directly participates, seeking to direct and influence the way in which the activity is conducted.

8 The list of technologies can be found in Appendix E. A subset of these technologies is used in the industry analysis in Chapter 8.

9 This includes consideration of the processes related to the planning, control, and execution of manufacturing operations, including design processes and the use of design technologies, such as 3D solid modelling or simulation technologies. However, it excludes consideration of business operations in general, (e.g. capital budgeting), and the activities of other functional departments, such as marketing. Except in their capacity to enable manufacturing processes, the research also does not cover communication infrastructure technologies (e.g. Intranet, distributed control networks).

10 To be precise, this a test of the model's plausibility (Tashakkori and Teddlie, 1998). It is not a test in the positivist sense used in quantitative analyses.

11 Examples are popular theories expounded in management journals. In two of the interviews, this was an evident drawback, as explained later in the chapter.

12 "New" in this context refers to a technology that is new to the user firm, though the specific machine a company purchases may only represent an incremental improvement in the technology.

13 As noted above in the discussion on methodology, these tabulations do not represent responses to direct questions.

14 Refer to the TEAM (1997) model in Chapter 2. 


\section{Chapter 8 The Strategic Uses of AMTs: Industry Survey Results}

A basic issue in the rise of AMTs is their impact on product markets. The Strategic Use Model holds that technology use creates technological momentum through a process of firms replicating the socio-economic trade-offs embedded in trajectories. New ways of organising production, configured around new process technology capabilities, set off changes in the terms of product competition. Given the success of a new technology, more and more firms will follow in the new direction of strategic advantage, strengthening its effects. The structure of a market - its size, the amount of product variety, and the rate of product changeover - is then, partially, a function of firms' manufacturing strategies. Thus, AMT use is not only in response to exogenous change in market conditions - AMTs themselves cause changes in the ways firms compete. These changes have consequences not only for industrial competitiveness but also sustainability.

This chapter presents findings from an industry survey conducted in the autumn of 2000 (Sonntag, 2000b). The survey's purpose was to study the linkages between changing patterns of consumption and the strategic uses of AMTs in three consumer product markets. The market shift towards faster product introductions and increased product variety reflects the evolution of time-based strategies. The issue for sustainability is whether current changes in the terms of competition parallel unsustainable consumption patterns characterised by faster product replacement, faster throughput, and more individuated consumption. As indicated by the survey results, the effective use of AMTs appears to strengthen system dependence on quantitative growth. Firms achieve faster product introductions and greater product variety at the cost of increasing system complexity and higher break-even sales volumes.

\subsection{Survey Content and Methodology}

The research objective was to gather and assess empirical evidence on the ways the current generations of production technologies structure the formation and growth of product markets. The research involves the application of the Strategic Use Model to an examination of AMT trajectories, in particular those promulgating faster product cycles and increased product differentiation. The method of investigation is to perform a statistical analysis of survey data. The survey questionnaire covered changes in firms' manufacturing strategy and product market structures in relation to the use of AMTs. Information was obtained on the use of 14 AMTs; competitive market conditions; 
manufacturing strategy outcomes; current manufacturing capabilities; plans for the development of manufacturing capabilities; and the sources of revenue growth.

Three consumer product industries were selected for study: bicycles, mobile (cellular) phones, and hand power tools. The aim was to compare industries with different market and industry conditions and technology use practices. The criteria guiding the selection of industries for investigation include the growth rate in the industry's markets (low/high) and the AMT use rates (low/high). According to these criteria, the three industries can be characterised as follows:

- Bicycles: Stable growth rate and low to moderate AMT use rates.

- Mobile phones: High growth rate and high AMT use rates.

- Hand power tools: Stable growth rate and moderate to high AMT use rates.

\section{Survey Hypotheses}

The dominant terms of product competition in today's markets include cost, quality, time-to-market, and customisation. These attributes of competitive products have correlates in a firm's competitive priorities and AMT capabilities. Table 8.1 presents a schematic of these relationships. The eight capabilities listed in the table are used in the survey to define the respondent firms' strategic uses of AMTs.

Table 8.1 Production/Consumption System Variables

\begin{tabular}{|c|c|c|c|}
\hline Manufacturing Capability & $\begin{array}{l}\text { Strategic } \\
\text { Focus }\end{array}$ & $\begin{array}{l}\text { Term of Product } \\
\text { Competition }\end{array}$ & $\begin{array}{l}\text { Market Structure } \\
\text { Characteristic }\end{array}$ \\
\hline $\begin{array}{l}\text { Ability to make large volumes of low- } \\
\text { cost products }\end{array}$ & Scale & Cost & Market size \\
\hline $\begin{array}{l}\text { Ability to make products of consistently } \\
\text { high quality }\end{array}$ & Scale & Quality & Product variability \\
\hline Ability to change product mix rapidly & Time & $\begin{array}{l}\text { Product } \\
\text { differentiation }\end{array}$ & Product variety \\
\hline $\begin{array}{l}\text { Ability to introduce new products } \\
\text { rapidly }\end{array}$ & Time & Time-to-market & Product cycle time \\
\hline Ability to make rapid deliveries & Time & $\begin{array}{l}\text { Order-to-delivery } \\
\text { time }\end{array}$ & Product availability \\
\hline Ability to customise product & Time & Customisation & $\begin{array}{l}\text { Concentration of de- } \\
\text { mand }\end{array}$ \\
\hline $\begin{array}{l}\text { Ability to add value through services to } \\
\text { product users }\end{array}$ & Value & Service & Service content \\
\hline $\begin{array}{l}\text { Ability to add value through unique } \\
\text { manufacturing processes }\end{array}$ & Value & Use benefit & -- \\
\hline
\end{tabular}

The first two capabilities, the ability to make large volumes of low-cost products and to make products of consistently high quality, are characteristic of mass, or scale-based, production. The next four - the ability to change product mix rapidly, to introduce new products quickly, to make rapid deliveries, and to customise product - are core capabilities in time-based manufacturing strategies. Two value-based capabilities are also included in the survey: the ability to add value through services to product users and the ability to add value through unique manufacturing processes. The relation of these emer- 
gent capabilities to the terms of competition and market structure is less defined than in the case of scale- and time-based capabilities, particularly as regards the ability to add value through unique manufacturing processes. This capability represents a paradigm shift in thinking about how value is constructed and how it is delivered (Kidd, 1997).

To test for these relationships a set of hypotheses was derived from the Strategic Use Model. The hypotheses describe several expected developments in firms' manufacturing strategies and their product market structures relative to AMT use. ${ }^{1}$ In keeping with the model's co-evolutionary framework, these relationships, previously described as manufacturing strategy linkages, are understood to be bi-causal: AMT use both results in changes to market structures and evolves in response to those changes. But, as argued in Chapter 7 , the effect of path dependence in technology use is to introduce a bias in strategy development and implementation towards current practice as embedded in the firm's production technologies. Consequently, we expect changes in the strategic orientation of firms to lag technology adoption. Likewise, the hypotheses are constructed to reflect the influence of learning-by-using on firms' strategic behaviour.

In the framework of the Strategic Use Model, the survey hypotheses are:

Firms learn new ways to achieve their business goals as an effect of the integration of new technology into their production systems. We then expect that the strategic uses of production technology will reflect the number of AMTs in use and the length of time they have been used such that:

Hypothesis 1: The more AMTs the firm uses and the longer they are in use, the greater the importance of time-based manufacturing capabilities is to the firm's achieving its business objectives.

Hypothesis 2: The more AMTs the firm uses and the longer they are in use, the more extensive will be the plans to develop time-based manufacturing capabilities.

Current patterns in the strategic use of production technologies set the terms of product competition. We then expect that the firms' experience and performance will reflect the strategic uses of production technology such that:

Hypothesis 3: The more time-based manufacturing capabilities a firm develops, the more extensive will be the following experiences:

- Increasing number of product variants

- Increasing break-even sales volume

- Shorter order to delivery times

- Shorter product development times

- Increasing machine utilisation

- Increasing concentration of sales in niche markets

The growing use of AMTs strengthens the firm's dependence on quantitative growth in product demand. We then expect that the firm's competitive success will reflect changes in market composition such that:

Hypothesis 4: The more extensive a firm's use of AMTs for emphasising faster product cycles and increased product differentiation, the more important faster product replacement and increased individuated consumption are to its market strategy.

An additional hypothesis on the relation between time-based capabilities and the experience of AMT-related trade-offs is discussed in Chapter 9. 


\section{Survey and Statistical Analysis Methodology}

Three consumer products industries were selected for study: bicycles, mobile (cellular) telephones, and hand power tools. The survey questionnaire was sent to firms in the three industries with more than 10 employees manufacturing product inside the European Union (EU). In the case of both mobile telephone and hand power tool firms, this included all the companies identified in two major European product directories or that were found in a systematic web search. ${ }^{2}$ In effect, the entire population of these two industries received questionnaires. In the case of bicycle companies, questionnaires were sent to all those for which appropriate contact information was available. This was an estimated $80 \%$ of bicycle firms manufacturing final product that have more than 10 employees.

The questionnaire was designed as a two page fax back survey to be completed within ten to fifteen minutes. A second survey response option was to complete the survey over the internet. The questionnaire was sent in one of four languages: English, German, Italian or French. Appropriate measures were taken to increase the survey response rate, including follow-up telephone calls to non-respondents. The response rate varied by industry, from a low of $24 \%$ for bicycle firms to $55 \%$ and $81 \%$, respectively, for hand power tool and mobile phone manufacturers.

Both descriptive analyses and multivariate regression techniques were used to analyse the survey data. A standard statistical package, Stata, was used in performing the analyses.

The descriptive analyses calculate means or frequencies of a variable for defined subcategories, such as firms with specific manufacturing capabilities. Statistical differences for the different industries are calculated after normalising the weighted results to the original sample and population sizes. All results are establishment weighted to provide an estimate of AMT use among EU firms in the studied industries with more than 10 employees.

The regression models are limited to a small number of independent variables since the sample and population sizes are particularly small. Stata has a provision for introducing a correction for finite population sizes to be included in the statistical algorithms. This adjustment is made to account for the reduction in variance that occurs when sampling without replacement, as compared to sampling with replacement.

The low response rate for bicycle firms affected the possibility of obtaining statistically significant results in this population and lowered the possibility for all firms. Nevertheless, all of the tests discussed below produced significant results $(\mathrm{p}<0.10)$, which is taken as an indication of the validity of the study. It should be noted, however, that a small population size combined with a low response rate, such as was the case for bicycle firms, undermines the assumption of statistical randomness.

A review of previous surveys of AMT use informed the development of the questionnaire. ${ }^{3}$ In all of these surveys, the indicators for AMT use are based on a count of the number of different types of AMTs the firm uses. Strictly interpreted, these indicators denote incidence of use - the number of technologies that are "in use" or owned by the survey respondents. The incidence of use does not tell us about the extent or intensity of use, that is, how frequently each AMT is used or whether a plant has only one or multiple units of the same AMT. However, the difficulty of obtaining, for example, reliable financial data on AMT investment, has precluded the development of other measures. 
Questions asking for more detailed information on AMT use also tend to lower the response rate because of the time involved in answering such questions.

For these reasons, a count of the different types of AMTs in use is also used as a variable in the regressions below, although two improvements to survey design were introduced to refine the analyses. First, the 14 AMTs were chosen to represent a balanced crosssection of the different generations of AMTs. These were divided into two groups of older and newer AMTs. This design provides a better indication of how advanced AMT use is. Previous studies assumed all AMTs are equally advanced. Second, care was taken to select only one of two or more technologies that either duplicate each other in function or that are hierarchically dependent. ${ }^{4}$ Duplicate counts are a common problem in earlier surveys.

A related problem to quantifying AMT use in previous surveys has been the interpretation of causation in multivariate regressions in the absence of data on when AMTs were put into use. In this survey, data was collected on the length of use for the two groups of AMTs. Other questions specified a time period, (e.g. "in the last three years"). These measures only approximate the temporal relationships among the variables of interest. However, as noted above, the Strategic Use Model also describes manufacturing strategy linkages as bi-causal, (refer to Figures 3. 1 and 7.1).

\section{Some Considerations Regarding Survey Limitations}

Chapter 7 presented a review of earlier empirical studies of production technology use. It is notable that of these, a qualitative approach is used in the studies focusing on the dynamics of technology use (the subject of this thesis). The one exception is the International Manufacturing Strategy Survey (IMSS) conducted by Spina and colleagues (1996, 1998) which analysed the responses of 443 manufacturing companies with employment of more than 100 employees (25\% response rate). The sampling and data collection for that survey, conducted in over 20 countries, were managed locally by a large team of researchers. Other surveys have been considerably smaller. For example, a mail survey by Swamidass and Kotha (1998) of U.S. manufacturing firms, looking at firm performance in relation to technology use, had a $22 \%$ response rate (comparable to other mail surveys) for a total of 177 completed responses. Hagedoorn's study (1988) of the process control equipment industry included 56 firms operating in the Netherlands ( $80 \%$ response rate). Chapter 7 also refers to the technology adoption surveys which tend to have larger sample sizes. The limitations of these surveys in analysing temporal relationships was discussed above.

On the scale of most technology use surveys, then, the small sample size in this study is evidently limited. However, the sample size, to begin with, was bounded by the population size, (all mobile phone and hand power tool firms were sent surveys and nearly all bicycle firms). The survey also returned higher response rates for mobile phone and hand power tools companies ( $81 \%$ and $55 \%$ respectively) than is usual for surveys. Also, as mentioned above, a finite population correction factor was used. We can therefore reasonably expect the survey results to be highly representative for the mobile phone and hand power tool industries despite the small sample sizes.

Yet, survey size is not the whole story with respect to the limitations of statistical analyses. Returning to the studies of Spina and colleagues $(1996,1998)$, noting the complex and multi-dimensional character of the phenomena under study (orientation to para- 
digm), they devised a model based on fuzzy logic which allowed them to evaluate the degree of orientation at a given time. McDermott et al. (1997) conducted a study of hand power tool companies operating in the U.S. using both quantitative and qualitative techniques to gauge the impact of AMTs on manufacturing practices and strategy. There sample was nine companies accounting for $95 \%$ of sales in the U.S. These two examples indicate that the small number of respondents in a survey analysis may be less problematical than the relevance of standard statistical analysis methods to studying system dynamics.

With this limitation in mind, the purposeful design of the empirical research in this thesis was to use a mix of research techniques. In addition to the survey results reported in this chapter, the research includes qualitative analyses of the nine industry roadmaps and forecast studies (see Chapters 4 and 9) and of the interviews with production technology users, suppliers, and service providers. In particular, the interview research was framed to focus on system dynamics and to provide a systematic representation of the reciprocal interactions characterising technology use. ${ }^{5}$

The number of participants in the interview research exceeded what is typically found in earlier qualitative studies of technology use, for example, Leonard's (1988) study included 12 firms. In addition, as was remarked in Chapter 7, the generalisability of the interview results was strengthened by the wide range of interview subjects, which included a number of technology suppliers and consultants whose observations on their customers' AMT use patterns effectively multiplied the number of observed cases. Likewise, the roadmaps/foresight analyses represents the synthesis of the conclusions of numerous industry experts and individual companies on the direction of production technology advance.

The question for each researcher is to find the balance between quality and quantity, depth and breadth in their observations. Using a mix of techniques, an additional critical measure of research validity is the fit of the results across the techniques. (Some methodological researchers maintain this criteria is paramount (Alford, 1998)). In this regard, the survey results are highly consistent with the interview results and the roadmaps/foresight studies analysis (keeping in mind that the main subject of the interviews was the model's validation, where the survey concerns the application of the model to studying the impact of AMT trajectories). For example, several of the interviewees (from industries other than those surveyed) attested to the need to increase break-even sales volumes as an effect of AMT use, a survey finding that is also remarked in the roadmaps and foresight analyses. ${ }^{6}$

The fit of the empirical results from the three analyses is further explored in the next chapter, in which we examine the evidence for AMT-related trade-offs. As a final reckoning, Chapter 11 presents a narrative summary of the research which integrates the findings from the three analyses with the thesis' theoretical arguments.

\subsection{Industry Profiles - Descriptive Statistics}

Three consumer products industries - bicycles, mobile phones, and hand power tools were chosen for study. The underlying assumption in taking a selection of industries is that the relationships of interest are influenced to some degree by the historical development of the respective industries' product markets. For example, the strategies of firms 
in a fast-growth, new product market, such as mobile phones, will be different than those of firms in an older, more stable market, such as bicycles or hand power tools. Similarly, firms have different strategies for commodity markets than for niche markets. At the same time, this study's theoretical premise is that the current strategic uses of AMTs, as configured around the time-based manufacturing capabilities embodied in AMTs, have consequence for product market structure. Tests of these relationships by industry allow us to account for the influence of different industry conditions on technology use.

\section{Industry and Market Conditions}

A factual review of industry and market conditions in the three industries established some important differences among them. The bicycle industry is considerably more fragmented (i.e., less concentrated) than the mobile phone and hand power tool industries and there is greater variation in manufacturing practices within the bicycle industry. The majority of larger bicycle firms focus more on assembly than on manufacturing, while many of the smaller European bicycle manufacturers emphasise customisation and hand craft methods of manufacture. The mobile phone and hand power tool industries are more similar in structure: a mix of mid-sized niche market producers and large mass producers with global markets and operations. Growth in the hand power tool industry has been fairly stable over several decades, whereas the mobile phone industry has largely come into existence in the last decade (the 1990's). The three industries are described next in more detail.

\section{Bicycles}

The European bicycle industry is undergoing a structural shift driven by vertical specialisation and the growing importance of mass retailers in bicycle sales. Large-scale production is typical of component manufacturing, while finished product assembly is becoming increasingly concentrated. (Assemblers purchase almost all manufactured parts of the bicycle, including frames, from component suppliers, although most manufacture their own wheels.) The assemblers' share of final sales is growing at the expense of firms that manufacture their own frames. ${ }^{7}$ Still, the segment of the industry which covers both the assembly and manufacture of finished product is highly fragmented compared to other consumer product industries.

As characteristic of firms in fragmented industries, the majority of bicycle companies are very small. Approximately two-thirds of European firms in the manufacture of motorcycles and bicycles industry classification have fewer than 10 employees and another 15\% have fewer than 20 employees (Eurostat, 1998). Competition from Asian manufacturers has caused European bicycle firms to concentrate on the high value-added segments in the market (European Commission, 1997). Many of the smaller manufacturers targeting the high-end market segment, e.g. racing bikes, still use hand-craft methods and consciously advertise their products as being hand crafted. ${ }^{8}$ These may only make a few hundred bicycles a year, although at high margins. Also, in comparison to other manufacturing industries, the bicycle industry has historically produced a greater range of models (Pratten, 1971). ${ }^{9}$ Production was correspondingly organised on a batch basis.

Several characteristics of firms in the bicycle industry may have contributed to a low survey response rate. The firms tend to be very small with fewer people in management positions; the majority of larger firms tend more towards assembly than manufacture; and many of the manufacturing firms specialise in hand craft methods. As a result, some of 
the questionnaire recipients may not have seen the survey as being pertinent to their operations or as difficult to respond to given their lack of familiarity with AMTs, (see below for the low mean AMT use rates of bicycle firm respondents).

\section{Mobile Phones}

The almost overnight appearance of the mass market for mobile telephones is an incredible growth story, epitomising the pace of technological change in the new regime. The rapid expansion in European companies' production, beginning in the early 1990's, was fuelled by the international adoption of the GSM (Global System for Mobile Communication) standard for digital mobile phones, the only standard covering data services such as email, fax, internet browsing, and intranet/LAN wireless access. Continuous rapid growth characterises the mobile phone industry. ${ }^{10}$ Total mobile telephone sales increased 65\% in 1999 (Eurostat, 2000). In addition to the mobile phone's technological advantages, product marketing also emphasises its lifestyle attributes. Business analysts surmise that the industry's long term growth plans are based on consumers buying multiple phones (BBC News, 1999).

While the mobile phone market is relatively young, some of Europe's largest and oldest consumer electronics companies make mobile phones. But there are also the companies that came "out of nowhere". Originally a paper manufacturer, then a rubber products producer, and next a smaller consumer electronics conglomerate, Nokia transformed itself into the world's largest mobile phone producer over the past decade. The industry's larger companies are complemented by several smaller, dynamic companies focussing on innovation. Given this picture of the industry as a mix of larger, older, but fairly technologically sophisticated electronics firms, and younger fast growth companies with new manufacturing plant, we might expect a high AMT use rate in the industry. Also, mobile phone product technology obviously complements the direction in AMT development towards information communication and management.

For this study, 21 firms producing phones within the EU were identified. The additional handful of European companies manufacturing abroad were excluded.

\section{Hand Power Tools}

The hand power tool industry manufactures a wide assortment of hand-held portable electric power tools for two distinct market segments, the professional market and for households. Niche manufacturers have targeted the professional market, but product differentiation has grown in importance throughout the industry over the last two decades. Black \& Decker produces 20 models of handheld power drills, while DeWalt, another division of $\mathrm{B} \& \mathrm{D}$, produces 36 models (Mraz, 1997). As with the bicycle industry, the role of mass retailers has also gained significance, causing power hand tool manufacturers to reorient their strategies for greater responsiveness to the retailers' demands.

The product technology is considered relatively stable (McDermott et al., 1997), though recently innovations in adding to tool functionality with microelectronics have created considerable product stir. Consumers are also buying tools with more power although "most people don't need it", according to one tool designer (Mraz, 1997, p. 49). Marketing also focuses on quality and value.

A total of 31 hand power tool companies, largely concentrated in Germany, were identified for inclusion in the study. This number compares to the nine firms identified in a 1997 study of US hand power tool firms (McDermott et al., 1997). These nine firms comprise 95 percent of the US market. 


\section{Descriptive Statistics}

This section compares the three industries to each other. Graphical representation of the descriptive statistics discussed below are provided in the charts on pages 172 to 176.

Chart 1, Firm Size Distribution by Industry, shows the sample distribution of firms by their size class for the three industries in relation to all firms included in the study. The questionnaire asked in which of the size classes did the firm belong. (Firms with ten or fewer employees were excluded from the survey sampling.) Of the three industries, only bicycles approximates the usual firm size distribution for that of the manufacturing sector as a whole, in which the number of firms decreases with firm size. By comparison, the hand power tool and mobile phone samples show a greater proportion of firms with more than 500 employees than is usual for manufacturing, but may be more typical of consumer products industries. These patterns suggest a sectoral effect on AMT use rates since firm size generally correlates with the number of AMTs in use (Northcott and Vickery, 1993).

Charts 2 through 5 show AMT use patterns by industry. The AMTs are divided into two groups, $\mathrm{A}$ and $\mathrm{B}$, each containing seven technologies. (The fourteen AMTs are described on the next page in Table 8.2. Appendix A provides further description of these technologies.) The two technology groupings map to different generations of AMTs, and, by implication, different capabilities. The AMTs in Group A are generally associated with flexibility and functional integration, whereas the Group B technologies include more information management technologies. ${ }^{11}$ The technologies in Group A have been on the market for a longer time.

For all firms, the AMT that is in greatest use is a computerised production planning system, followed by the electronic exchange of product and process data. The Group B AMT with most frequent use by all firms is a computerised process planning system. The AMT that is least used is process simulation. This low use rate may not be representative of all discrete parts manufacturers since the ease of modelling the relevant processes varies by industry. For example, process modelling at the machine level is not unusual in the plastic process industries, according to firms interviewed in the earlier research.

Some differences by industry emerge in the types of technologies used. Of the Group A AMTs, machining centres are generally not applicable to mobile phone manufacture. ${ }^{12} \mathrm{~A}$ surprisingly high percentage of bicycle firms relative to firms in the other two industries use computerised production planning systems. Bicycle firms also use product modelling and simulation AMTs more frequently. This may relate to the large amount of customisation work they do. In the Group B technologies, we find a very high number of product data management systems in the mobile phone sample. The fast rate of product evolution and the recent emergence of the mobile phone market may have opened a particular window of opportunity for the application of this technology in the industry. A notable percentage of power hand tool firms use machining centres and cellular manufacturing practices than do firms in the other two industries.

The survey findings show no statistically significant differences in AMT use patterns for the mobile phone and hand power tool firms, either by measure of the mean number of technologies used or by the mean number of years the technologies have been in use. 
Table 8.2 Generic Advanced Manufacturing Technologies and Practices

\begin{tabular}{|c|c|}
\hline AMT & Description \\
\hline \multicolumn{2}{|l|}{ Group A AMTs } \\
\hline Multi-axes machining centre & $\begin{array}{l}\text { Programmable metal machining equipment with more than two } \\
\text { machining axes. }\end{array}$ \\
\hline High speed machining centre & Machining centres operating at speeds of $12,000 \mathrm{rpm}$ or higher. \\
\hline $\begin{array}{l}\text { Cellular manufacturing or group } \\
\text { layout }\end{array}$ & $\begin{array}{l}\text { Method of organising production around groups of complementary } \\
\text { machines to facilitate manufacture of families of parts or products. }\end{array}$ \\
\hline $\begin{array}{l}\text { Computerised production plan- } \\
\text { ning system }\end{array}$ & $\begin{array}{l}\text { Software that directs ordering, procurement, production planning } \\
\text { and routing, and material storage. }\end{array}$ \\
\hline $\begin{array}{l}\text { Product modelling and simula- } \\
\text { tion }\end{array}$ & $\begin{array}{l}\text { Software providing computer-based visualisations of product physi- } \\
\text { cal or performance parameters. }\end{array}$ \\
\hline $\begin{array}{l}\text { Electronic exchange of product } \\
\text { design and process data }\end{array}$ & $\begin{array}{l}\text { Electronic transfer of data across different platforms to co-ordinate } \\
\text { operations. }\end{array}$ \\
\hline $\begin{array}{l}\text { Automated parts identification } \\
\text { devices }\end{array}$ & $\begin{array}{l}\text { Machine readable labels which are printed, attached or scribed on } \\
\text { parts which enable the parts to be monitored, counted or recorded } \\
\text { during manufacturing processes. }\end{array}$ \\
\hline \multicolumn{2}{|l|}{ Group B AMTs } \\
\hline Rapid set tooling and fixturing & Programmable placement of tooling and fixturing. \\
\hline Rapid prototyping & $\begin{array}{l}\text { Production of a physical model of a finished part or product from a } \\
\text { computer model. }\end{array}$ \\
\hline $\begin{array}{l}\text { Computerised process planning } \\
\text { system }\end{array}$ & $\begin{array}{l}\text { Software that directs the selection and sequencing of equipment } \\
\text { operations, e.g. determination of set-ups and calculation of machin- } \\
\text { ing times and costs. }\end{array}$ \\
\hline $\begin{array}{l}\text { Product data management sys- } \\
\text { tem }\end{array}$ & $\begin{array}{l}\text { Software for capturing and codifying manufacturing-related product } \\
\text { characteristics. }\end{array}$ \\
\hline Process simulation & Use of computer-based models to simulate process performance. \\
\hline Knowledge-based systems & $\begin{array}{l}\text { Software system that employs rules based on domain knowledge to } \\
\text { generate solutions for control of manufacturing processes. }\end{array}$ \\
\hline $\begin{array}{l}\text { On-line intelligent process con- } \\
\text { trol }\end{array}$ & $\begin{array}{l}\text { Monitoring and control of process by sensing and adjusting process } \\
\text { parameters in real time. }\end{array}$ \\
\hline
\end{tabular}

The sample mean for the number of technologies used is slightly higher for mobile phones than hand power tools firms. Hand power tool manufacturers have used the Group A AMTs slightly longer than have mobile phone firms, while the reverse is true for Group B AMTs. ${ }^{13}$ The greatest number of years any technology has been used was fifteen "plus" years.

Both hand power tool and mobile phone firms use a statistically significant greater number of AMTs than do bicycle firms. On average, bicycle firms use 2.4 of the AMTs in Group A and less than one technology from the Group B list, whereas the mean number for mobile phones and hand power tools is about half of the technologies in Group A (3.5 AMTs), and 2.4 and 1.9 of the seven Group B AMTs respectively. Only in the number of years that the Group A AMTs are in use is the experience of bicycle firms somewhat comparable to that of firms in the other two industries. For Group A AMTs, hand power tools, bicycles, and mobile phones have sample means of 6.7, 6.6, and 6.5 years respectively. However, the difference for bicycle firms as to the number of years of 
experience with Group B AMTs is pronounced. Bicycle firms have used any Group B AMT at a mean of 1 year, compared to 4 years use for hand power tool firms and 5 years use for mobile phone manufacturers.

Chart 6, Manufacturing Practices by Industry, depicts the distribution of firms for the three industries by their basic methods for executing the production process and determining production lot size. The practices differ in the order of which design, manufacture, and purchase ordering activities are carried out. Generally, we might expect that those firms closer to the design-to-order end of the continuum, (that is, when the purchase order precedes design), will have smaller lot sizes and a greater ability to customise.

More than one in five firms for all three industries say they design, engineer and manufacture-to-order and both mobile phone and hand power tools firms identify their principle practice as manufacturing previously designed product to order. At first consideration, this implies a very sophisticated level of customisation for these industries. However, these high percentages for manufacturing to order are probably explained by the presence of retailers. Thus, these firms actually manufacture to retailers' orders, but not to final consumers' orders. It would appear that an additional term for describing customisation strategies is needed to describe this distinction as it entails a very different relationship with the final consumer.

It is more likely that bicycle firms that design-to-order do design to the specifications of the final consumer. Many specialty bicycle firms take custom orders over the internet. Interestingly, an equal number of bicycle firms in the sample describe their practices at either end of the manufacturing practice continuum, about a third of the firms each. This distribution may reflect a split between firms that assemble large numbers of bicycles and those that manufacture by craft methods. However, it is not possible to confirm this for the small sample of bicycle firms in this study as it is also likely that there is response bias between the two different types of firms (assemblers, manufacturers) according to size.

Chart 7, Industry Drivers, depicts the percentage of survey respondents, by industry, which consider the different terms of product competition as driving competition in their industry. As might be expected for consumer products industries, cost and quality are cited by nearly all the respondents as driving competition for the majority of firms in their industries. For mobile phone companies, product development time (the time it takes to conceive, design, and get a product into production) is the next most important driver, followed by customisation. For hand power tool companies, delivery time (the elapsed time from receiving an order to delivery) and value based on product features are considered important. For bicycle firms, delivery time, as well as delivery reliability, are major competition drivers. Interestingly, customisation is not regarded as a significant industry driver by most of the bicycle firm respondents, although as explained above, many bicycle firms compete on customisation.

Chart 8, Current Manufacturing Capabilities by Industry, shows which manufacturing capabilities give the respondent firms a competitive advantage. For all firms, the ability to make products of consistently high quality is the most frequently cited manufacturing capability of competitive advantage. Making rapid product deliveries is an important capability for both hand power tool and bicycle firms, while the ability to add value through services stands out for mobile phone manufacturers. The least cited capability for all firms is adding value through unique processes, although this capability is of 
moderate importance for hand power tool manufacturers. In all three industries, the ability to make large volumes of low cost products is not commonly considered a competitive advantage. The least cited current time-based capability is the ability to change product mix rapidly.

Chart 9, Manufacturing Capability Improvement Plans by Industry, shows which manufacturing capabilities the respondent firms have plans to improve through the implementation of additional AMTs. Introducing new products quickly is a focus for both mobile phone and bicycle manufacturers. A high percentage of mobile phone companies also plan to implement technologies for adding value through services and making products of consistently high quality. Also, mobile phone firms, on average, have plans to invest in a wider range of technologies than firms from the other two industries. The ability to customise product is the most frequently cited capability for improvement by hand power tool manufacturers, and the second most frequently cited by bicycle manufacturers. Firms plan least frequently to implement technologies for adding value through unique processes and making large volumes of low cost products. We might surmise that these two capabilities are not significant elements in a majority of firms' manufacturing strategies, since they also are the least cited of the current capabilities conferring competitive advantage.

A comparison of Chart 8, current manufacturing capabilities, to Chart 9, planned improvements, indicates a continuing shift towards the emphasis of time-based capabilities, with the exception of mobile phone manufacturers' plans to invest in value-adding service capability. Of particular note is the low percentage of firms planning to invest in technologies to improve their ability to manufacture products of consistently high quality compared to the number of firms that cite this ability as giving their firms a competitive advantage. However, the shift towards time-based manufacturing strategies has not displaced cost and quality as important terms of product competition, as indicated by Chart 7, Industry Drivers. Interestingly, while customisation is not currently considered by many of the respondents as a significant industry driver, a fair number of firms are planning investment to increase their ability to customise product. On the other hand, value or performance based on product features is considered to drive industry competition by a moderate number of firms, yet few firms cite the ability to add value through unique manufacturing processes as giving their firms a competitive advantage or have plans to invest in this capability.

\subsection{Regressions}

The survey findings, in general, provide evidence to support the model. In particular, the results for the mobile phone and hand power tool industries corroborate the hypotheses drawn from the model. The bicycle industry results were complicated by the low response rate of bicycle firms to the survey questionnaire and, as explained below, by the apparent confounding of time-based capabilities based on craft production techniques with capabilities that are traditionally cultivated by bicycle firms. The difference in results by industry suggests that industry variables have a significant influence on the strategic use of AMTs. At the same time, the Strategic Use Model seems to apply generally across consumer products industries.

The regression results are presented in Tables 8.3 through 8.6 on pages 177 to 180 . 


\section{Findings on Hypotheses 1 and 2}

Hypothesis 1 states that the more AMTs the firm uses and the longer they are in use, the greater the importance of time-based manufacturing capabilities is to the firm's achieving its business objectives.

The questionnaire asked the respondents to identify which of eight manufacturing capabilities gave their firms a competitive advantage. In the analysis, four of these are designated as time-based capabilities. Table 8.3 gives the results of an ordered logit regression for all firms showing the number of time-based capabilities as a function of the number of AMTs in use and the number of years that any one of these AMTs have been in use, and the results of the same regression for each of the industries separately. The ordered logistical regression form is thought to best represent the fact that manufacturing capabilities are not strictly additive. ${ }^{14}$ In the model, the dependent variable, time-based capabilities, is an ordinal variable on a nominal scale, its value (from one to four) corresponding to the number of different time-based capabilities the firms cited as giving the firm a competitive advantage. The independent variables include the number of AMTs the firm routinely uses (ordinal variable on a nominal scale), the number of years any AMT has been in use (interval variable), and a nominal variable indicating whether the industry competes on cost. The regressions also contain an independent variable which codes for whether the observed firm considers cost to be driving competition in the industry. ${ }^{15}$

In general, the findings indicate that increasing AMT use leads firms to emphasise timebased manufacturing capabilities as a means of competition. This is especially the case for hand power tool manufacturers and also true for mobile phone manufacturers. The number of AMTs appears to be less of a factor for mobile phone companies in the development of time-based capabilities.

Another possible interpretation of the results, expressing the reverse causality of Hypothesis 1 , is that firms which are most concerned with time-saving strategies will be the first to adopt AMTs. This interpretation, however, is inconsistent with the implications of the Strategic Use Model and the findings in Chapter 7. These findings indicate that firms are more likely to change their operational strategies as an effect of technology use. In the early stages of a technology's diffusion, its strategic uses have yet to be developed as these depend on the reorganisation of production of which there is no experience. Instead, firms usually acquire new technology to enhance existing capabilities. For example, U.S. firms originally bought $\mathrm{NC}$ and $\mathrm{CNC}$ equipment to improve precision in machining (Mazzoleni, 1997). Other studies have shown that firms, on first adopting technologies, fail to take advantage of strategic uses and that strategy development lags technology adoption (Jaikumar, 1987; Kakati, 1997). Most likely, the reasons for technology adoption evolve over time as change occurs in the firms' product markets.

The limitations of statistical models in describing the inherent complexity of path dependent and co-evolutionary processes were noted in Chapter 7 and discussed in Section 8.1 above. As such, we must then take the regression findings as corroboration, not confirmation, of Hypothesis 1. This said, in the case of the hand power tool industry, there are strong supportive results for Hypothesis 1. Both the number of technologies used and the number of years the technologies are in use are positively correlated with the number of time-based capabilities. The results for mobile phone companies are more mixed. They indicate a positive relationship between the number of years any AMT has 
been used and the number of capabilities, but the number of AMTs in use has no effect on the number of time-based capabilities $(p>0.732)$. The bicycle firm results do not fit the model. For all firms, we see that the number of time-based capabilities goes up with the number of AMTs in use, but the negative correspondence between the number of years the AMTs are in use and the number of time-based capabilities runs counter to the first hypothesis.

The lack of results for bicycle firms suggests that production technology use in this industry differs from that of the firms in the other two industries. Investigation of the bicycle firm sample shows a moderately strong negative sample correlation (Spearman's rho $=-0.62)$ between the number of time-based capabilities and the number of years the technologies have been in use and a negligible relationship between the number of capabilities and the number of technologies used. One possible explanation of the negative interaction between the number of years any technology has been in use and the number of time-based capabilities is the use of craft-based and batch production techniques to support product differentiation strategies.

Compared to most other consumer products, bicycles have always come in a wide range of models - no one bicycle size fits all users. Larger bicycle manufacturers used batch production technologies to meet the demand for variety, while smaller manufacturers specialized in custom-built bicycles. Craft techniques have historically aided product customisation and innovation but not as a function of saving time. The ability to customise, for example, does not presuppose the firm is competing on time. Whereas time-based capabilities evolved as a means of producing greater variety at prices close to that of mass production, bicycle manufacturers were already producing this variety. ${ }^{16}$ In consequence, bicycle manufacturers also have capabilities that are associated with time-saving in the shift from scale- to time-based strategies - except not as a result of using time-saving techniques. If this explanation is correct, we would expect that some bicycle firms with few years of AMT use citing high numbers of the "time-based" capabilities. A visual inspection of a scatter plot for the two relevant variables bears this out.

Evidence to support this explanation is also found in the relationship between specific capabilities and the number of years the technologies have been in use. For the survey's bicycle firm respondents, the number of years of technology use is only positively correlated with one of the designated time-based capabilities, the ability to change product mix rapidly. From our knowledge of the technologies involved, we could reasonably argue that the operationalisation of this capability is more reliant on AMTs than the three other designated time-based capabilities. ${ }^{17}$ By comparison, crafts-based and batch-production firms can plausibly develop the other capabilities without investing in AMTs or investing in only a small number of AMTs, for example, computer-aided drafting.

The influence of bicycle firms on the regression results for all firms would also explain the weak negative correspondence in that regression between time-based capabilities and the number of years of AMT use. Removing bicycles from the sample does, in fact, reverse the sign of the coefficient for the number of years of AMT use in the regression results.

For mobile phone companies, the lack of any relationship between the number of AMTs in use and time-based capabilities as a means of competition appears to be influenced by whether firms see cost as driving industry competition. Mobile phone firms that see cost as a principle driver place an emphasis on economies of scale (the ability to make large 
volumes of low cost products) as a competitive capability, while tending to see fewer time-based capabilities as competitive advantages. Firm size also affects whether cost is seen as a competitive driver, with the very largest and the very smallest firms citing it as a factor in industry competition. Scale-based competition might then partly explain the results for mobile phones - although some of the industry's largest firms could support time-based competition based on their AMT investments, instead they remain focussed on economies of scale as their principle means of competition.

Hypothesis 2 states that the more AMTs the firm uses and the longer they are in use, the more extensive will be the plans to develop time-based manufacturing capabilities. The questionnaire asked respondents to indicate their plans for improving each of the eight manufacturing capabilities by way of implementing additional AMTs in the next two years to support those capabilities. An ordered logit regression model similar to that constructed for Hypothesis 1 returned no significant results.

The lack of results may be an artefact of the way in which the question was worded and presented. Similar questions in other surveys of AMT use ask respondents if they plan to implement AMTs that they do not already have, not whether they will improve their capabilities by implementing additional AMTs. In addition, plans to invest in additional capabilities may be affected by how recently the firm invested in developing existing capabilities, that is, future possibilities for investing are limited because of previous investments. In support of this explanation, we note a negative sample correlation between the number of current time-based capabilities and the number of capabilities which the firms plan to improve through implementing additional AMTs for both bicycle and hand power tool firms. There is also the question of whether new terms of competition are influencing firms' development plans as an effect of recent directions in the development of AMTs along the knowledge systematisation and adaptability trajectories.

To summarise the findings for Hypotheses 1 and 2: The tests of Hypothesis 1 produce moderate to strong support for the hypothesis in the cases of the mobile phone and hand power tool industries, but inconclusive results for bicycle firms. With regard to the bicycle industry, it is likely that craft-based and batch production technologies are also associated with those capabilities, which for industries not using these techniques would be time-based. The tests of Hypothesis 2 returned no evidence for its being true.

\section{Findings on Hypotheses 3}

The Strategic Use Model says that strategy is influenced by firms learning new ways to achieve their goals as an effect of technology use. With increasing AMT use, we would then expect a change in firms' operational outcomes. The findings on Hypothesis 3 indicate that the greater the number of time-based manufacturing capabilities the firm uses to compete, the more likely will be the following operational outcomes: increased breakeven sales volumes, increased machine utilisation, and increased concentration of sales in niche markets. In addition, for mobile phone and hand power tool firms, time-based manufacturing capabilities are associated with an increase in the number of product variants and decreases in product development and order to delivery times.

The questionnaire asked which of a number of specific operational outcomes the respondents had experienced in the previous three years. Charts 10A though 10D show the percentage of affirmative responses for each operational outcome by industry. For all industries, the trend was towards increasing break-even sales volumes. The majority of 
mobile phone firms saw decreases in product development and order to delivery times, while a nearly equal number of hand power tool firms saw a decrease or no change in their product development and order to delivery times. Bicycle firms had a more mixed pattern of improvement: the majority experienced either a decrease or no change in order to delivery time, but an equal number of firms experienced either increases or no change in product development time. Bicycle firms were the only industry in which firms experienced decreases in the number of product variants. In all three industries, a majority of firms responded that there was a decrease in the concentration of niche market sales.

Tables 8.4 and 8.5 present the test results for Hypothesis 3, which relates the number of time-based capabilities firms have to measures of their operational outcomes for the preceding three years. The outcomes, e.g. increase/decrease in break-even sales volume, are described as ordinal variables. ${ }^{18}$ To determine the association between time-based capabilities and operational outcomes, we compare the mean number of time-based capabilities in the sample for each operational outcome. For example, for all firms, the mean number of time-based capabilities is 1.9 for firms that have seen an increase in break-even sales volume, 1.3 for those whose sales volume has remained constant, and 0.7 for firms whose break-even sales volumes have decreased over the preceding three years. An adjusted Wald test is used to test whether the differences between paired means are statistically significant (probability of difference between the means being equal to zero is less than 0.10). These results are reported in the tables. In the case of break-even sales volumes, all differences in the means are statistically significant.

In assessing the results of the Hypothesis 3 tests, a determination of support was made according to the following criteria: The hypothesis is said to be strongly supported when the mean number of time-based capabilities increases or decreases according to the hypothesis prediction and the differences by outcome are statistically significant. Moderately strong support is indicated when the mean for the outcome measure predicted by Hypothesis 3 as most likely to be associated with time-based capabilities is as predicted and there is a statistically significant difference between this mean and the means for the other measures of the outcome. Inconclusive results means that the highest mean is associated with the outcome predicted in the hypothesis, but that this mean is not statistically different from the means for the other measures of the outcome.

The tests show that Hypothesis 3 holds true to the following degree for all firms:

- Strong support that time-based capabilities are associated with increases in break-even sales volumes.

- Moderately strong support that time-based capabilities are associated with increases in machine utilisation and increases in the concentration of sales in niche markets. ${ }^{19}$

- Inconclusive results that time-based capabilities are associated with increases in the number of product variants.

The Hypothesis 3 tests for faster product development times and shorter order-todelivery times indicate more complex results. The results were indeterminate on whether time-based capabilities are associated with decreases in product development time and order-to-delivery time when all firms were included in the test. However, the same tests, excluding bicycle firms, indicate the expected outcomes. For mobile phone and hand power tool firms, there is strong support that time-based capabilities are associated with decreases in product development time and moderately strong support for an association between time-based capabilities and decreases in order-to-delivery time. 
Although we cannot draw conclusions regarding the association of faster product development times and shorter order-to-delivery times with time-based capabilities in the case of all firms, we observe there is a bi-modal pattern in the responses: the tests indicate both increases and decreases in product development and order-to-delivery times. One explanation is that increases might, paradoxically, be an indication of success. For example, it is not uncommon for firms, in reducing their order to delivery times, to win a larger share of bids resulting in an increase in the time required to fill an order.

However, it is more likely that the soft findings in support of Hypothesis 3 for the faster product development times and shorter order-to-delivery times outcomes is attributable to bicycle firms negatively influencing the results. We surmise that a number of bicycle firms claim a competitive advantage in new product introductions and making rapid deliveries but rely on traditional production techniques to support these advantages. If this is true then we would not expect time-based advantages in reducing product development times or order-to-delivery times to follow. Such appears to be the case for bicycle firms. (Also, the bi-modal response pattern disappears on removing bicycle firms from the sample.) A similar change in results for the tests of new product variants occurs when bicycle firms are taken out of the test sample. The results of the Hypothesis 3 tests by industry then tend to corroborate the explanation of the Hypothesis 1 results for bicycle firms.

Overall the findings for Hypothesis 3 indicate that increasing AMT use leads to changes in implemented strategy as evidenced by changes in operational outcomes.

\section{Findings on Hypothesis 4}

Hypothesis 4 states that the more extensive a firm's use of AMTs for emphasising faster product cycles and increased product differentiation, the more important faster product replacement and increased individuated consumption are to its market strategy.

The survey asked which market conditions were important to the respondents' future revenue growth. Chart 11, Sources of Future Revenue Growth by Industry, shows the percentage of firms that cited each of five sources as important to revenue growth. In order of importance the five sources are: increased demand for higher value-added products (54\%); increased access to global market (50\%); increasing market size due to faster product replacement (44\%); increasing market size due to more individualised consumption (36\%); and lastly, increasing market size due to growth in first time users $(22 \%)$.

The findings show that the expectation of revenue growth from individualised consumption is associated with time-based capabilities and that both scale- and time-based capabilities are related to the expectation of growth from faster product replacement. Thus, the development of time-based capabilities appears to strengthen firms' dependence on increasing product consumption to support future revenue growth.

Specifically, the results of logit regressions for each source indicate significant relationships between strategies based on manufacturing capabilities and three of the five sources: increased demand for higher value-added products, increasing market size due to faster product replacement, and increasing market size due to more individualised consumption. These results are presented in Table 8.6. No association exists between the development of manufacturing capabilities and seeing new product users and increased access to global markets as important sources of future revenue growth. 
Faster product replacement is considered an important source of revenue growth for firms that stress time- and scale-based capabilities in combination, whereas increasing market size as a result of more individualised consumption figures as an important source in relation to firms' time-based capabilities alone. These findings concur with Hypothesis 5. The finding that scale-based as well as time-based are a factor in expecting future growth from faster product replacement seems logical in the context of volume demand.

In the case of mobile phone and hand power tool companies the regression results for increased demand for higher value products indicate a significant relationship with increases in both the total number of manufacturing capabilities and the number of AMTs used. The other four sources of potential revenue growth did not fit this model. For the same sample of firms, growth in demand for higher value-added products is an important source of future revenue growth for those firms that currently have the ability to add value though services and with the capability to make products of consistently high quality. These results, taken together, suggest that a range of manufacturing capabilities supports the development of a value-based strategic orientation.

In sum, the two sources of future revenue growth considered most likely to support growth in product consumption by individual product users - faster product replacement and more individualised consumption - are associated with an increase in time-based capabilities, as predicted by Hypothesis 5. Future revenue growth from higher value-added products appears to be supported by the entire range of manufacturing capabilities, including the ability to add value through services.

\subsection{Consumption Growth and the Strategic Use of AMTs}

The application of the Strategic Use Model to the investigation of time-based strategies yields a general theoretical construct of how current generations of production technologies shape product markets. The model says that firms learn new ways to achieve their competitive goals as an effect of the integration of new technologies into their production processes and that the resultant change in strategy alters the terms of competition in product markets and, thus, their structure. The market shift towards faster product introductions and increased product variety reflects the evolution of time-based strategies in which the effective use of AMTs evidently compounds dependence on growth in product consumption. The sources for this growth are faster product replacements and increasing individualised consumption.

The survey findings presented above provide evidence to support the model. In particular, the results for the mobile phone and hand power tool industries validate hypotheses drawn from the model. The bicycle industry results were complicated by the low response rate of bicycle firms to the survey and by the apparent confounding of time-based capabilities with the crafts-based and batch production capabilities traditionally cultivated by bicycle firms. The difference in results by industry suggests that industry variables have a significant influence on the strategic uses of AMTs. At the same time, the Strategic Use Model seems to apply generally across all consumer product industries as indicated by the consistency of the survey results with the industry interviews.

To reiterate the main supportive findings for the model in its applied form:

1 The more AMTs a firm uses and the longer they are in use, the greater the firm's emphasis on time-based manufacturing capabilities as a means of competition. This is 
especially the case for hand power tool manufacturers and also true for mobile phone manufacturers but the number of AMTs appears to be less of a factor in the development of time-based capabilities for mobile phone companies.

2 The greater the number of time-based manufacturing capabilities the firm uses to compete, the more likely will be the following operational outcomes: increased breakeven sales volumes, increased machine utilisation, and increased concentration of sales in niche markets. In addition, for mobile phone and hand power tool firms, time-based manufacturing capabilities are associated with an increase in the number of product variants, and decreases in product development and order to delivery times.

3 Faster product replacement is considered an important source of revenue growth for firms that stress time- and scale-based capabilities in combination, whereas increasing market size as a result of more individualised consumption figures as an important source in relation to firms' time-based capabilities alone. In addition, for mobile phone and hand power tool firms, the entire range of manufacturing capabilities supports the development of a value-based strategic orientation. In comparison, there is no association between time-based capabilities and seeing either increased access to global markets or new product users as important sources of future revenue growth.

I would also claim that findings 1 and 2 are largely what might be expected based on a current reading of the AMT literature (we know that AMTs are used to compete on time and that their use reduces product development and delivery time), whereas finding 3 is a reasonable expectation following from any general theoretical construct of strategy. This noted, we must also acknowledge the limitations of statistical analysis for studying bicausal interactions (on, in system's terms, feedback relationships) and of this particular study for studying time-dependent relationships. The findings, however, seem to merit further research into these relationships. Particularly, it is to be hoped that the connection between the rise of time-base strategies and changes in specific consumption patterns could be investigated.

In this chapter, we set out to examine the effect on consumption of faster product cycles and increasing product differentiation. There is evidence from the survey analysis to suggest that the development of time-based capabilities reinforces firms' dependence on quantitative growth in output. AMTs enable faster product introductions and increases in the number of product variants the firm offers. Faster product replacement and increased individuated consumption are the corresponding ends of these means. Increases in the concentration of sales in niche markets may also be linked with increasing product consumption among status-conscious consumers. Higher break-even sales volumes go hand in hand with an increasing emphasis on time-based strategies. In conclusion, the interdependency between the growth of product consumption and the current strategic uses of AMTs should alert us to the danger in continuing to follow the current directions in AMT use. 
Chart 1: Firm Size Distribution by Industry

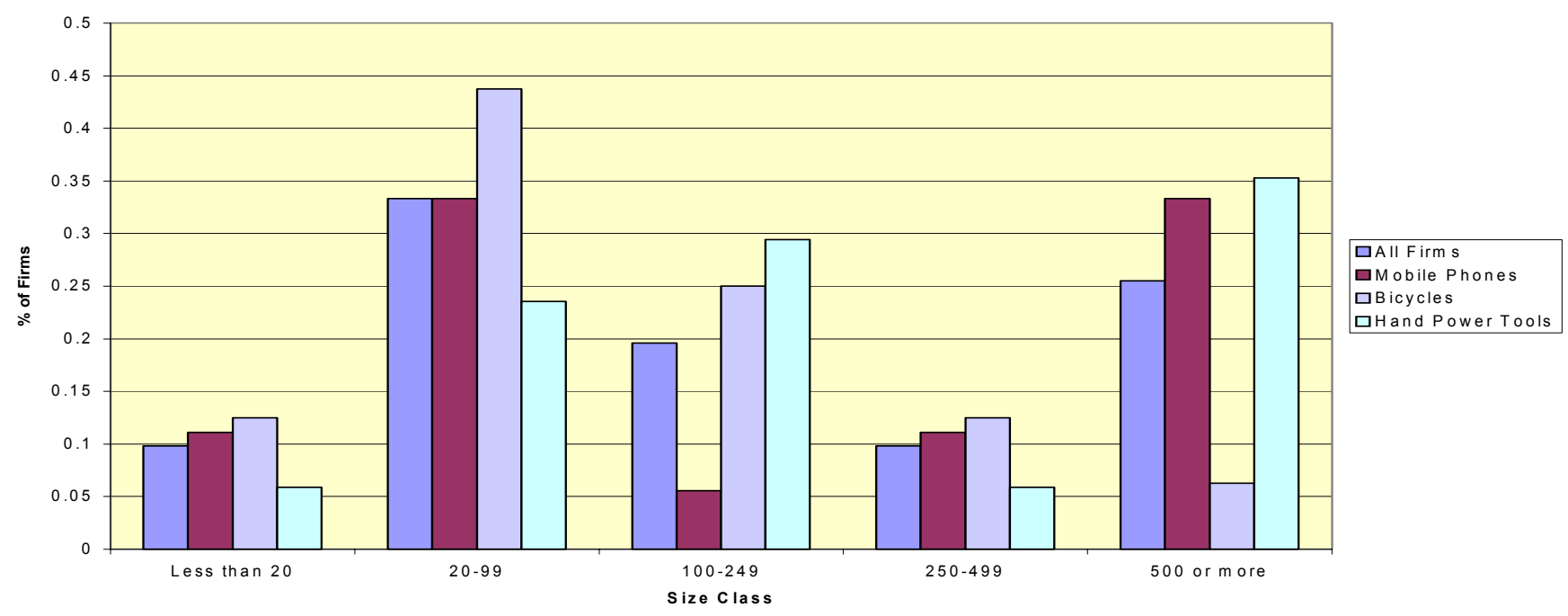

Chart 2: Specific Group A Technologies by Industry

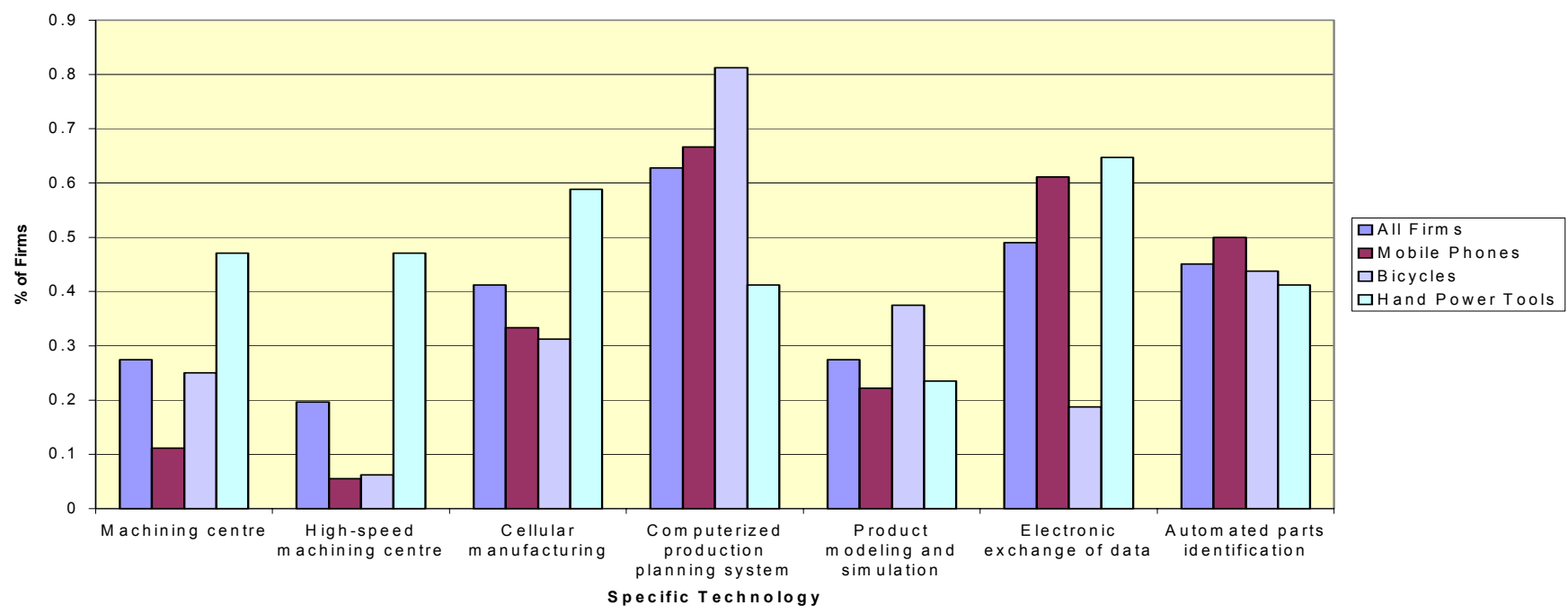

Chart 3: Group B Technologies by Industry

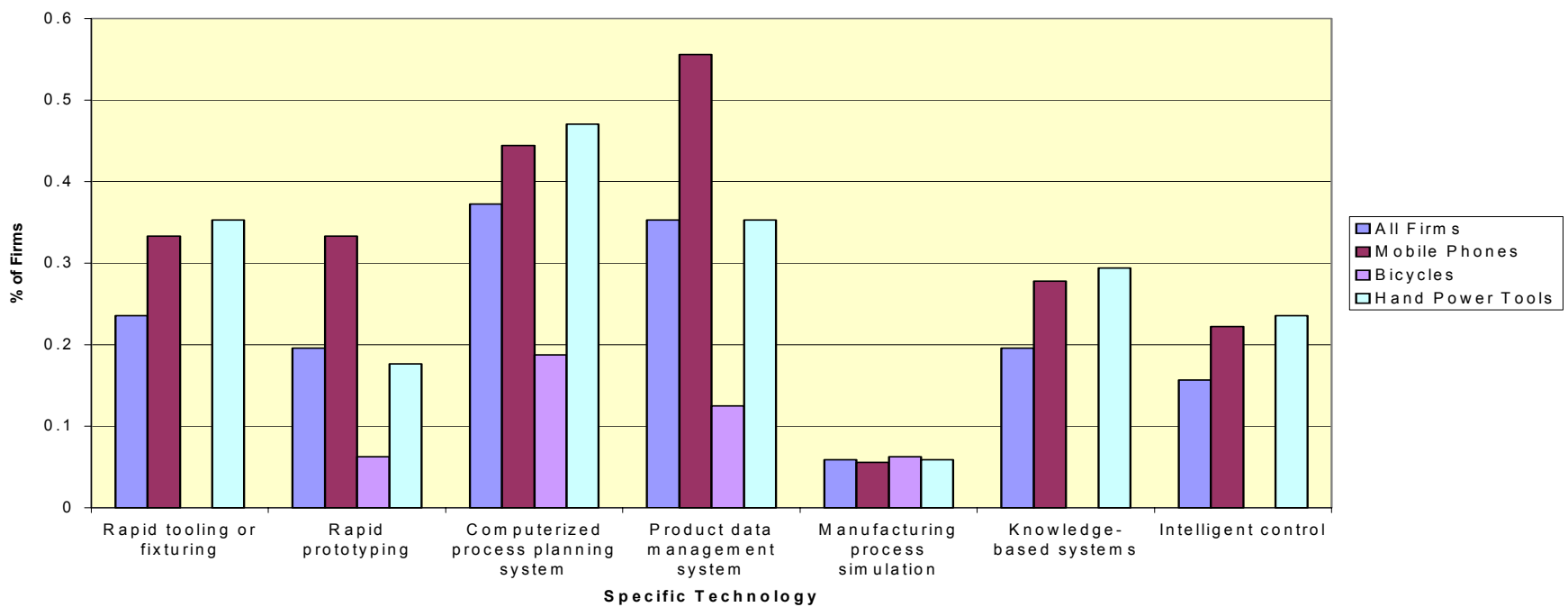


Chart 4: Years Technologies in Group $A$ in Use

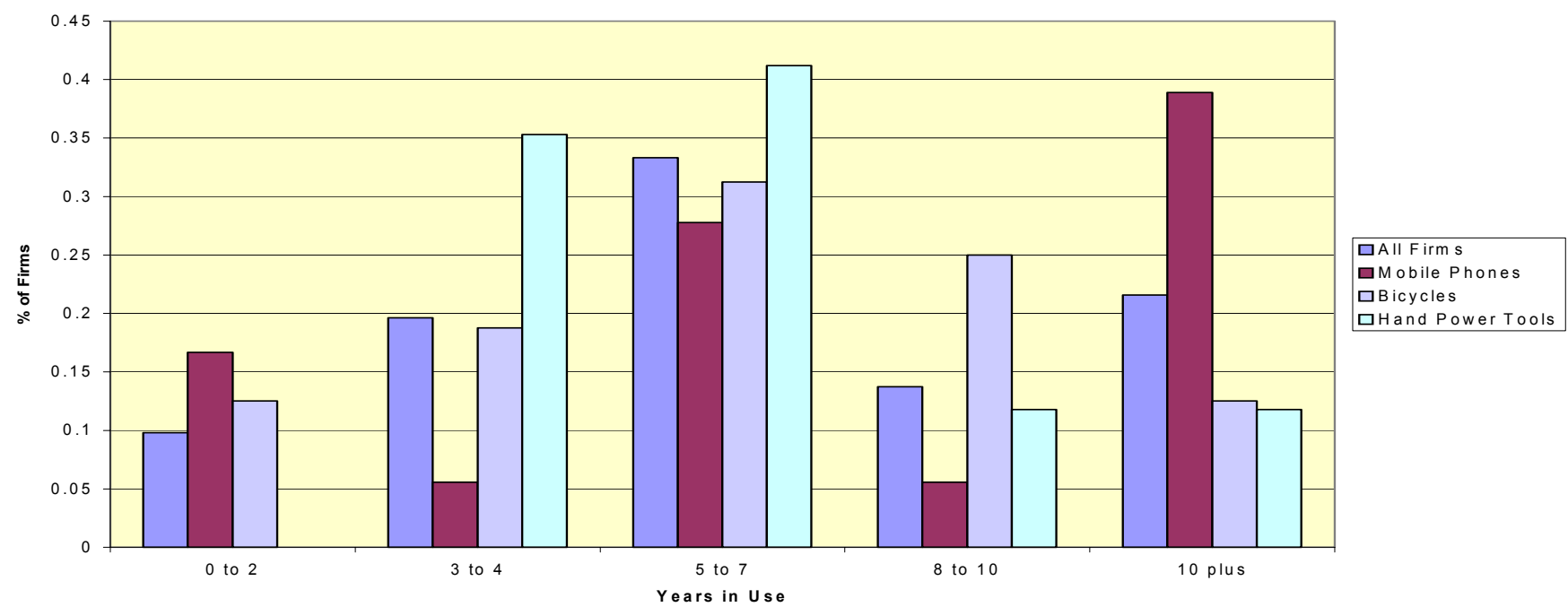

Chart 5: Years Technologies in Group B in Use

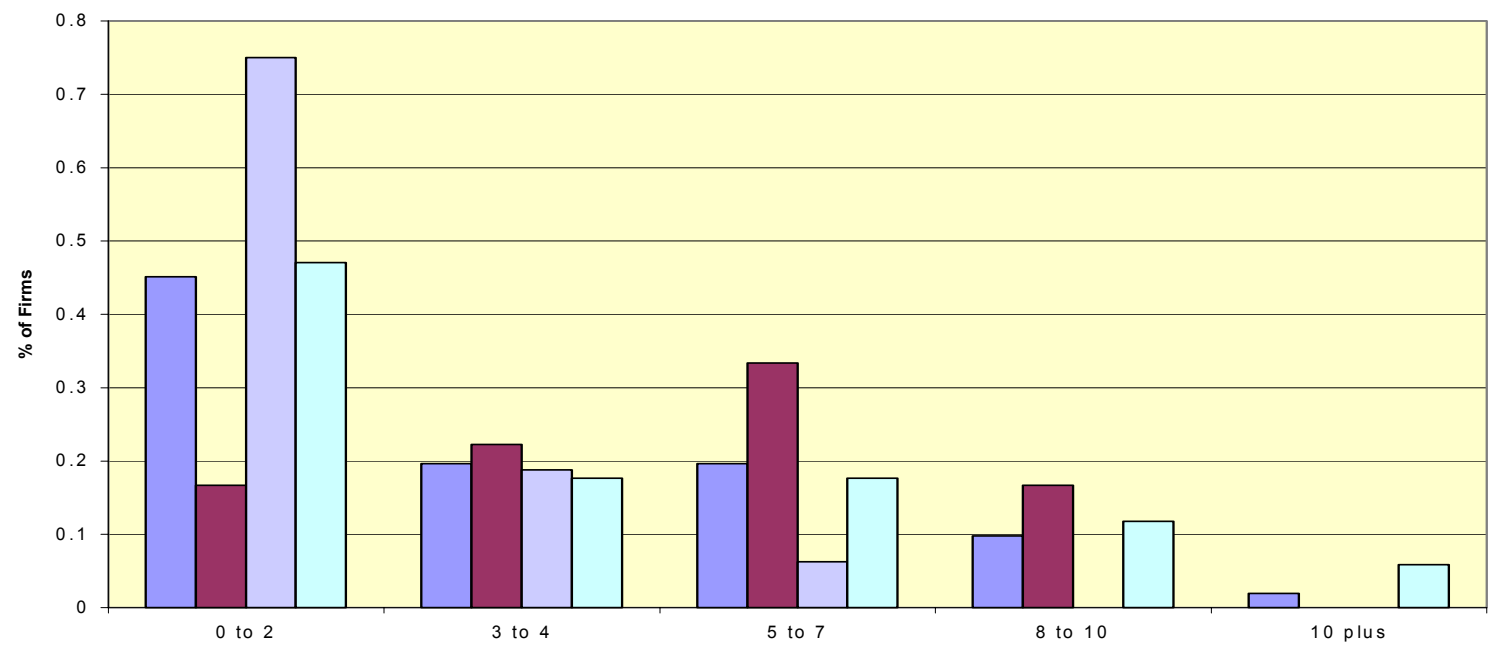

$\square$ All Firm

Mobile Phones

$\square$ Bicycles

$\square$ Hand Power Tools

Years in 4 se

Chart 6: Manufacturing Practice by Industry

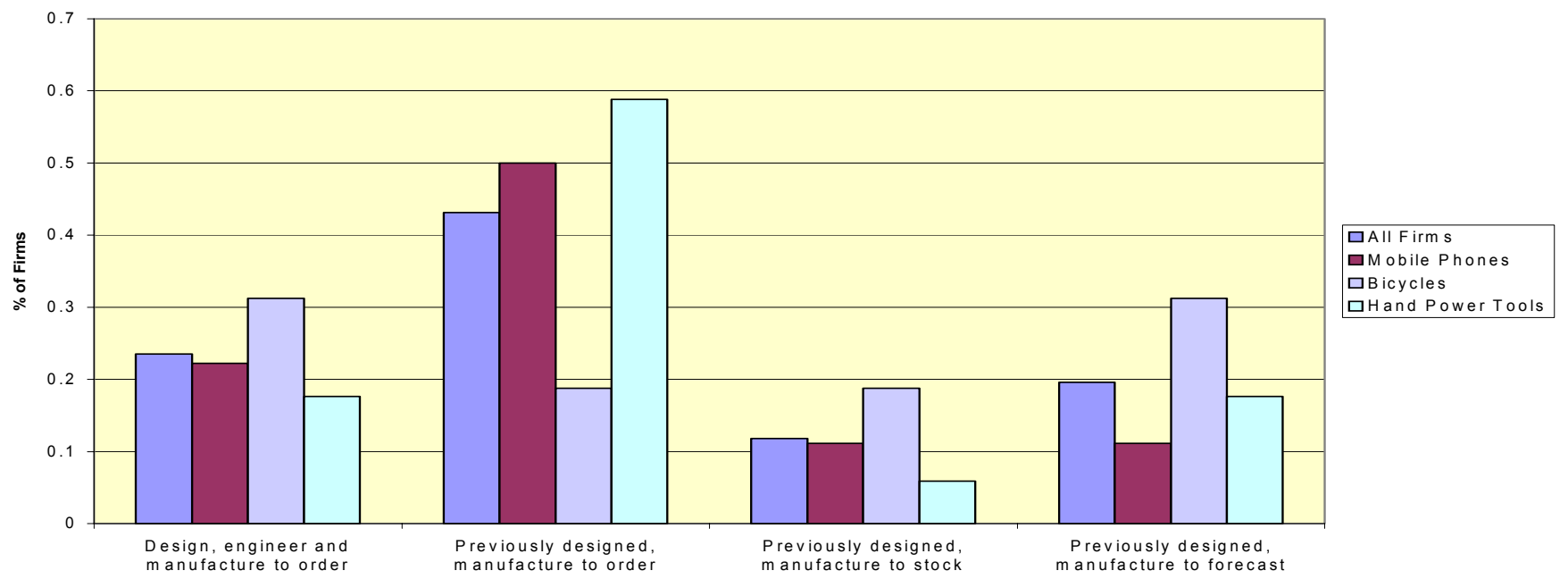
Basic Manufacturing Practice 


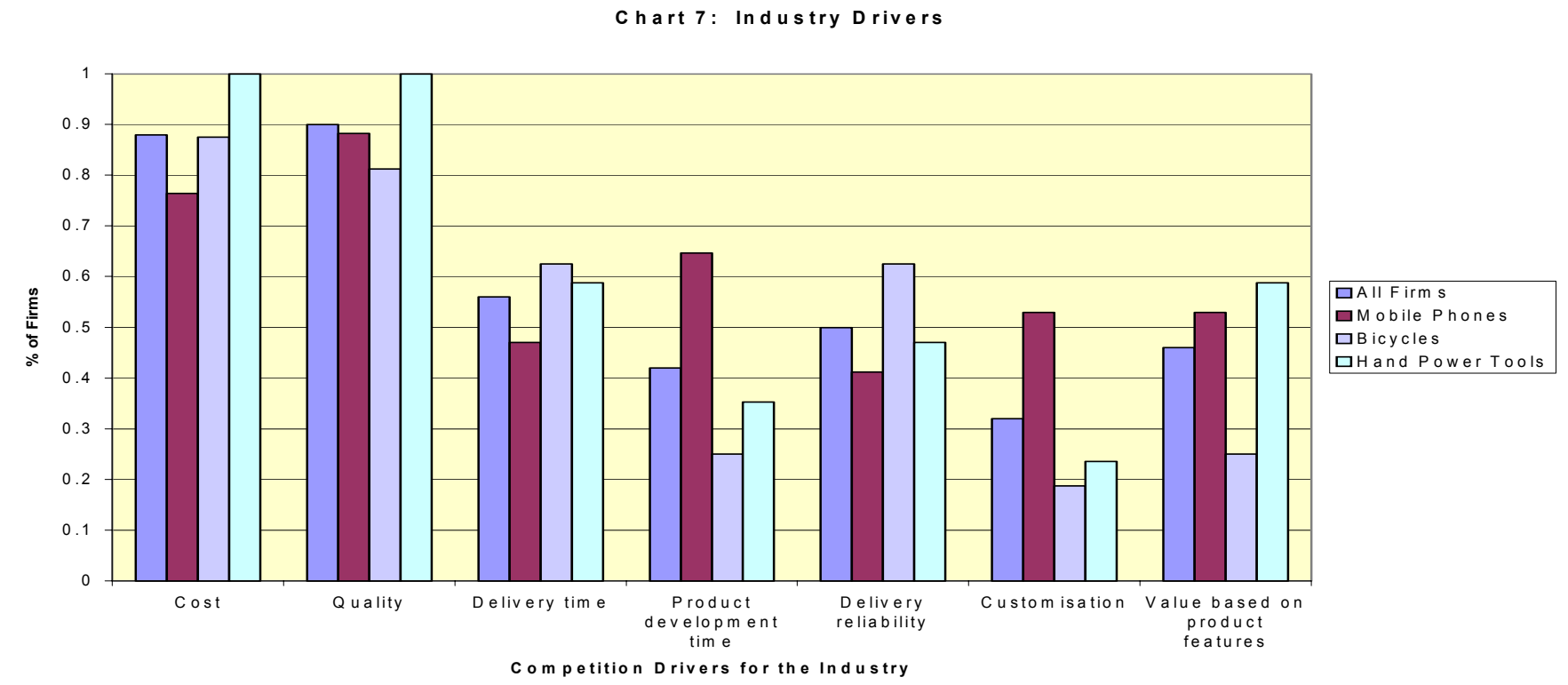

Chart 8: Current Manufacturing Capabilities by Industry

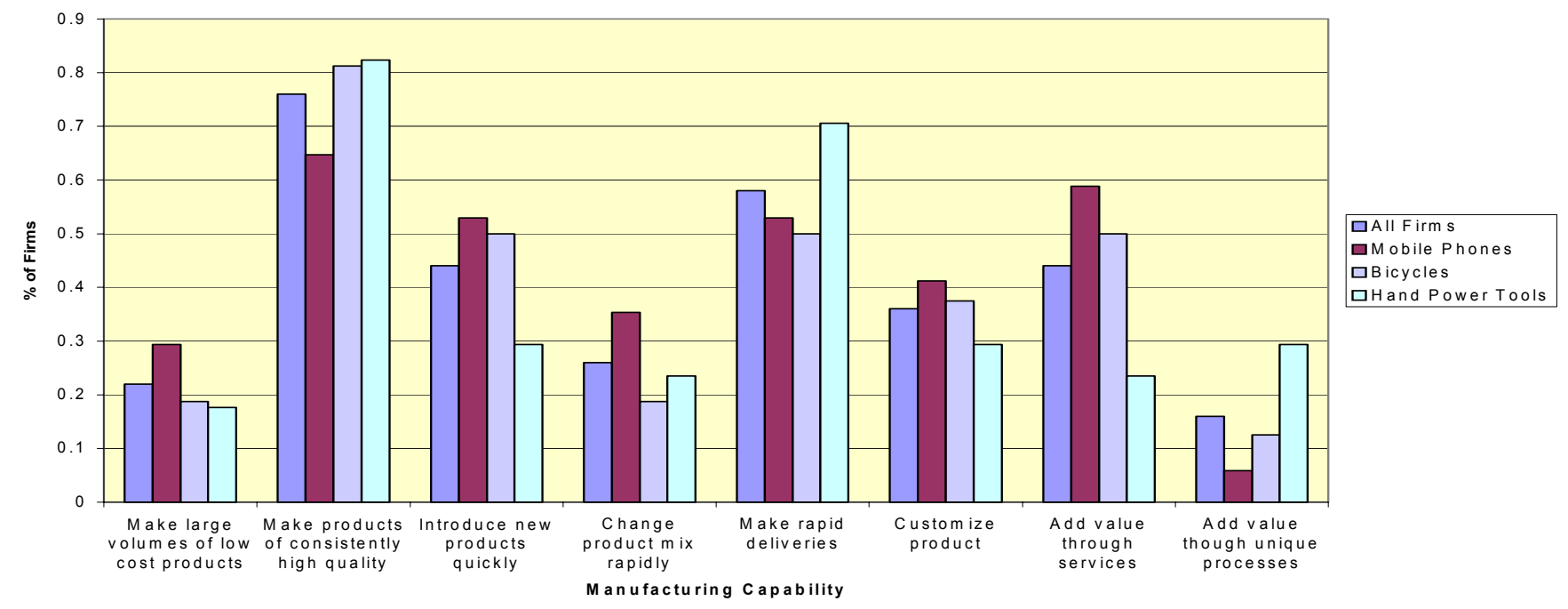

Chart 9: Manufacturing Capabilities Improvement Plans by Industry

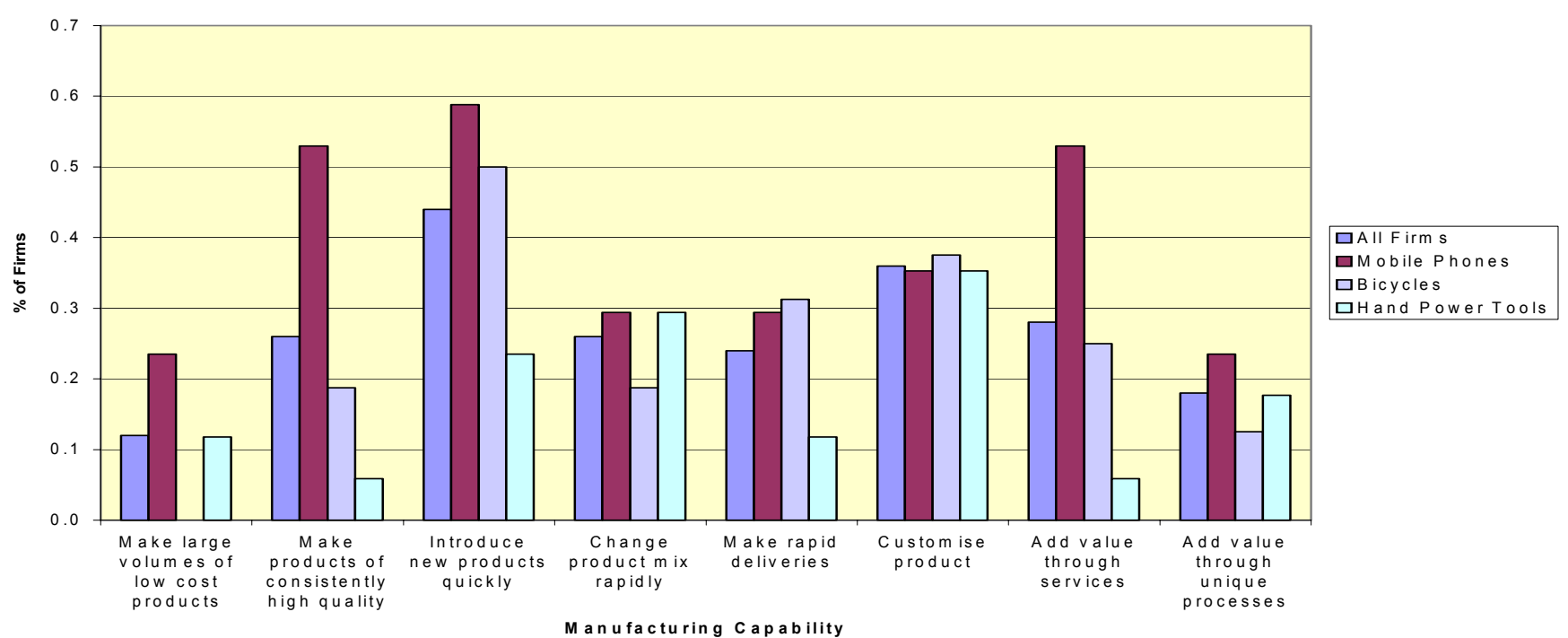


Chart 10A: M obile Phone Firms operationaloutcomes

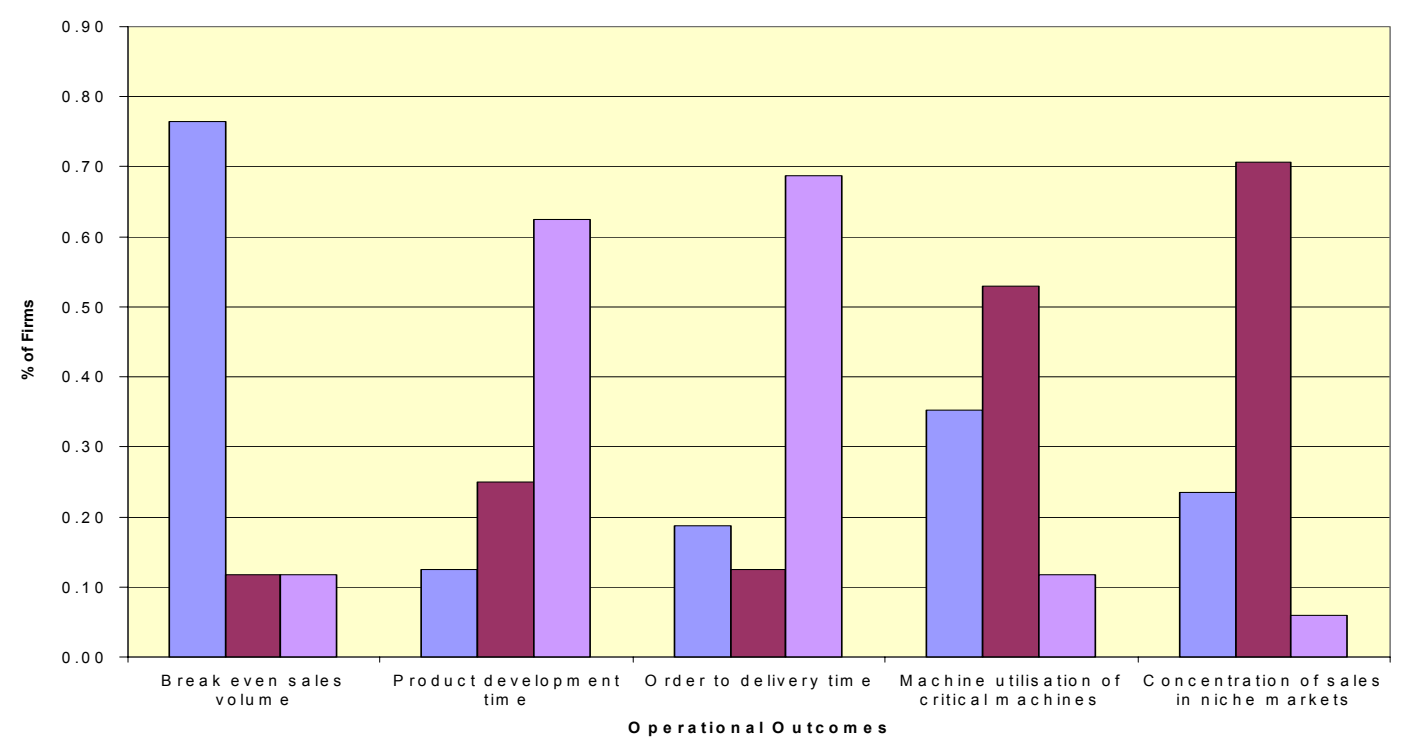

Increased

Stayed the Same

perational Outcomes

Chart 10 B: B lcycle Firms opertionaloutcomes

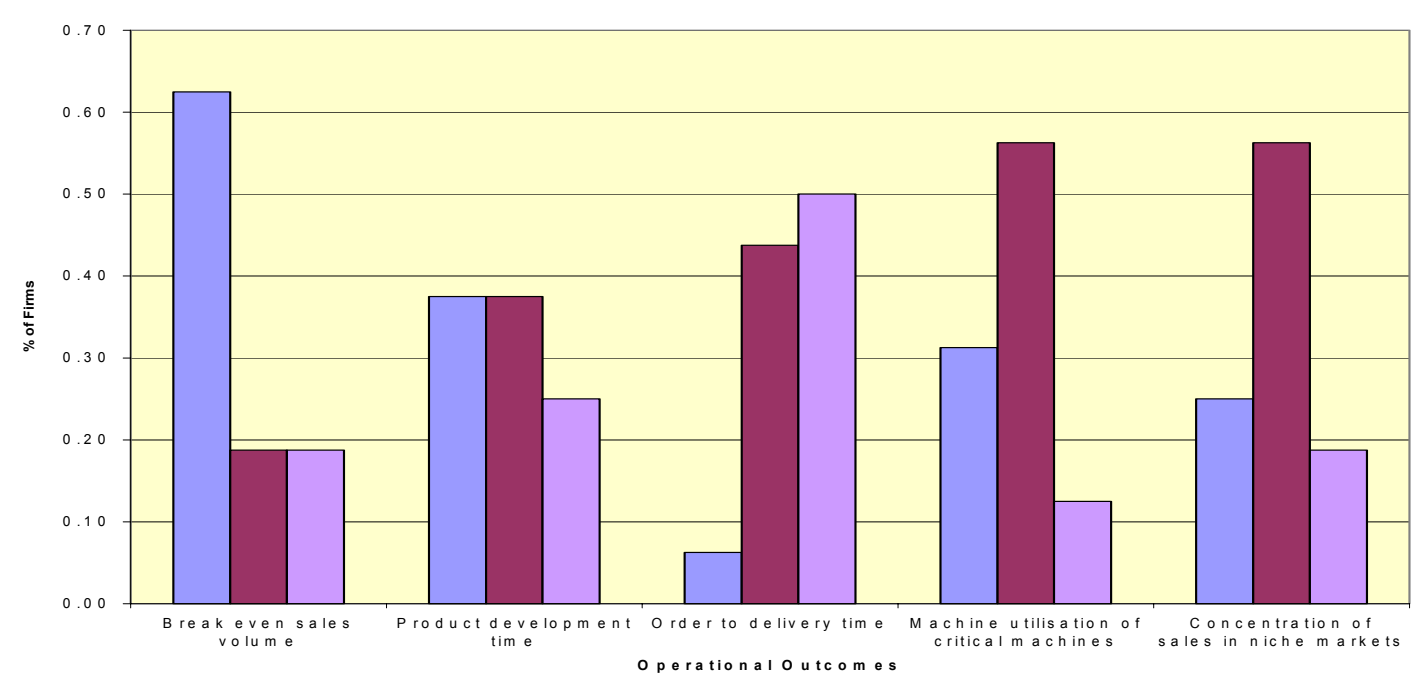

DIncreased

Decreased

Chart 10C: Hand Power Tool Firms' Operational Outcomes

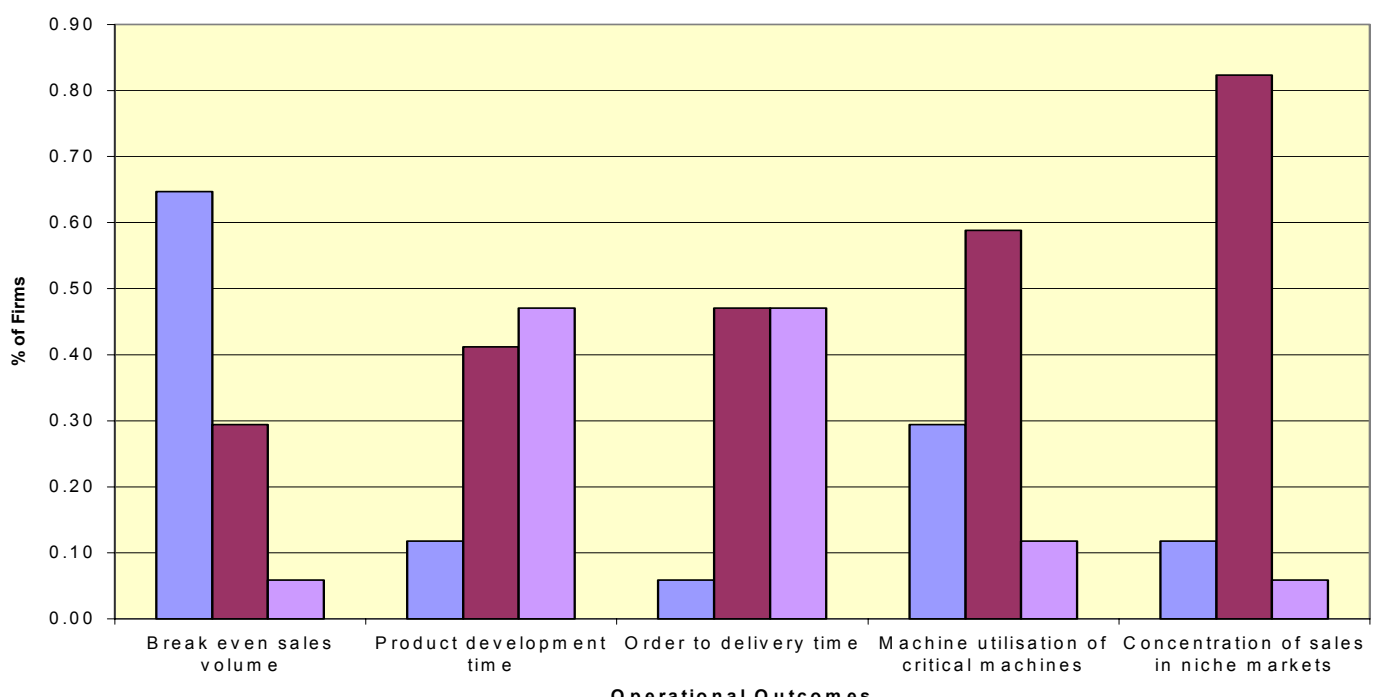


Chart 10D: Change in Number of Product Variants by Industry

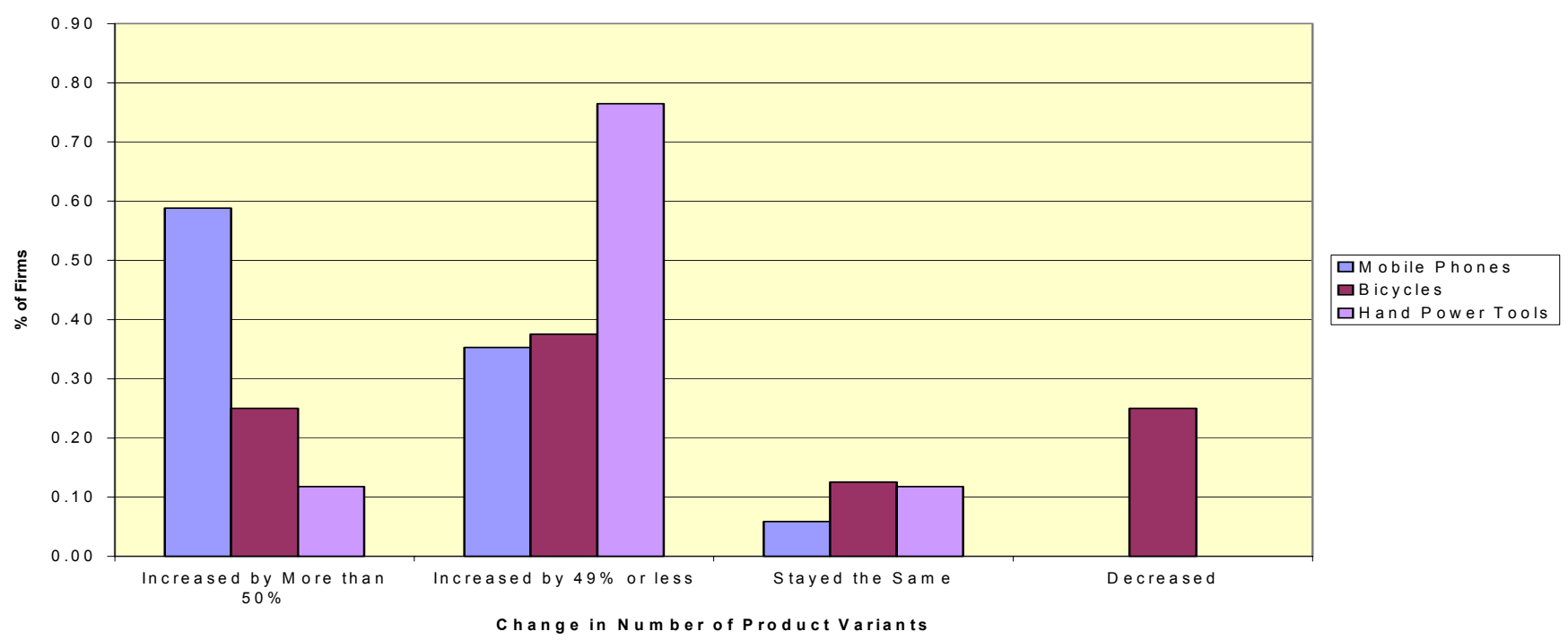

Chart 11: Sources of Future Revenue Growth by Industry

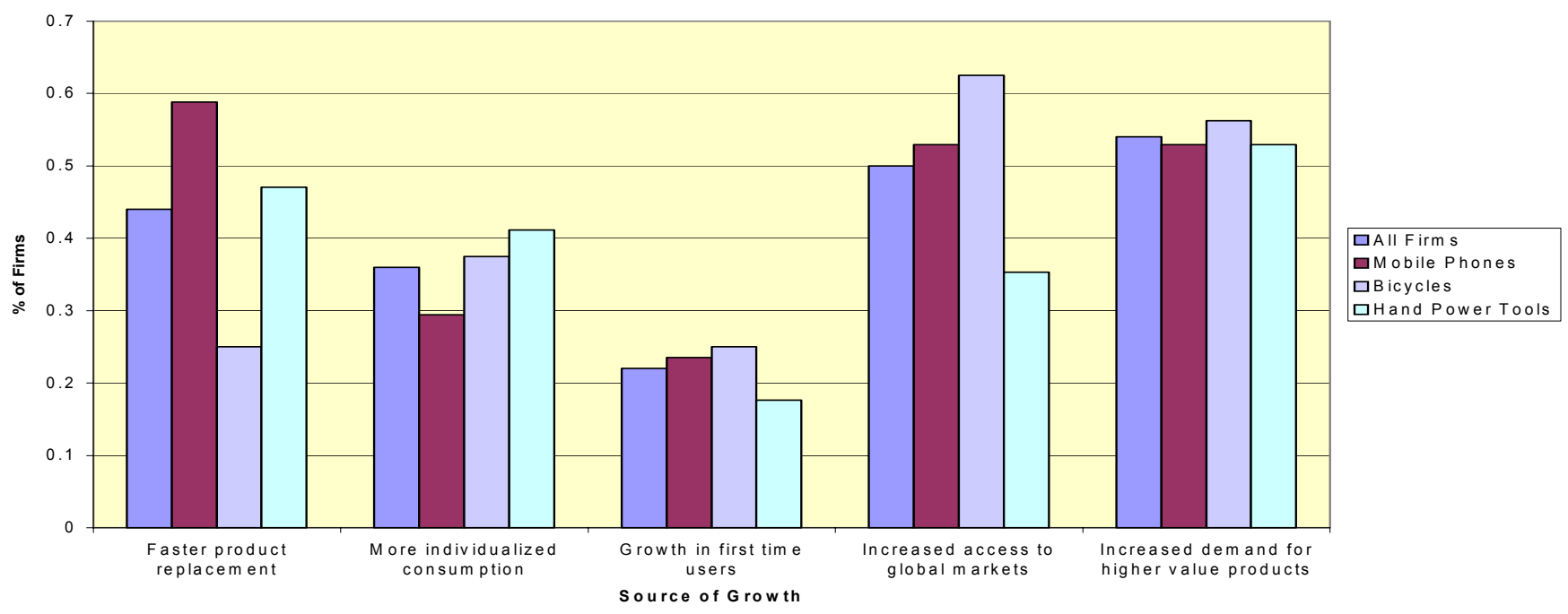


Table 8.3 Ordered Logit Regression for Time-Based Capabilities on AMT Use Patterns

\begin{tabular}{|c|c|c|c|c|c|c|c|c|}
\hline & $\begin{array}{l}\text { All Firms } \\
\text { Sample Size: } 50 \\
\text { Pop. Size: } 137\end{array}$ & $\begin{array}{l}\text { Model } \\
\text { Probability } \\
.0026 \\
\end{array}$ & $\begin{array}{l}\text { Bicycles } \\
\text { Sample Size: } 16 \\
\text { Pop. Size: } 85 \\
\end{array}$ & $\begin{array}{l}\text { Model } \\
\text { Probability } \\
.0534 \\
\end{array}$ & $\begin{array}{l}\text { Mobile Phones } \\
\text { Sample Size: } 17 \\
\text { Pop. Size: } 21 \\
\end{array}$ & $\begin{array}{l}\text { Model } \\
\text { Probability } \\
.0010 \\
\end{array}$ & $\begin{array}{l}\text { Power Tools } \\
\text { Sample Size: } 17 \\
\text { Pop. Size: } 31 \\
\end{array}$ & $\begin{array}{l}\text { Model } \\
\text { Probability } \\
.0050 \\
\end{array}$ \\
\hline & Coef. & $\mathrm{P}$ & Coef. & $\mathrm{P}$ & Coef. & $\mathrm{P}$ & Coef. & $\mathrm{P}$ \\
\hline \# of AMTs & 1.44 & .015 & -.87 & .463 & -.14 & .732 & 3.30 & .003 \\
\hline Years in Use & -.13 & .096 & -.39 & .024 & .22 & .001 & .55 & .006 \\
\hline Industry Competes on Cost & -1.53 & .002 & -1.47 & .102 & -2.52 & .000 & $*$ & \\
\hline$\mu 1$ & -3.81 & 2.000 & -7.27 & 0.007 & -3.79 & 000 & 2.77 & 2.051 \\
\hline$\mu 2$ & -1.99 & .002 & -4.96 & .005 & -1.66 & .003 & 5.44 & .003 \\
\hline$\mu 3$ & 1.26 & .067 & -.76 & .503 & 1.95 & .000 & 10.64 & .001 \\
\hline
\end{tabular}

* This variable dropped since all hand power tool firms in the sample cite cost as a product attribute driving competition in their industry.

Notes:

1. The value of the dependent variable, time-based capabilities, corresponds to the number of time-based capabilities the firms cited as giving the firm a competitive advantage. In the table, the $\mu$ 's, or ancillary parameters, model the categorisation of time-based capabilities.

2. The independent variables include the number of AMTs the firm routinely uses (ordinal variable), the number of years any AMT has been in use (interval variable), and a nominal variable indicating whether the industry competes on cost.

3. The significance of an ordered logistical regression is determined in three ways: whether the model probability is 0.10 or less; whether the probability of each ancillary parameter is 0.10 or less; and whether the $\mu$ 's coefficients increase or decrease monotonically.

4. P indicates the significance level of the coefficient in question being different from zero. 
Table 8.4 Means of Time-Based Capabilities by Operational Outcomes

\begin{tabular}{|c|c|c|c|c|c|c|}
\hline & \multicolumn{3}{|c|}{ ALL Firms } & \multirow{15}{*}{\multicolumn{2}{|c|}{$\begin{array}{l}\text { Sample Size, All Firms: } \\
\text { Sample Size, Mobile Phone } \\
\text { and Hand Power Tool Firms: } \\
\text { Population Size, All Firms: } \\
\text { Population Size, Mobile Phone } \\
\text { and Hand Power Tool Firms: }\end{array}$}} & \\
\hline Break-Even Sales Volume & Increased & Stayed the Same & Decreased & & & \\
\hline Mean of Capabilities & 1.9 & 1.3 & 0.7 & & & \\
\hline Paired with Mean of Increased & -- & 0.010 & 0.000 & & & \\
\hline Paired with Mean of Stayed the Same & 0.010 & -- & 0.062 & & & \\
\hline Paired with Mean of Decreased & 0.000 & 0.062 & -- & & & \\
\hline Machine Utilisation & Increased & Stayed the Same & Decreased & & & \\
\hline Mean of Capabilities & 1.5 & 1.5 & 2.1 & & & \\
\hline Paired with Mean of Increased & -- & Not significant & 0.016 & & & \\
\hline Paired with Mean of Stayed the Same & Not significant & -- & 0.012 & & & \\
\hline Paired with Mean of Decreased & 0.016 & 0.012 & -- & & & \\
\hline Concentration of Sales in Niche Markets & Increased & Stayed the Same & Decreased & & & \\
\hline Mean of Capabilities & 2.0 & 1.5 & 1.1 & & & \\
\hline Paired with Mean of Increased & -- & 0.005 & 0.014 & & & \\
\hline Paired with Mean of Stayed the Same & 0.005 & -- & Not significant & & & \\
\hline Paired with Mean of Decreased & 0.014 & Not significant & -- & Mobile Pho & nd Hand Power' T & rms Only \\
\hline Product Development Time & Increased & Stayed the Same & Decreased & Increased & Stayed the Same & Decreased \\
\hline Mean of Capabilities & 2.0 & 1.0 & 1.9 & 0.9 & 1.3 & 2.0 \\
\hline Paired with Mean of Increased & -- & 0.000 & Not significant & -- & Not significant & 0.000 \\
\hline Paired with Mean of Stayed the Same & 0.000 & -- & 0.000 & Not significant & -- & .001 \\
\hline Paired with Mean of Decreased & Not significant & 0.000 & -- & 0.000 & .001 & -- \\
\hline Order to Delivery Time & Increased & Stayed the Same & Decreased & Increased & Stayed the Same & Decreased \\
\hline Mean of Capabilities & 2.2 & 1.2 & 1.8 & 1.4 & 1.3 & 1.8 \\
\hline Paired with Mean of Increased & -- & 0.017 & Not significant & -- & Not significant & 0.035 \\
\hline Paired with Mean of Stayed the Same & 0.017 & -- & 0.008 & Not significant & -- & 0.012 \\
\hline Paired with Mean of Decreased & Not significant & 0.008 & -- & 0.035 & 0.012 & -- \\
\hline
\end{tabular}

Notes:

1. This table gives the means of the number of time-based capabilities for each of five operational outcomes. Outcomes are categorised according to whether there was an increase, decrease, or no change in the outcome over the preceding three years, that is, by an ordinal measure of the outcome.

2. The Adjusted Wald test was used to test for statistically significant differences in pairs of means for the different categorical measures of an outcome. There are then three possible pairs of means for each outcome: increased-stayed the same, increased-decreased, and stayed the same-decreased. Probabilities are given for all pairs of means where the probability of the difference between the means being equal to zero is less than 0.10 . 
Table 8.5 Means of Time-Based Capabilities by Measures of the Number of Product Variants for ALL Firms

\begin{tabular}{|l|c|c|c|}
\hline & Increased by more than $50 \%$ & Increased by $49 \%$ or less & Stayed the same \\
\hline Mean of Capabilities & 1.9 & 1.5 & 0.069 \\
\hline $\begin{array}{l}\text { Paired with Mean of In- } \\
\text { crease by More than } 50 \%\end{array}$ & -- & Decreased & Not significant \\
\hline $\begin{array}{l}\text { Paired with Mean of In- } \\
\text { creased by 49\% or less }\end{array}$ & 0.069 & Not significant & Not significant \\
\hline $\begin{array}{l}\text { Paired with Mean of Stayed } \\
\text { the Same }\end{array}$ & Not significant & Not significant & Not significant \\
\hline $\begin{array}{l}\text { Paired with Mean of De- } \\
\text { creased }\end{array}$ & Not significant & -- & Not significant \\
\hline
\end{tabular}

Notes:

1. This table gives the means of the number of time-based capabilities for four measures of the outcome number of product variants. The outcome is categorised according to whether there was an increase of more than $50 \%$ in the number of product variants, an increase of less than $49 \%$, a decrease, or no change in the outcome over the preceding three years.

2. The Adjusted Wald test was used to test for statistically significant differences in pairs of means for the different categorical measures of an outcome. There are then four possible pairs of means. Probabilities are given for all pairs of means where the probability of the difference between the means being equal to zero is less than 0.10 . For all firms, there is only one pair of means that returns statistically significant results. 
Table 8.6 Logit Regressions for Importance of Sources of Revenue Growth by Time-Based Capabilities and AMT Use

\begin{tabular}{|c|c|c|c|c|c|c|}
\hline & \begin{tabular}{|l|} 
Faster Product \\
Replacement
\end{tabular} & $\begin{array}{c}\text { Model Probability } \\
.0491 \\
\end{array}$ & $\begin{array}{l}\text { More Individual- } \\
\text { ised } \\
\text { Consumption }\end{array}$ & $\begin{array}{c}\text { Model Probability } \\
.0223\end{array}$ & $\begin{array}{l}\text { Demand for } \\
\text { Higher Value } \\
\text { Products* }\end{array}$ & $\begin{array}{c}\text { Model Probability } \\
.0193 \\
\end{array}$ \\
\hline & Coef. & $\mathrm{P}>|\mathrm{t}|$ & Coef. & $\mathrm{P}>|\mathrm{t}|$ & Coef. & $\mathrm{P}>|\mathrm{t}|$ \\
\hline \# of Time-Based Capabilities & -- & -- & .834 & .022 & & \\
\hline \# of Scale- \& Time-Based Capabilities & .588 & .049 & -- & -- & & \\
\hline Total \# of Capabilities & -- & -- & -- & -- & .401 & .053 \\
\hline \# of AMTs in Use & -- & -- & -- & -- & 1.38 & .026 \\
\hline Constant & -2.17 & .011 & -1.91 & .007 & 2.208 & .016 \\
\hline
\end{tabular}

* Results for mobile phone and hand power tool firms only.

Notes:

1. See Table 8.3 for notes pertaining to ordered logit regressions on how to interpret regression results. In these regressions, the dependent variables are nominal variables denoting whether the firm considered a particular source of market as important to the firm's future revenue growth. 


\section{Chapter 8 End Notes}

1 The limits of statistical analysis in describing co-evolutionary processes are discussed in the review of previous empirical studies in Chapter 7 and are again discussed below.

2 Europages and the Thomas Register of European Manufacturers are the most comprehensive sources of company information by product category for Europe as a whole (Pagell and Halperin, 1997).

3 Including among others, U.S. Bureau of the Census, Economics and Statistics Administration, 1994; Baldwin and Diverty, 1995; Gate, 1997; and Shapira and Rephann, 1996; Youtie and Shapira, 1997; and Sabourin and Beckstead, 1999. See Footnote 4 to Chapter 7.

4 An example of hierarchically dependent technologies is computerised process planning systems and computer-integrated-manufacturing (CIM), planning programs being one element of CIM systems.

5 The importance of new qualitative approaches to studying manufacturing strategy was noted as a factor in the selection of a paper based on the Chapter 7 research (Sonntag, 2003) as a best of conference paper at an international conference on strategic manufacturing.

6 The problem of large break-even sales volumes also came up in other studies, although most often as an aside. For example, the power hand tools study (McDermott et al., 1997) notes, "The cost of these systems was very high, however ... automated motor production lines cost $\$ 3$ million and to break even needed a production volume of one million motors per year." (p.73)

7 Conversation with Brian Montgomery, Association Director, European Bicycles Manufacturers Association, June 2000.

8 For example, a site promoting Italian bicycles has these company descriptions: “... creates hand made road bikes that are custom made to your specifications," and "For the past 42 years, ... has built bicycles by hand." (See http://www.virtualitalia.com/sports/bike_manuf.shtml).

9 Of course, the range is small compared to what is possible today. Pratten (1971) cites twenty models for one company as an indicator of product diversity.

10 The economic downturn in 2001 has stilled this growth, but it is likely that the industry's expansion will continue when the economy fully recovers, albeit at a slower pace.

11 AMTs from the adaptability/reconfiguration trajectory were not represented in the survey as it was known from the interview research that these technologies were being used in only the most advanced companies.

12 For the mobile phone firms where machining centres were not applicable to the manufacturing process, the Group A AMT use rate was normalised over a count of five technologies.

13 This may be because hand power tool manufacturers have been in existence longer than the mobile phone companies and because machining centers, one of the oldest AMTs, are not used in the mobile phone industry.

14 As it is assumed that residual variances of the three industries differ, a variance-constrained, pooled data linear regression was not considered.

15 Inclusion of two industry dummy variables did not prove statistically significant, so these were dropped from the final model.

16 Ranta (1997) notes in his study of the effects of AMT Use on strategy across different size firms that it is the large-scale mass producers who are competing on time.

17 Rapid deliveries, for example, are possible through holding large inventories.

18 The categorisation is according to whether there is an increase for the outcome, no change for the outcome (i.e. operations stay the same), or a decrease in the outcome, with the exception that for the number of product variants, an increase is recorded as either an increase of $50 \%$ or more or an increase of less than $50 \%$.

19 Increasing sales in niche markets is allied to visible product consumption used to signal status. As everyone cannot consume an increasing number of all products, they select product areas in which to concentrate their consumption. These consumption areas correspond to niche consumer markets. 


\section{Chapter 9 AMT-Related Trade-Offs: Evidence from the Interviews \& Survey}

A key question in judging the long-term economic viability and sustainability of AMTbased strategies is: What new trade-offs result from AMT use? Formerly, under the mass production regime, economies of scale and scope were seen as fundamentally different goals. The new production system models suggest that cost reduction and product differentiation are complementary strategies. Yet, as argued in earlier chapters, flexibility has come at the cost of increasing complexity and higher material throughputs. New directions in technology use have thus altered the choices for realising both competitiveness and sustainability.

For the firm, the wide-spread diffusion of AMTs has meant that the familiar categorisations of production systems deriving from the mass production paradigm are being replaced. The old choices no longer apply. An idea of what the emerging AMT-related trade-offs are can help firms make investment decisions on which capabilities to develop. For policy makers, the question is how to influence the direction of technological change in a more sustainable direction. To succeed, policy must align itself with the forces shaping the regime's development or act to change the direction of development in response to the unsustainability of emerging trade-offs.

This chapter collects the research findings on AMT-related trade-offs. It combines the evidence for trade-offs found in the roadmap and foresight documents with an analysis of the interview and industry survey data on trade-offs. Necessarily, the evidence presented here is preliminary for several reasons. The emergence of a new trajectory is a gradual, co-evolutionary process. Consequently, the perception of the strategic import of a new technology will vary as the technology's use environment changes. This is particularly the case with regard to the higher order, socio-economic and socio-environmental impacts of technology use. In addition, it takes time for perceptions to diffuse and consensus to form as to a technology's consequences. ${ }^{1}$ This is the point made previously in this thesis that the thinking about a phenomena evolves with an increase in its occurrence. Moreover, the analytical framework of trade-off analysis itself is new. Thus, we might expect that trade-offs as a subject of inquiry, within industry or among researchers, has received scant attention. Finally, given the scale of the transformations, empirical confirmation of particular trade-offs goes beyond the scope of this thesis. This would require the development of suitable data sources.

All the same, the evidence presented in this chapter makes a strong case for the existence of AMT-related trade-offs and the need for more research along this new direction of inquiry. 


\subsection{Emergence of the AMT Regime}

Each trajectory contains within itself the limits of its own technical and socio-economic duration. As Sahal (1985), who was among the first to research technological path dependence, puts it, "There is a limit to the growth of every system of a given form." (p. 63) With reference to manufacturing systems, this is also Clark's (1996) observation: "Like any complex technical system, a manufacturing operation confronts limits on its ability to perform in any specific dimension." (p.45)

This notion of system limits can be expressed in terms of trade-offs. To wit: the system's limits are ordained by the trade-offs inherent to the current direction of technology development inasmuch as each generation of technologies embodies specific trade-offs that firms make relative to the available opportunities for technological advance. Or, in Sahal's words: "The very processes that initiate the development of a system eventually limit its future evolution." Accordingly, each trajectory also carries within it the seeds of change. For a system to continue to evolve, the trade-offs embodied in the technologies currently in use must be resolved once they become limiting. Again, in Sahal's words, "The origin of innovations lies in learning to overcome the constraints that arise from the [system] process." (p. 63)

Through new technology use, firms learn how to overcome the strategic limits placed on them by earlier technologies. In this way, Toyota and other Japanese companies began to use computers in production in the early 1960's to reduce the costs of manufacturing a mix of products, thereby redefining the markets for consumer goods. The subsequent evolution of AMTs is detailed in Chapter 4. The analysis there points to four successive AMT trajectories embodying specific adaptations.

The adaptations by trajectory are:

Product Differentiation/Flexibility: The automation of flexible manufacturing techniques lowers the cost of product variety, making it possible to pursue low cost and product differentiation goals simultaneously.

System Optimisation/Integration: Through enhancing system interactions, the integration of manufacturing and business processes overcomes system inefficiencies characteristic of the fragmented, linear processes found in mass production.

Knowledge Systematisation/Information Management: New processes for managing knowledge enhance firms' abilities to exploit opportunities in the unpredictable, rapidly changing markets that have superseded the homogeneous, stable markets of mass production.

Adaptability/Reconfigurability: The ability to reconfigure products and processes through the instrumentation of autonomous modules addresses the need to rationalise variety and keep AMT process complexity manageable.

A shift from one trajectory to another thus signals a major technological adaptation corresponding to the resolution of a trade-off embedded in the earlier trajectory. But the emergence of a new trajectory also signals the development of a new trade-off. The investigation in this chapter focuses on what trade-offs are associated with AMT use as evidenced by what firms say concerning the challenges they face in using AMTs. 
The unmet needs of both AMT users and of the users of their products give clues as to what trade-offs are associated with AMT use. These needs develop in tandem with the use of AMTs such that different generations of AMTs result in different trade-offs. We would expect that trade-offs are felt by AMT users to varying degrees, depending on which AMTs have been implemented and the strength of their influence on product markets. The present actuality of AMT-related trade-offs is thus predicated on the use of AMTs and the development of distinct capabilities associated with their use. Moreover, production resource needs, that is, the need for new capabilities, develop in relation to changes in the terms of competition in firms' product markets, reflecting the coevolution of production technologies and product markets (refer to Figure 3.1). Thus, changes in the terms of competition also signal new trade-offs and the emergence of new capabilities in response.

In this section, we review the evidence on use, manufacturing capabilities, and product market conditions from the interviews and survey, before turning to a discussion of the evidence on specific AMT-related trade-offs. The relevant interview data are recorded in Appendix E.

\section{AMTs in Use}

AMTs are now pervasive, placing production technology use well along the flexibility trajectory. Except in cases where very particular technical functionality is required (for example, extreme high precision), conventional machine tools are no longer a choice when purchasing new equipment. The current focus of modernisation efforts are the integration technologies, and to a lesser extent, knowledge systematisation technologies. This assessment is supported by the interview and survey findings.

AMTs are used routinely in the interview population in the following frequency (refer to Table E1 in Appendix E): product differentiation/flexibility AMTs are in highest use, followed by AMTs for system optimisation/integration, and then knowledge systematisation/information management technologies. This frequency is in the same order of the technologies' appearance in the market. Among the interview participants there were very few instances of modular process technology use - in fact, most of the interviewees were, as yet, unfamiliar with modular technologies. A few interviewees also were unfamiliar with knowledge-based systems, in contrast to their ready familiarity with the other AMTs.

These findings concur with the pattern of AMT use for the three industries reported in Chapter 8 survey results (see Charts 2 and 3 in that chapter). Although there are differences in use by industry according to the technology's applicability to the industry's processes, overall the earlier flexibility and integration technologies have the highest incidence of use.

\section{Manufacturing Capabilities and Competitive Priorities}

The survey evidence presented in Chapter 8 indicates a shift towards time-based capabilities with the growing use of AMTs. However, as surmised in Chapter 4 in the section on examining trade-offs, the new AMT-based capabilities do not necessarily displace those associated with mass production but more likely represent a new frontier of competition. Three-quarters of the survey respondents cited their ability to make products of consistently high quality as a competitive advantage, while just over $20 \%$ cited their ability to 
make large volumes of low cost products. The percentages citing time-based capabilities ranged in-between these percentages for the two scale-based advantages.

In the interviews, participants were asked about the growing importance of different manufacturing objectives (or competitive priorities in the terminology used previously). The manufacturing objectives commonly regarded by the interview participants as gaining in importance over the last three to five years are increasing flexibility and increasing productivity, and to a lesser extent, faster product cycle times. These observations are consonant with a shift in strategy owing to the use of AMTs from the product differentiation and system optimisation trajectories.

Speed, in and of itself, is not frequently regarded as an important manufacturing objective, but is considered important as a means to an end. For example, one interview participant observed, "You need to be very quick, dynamic, to react immediately to every market change, to new models, to cost evaluation changes. Big customers are asking for customization. Customization is a way to gain orders. You can't afford customization by carrying inventory in your warehouse, so you need a quick cycle," but did not cite speed as an important objective.

Several of the interview comments showed awareness of AMTs' significance to the resolution of the low cost-flexibility trade-off, as in this observation: "Productivity and speed are very close to each other. We are looking to see how we can combine flexibility with productivity. Five years ago there was more of an opposition between these goals."

\section{Terms of Competition}

While cost and quality remain important competitive features in today's markets, they are considered requisite to being in the market, that is, they are not regarded so much as sources of competitive advantage but as baseline conditions for market participation. ${ }^{2}$ As one interviewee commented, "Quality is an overriding factor but it is not a "discriminator', that is it does not differentiate the product in the market, but it is a requirement," and another offered the observation that "Quality becomes just a given. If you don't make the product to the given standard, it would never even be launched." Consistent with this, the survey respondents cited cost and quality as driving competition most often (see Chart 8.7). The next most cited competition driver was delivery time, followed by delivery reliability.

In the interviews, distinctive product features, customisation, and faster product development were the most frequently named important terms of product competition. The impact of faster product cycles appears significant. One interviewee commented, "The cycle times of products are getting even shorter all the time. They have cycle lifetimes of less than a year. Nobody knows what product will be in demand 3 years from now." Another observed, "The pace is increasing year by year. For example, the automotive industry has halved their times to market in the past five years. And the same is happening in the machining industries. The speed of development is growing." As well, a number of the interview subjects linked these new terms of competition to increasing market volatility, as commented in one interview, "The markets are not stable; they are always rapidly changing. Customers are constantly asking for shorter production times and novelty products. Every year sees new ideas."

Interviewees also considered service content and rapid response to changing customer requirements as gaining in importance as means of competition. Environmental friendli- 
ness of the product was mentioned in only one interview as important to competition. Instead, from an operational viewpoint, interviewees hold the opinion, given by one interviewee, that "Environmental friendliness is not a market emphasis."

\section{2 Dynamics of Technology Use in the AMT Regime}

The AMT-based production regime arose with the application of computers and microelectronics in production and the consequent reorganisation of production to reap economies of speed. New terms of product competition have come into force and firms have developed new capabilities. This regime is now well established after three decades of wide-spread computerised production technology use. Its existence is confirmed by the dominance of AMTs over conventional machine tools. Further, the evidence points to the establishment of a core group of time-based capabilities and a corresponding set of market characteristics (refer to Table 8.1).

The interview and survey findings presented above also support the Chapter 4 analysis. Specifically, the pattern of use as detailed in the interviews and survey reflects the successive emergence of three trajectories: the product differentiation/flexibility, system optimisation/integration, and knowledge systematisation/information management trajectories. We also see evidence for the idea that while the new regime indicates new directions in the organisation of production, the new capabilities do not necessarily supplant the old ones. Hence, the market's emphasis on quality remains.

However, the sum of the evidence up to this point in the chapter, indicates no more than observed by many other manufacturing strategy content researchers that AMTs have changed the rules of market competition. Kim and Lee (1993), for example, state that, "The new manufacturing technologies increase flexibility, integration, speed, and information of manufacturing systems," (p.4) and propose a new "generic" typology to cover the choice of combining low cost and product differentiation objectives in one strategy. Other examples of AMT-based typologies include those by Kathuria and Igbaria (1997) and Swink and Hegarty (1998). But these typologies treat technological change in a static manner, suggesting that there is some optimal fit between the firm's capabilities and its business goals. By contrast, the model developed in this thesis stresses the importance of learning in the strategy process., that is, adaptation.

In earlier chapters, we remarked a continuous change in the interpretation of the socioeconomic significance of the post-mass production regime as reflected in the names attached to it. Beginning with flexible automation, the new regime has been variously described as lean production, flexible production, mass customisation, and agile production. Considering that a regime evolves through the successive applications of a new technology, this progression is not surprising. What is implied is that these characterisations have, to some degree, followed the succession of different AMT generations. But these name changes can also be read as an indication of the dynamic systems character of technology use.

While the emergence of a new regime can be understood as the establishment of a new dominant pattern of organisation in production-consumption relationships, it would be a misconception to assume this implies a continuous uniform increase in the regime's properties. For one thing, new uses are learned in specific contexts, so it is possible for more than one pathway to develop according to the initial use conditions. Mazzoleni's 
(1997) study of the different directions the computerisation of machine tools took in Japan and the U.S. is to the point here. While U.S. companies were aiming for greater machining precision, Japanese companies sought to adapt machine tools to small lot production. These choices reflected differences between the two countries in the demand composition of finished product markets. Machine tool design continued to evolve in two directions until the success of the Japanese model with regard to the organisation of production for global markets became apparent. Even then, it was some time before U.S. and European companies were able to make the transition to the flexible production model.

It is also clear that the dominance of certain production-consumption relationships in a regime does not preclude others. Small-scale production exists in mass production regimes, for example. In fact, small-scale producers may be necessary to mass production regimes as a means of answering the need for specialised - that is, differentiated - product. In the last chapter, we remarked that bicycles are one such product. Mass production machinery is highly specialised as well. As a consequence, we can reasonably surmise that improvements in sub-dominant trajectories are also likely to effect regime conditions, though not necessarily in ways that reinforce the dominant direction of technology development.

But there is another major reason for variation in regimes: new technologies engender new trade-offs - the implication being that a regime's dynamics are the effect of tradeoffs that come into being with the technologies' use. Consider that given the success of an adaptation, more and more firms will follow the new direction of strategic advantage, strengthening its effects. In the process, firms replicate the socio-economic trade-offs embedded in the trajectory. Furthermore, these trade-offs are not just the result of new technology use, but the cost (in its broader sense) of using these technologies. It may be some time before the costs become apparent, but when they do, we would expect a reaction to their appearance. To begin with, this may be a matter of shifting the costs to other parts of the system, but there will also be efforts to manage the trade-offs. However, such efforts may actually reinforce the conditions firms are attempting to address, as when expanding output to cover higher costs results in price drops, leading to new rounds of expansion.

As costs accumulate, they too alter the environment. New trajectories are then likely to be marked by considerable fluctuations in cause and effect, making their long term outcomes difficult to detect, particularly at the firm level. As Freeman and Perez (1988) have observed, regime transitions are periods of turbulence. At the industry level, learning the effective use of a new technology involves learning to cope with the associated trade-offs.

In sum, new capabilities represent an adaptive response to changes in the environment. Along with new technology uses, the Strategic Use Model argues there will be the development of new trade-offs since each trajectory contains within itself the limits of its own development. Effectively, then, the influence of trade-offs underlies the dynamics of technology use.

\section{Emerging Trade-Offs}

The Next Generation Manufacturing roadmap (Agility Forum, 1997) in outlining a course for improving manufacturing competitiveness addresses specific dilemmas "inher- 
ent in the new competitive environment" (p. 2). 3,4 Dilemmas, which are also referred to as paradoxes in the roadmap, represent the situation that "many desired characteristics of the evolving business environment are in apparent conflict." (p.4) Moreover, the report states that, "Future competitive advantage lies in the successful resolution of these dilemmas and will require the same kind of innovative thinking that solved similar challenges in the past. For example, the transition from mass production to lean production can be attributed in large part to breaking the dilemma of simultaneously achieving low cost and high quality." (p. 23) It can be readily appreciated that this notion of dilemmas is very close in concept to that of trade-offs as used in this thesis. This roadmap, however, is an exception. ${ }^{5}$ While we would expect that the challenges associated with AMT use to receive attention in the literature, there has been little research into trade-offs per se.

The discussion that follows is based on a qualitative analysis of the references to tradeoffs found in two sources: the roadmaps and foresight analyses and the trade literature on AMTs. Table 9.1 lists the trade-offs found in this literature. The four core trade-offs correspond to the four AMT trajectories.

\section{Core Trade-Off 1: Increasing Flexibility at the cost of Greater Complexity}

AMTs lower the costs of manufacturing a greater mix of products and enable shorter product development times. Not only are there more products but products can include millions of parts and interactive components (NRC, 1995). The additional manufacturing flexibility needed to produce this variety and speed up product introductions means greater process complexity, which, in turn, increases the difficulty of use and of learning the equipment's operation.

Greater capital intensity is closely related to the increasing sophistication of AMTs, since the additional capability is incorporated at greater cost. The cost of integrating new equipment into a system also goes up as the technologies become more sophisticated (NCMS, 1996). ${ }^{6}$ And, as product variety increases, operating costs per unit go up. While shorter set-up times reduce the cost of a set-up, more variety means there are more setups. In consequence of increasing product variety costs, the optimum scale for a flexible factory tends to be even greater than for a conventional plant based solely on economies of scale (Stalk, 1988).

Too much flexibility can also cause problems, such as: carrying excess stock, capacity, and labour; degradation of quality and efficiency; more time spent in changeovers and communicating requirements; and ineffective use of resources (Harvey, 1996; Efstathiou et al., 1998; Marshall et al., 1999). Poor practices like "fire-fighting" and manufacturing product variants at unknown costs get justified as "responding to the customer".

While AMTs enable faster product development times, at the same time they amplify the demand for greater product variety. The challenge is how to manage fast and overlapping product life cycles (Ranta, 1997). The question then arises of how to cover large threshold design costs that cannot be averaged over multiple units. Changes in product requirements also date equipment. Specific capabilities may be needed for times that are short in comparison to the potential lives of the process equipment. ${ }^{7}$ This means that capital costs must be amortised over shorter and shorter periods. ${ }^{8}$

In markets where the order of product introductions influence market share, volume (or scale) flexibility presents a major challenge, especially considered over the products' life cycles. ${ }^{9} \quad$ A critical need is to find methods to reduce the per-piece cost of small lot 
Table 9.1 Core AMT-Related Trade-Offs

\begin{tabular}{|c|c|c|}
\hline Core Trade-off & $\begin{array}{l}\text { Dimensions of } \\
\text { Trade-off }\end{array}$ & Summary Assessment \\
\hline \multirow[t]{4}{*}{$\begin{array}{l}1 \text { Increasing } \\
\text { Flexibility but Greater } \\
\text { Complexity }\end{array}$} & $\begin{array}{l}\text { Increasing Process } \\
\text { Complexity }\end{array}$ & $\begin{array}{l}\text { The added functionality needed to produce greater } \\
\text { product variety increases the equipment's com- } \\
\text { plexity, in turn, increasing the difficulty of use. }\end{array}$ \\
\hline & $\begin{array}{l}\text { Greater Capital } \\
\text { Requirements }\end{array}$ & $\begin{array}{l}\text { Greater capital intensity is closely related to AMTs' } \\
\text { increasing sophistication, since the additional } \\
\text { functionality is incorporated at greater cost. }\end{array}$ \\
\hline & Greater Operating Costs & $\begin{array}{l}\text { As product variety increases, the cost of additional } \\
\text { set-ups increases the per unit cost . }\end{array}$ \\
\hline & $\begin{array}{l}\text { Increasing Diseconomies } \\
\text { of Scope }\end{array}$ & $\begin{array}{l}\text { While AMTs enable faster product development } \\
\text { times, specific capabilities are needed for times that } \\
\text { are short in comparison with the potential lives of } \\
\text { the process equipment. }\end{array}$ \\
\hline \multirow[t]{2}{*}{$\begin{array}{l}2 \text { Higher Levels of } \\
\text { Integration but } \\
\text { Increasing } \\
\text { Standardisation }\end{array}$} & $\begin{array}{l}\text { Increasing System } \\
\text { Complexity }\end{array}$ & $\begin{array}{l}\text { The object of system integration is to balance } \\
\text { complex system requirements, but the more struc- } \\
\text { tured process management becomes, the less } \\
\text { robust the system is. }\end{array}$ \\
\hline & $\begin{array}{l}\text { Increasing Operational } \\
\text { Standardisation }\end{array}$ & $\begin{array}{l}\text { Systems management currently relies on hierarchi- } \\
\text { cal control schemes, which provide good definition } \\
\text { of system elements and interactions but provide } \\
\text { for little initiative at operational levels. }\end{array}$ \\
\hline \multirow[t]{3}{*}{$\begin{array}{l}3 \text { Better Information } \\
\text { Management but } \\
\text { Increasing Knowledge } \\
\text { Commoditisation }\end{array}$} & $\begin{array}{l}\text { Faster Knowledge } \\
\text { Obsolescence }\end{array}$ & $\begin{array}{l}\text { The resource value of codified knowledge has } \\
\text { grown, but knowledge also loses value quickly as } \\
\text { the rate of new product introductions increases the } \\
\text { need for new knowledge and technologies. }\end{array}$ \\
\hline & $\begin{array}{l}\text { Increasing } \\
\text { Commoditisation }\end{array}$ & $\begin{array}{l}\text { Knowledge systematisation can lead to the loss of } \\
\text { flexibility and creativity as information is processed } \\
\text { to specification. }\end{array}$ \\
\hline & $\begin{array}{l}\text { Increasing } \\
\text { Service Content }\end{array}$ & $\begin{array}{l}\text { Manufacturing to specification requires new ways } \\
\text { of determining needs and servicing the products } \\
\text { once in use, raising the service content of prod- } \\
\text { ucts. }\end{array}$ \\
\hline \multirow[t]{2}{*}{$\begin{array}{l}4 \text { Greater Agility but } \\
\text { Increasing Resource } \\
\text { Needs }\end{array}$} & $\begin{array}{l}\text { Increasing Resource } \\
\text { Commitments }\end{array}$ & $\begin{array}{l}\text { The ability to respond rapidly to changing market } \\
\text { conditions requires firms to continuously develop } \\
\text { new processes and invest in resources that may } \\
\text { have no immediate application. }\end{array}$ \\
\hline & Greater Risk of Failure & $\begin{array}{l}\text { Process stability becomes a concern as firms re- } \\
\text { configure themselves at an increasing rate. }\end{array}$ \\
\hline
\end{tabular}

production orders to that of higher volume orders (NCMS, 1996). The practice of sizing equipment for the highest projected demand, not for what is currently needed, results in the equipment's under-utilisation (Agility Forum, 1997).

In sum, the increasing use of AMTs is associated with greater process complexity and higher throughputs. Greater break-even sales volumes (more sales to turn a profit) are needed because of the higher capital and operating costs associated with the additional product variety. 


\section{Core Trade-off 2: Higher Levels of Integration at the cost of Increasing Standardisation}

Integration results in greater system efficiencies, including resource efficiency (fewer resources used per unit of activity). It is a function of the ordered relationships among multi-dimensional, coupled parameters, the object of which is to balance complex system requirements (Eureka, 1995), including those resulting from increased flexibility. ${ }^{10}$

Integration AMTs facilitate the management of complex processes through facilitating information communication, but the more structured process management becomes, the greater the risks (St. John et al., 2001). Implementation failures can result when the data flow requirements exceed the capacity of the system to communicate (Efstathiou et al., 1998). In one example, a new computerised planning system was installed to handle a multitude of parts, but because of the complexity of the sequencing task, the machinery starved for work, forcing a simplification of the product line (Greaseley, 1999). The difficulty of predicting outcomes, which grows with the range of a system, makes systems less robust, more vulnerable to failure.

While the technical goal in AMT development (and IT development, in general) is cooperative interaction of autonomous system elements in a heterogeneous, open system structure (Lleuwen and Norrie, 1997), such systems are not yet commercially available. Instead, state-of-the art systems management relies on hierarchical, deterministic control schemes (IMS, 1994; TEAM, 1997). ${ }^{11}$ These provide good definition of system elements and interactions but provide for little discrimination or initiative at operational levels (Gould, 1997; Anderson and Fagerhaug, 2001). Hierarchical systems favour static over dynamic efficiency and centralised decision-making over sub-system autonomy.

Integration thus drives standardisation. Automated interactions with customers and suppliers depend on information compatibility across multiple applications and platforms. Participants in "virtual enterprises" must follow common rules (Harrison, 1997), exerting pressure on suppliers to conform to their industrial customers' standards. Suppliers can find themselves on the "backend" of system development (i.e. obligated to participate) without partaking in the benefits (Luria, 1997; Gould, 1997). To ensure compatibility, integration may also impose constraints on the development of capabilities, especially between different generations of processes (Marshall et al., 1999). Likewise, as companies adapt their operations to meet the performance of off-the-shelf organisational systems, such as ERP, they risk their distinctiveness.

In sum, higher levels of integration can constrain firms' unique development through standardisation of the interactions between system elements.

\section{Core Trade-Off 3: Better Information Management at the cost of Increasing Knowledge Commoditisation}

The ability to manipulate large volumes of data provides firms the means to increase resource utilisation. Knowledge AMTs are instrumental in eliminating trial and error costs during product and process development, but their use may also mean a loss of opportunity to gain experiential knowledge. Next generation knowledge technologies aim to support context sensitivity, the ability to understand system user behaviour and adapt the system's responses (Cahill and Scapola, 1999), but robust methods for handling the complexity and uncertainty of information are also needed to ensure reliable operation. 
These challenges raise the question of what degree of "information automation" is best? (NRC, 1995) AMTs play an essential role in the transition from experience- to knowledge-based production by making possible the application of new knowledge domains in manufacturing. The intent is to transform knowledge into a "transportable commodity", readily applied in manufacturing processes (Agility Forum, 1997). In consequence, the resource value of codified knowledge has grown significantly. Yet, skills, knowledge and technology lose value quickly as the rate of new product introduction increases.

Information management, in turn, figures prominently in the ability to bring differentiated and customised product to market. Efforts to capture knowledge on consumer behaviour have triggered issues of privacy. On the other hand, manufacturing to specification requires new ways of determining needs, thus raising the service content of products. A major trend in customisation is to individuate products with software that is service-intensive. As each product will have different maintenance and repair requirements, service complexity will also grow with product customisation (NRC, 1995).

Past experience also indicates that knowledge systematisation can lead to the loss of flexibility and creativity. Specifying knowledge content presupposes the firm knows the value of the knowledge. Firms start to ask such questions as, "What would it look like for [my company] to place a 30 to $40 \%$ cost reduction goal on [my] university talent supplier?" (Agility Forum, 1997) Capturing knowledge by reducing the cost and complexity of knowledge systems reduces knowledge itself.

In sum, information management can end in a de-valuing of knowledge consequent to its commoditisation.

\section{Core Trade-off 4: Greater Agility at the cost of Greater Resource Needs}

The emergent dominant focus of production technology development is agility, the ability to respond rapidly to changing market and industry conditions. Agile technologies provide firms the capacity to meet widely varied customer requirements on demand. In order to sustain this rate of product creation, companies must continuously develop new production systems and best practices (Ranta, 1997).

For manufacturers, this raises the question of how to provide support for current processes while investing in equipment and people that can handle tomorrow's needs (Efstathiou, 1998). Firms must be prepared to invest in equipment that has no immediate work and to reward learning instead of performance (Agility Forum, 1997). But resource building implies unused potential (Harrison, 1997).

Adaptability, the ability to rapidly reconfigure production processes, is closely allied to agility. Adaptability increases the utilisation of resources - knowledge, people, and technology - by facilitating new ways to exploit their value. This opens the firm to new risks as resources are used more intensively. For example, the value of employees trained in a system's complexities increases the demand for worker loyalty.

Process stability also becomes a concern as firms reconfigure themselves at an increasing rate (Eureka, 1995). Speed dictates that technologies be robust as well as agile. Moreover, as the technologies become more sophisticated, the cost for development, testing, validation and training continues to increase.

In sum, increasing agility and adaptability prefigure increasing resource commitments. 


\subsection{Evidence for Emerging Trade-Offs}

The interviews and survey included exploratory questions on AMT trade-offs. In the interviews, a short explanation and examples of trade-offs were given before asking the participants whether they associated different trade-offs with AMT use. The survey included questions concerning the respondents' experience in facing different operational challenges. Two of these challenges represented AMT-related trade-offs.

\section{Interview Findings}

The interviews returned evidence of AMT-related trade-offs predicted by the trajectory analysis presented in Chapter 4 and the section above. Growing complexity related to increasing flexibility and integration was the most commonly experienced AMT-related trade-off. A significant number of the interviewees also thought that increasing flexibility is linked to increasing capital intensity and increases in required sales volumes. Also frequently mentioned was the tension between increasing system integration and its effect on operational decision-making. Not surprisingly, firms had fewer experiences of tradeoffs associated with the recent generations of AMTs from the knowledge systematisation and adaptability trajectories.

The complexity associated with AMT use was repeatedly stressed. One interviewee commented, "Everything gets so complex that it's very difficult to handle this.... These machines are a new dimension." This complexity takes several different forms. The interview participants remarked on the increasing complexity of the machinery itself, of the products, of the production process, and of the relationships between suppliers and OEMs.

One aspect of complexity that came out in the interviews is AMTs' growing service complexity. One interview participant summed the situation in this way, "As service content gets bigger and bigger, the hardware part can't cover the service price as well. Some examples include: programming, pre-assembly on through to recycling, take-back services, training. ... The service part grows and grows. ... Suppliers can't include this support in the initial price because it would then make the initial price out of range. Technology buyers aren't thinking about how they need these services. But you also have to sell services up front, set up a service account, otherwise the machine never does perform correctly." Moreover, service complexity seems to have increased partly in response to the problem of the equipment complexity. As one user commented, "Suppliers are using electronics to make things easier for the user. ... At the same time servicing of the equipment is becoming more complex."

It is worth noting in this context that process simplification was cited in only four of the twenty-one interviews as being an important manufacturing objective. This may be because the complexity trade-off forecloses this option, that is, manufacturers regard complexity as inherent to AMT use. In this regard, one interviewee commented, "We don't see process simplification happening. The processes are always very complicated. There has been talk, about it, but it does not occur in general." However, this is not always the case. Another manufacturer observed, "We are always looking at the possibility of process simplification. We look at different processes from a system viewpoint - different techniques to simplify the processes." 
Of the other aspects of the flexibility-complexity trade-off, AMT users see higher equipment costs and the concurrent need for large sales volumes as an outcome of faster product cycles and greater product diversity. One manufacturing manager explained, "[Y] ou don't need a huge volume of the same thing but at the same time you need sales volume. Of course it means higher fixed costs and consequently a higher volume to spread them over. The cost of investment must be spread over a higher number of hours to recover the costs of investment ... To work one shift is not possible." One very telling statement of the dynamics of technology use came from the CEO of a mid-sized manufacturer firm: "The important trade-off for us is the bigger break-even sales volumes. The investment [in AMTs] is getting larger and larger in each single case, which brings up the break-even volume. That in itself brings up the demand even more, because if we want to get that volume, we have to come down in price, which means that margins are smaller and smaller. Then we have to increase the volume in order for us to get the same mount of revenue. New equipment tends to drive the volumes extremely large." These are significant remarks in light of the analysis of economies of speed in Chapter 5 and the impact of higher throughputs on sustainability in Chapter 6.

A number of comments were also made as to how AMT use also drives product variety. What is significant about this development is that many manufacturers no longer feel that they have a choice as but to increase variety. One interviewee commented, 'We can't say that we introduce ten products and half of them will fail. It's not acceptable. We can't take that anymore. It was possible ten years ago. It wasn't an issue, but now the cost of the equipment has come up to a much more risky level." This statement implies that corresponding to break-even sales volumes, there are now "break-even product variety" levels. In other words, manufacturers can cost effectively produce greater product variety provided that the variety is great enough to sell.

In tandem with growing break-even sales volumes and increasing product diversity, firms must find ways to manage large production volumes of diverse products, in one manager's words: "There is a lot of variance in the volume requirements which dictates volume flexibility. The main objective is to have the ability to change the product quickly while still answering to the demands of volume."

Also significant, in terms of the dynamics described in the Strategic Use Model, is that complexity in AMT use has led to the emergence of a new trajectory stressing adaptability. Several interview subjects commented on the emergence of this trajectory. For example, one remarked that, "Modularity, more than a goal by itself is a weapon to try to challenge the complexity of [the machinery]." This statement reflects the thesis that new trajectories embody adaptations which resolve trade-offs embedded in earlier trajectories.

Interview comments regarding the other core AMT trade-offs were fewer. Of these, several interviewees offered detailed comments regarding the costs of growing system integration, indicating an increased awareness of its "costs". Many of these comments were directed at how integration impacts decision-making. With the rise in supply chain management, suppliers are seeing customer requirements forcing their operational decisions. One supplier commented, "You are much more tightly controlled and need to use the same systems. All capabilities must be declared for all the machines you intend to use to manufacture the customer's products. As soon as you apply to become a supplier they send you a huge questionnaire about capabilities. You start to be controlled even before you start to work with them." Several interview participants mentioned the limitations 
production planning systems place on decision-making. For example, one manufacturer observed, "The computers are telling you what the system should be [on the shop floor] not the other way around. The system is stiff, not responsive enough. We have heard about this from other companies. You need to have a system where you can make the changes."12 These comments suggest that integration leads to less flexibility in decisionmaking as a result of increasing standardisation. Higher levels of integration also have implications for system design, as one supplier commented, "When you select one component, you are forced to select all the other components in the different systems - these are not independent from each other."

While knowledge systematisation AMTs have not yet made the impact that the AMTs for flexibility and integration have, there is the perception of challenges to come, as reflected in this comment, "AMTs can help in managing knowledge, but the knowledge does become old rapidly. There is a lot of room to develop new organisational models the knowledge enterprise."

Solutions based on adaptability also figured in the interviews (as mentioned above), but less frequently than the mention of other trajectories. One approach is incremental change: "By introducing small systems, people can learn how to work with the system, then you can add more." One of the challenges involved in the development of adaptable systems may be their robustness. One supplier observed, "Reusing means having some mechanical modules that can be used in different contexts. These provide a high level of flexibility, but nevertheless, we have to provide reliable systems. And when you make one customer one specific manufacturing system, not sometimes, but always, you need to make some trade-offs with reliability - with a product that can compete with those offered by firms that produce big volumes of identical machines - because you have less testing for these products." This reflection implies that adaptable systems for the immediate future will be factory specific.

On the whole, however, the research indicates that the practical considerations of what constitutes agility, or adaptability, as distinct from current practices, is not yet clear to most manufacturers.

To conclude this summary of the interview data, it is worth remarking that just as there were additional aspects of the core trade-offs that emerged during the interviews, (e.g. the service complexity of AMTs and break-even product variety), the interviews also revealed trade-offs that the participants seemed to associate with AMT-based strategies in general. One was that a focus on speed of delivery might compromise product quality. As one consultant remarked, "There is a tension between quality and time-to-market."

\section{Survey Findings}

The Strategic Use Model suggests that firms are more likely to experience trade-offs specific to AMT use the more AMT-based manufacturing capabilities they have. Trade-offs related to flexibility and integration are then likely to have been encountered by a large percentage of firms as these are the oldest of the AMT trajectories.

Chart 9.1, Operational Challenges by Industry, depicts the percentage of firms, by industry, citing five different operational challenges in the industry survey. Of the five challenges, two are associated with the rise in AMT use - process complexity and system compatibility requirements. In addition, the survey asked about the firm's experience with three other challenges: changes in the total volume of demand, changes in the mix 
of products, and low capacity utilisation. The most frequently cited challenge, named by three out of five firms, is process complexity. Low capacity utilisation presents the least frequently cited problem. ${ }^{13}$

\section{Chart 9.1 Operational Challenges by Industry}

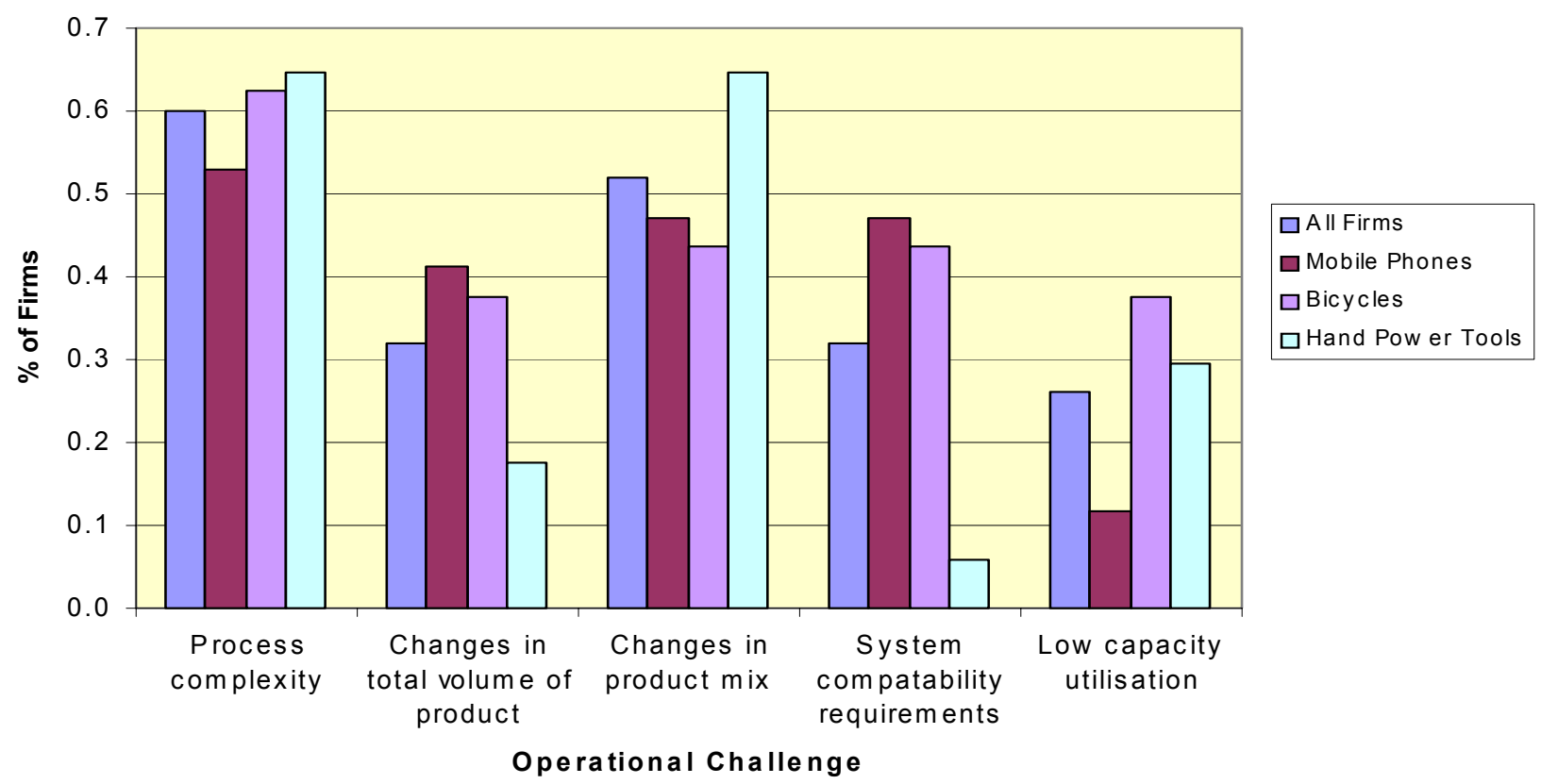

Of the five challenges, we would expect process complexity to be strongly associated with AMT use. Conversely, with respect to changes in product mix presenting a significant operational challenge, we might expect a reduction in significance with an increase in AMT-related capabilities since AMTs are purposefully designed for operational flexibility. On the other hand, the ability to change product mix rapidly does not become an operational factor until the firm begins multi-product production.

System compatibility requirements might also be expected to rise with AMT use. However, in retrospect, the selection of system compatibility requirements as a proxy for the integration/operational standardisation trade-off may have presented an interpretation problem for the survey respondents. The intent was to ask, (within the constraints of the survey), whether firms experienced a problem with a rise in the standardisation of operational requirements. Yet, the question might also have easily been interpreted as asking whether the company faced interoperability problems. The low percentage of hand power tool firms and the high number of bicycle firms citing system compatibility requirements as a challenge suggests that some respondents gave the question this latter interpretation.

The remaining two challenges have no particular association with AMT use in the literature. However, in the model validation interviews, several firms mentioned "volume flexibility" as a significant challenge, but whether this challenge increases with AMT use was not evident from how the interviewees referred to the problem.

Table 9.2 presents two-way tabulations of whether firms perceive the five operational challenges as significant (yes/no) against the number of time-based capabilities the firms have. The results for Pearson's chi-squared tests of the independence of the data are also given in the table. 
Table 9.2 Proportion of Mobile Phone and Hand Power Tools Firms that Experience Specific Operational Challenges by Number of Time-Based Capabilities the Firm Claims

\begin{tabular}{|c|c|c|c|c|c|c|c|}
\hline & & $\begin{array}{l}0 \text { Capa- } \\
\text { bilities }\end{array}$ & $\begin{array}{c}1 \text { Capabil- } \\
\text { ity }\end{array}$ & $\begin{array}{l}2 \text { Capa- } \\
\text { bilities }\end{array}$ & $\begin{array}{l}3 \text { Capa- } \\
\text { bilities }\end{array}$ & Total & \\
\hline \multirow{2}{*}{ Process Complexity } & no & .374 & .270 & .342 & 1 & .4 & \multirow{2}{*}{$\begin{array}{l}\mathrm{P}= \\
.001\end{array}$} \\
\hline & yes & .626 & .730 & .658 & 0 & .6 & \\
\hline Changes in Mix of & no & 1 & .5 & .318 & .202 & .424 & \multirow{2}{*}{$\begin{array}{c}\mathrm{P}= \\
.0009\end{array}$} \\
\hline Products & yes & 0 & .5 & .682 & .798 & .576 & \\
\hline System Compatibility & no & 1 & .922 & .754 & .298 & .775 & \multirow{2}{*}{$\begin{array}{c}\mathrm{P}= \\
.0003\end{array}$} \\
\hline Requirements & yes & 0 & .078 & .256 & .702 & .225 & \\
\hline
\end{tabular}

Notes:

1. The table gives the proportion of firms with a given number of capabilities that experience a tradeoff, i.e., the proportions for the two responses, yes/no, regarding the experience of the trade-off, sum to 1.

2. P represents the p-value for the Pearson's chi-squared statistic calculated assuming the data distribution within a finite population. It indicates the data's independence, that is, the probability that the difference between cell counts is due to chance alone.

The results for mobile and hand power tool firms support the hypothesis that there are specific trade-offs related to AMT use, but also indicate that there are varied responses to these trade-offs. Bicycle firms are not included in the findings. Much as with the hypotheses tests in Chapter 8, the inclusion of bicycle firms tended to weaken the test results or render them non-significant.

The test results show an increase in the perceived significance of system compatibility requirements by mobile phone and hand power tool manufacturers as a significant operational challenge with the number of time-based capabilities. However, as explained above, these results should be treated with caution because of the interpretation problem noted above. The test for increases in process complexity indicate a more complex response. Process complexity seems at first to present a challenge, then to diminish in importance, with increases in time-based capabilities. The three other operational challenges bear no significant relationship to time-based capabilities.

The explanation of firms' varied response to complexity is that complexity is less of a problem with the newer AMTs, as reported in the model validation interviews. As the number of AMT-related capabilities goes up, the firm becomes more adept at managing complexity. To summarise, the survey results for process complexity appear to agree with the interview findings and to bear out the emergence of a new direction in AMT development towards managing operational complexity.

Firms are also likely to experience a change in product mix as a significant challenge with rising time-based capabilities. This result, at first, seems to run counter to the expectation that AMTs resolve the trade-off between flexibility and economies of scale. However, although we might expect that the difficulty of changing product mix to decrease with AMT introduction, in practice, firms experience an increase in difficulty since they were not attempting changes in mix prior to introducing AMTs. As noted in the discussion of Hypothesis 1 in Chapter 8, rapid changes in product mix are the most AMT-dependent of the four capabilities linked to time-based strategies. These results are also consistent 
with the pattern in results from other surveys, in which the perception of the significance of a problem tends to go up once firms attempt to correct for the problem.

As a whole, the results can be taken as confirmation of the hypothesis that firms are likely to experience trade-offs specific to AMT use, the more AMT-based manufacturing capabilities they have. However, the results also suggest that a number of factors mediate firms' perceptions of trade-offs. More research is indicated to expand our understanding of how firms respond to and manage the impacts of trade-offs as they emerge.

\subsection{Sustainability in Light of AMT Trade-Offs}

Firms adapt to change in their product markets by using new production technologies, changing the structure of those markets in the process. This interaction, between the terms of competition and the use of production technologies, contributes to the complexity and rapid change that typify today's markets. Under these conditions, a firm's ability to adapt is a critical success factor. As argued in Chapter 6, adaptability is also a signature condition for sustainability. Industry's ability to respond to change is essential to realising social and environmental balance as well as economic stability. In this regard, the growing use of AMTs opens new possibilities for realising sustainability, but it also presents new constraints since firms replicate the trade-offs embedded in current trajectories.

This thesis has also argued previously that growth in throughput consequent to AMT use marks an unsustainable direction of development. Here, we review this argument in light of the trade-off analysis carried out above. The two roadmaps that hold sustainability to be a central proposition for future well-being provide a useful starting point for this inquiry.

The Gnossis roadmap begins with the observation that as the current development of integrated production networks "effect[s] not only the manufacturing industry but the society in total (and worldwide), the significance of an investigation towards future production paradigms becomes obvious." (p. 6) The report then describes the need for radical change in economic behaviour and what direction that change should take.

With regard to the current organisation of production, the report observes: "Because of market globalisation and information technology advances, producers are under ever greater pressure to increase product variety and reduce the cycle times for product design, development, and introduction." (p.10) Moreover, "Current patterns of mass production and mass consumption, and the technologies that support these patterns, result in non-sustainable forms of economic activities," (p.8) as production depends on both the absorptive capacity of consumer markets and of the environment, but these capacities are limited. The report also notes that there is doubt that "the traditional way to organise manufacturing systems is still appropriate within a turbulent market environment." (p.8)

According to the Gnossis analysis, the post-mass production paradigm calls for rapid adaptability that surmounts the limits of the deterministic approach embedded in today's technologies and the "maintenance of total value" coupled to a reduction in the volume of goods produced. The creation of open, self-organising systems is key to the development of autonomous, reconfigurable products and processes with long lives and high use values given the challenge of their complexity.

Another joint effort in describing the post-mass production paradigm is a framework developed by the IEE's Next Generation Manufacturing Enterprise (NGME) PG17 
Committee. ${ }^{14}$ The IEE committee's purpose was to provide a model that distinguished between today's best manufacturing practices and a longer term perspective needed to address the problem of mass consumption. In their estimation, "[A]n economic system based on mass consumption is in the long term unsustainable and, if left unchecked, is likely to lead to global environmental collapse." (IEE, 1998, p.2) Increasing change and uncertainty will lead to the creation of the adaptive enterprise. Their vision of the postmass production economy is one of enterprises guided by system principles and product/service combinations that offer total solutions to consumer needs. "These solutions will be reconfigured instantaneously" (p. 8) to meet changing customer requirements.

These two roadmaps describe a vision of sustainability in which the ability to reconfigure embodied technologies and systems creates added use value. This speaks to a central dilemma facing manufacturers today - how to sustain the value of their products. But to take the other seven roadmaps as representative of the manufacturing viewpoint, we see that generally these initiatives do not address sustainability issues much beyond the implications of unstable markets for firm competitiveness.

The perceived lack of connection between manufacturing activities and sustainability by the manufacturing community as a whole was also remarked on in the interviews. ${ }^{15}$ In only one interview of the twenty-one conducted was environmental friendliness cited as an important market driver. Instead the consensus appeared to be, in the words of one interviewee, that, "Environmental friendliness is not a market emphasis." Firms clearly do not frame their strategies in terms of sustainability.

However, this is not to say that firms are not concerned about environmental impacts or do not experience challenges related to sustainability. To the contrary, the evidence from the interviews indicates that sustainability issues are often pivotal operational considerations. For example, concerning the growth imperative in the new regime, one firm observed: "The important trade-off for us is the bigger break-even sales volumes. The investment [in AMTs] is getting larger and larger in each single case, which brings up the break-even volume. That in itself brings up the demand even more, because if we want to get that volume, we have to come down in price, which means that margins are smaller and smaller. Then we have to increase the volume in order for us to get the same mount of revenue. New equipment tends to drive the volumes extremely large."16 Another growing concern associated with the use of AMTs is the potential loss of experiencebased capabilities. Substituting technology for hands-on process experience can dampen creativity and hence firms' ability to respond to change.

These concerns regarding the influence of AMT-related trade-offs on sustainability and firms' adaptability point to a fundamental issue. AMT use is not only in response to exogenous change - AMTs themselves cause changes in the ways firms compete. Moreover, because of path dependence, today's technology choices determine firms' future capabilities. How firms then use technology to organise production in responding to change emerges as a critical link in the transition to sustainability.

The Strategic Use Model implies that a firm's objectives must be embedded in its technologies and practices to take hold. This follows from the persuasion that firms learn new goals as an effect of the integration of new technology into their production systems. Previously, we remarked in Chapter 6 that some of the proposed practices to increase sustainability, such as industrial ecology, are generally neutral with respect to production technology use. It is unlikely that production technologies will evolve to support the de- 
velopment of such practices without conscious effort to recast their strategic value in terms of AMT use.

The greatest potential for change lies in resolving trade-offs related to the current strategic uses of AMTs. This conclusion comes across strongly in the manufacturing technology roadmaps, both those that address sustainability and those that do not. But how we choose to resolve those trade-offs is another matter. It may be that we have the opportunity to go in a new direction. AMTs could be used to increase firms' adaptability and embed higher use values in products and processes. However, AMTs' current strategic uses has us pointed in the direction of increasing product throughput for the sake of competitiveness. This direction opposes the prudent use of our technological, social and natural resources.

What then are our opportunities for bringing resource use into balance with meeting needs? 'The next chapter looks at how we might redirect AMT use onto a path of qualitative economic development. 


\section{Chapter 9 Endnotes}

1 The evolution of the debate on climate change comes to mind in this regard. It was necessary to develop an analytical framework in order to advance policy discussions on the need for CO2 mitigation.

2 In business, this distinction is referred to as the difference between "order qualifiers" and "order winners".

3 Based on number of citations, the Agility Forum roadmap is far and away the most influential of the roadmap and foresight analyses documents analysed in this thesis.

4 The list of specific dilemmas addressed in the Agility Forum roadmap includes how to: have employee security without lifetime employment; simultaneously satisfy all stakeholder needs; practice collaborative knowledge sharing within knowledge-based competition; control core competencies without owning them; recover rising plant and equipment costs with shorter product and process lifetimes; manage company assets, when the most valuable asset is knowledge; keep domestic jobs while developing global markets; reward learning in a reward-for-doing environment; maintain national economic and military security with R\&D increasingly being done globally (Agility Forum, 1997, p. 4). It is notable that none of these dilemmas speak to sustainability.

5 It could be argued that the notion of barriers also is related to that of trade-offs. However, the analytical notion of barriers commonly implies an externally imposed limitation that can be removed, not a limitation that is inherent to the direction of development.

6 The complexity of manufacturing systems, with many machines working together in coordinated fashion, leads to complexity in their control systems. The cost of the control systems can be up to half the system's construction time and cost.

7 Flexible machine tools are designed to produce families of parts, not different generations of products or to produce different products altogether (e.g. bicycles and lawn mowers).

8 Another solution is, as Ranta (1997) discusses, is the networked company. According to Ranta, the need to resolve the question of how to prolong equipment life cycles drives companies into multiple production networks.

9 We define volume flexibility as the ability to vary production volume rates cost effectively.

10 Integration is discussed in Chapter 5 as an approach to reducing variability, hence increasing efficiency.

11 Applied to the product realisation process, hierarchical control is referred to as "deterministic manufacturing" (TEAM, 1997).

12 This quote was also cited in Chapter 8.

13 This finding may not hold during a downturn in the economy.

14 The Institution of Electrical Engineers (IEE) is the world's largest engineering professional association and is comprised of a number of engineering disciplines. The framework draws extensively on the work of Paul T. Kidd (1997), the author of Agile Manufacturing.

15 See Appendix E for a record of interview remarks regarding sustainability.

16 This observation is also quoted in the analysis in Chapter 7. 


\section{Chapter 10 Towards Balanced Consumption}

The most striking thing about modern industry is that it requires so much and accomplishes so little.

E.F. Schumacher: Small is Beautiful

Persistent growth in materials and energy consumption darkens our progress towards sustainability. What gains we make through efficient resource use are eaten away in expanding economic activity marked by growth in quantitative output. In this it seems that technological progress offers both promise and peril. On the one hand, AMTs have the potential to enable substantial dematerialisation of the economy. At the same time, there is cause for alarm that faster product introductions and greater product variety the current focus of AMT development - stimulate over-consumption in the highly industrialised countries by reinforcing our dependence on quantitative growth.

Technology use plays a critical role in firms' adaptation to changes in their competitive environments, changing the nature of those environments in the process. Thus, the growing use of AMTs raises critical questions on current policy for managing large-scale industrial transformation. In particular, can the strategic use of AMTs be used to create technological momentum, not only in the direction of greater competitiveness, but also greater sustainability?

This chapter presents a policy analysis examining the problem of over-consumption in the highly industrialised economies as it is linked to the increasing pace and scale of production activities. ${ }^{1}$ The emphasis is on framing different policy options for bringing material goods consumption into balance with social and environmental needs. The intent is to discern the elements of a technology/sustainability policy that will redirect AMT use onto a path of qualitative economic development.

\subsection{The Sustainable Worldview}

Sustainability can be understood as both a process and an outcome. In process terms, sustainability is the intentional care and preservation of human and natural resources necessary to society's well-being in the present and for the future. It is about making prudent choices in the way we live today, so that we will live in a better world tomorrow. That world will provide for economic vitality, environmental quality, and social equity. 
Examining potential targets for policy action from the dual perspective of sustainability as both process and outcome suggests that goals for developing the capability to direct the uses of production technologies must be integral elements of a policy agenda to foster sustainability. It also suggests that the development of a technology policy process that encompasses reflexive consideration of social and ecological needs is imperative to realising economic stability as it is embodied in the organisation of production.

In addition to the literature, the analysis in this section draws on the thinking from two exchanges conducted as part of the background research for this thesis: a workshop involving the participation of researchers from both the social and technical sciences and an on-line public forum geared towards policy practitioners (Sonntag, 2000c). The intent of the workshop was to develop a shared conceptual framework among the participants for examining technological, social, and economic forces driving increasing material goods consumption. The forum's purpose was to engage policy makers and concerned stakeholders in helping to define the issues involved in changing the patterns of consumption and production to attain greater sustainability.

\section{The Systems Perspective}

The foundational premise of sustainability - that sustainability can only be achieved by integrating the economic, social and ecological dimensions of human development (Hinterberger et al., 2000) - represents a conceptual shift away from a static worldview to a complex, adaptive systems perspective (Hwang, 2000). As the study of the interrelations between the three dimensions of sustainability is recent, the policy implications of this shift in understanding have yet to fully emerge. Yet, it is clear that reducing the problems of complex systems to linear cause-effect relationships no longer suffices to inform the development of viable policies that will simultaneously protect the environment, advance social justice, and maintain economic stability (Norgaard, 1994; Hinterberger et al., 2000).

Instead, strategies for change must be based on integrative frameworks that address the multiple environmental and social dilemmas embedded in current production and consumption patterns (Sonntag, 2000c). Further, the analytical difficulty of perceiving emergent system properties, which are inherent to all dynamic contexts, suggests that we need to design processes rather than outcomes (Kemp and Rotmans, 2001). ${ }^{2}$ What such policy approaches would involve in the transition to sustainability is the subject of discussion here. We are specifically concerned with the impact of technology/sustainability policy on the organisation of production. ${ }^{3}$

Recent expositions of a sustainable systems perspective (Norgaard, 1994; Hwang, 1998; Hinterberger et al., 2000; van der Leeuw, 2001) provide some ideas of what elements such processes might include. Necessarily, the following discussion focuses on the theoretical rather than actual practice, given the recent development of system's perspective policy approaches. Nevertheless, such a practice has already evolved to some degree in the various technology roadmap and foresight initiatives for guiding production system technology development. Because of the centrality of these initiatives in the implementation of competitiveness policy and thus their substantial influence on the future organisation of production, this section concludes with a brief assessment of these efforts in terms of their implications for achieving sustainability. 
The implications deriving from a dynamic systems perspective for the operationalisation of sustainable production/consumption policy are that the policy process will:

First, address the integration of the social, ecological, and economic dimensions of sustainability. The challenge is to develop a serviceable understanding of the mutual subsystem dependencies for use in guiding the co-evolutionary processes that govern system organisation. ${ }^{4}$ Basic to this understanding is the observation that the economic subsystem is dependent on the eco-sphere for matter and energy and the social sphere for information. Treating social and ecological outcomes as spillovers and externalities to the economic process is contrary to such an understanding.

Second, incorporate change as a conditional parameter of system viability. Processfocussed designs explicitly include the consideration of time (Yoshikawa, 1995). The challenge is to provide for resilience as well as efficiency in system organisation. The problem with respect to sustainability is that different time scales obtain in the ecosystem and the economy. As the dynamics of the ecosystem are slower than that of the economy's (van der Leeuw, 2001), the entropy release from production and consumption exceeds the regenerative capacity of the ecosystem. Resilience, the functional capacity to modulate system behaviour in the face of change, is then critical to maintaining economic stability without causing undue pressure on the eco-system. It is effected through increasing flexibility and diversity.

Third, allow for the uncertainty of outcomes inherent to complex dynamic systems. The challenge is to navigate change, not to control it. Moving to a different pathway requires knowledge of the possible directions in which to turn and knowledge of how different policy interventions affect our sense of the possibilities (Sonntag, 2000c). ${ }^{5}$ Given the complexity of the change process, this knowledge is best derived from experience (Kemp and Rotmans, 2001). Because system properties only emerge at the systems level and since each synthesis of system elements is unique, a process focus in policy design facilitates change. Interestingly, this principle is also articulated in a well-known paper by Hayes (1985) on strategic planning. Hayes, one of the pre-eminent management scientists, argues that planning requires a compass, not a roadmap, that is, the need is not to determine a specific way to reach a goal, but to "create an organisation that can spot and solve its own problems." (p. 116)

Fourth, use principles to guide system development. ${ }^{6}$ The challenge is to design appropriate learning mechanisms around these principles. The need is for an open system of diverse elements exciting information flow rather than the institution of a sequential reduction in information to secure particular outcomes (Nonaka, 1990). ${ }^{7}$ Instead, learning takes place through the reflexive consideration of the system's principles as applied to its operations (Sonntag, 2000c). Once the semantic knowledge is created, the system seeks similar meaning in its efforts to self-organise (Nonaka, 1990), out of which develops a shared framework (Stacey, 1993).

Fifth, provide incentives for change by changing system conditions. The challenge is to create technological momentum in the direction of sustainability. A transition from one regime to the next requires the implementation of mutually reinforcing activities that generate system benefits (Schütz, 1999). There is the need for resources to apply in reorienting existing system dynamics towards new goals (Stacey, 1993; Levinthal, 1998). 
What is to be hoped is that the application of system concepts in policy design will both advance the efficient use of resources and industry's adaptability through expanding technology choice in the organisation of production.

\section{Redirecting AMT Use}

We have argued above for a process focus in policy design and implementation. How this applies to current technology policy efforts is of relevance to understanding the possibilities for making changes in the direction of technology development. Within the technology policy arena, manufacturing roadmap and foresight initiatives, (similar to those providing the source materials for the Chapters 4 and 9 trajectory analysis), come closest to having a process focus.

It seems fair to say that the goal at stake in the majority of roadmap and foresight initiatives is growth in the guise of industrial competitiveness. This policy focus undoubtedly serves to limit the roadmap/foresight analyses to economic considerations, especially as innovation is regarded by the manufacturing community as a way to solve problems, not as something that may contribute to them (see Section 6.3 for a discussion of the debate on technological progress). But the focus on competitiveness is also an effect of industry's technology development and use practices, including the roadmap and foresight initiatives. Which brings us to the need to integrate social and ecological concerns into the policy process itself.

The amount of resources devoted to forming policy for managing AMT development and modernisation is considerable. These efforts largely determine the development paths to which both public and private resources are committed. Yet, they have failed to offer a vision of sustainable production and consumption with sufficient impetus to redirect AMT development towards sustainability. More fundamentally, they have also failed to consider what constitutes a viable change process for balancing social, environmental, and economic considerations.

Nevertheless, the roadmap and foresight initiatives demonstrate the potential for guiding the development of technology use along the lines suggested in this thesis. In particular, the rapid advance of agility onto the manufacturing agenda may be attributed to the very successful Next Generation Manufacturing project (see Agility Forum, 1997). As described in Chapter 4, these initiatives commonly involve a determination of change drivers and corresponding technology needs. The Next Generation Manufacturing project also identifies "dilemmas" in the way of achieving attributes a company should possess in order to respond to change. ${ }^{8}$ But, unlike the trajectory analyses performed in this work, there is no explicit determination of the sustainability trade-offs involved in current technology uses in the nine roadmap and foresight reports with the exception of the Gnossis project roadmap.

Interestingly, the two sustainability-focussed roadmaps discussed in Chapter 9, the Gnossis and IEE project reports, are also the most explicitly systems-oriented. For example, the IEE model of the post-mass production paradigm attempts to embody several system's principles, namely: the enterprise is a part of a total system; the whole is contained in the parts; and the whole works to contain opposites. This supports the need for a dynamic systems perspective in the conduct of these initiatives as argued above. 
It is relatively easy to imagine AMTs that would prove more sustainable than those from the current trajectories. (Some possible directions for sustainable AMT research, including those found in the Gnossis and IEE roadmaps, were discussed in Chapters 6 and 9.) It is much more difficult to engage sufficient resource commitments towards realising these new directions of development and use, at least in comparison to the amount spent on improving industrial competitiveness. ${ }^{9}$ Even if a sustainable AMT research programme were mounted using the assessment criteria discussed in Chapter 6, it would still be difficult to mainstream these technologies without a policy process for doing so. This has proven the case with past and existing sustainable technology R\&D programmes in the absence of a market pull mechanism and with programmes that are exclusively oriented towards the technology aspect of systems innovation, (see Kemp and Rotmans, 2001 for examples). It is critical that the programme's ends are embedded in its means.

If we consider sustainability to be a primary societal concern, we must then consider putting sustainability at the centre of any future AMT roadmap and foresight initiatives. Further, their implementation frameworks should be based on an assessment of the different policy approaches to changing the direction of AMT use. Such an assessment is offered next.

\subsection{Policy Options for Qualitative Economic Development}

Given the evidence of pressures to increase quantitative output stemming from AMT use, what policy options are available for moving onto a more sustainable path relative to reducing quantitative consumption? Decidedly, the transition to sustainability must involve supporting new directions in the strategic use of advanced manufacturing technologies - essentially, the reorganisation of production to decrease quantitative output while maintaining economic stability.

The policy analysis undertaken here tackles the issue of how the diffusion of AMTs affects the overall pattern of consumption and production. This approach places the analysis squarely within the context of the deliberation on policy for promoting sustainable consumption and production, (of which there are many aspects not considered here, for example, what social and psychological forces drive increasing individualised consumption), but it also links the analysis to discussion of competitiveness policy.

In Chapters 5 and 6, we examined some possible implications of growing AMT use for achieving sustainability. In particular, we noted the effects of shorter product cycle times and increased product differentiation on increasing consumption. This leaves us to contrast what a policy that focuses on changing the parameters of the current production/consumption regime might look like in comparison to other policy approaches without this emphasis. We will consider the merits of two alternatives, ecoefficiency and corporate responsibility, both of which have been widely endorsed. ${ }^{10}$ The third option involves the "seeding" of a sustainable production/consumption regime. This option builds on the principles of Strategic Niche Management and parallels the aims of a newly elaborated process-focussed policy approach, Transition Management (Kemp et al., 2001; Kemp and Rotmans, 2001).

All three alternatives rely on pro-active policy measures over regulatory or economic instruments. ${ }^{11}$ The principle consideration for this is that technology policy most often takes the form of pro-active policies. Examples are subsidisation of research and devel- 
opment and modernisation programmes. It is also difficult to imagine the political viability of any regulatory attempt to curtail production output.

The three options are not mutually exclusive and, in many ways, are complementary. This is germane to the assessment in that effective policies almost always entail a mix of policy tools. The purpose here, however, is to elucidate the strengths and weaknesses of the alternative approaches and, therefore, the analysis focuses on more non-traditional areas of policy concern. I shall first describe the approaches before assessing their potential to moderate the pace and scale of production and consumption.

Eco-efficiency has been defined in socio-economic terms as "the efficiency with which environmental resources are used to meet human needs" (OECD, 1998). Effectively, it describes an approach to de-linking industrial activity from negative environmental impacts in which firms exploit the lower costs of efficient resource use. The World Business Council on Sustainable Development (WBCSD), a leading proponent of ecoefficiency, elaborates seven criteria for realising this approach: minimising the material intensity of goods and services; minimising the energy intensity of goods and services; minimising toxic dispersion; enhancing material recyclability; maximising the use of renewable resources; extending product durability; and increasing the service intensity of goods and services (DiSimone et al., 1997).

The eco-efficiency approach dovetails neatly with the lean production operations management philosophy in its emphasis on waste reduction. Innovation too plays a key role in the eco-efficiency philosophy (see, for example, WBCSD, 2000). It is estimated that resource productivity may be increased up to factors of ten through the development and use of resource efficient technologies.

The policy thrust is to advocate win-win, market-driven solutions to inefficient resource use. As well as government-sponsored innovation programs focussing on clean and resource efficient technologies, eco-efficiency policy measures include support for the development of indicators and goals, green procurement programmes, and the promotion of research and development and information exchange on eco-efficient practices (OECD, 1998). Recently, the idea of harnessing supply chain management to the cause of eco-efficiency has gained attention (ISEE, 2001).

The focus of the corporate responsibility approach is on making business decisions that benefit the environment and society, as well as the company. It presumes the assumption of wider social responsibilities by firms and their commitment to improving the impacts of their activities on society. In this way, businesses aim for business excellence through responding to stakeholders' needs and they gain in tangible value through enhanced relations with their stakeholders.

Corporate responsibility stresses participation in public discourse and accountability to the public. Other practices include corporate community investment and cause-related marketing. Some of the main tools are stakeholder dialogues, corporate codes of conduct, and ethical and environmental auditing and reporting to demonstrate accountability and reduce liability. For directing internal operations, integrative environmental management systems are gaining acceptance.

Voluntary agreements and producer responsibility legislation are among the policy measures which support corporate responsibility initiatives. The International Standards Organisation (ISO) has instituted a special series of environmental management standards, ISO 14000, to which companies can be certified. 
The intent of transition management is to initiate system change - a transition - by turning social and technological innovations into sustainable ways of fulfilling individual and social needs. The transition management approach describes a strategy development and implementation process centring on the articulation of needs and the experiential coupling of social values, needs, and technological and organisational possibilities. It focuses on managing the transition to sustainability in a "reflexive, iterative and stepwise manner" (Kemp and Rotmans, 2001). Transition management thereby differs from traditional planning approaches in that the goals are not fixed, there is no "blueprint" to follow, and it stresses the continuous reassessment and realignment of policy. The approach is unique in that it uses existing system dynamics to stimulate change and experimentation and learning through experimentation to inform choice in strategy development and implementation. The process provides an integrative framework for guiding interactions among stakeholders and creating momentum in the direction of long-term goals.

As applied here, the aim of a transition management approach is to foster a regime shift through expanding the set of viable choices in AMT use. Learning is focused on how the implementation of new technologies with specific capabilities might shape the future. At the context-driven level, the need is for practices that enable learning about the technologies in question and the social needs they fulfil. At the concept-driven level, the need is to address the social, technological, economic and institutional conditions in which the change process takes place. The role of policy is thereby fairly broad: to provide for the validation of new technologies; to disseminate information; to aid in capabilities and trade-off assessment; and to act as a catalyst for the interaction of stakeholders.

Examples of initiatives that could support a change in the direction of AMT use include:

- Sponsoring AMT roadmap/foresight initiatives which have sustainability as the stated goal.

- Supporting the development of tools for small- and medium-sized manufacturers to assess the impact of alternative AMT choices on sustainability. In general, there is a need for expert services to assist firms in developing and implementing manufacturing strategies and supporting practices.

- Identifying product consumption reduction targets by industry and implementable means for achieving these through AMT use. One possible research avenue is analysing how firms go about creating capabilities based on firm-specific technology applications. Emphasis should also be given to understanding what capabilities are needed in developing products with higher use values.

- Providing resources for community-based networks of small companies to experiment and validate the use of AMTs in meeting local needs. Research should focus on reconfiguring the producer-consumer relationship to incorporate the articulation of socio-environmental needs.

- Sponsoring industry-wide demonstration and trial-use sites for experimenting with product manufacture on modular, user-friendly AMTs. User-friendly equipment not only facilitates the adoption of new technologies but supports experimentation in their use.

- Implementing demand management programmes for material commodities such as concrete, similar to those in the energy industry. 
- Convening stakeholders along product category lines (e.g., office printing paper) to identify how to change incentives from a quantity of product sold standard to payment for use value. For example, major car companies remit their painting subcontractors on the basis of the number of cars painted, not the amount of paint applied. This creates an incentive for the paint company to minimise paint use.

The limited agency of individual firms in affecting new directions of change suggests that there is an important governmental role in catalysing co-operative initiatives to explore new directions in AMT use. Further, as indicated from the short list above, transition management initiatives can address the issue of individual firms' adaptability, (for example, by subsidising experimentation) and hence, the possibility for redirecting technology use at the firm level. The key to this is using the internal dynamics of AMT use to create momentum in the direction of sustainability.

\subsection{Assessing the Options}

Reducing the scale of resource consumption while maintaining economic stability promises to be one of the foremost policy challenges we face in building a sustainable society. The issues involved in changing the pattern of consumption and production are complex and demand no less than the restructuring of consumer markets (World Resources Institute, 2000b). What follows is an assessment of the potential of each of the three policy approaches to support a process of transition to sustainability with respect to the strategic uses of AMTs. This is done according to a set of six criteria chosen for their relevancy to the scope of the challenge inherent to systemic change.

The inclusion of the first criteria - impact on material consumption levels - speaks to the paramount need to curb the accelerating pace of product consumption. The next three criteria reflect the significance of the co-evolutionary interdependence of product market structures and the organisation of production. These three criteria cover factors instrumental to production regime changes: impact on incentive structure and strategy; impact on firms' adaptability; and impact on the evolution of the production/consumption system. The remaining two evaluation measures, ease of policy implementation and level of policy acceptance, gauge the socio-political feasibility of the various approaches. Ease of policy implementation refers to the practicality of putting into place the institutional arrangements needed to carry out the policy. The level of policy acceptance indicates how well the policy fits the existing political paradigm.

The potential of the three policy alternatives to effect system change is summarised in Table 10.1. Each approach is discussed in terms of its potential to realise sustainable solutions according to the criteria. While assessment at this early stage of the policy debate on sustainable consumption must remain necessarily qualitative, there is also an attempt here to give some "weight" to the comparisons and to sum those weights. Otherwise, there is the risk of zeroing in on a limited few qualitative factors. For example, a policy that cuts the level of materials consumption the most may seem favourable. But if the possibility of the implementation of this policy is negligible relative to other solutions with less impact on materials consumption, then the latter policies may be better choices. The balance towards satisfying the criteria is shown in Figure 10.1, "Sustainability Balance by Policy Approach", where the criteria in Table 10.2 form the axes of the figure. The figure conveys a sense of the socio-economic trade-offs within each policy approach. 
The weighting scheme is on a relative basis, that is, the potential of the approach to satisfy a criteria is weighed in relation to the potential of the other approaches. The weighting is done on a scale of one to five, one being a low degree of satisfying the criteria, five being high. These weights are entered in the table at the bottom of each cell. It should be stressed that the weights are estimates of the relative impacts of the qualitative factors. The sums of the weights for the three approaches are represented by the bounded areas in the figure.

Following the figure, there is a comparative discussion of the three approaches.

Table 10.1 Transition Potential by Policy Approach

\begin{tabular}{|c|c|c|c|}
\hline $\begin{array}{l}\text { Assessment } \\
\text { Criteria }\end{array}$ & Eco-Efficiency & $\begin{array}{l}\text { Corporate } \\
\text { Responsibility }\end{array}$ & $\begin{array}{l}\text { Transition } \\
\text { Management }\end{array}$ \\
\hline \multirow[t]{2}{*}{$\begin{array}{l}\text { Impact on } \\
\text { Materials } \\
\text { Consumption } \\
\text { Levels }\end{array}$} & $\begin{array}{l}\text { Proven effect on reducing } \\
\text { resource intensity. Prob- } \\
\text { lem of growth effects - } \\
\text { production output rises } \\
\text { with efficiency gains. }\end{array}$ & $\begin{array}{l}\text { Inherent conflict between } \\
\text { reducing product con- } \\
\text { sumption and business } \\
\text { growth objectives. }\end{array}$ & $\begin{array}{l}\text { Articulation of socio- } \\
\text { environmental needs and } \\
\text { coupling of needs to val- } \\
\text { ues of all stakeholders. }\end{array}$ \\
\hline & Weight: 3 & Weight: 2 & Weight: 5 \\
\hline \multirow[t]{2}{*}{$\begin{array}{l}\text { Impact on } \\
\text { Incentive } \\
\text { Structure and } \\
\text { Strategy }\end{array}$} & $\begin{array}{l}\text { Uses existing incentive } \\
\text { structure - no essential } \\
\text { change in strategy. Eco- } \\
\text { efficiency measures have } \\
\text { low strategic priority. }\end{array}$ & $\begin{array}{l}\text { Integration of environ- } \\
\text { mental values into } \\
\text { corporate strategy. }\end{array}$ & $\begin{array}{l}\text { Development of use } \\
\text { value-based strategies } \\
\text { marks paradigm shift } \\
\text { with new opportunities. }\end{array}$ \\
\hline & Weight: 1 & Weight: 4 & Weight : 5 \\
\hline \multirow[t]{2}{*}{$\begin{array}{l}\text { Impact on Firm’s } \\
\text { Adaptability }\end{array}$} & $\begin{array}{l}\text { Improvements in efficiency } \\
\text { tend to reduce system di- } \\
\text { versity and individual } \\
\text { firms' autonomy. }\end{array}$ & $\begin{array}{l}\text { Reflexive consideration of } \\
\text { socio-environmental goals. } \\
\text { Possible reduction in cor- } \\
\text { porate liability. }\end{array}$ & $\begin{array}{l}\text { Focus on development } \\
\text { of dynamic capabilities. }\end{array}$ \\
\hline & Weight: 1 & Weight: 4 & Weight: 5 \\
\hline \multirow[t]{2}{*}{$\begin{array}{l}\text { Impact on } \\
\text { System Evolution }\end{array}$} & $\begin{array}{l}\text { Improvements are incre- } \\
\text { mental and rarely change } \\
\text { relationships between sys- } \\
\text { tem elements. }\end{array}$ & $\begin{array}{l}\text { Can motivate strategic } \\
\text { change. Constraints on } \\
\text { firms assuming responsibil- } \\
\text { ity for global common's } \\
\text { problems. }\end{array}$ & $\begin{array}{l}\text { Concurrent change in } \\
\text { consumption and pro- } \\
\text { duction patterns; no } \\
\text { assumption of technical } \\
\text { fixes. }\end{array}$ \\
\hline & Weight: 2 & Weight: 3 & Weight: 5 \\
\hline \multirow[t]{2}{*}{$\begin{array}{l}\text { Level of Policy } \\
\text { Acceptance }\end{array}$} & $\begin{array}{l}\text { Win-win solutions guaran- } \\
\text { tee acceptance with small } \\
\text { cost to learn. Fits with } \\
\text { growth paradigm. }\end{array}$ & $\begin{array}{l}\text { Proactive approach results } \\
\text { in improvement in busi- } \\
\text { ness results. Resistance to } \\
\text { assuming responsibility for } \\
\text { reducing output. }\end{array}$ & $\begin{array}{l}\text { Experimentation is } \\
\text { costly. Allows for stake- } \\
\text { holder involvement. }\end{array}$ \\
\hline & Weight: 5 & Weight: 3 & Weight: 3 \\
\hline \multirow[t]{2}{*}{$\begin{array}{l}\text { Ease of Policy } \\
\text { Implementation }\end{array}$} & $\begin{array}{l}\text { Viewed as the pragmatic } \\
\text { approach, particularly by } \\
\text { business. }\end{array}$ & $\begin{array}{l}\text { Consistent with current } \\
\text { business excellence prac- } \\
\text { tices. }\end{array}$ & $\begin{array}{l}\text { Focus on long-term than } \\
\text { short-term solutions, and } \\
\text { radical change that pro- } \\
\text { ceeds through gradual } \\
\text { adaptation. }\end{array}$ \\
\hline & Weight: 5 & Weight: 4 & Weight: 3 \\
\hline
\end{tabular}




\section{Figure 10.1 Sustainability Balance by Policy Approach}

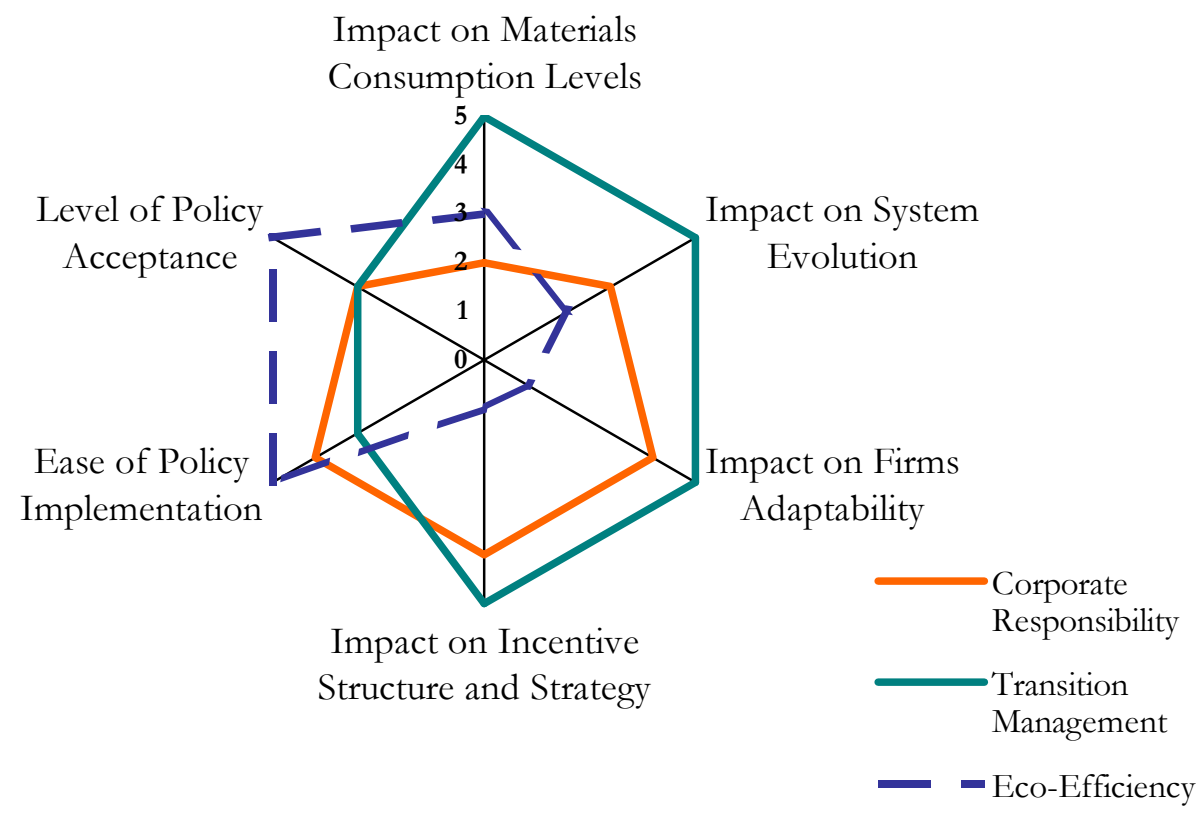

In terms of stimulating a regime shift towards sustainability, the eco-efficiency approach is seen to have the least potential, largely because existing incentives to increase output go unchallenged and because efficiency is promoted over firms' adaptation to local ecosystem conditions (Hukkinen, 2001). Moreover, gains in resource efficiency are offset by increases in production output. This accounts for the moderate impact on materials consumption levels. As remarked in the OECD (1998) document on eco-efficiency, "Where efficiency measures alone are sought, there is a risk that increases in economic activity will outweigh any reduction in environmental impact per unit of activity." (p. 39) As to the potential for system change, the eco-efficiency approach fits neatly within the framework conditions of the current AMT trajectories, which explains its popularity in the business community. But this alignment also indicates the lack of incentives within the approach for reducing production output. It is also likely that eco-efficiency measures reinforce current productivity strategies that reduce system diversity and firms' autonomy. Also, the eco-efficiency approach requires that additional effort must be made to move from consideration of the site-specific to industrial systems as a whole (DiSimone et al., 1997), indicating a focus on sub-optimisation and a lack of a system's perspective.

By contrast to eco-efficiency, the corporate responsibility movement is expected to have a substantial impact the firms' adaptability to changing market/regime conditions and a moderate impact on the regime's incentive structure. As the name for the approach implies, firms engage in a process of consciously reviewing their corporate objectives in light of their social and environmental responsibilities. In and of itself, this process can help to increase the firm's adaptability and may help to change the incentive structure.

However, there is no particular reason to believe that the responsibilities that the firm voluntarily chooses to act on will include those which would require the firm to reorganise production. A review of case studies at one site devoted to firms in the corporate responsibility movement turned up no cases where the firm marketed either a longer life 
or a higher use intensity product. There is also the question of how much is actually being invested in these efforts. For example, British Petroleum spent more money in 2000 advertising its green image than it did on its renewable energy programme in 1999 (White, 2000). It would also seem that many of the corporate responsibility efforts todate, while entirely laudable in their philanthropic intents, have no effect on product competitiveness, that is, they have little intrinsic strategic value - hence, they may not last. Further, the number of businesses actively participating in the corporate responsibility movement is very small. It is likely the resources required to do so effectively (with hope of engaging competitive advantage) may be well beyond the typical firm's means (Business and the Environment, 1995). Policy, however, can help to strengthen the impacts of this approach. An example is producer responsibility laws that make producers responsible for the disposal of packaging waste. Whether this contradicts the spirit of "corporate responsibility", i.e. forces responsibility by policy, remains to be argued.

Of the three policy approaches, transition management holds the greatest promise for effecting a regime shift. In this approach, the effort is to strengthen firms' ability to adapt to changes in regime conditions through supporting their learning new AMT uses. It builds on existing system dynamics where there is a need to resolve the tension between the effective use of resources and market unpredictability. The decision to invest in building a firm's dynamic capabilities is usually a top down management decision, but change also comes from the bottom up. Firms learn new strategies as an effect of incorporating technology with new capabilities into their production systems. And as new production technologies come into use, new opportunities open to satisfy consumption needs. In effect, change in technology use changes firms' strategy and incentives.

Further, this approach allows for explicit consideration of stakeholders' needs as critical elements in the changing regime, promoting system evolution. As one example, consider that the capacity to flood the market with a plethora of product variants (the core capability in a mass customisation strategy) is a far cry from the ability to reconfigure products on order to fulfil immediate needs. The latter strategy supports extension of product life, whereas mass customisation, as it is now practised, stimulates ever faster product replacement.

Policy measures can do much to advance transition management goals and in this lies its weakness. Firms may be coming to the realisation that adaptability is the new competitive frontier, but there is the still the tendency to persist with the old ways of doing things. For firms to change requires a considerable investment of resources. The most obvious drawback in the transition management approach is the cost of learning through experimentation. But the potential of transition management to address the challenge of qualitative economic development then again justifies public investment.

\subsection{Towards Balanced Consumption}

The interdependency of market needs and the strategic use of AMTs will influence the success of any policy to reduce consumption and promote sustainability. This dictum applies equally to accounting for the effects of current AMT use on increasing consumption levels and to the possibilities for redirecting AMT use onto a path of greater sustainability.

The present direction in the strategic uses of AMTs spurs increases in materials consumption as an effect of faster product introductions and greater product variety. In the 
view of Hiroyuki Yoshikawa (1995), genitor of the international collaborative research program on intelligent manufacturing systems, these developments have led to a deluge of goods that do not answer real consumer needs or wants. But technological change can also provide the impetus for change. In AMTs there is the technological potential to develop manufacturing strategies that foster the balanced use of resources in meeting societal needs.

We have said that firms learn new ways to achieve their business goals as an effect of the process reorganisation brought on through the integration of new capabilities into the production system. It stands to reason that firms with a developed understanding of the strategic range of AMTs could use them to experiment in new ways to create products with higher use values. Flexible, reconfigurable technologies could extend the range of output levels at which profitable operations are possible to smaller scales suitable for local economies. The development of dynamic, adaptive capabilities could enhance the ability of firms to respond to changes in environmental and social conditions, as well as to changes in market signals. Firms could learn to satisfy consumption needs through sustainability-based strategies, breaking with their dependency on quantitative growth.

We are also concerned with the process of making technology choices. Moving to a different pathway requires knowledge of the possible directions in which to turn and knowledge of how our interventions affect our sense of direction. How might production technology use support our becoming a learning society? Experiential knowledge generated at the point of production is key to adaptability.

Ultimately, we are interested in technology supported system innovation to bring about change in entire regimes of use. Fundamental to this is the reorganisation of production. To this end, we must first develop policy that will advance the viability of sustainabilitybased manufacturing strategies for the goal of qualitative economic development. The eco-efficiency and corporate responsibility movements are promising starts. More should be done.

This policy analysis concludes that sustainability lies in the direction of reducing the pace and scale of materials transformation processes to achieve balanced consumption. Transition management is a policy approach that could support the necessary change. 


\section{Chapter 10 End Notes}

1 The methodology used to conduct the analysis follows that of a formal policy analysis where the objective is to reveal trade-offs among different policy options (Meltsner, 1975; Patton and Sawicki, 1986). The intent is more structured than would generally be expected of a policy issue analysis based on a disciplinary framework, e.g. economics.

2 The system of reference in this analysis is the production/consumption system except where noted.

3 As discussed in Chapter 6, much of the sustainable consumption policy discussion focuses on the need to modify consumer practices and there are many important policy initiatives to this end. The intent here, however, is to understand how policy addresses AMT use regarding its effect on the organization of production and consumer markets. For a discussion of how technological change affects consumer choices, see Røpke (1999, 2001a, 2000b).

4 Here system refers to the integrated socio-natural system, whereas sub-systems refer to the constituent eco-, the socio-cultural and economic systems. However, the injunction to develop a model of system interactions is the same approach as taken in this thesis.

5 This is to say that the policy process, like technological change, also exhibits path dependence.

6 One example of such principles are the Natural Step programme's "system conditions", e.g. "In order for a society to be sustainable, nature's functions and diversity are not systematically subject to increasing concentrations of substances extracted from the Earth's crust." (ISEE, 2001)

7 The open versus closed system design is reprised in the Linux-MS Windows operating systems debate.

8 See Chapter 9 for additional discussion on this point.

9 This is no different than what is taking place with regard to energy technology development. Even though the environmental limits of carbon-based energy technologies have been known for some time, the amount of funding going into renewable energy development is dwarfed by the problem.

10 One could reasonably debate whether eco-efficiency constitutes a policy approach, as opposed to a policy or a management strategy; and whether corporate responsibility and transition management are policies, as opposed to policy approaches. The difficulty comes in comparing policy options that are a mix of content and process and that emphasise these in varying proportions. However, the three options represent distinct strategies for effecting a transition to sustainability and thus serve the intent of a policy analysis.

11 The emphasis in the analysis is on government measures, but in actuality "policy" describes the joint actions of both public and private actors and civil society (primarily non-governmental/non-profit organisations). This is particularly true of pro-active policy in which government tends to play a supportive or catalyst role. 


\section{Chapter 11 Sustainability as Process}

Each moment is all being, is the entire world. Reflect now whether any being or any world is left out of the present moment.

Dogen: Shobogenzo

The power of new technology to transform everyday life and change the structure of social and economic institutions confronts society with profound choices, holding both opportunity and risk. The scale and complexity of these transformations, and the speed at which they occur, also affects society's ability to anticipate and prepare for change. Often we find that we have made choices without ever having paused to consider whether there was a better alternative, a different direction we might have taken, another way to live.

But consequences arise. The use of information technology to speed up production has advanced the rate of product consumption to the point of our causing grave, irreversible harm to the environment. In meeting our needs, we risk the economic well-being of generations to come. Even now, people worldwide are being made to suffer the demands of the wealthy countries' rampant consumerism. To then propose that what we need for a better future is the capacity to produce an ever greater assortment of products is to be blind to what industrial growth is now costing us. It is at this moment that we must consider the possibilities for changing our present unsustainable pattern of consumption and production.

This thesis presents the argument that the dilemmas we face in reducing the scale of resource consumption to sustainable levels concern the question of how to organise production for the promotion of our collective well-being. Moreover, it contends that firms' operational strategies, as conditioned by the technologies they use, shape product market formation and growth. Hence, we face a societal choice concerning the direction of production technology development. More immediately, we need to develop the means to exercise that choice. To this end, support for alternative uses of AMTs ought to be a decided focus of sustainable consumption policy. This focus is not proposed in lieu of policy efforts to promote sustainable consumer practices or green product development. Rather, in a co-evolutionary world, policy initiatives aimed at changing the direction of production technology development and those focussed on changing the patterns of consumption will reinforce each other. 
In this final chapter, I return to the themes introduced at the thesis' beginning - growth, sufficiency, and technology choice - but especially technology choice, since realising a vision of a sustainable world hinges on the means we use to take us there.

\section{The Limits of Consumption}

The interaction between consumption growth and economies of scale is a well-known feature of mass production regimes. The declining costs of producing goods as a function of economies of scale leads to an increase in demand, which in turn provides industry with the incentive to seek additional economies of scale.

In mass production regimes, the limits of consumption are defined by a dwindling unmet demand for standardised goods. At some point, people want something other than a duplicate of what they already have. Greater product variety, however, requires flexibility in production, which, before AMTs, precluded economies of scale in multi-product production. The structural economic crisis that marked the mid-1970s, when growth halted as an effect of saturation in the markets for standardised product, opened the way for the emergence of a new system of production based on automating flexible manufacturing techniques using the new information technologies (Piore and Sabel, 1984). ${ }^{1}$ The resultant increase in product variety effectively raised the ceiling on market saturation and consumption growth resumed in the highly industrialised economies.

Faster product cycles and low-cost product variety define today's markets, just as economies of scale and low-cost standardised product defined mass production. This structural shift in production and consumption reflects the evolution of time-based manufacturing strategies as embodied in AMT use. Since it is no longer possible to compete on cost alone, manufacturers must produce an ever greater variety of products. Continuous expansion in product choice is based on the capacity to quickly design, produce, and deliver highly differentiated product at prices close to that of mass production. Mass customisation - the organisational means of "keeping customers satisfied" by churning out new product - is widely held to be the future of manufacturing.

But time-based strategies are critically dependent on speed as their organising principle. ${ }^{2}$ Speed reduces the operational costs of product variety providing for economies of scope, but only at greater volumes than in product-specific production, that is, AMTs lower the cost of manufacturing a mix of products, not small individual lots. ${ }^{3}$ Also, owing to their greater complexity, AMTs cost more than conventional machinery. In turn, higher operating and capital costs amplify the need for scale in production. Thus, given speed's multiplier effects on economies of scale and scope, the effective use of AMTs puts pressure on firms to grow through increasing output.

From a socio-ecological standpoint, time-based strategies portend unsustainable growth in product throughput. Manufacturers offer more variety at declining prices to get consumers to buy more of their product or (as it may be) to meet consumer demand. But the increase in speed needed to produce this variety is paid for by increasing throughput rates. In consequence, increasing consumer demand for differentiated product figures critically in productive efficiency. Effectively, the demand for greater product variety and the means of producing this variety co-evolve.

AMT use also raises new contradictions for firms in their efforts to overcome the limits to consumption. Firms' expectation of revenue from faster product replacement and more individualised consumption grows with the use of AMTs, ${ }^{4}$ which leads to further 
investment in AMTs. To realise a return on these investments, manufacturers must keep the products coming, but as new products enter the market, premiums shift from established products to the latest offering. Thus, as firms strive to keep up with the accelerating pace of product differentiation, they open themselves to the risk of devaluing their current product. Under such conditions, it is difficult to sustain profitability.

In the long term, it would then seem that endless product variety cannot serve to overcome either the ecological or economic limits to consumption. This conclusion can be derived from an analysis of time-based strategies, as in Chapters 5 and 6 of this thesis, or arrived at through examining firms' strategic behaviour in relation to the growing use of information technology in production. This latter approach is the basis for the development of the Strategic Use Model in Chapters 3 and 4 and its validation in Chapters 7 through 9 .

\section{Adapting to Change}

Current patterns in industrial transformation stem largely from AMT use. AMTs have brought new economies of scope and scale into play in manufacturing, particularly in the discrete parts industries. They have enabled functional integration across organisations with consequent major structural realignment in a number of manufacturing and service industries. Information processing is blurring the division between services and manufacturing, leading to the development of the "knowledge economy". And the emerging ability to reconfigure production processes at will presages the age of "variable capital".

The magnitude of these developments argues for a more complete understanding of the effects of technological change in relation to the firm's ability to adapt to changes in its environment. We are concerned with such questions as: What market and industry forces are currently driving firms' technology choices? And what alternative paths might be open to industry? But to effect a change in the direction of technology use, the theory must also comprehend the process of technological change as it influences the organisation of production.

The Strategic Use Model was developed with such a purpose in mind - to explain the interdependency of market demand and the strategic uses of AMTs. It offers an explanation of the role of manufacturing strategy that is complementary to its depiction in prevailing models of manufacturing strategy, particularly as described by the paradigm and dynamic capabilities models.

In common with the paradigm representation of manufacturing strategy, the Strategic Use Model suggests that, to succeed, a firm's technology choices must fit the prevailing technological paradigm. It also maintains, as do paradigm models, that technology choices will result in different strategic outcomes given the specificity of each technology application, that is, there is room for strategic play in the use of AMTs. In point of fact, there is additional emphasis in the Strategic Use Model on experiential learning as key to the strategy process. This dimension of the model gives added weight to the role of implementation in identifying and developing strategic opportunities.

The Strategic Use Model also advances the need for dynamic capabilities. It submits that adaptability is contained in strategy development and implementation. Specifically, adaptability is the development of capabilities that give the firm the power to reorganise production in response to emerging opportunities and challenges. But the model also makes the case that technology choices involve irreversibility because of path depend- 
ence. The question then becomes what capabilities position the firm to respond to change without limiting its future potential, that is, what trade-offs are involved. For example, the additional manufacturing flexibility needed to produce greater product variety and speed up product introductions means greater process complexity. What capabilities are then needed to manage this increase in complexity?

Rapid change and market unpredictability appear to be dominant features in the current regime. Shorter product cycles, rising demand for customised product, and the increasing pace of product introductions are the regime's hallmarks. These conditions have led to competitive strategies that emphasise flexibility and responsiveness to customer demands - strategies which perpetuate market volatility.

Missing from these strategies is a process for assessing the impact of path dependence in production technology use on the organisation of production and, by extension, product market structure. The Strategic Use Model maintains that AMT use is not only in response to exogenous change - AMTs themselves cause changes in the ways firms compete. Because of path dependence, today's technology choices determine firms' future capabilities. How firms then use production technologies to respond to change emerges as a critical link in the transition to sustainability.

\section{Sustainability as Resolution}

From a resource perspective, the long term viability of strategies that depend on continuous growth is problematical, but not only for ecological and social reasons. Two dilemmas, in particular, stand out with current firm strategies to accelerate the pace of product differentiation.

First, there is the problem of the drift towards commoditisation, the diminution of product value as firms compete for market share by continuously introducing new product variants. To compete on this basis, firms must undergo continuous change. The resource costs to firms in terms of superseded products and processes, and often as not, the loss of organisational knowledge as firms restructure, are undoubtedly tremendous.

More significantly, time-based strategies ratchet up the problem of market volatility. The interaction between the growing use of AMTs and the increasing demand for differentiated product creates a powerful technological momentum in the direction of more and more product variety and faster and faster product introductions, with the consequence that firms must grow in order to compete. But firms are hard pressed to realise the value of their investments if they also have to lower prices in order to increase sales.

Fundamentally, these dilemmas involve a conflict between the accelerating use of resources in order to pursue time-based strategies and industry's ability to acquire and develop these resources without undue social and environmental damage. In the context of the Strategic Use Model, these dilemmas reflect the firm's strategic behaviour. To wit: there is the drive to exploit new opportunities in order to gain additional resources, but there is also the need to make effective use of available resources in pursuing these opportunities. The current imbalance between these objectives is found at all levels of organisation in the production/consumption system - the firm, industry, society, and the eco-sphere. The increasing speed of production beggars our resources.

This thesis proposes that firms' competitive advantage ultimately depends on their ability to use resources strategically, that is, to balance the pursuit of new opportunities with the 
effective use of resources for this purpose. Which is but another way is to say that the way forward lies in resolving the trade-offs embedded in current AMT use. I would argue that the practice of sustainability, the care and preservation of resources, is such a resolution. In effect, we need to put sustainability at the heart of manufacturing strategy.

By reason of the complexity of the interactions between the economy and the ecosphere, sustainability is closely allied to adaptability. Dynamic capabilities enhance firms' ability to balance their resource use by nurturing their ability to respond to change. At the centre of a sustainability-focused strategy then is the cultivation of strategic change practices. To this end, two of this study's key findings are: firms learn how to manage change through experience, and an incremental, gradual approach to radical change and developing new capabilities supports deeper learning. Implicit in these findings is the observation that adaptation requires the reflective consideration of choices. One such practice is the examination of the trade-offs embedded in production technology trajectories. Firms with a developed understanding of the strategic range of AMTs can use them to experiment in new ways to create and preserve value.

In turn, experimentation informs choice in strategy development and implementation. Adaptive capabilities develop out of firms learning how to manage the dynamic relationships involved in resource use. As technology use is embedded in local, socio-historical contexts, this is mainly an experiential process. Experimentation is essential to this learning, particularly during regime transitions. Managing transitions is, in essence, an iterative, incremental process based on experiential learning.

Sustainability-focused manufacturing would also support the creation of higher use values through the care and preservation of product and process value as embodied in the organisation of production. ${ }^{5}$ The opportunity is to point AMT use in a direction that both supports firms' long term viability and the balancing of environmental, social and economic concerns. Moreover, capabilities based on the creation of use value offer firms a strategic advantage as use value is predicated on a practical understanding, coming from the firm's unique experience, of how needs are met. This last point is crucial, because it is through grounding change in actual practice that change actually occurs.

Thus, use value-based strategies address two weaknesses found in current approaches to sustainable strategy development. By contrast to current approaches, use value-based strategies take into account the strategic value of unique manufacturing capabilities and they address the root problem of unsustainable consumption growth - the organisation of production in relation to consumption.

One can also reason that sustainability-focused, use value-based strategies will also lead to the emergence of vibrant local economies. To begin with, these strategies are founded on the practice of prudent resource use that rests on a knowledge of local eco-system relationships. High use value products are also likely to require long term relationships between product suppliers and users at the local level as an understanding of the product user community's needs develops out of a local dialogue between producers and consumers in deciding what those needs are and how they can be met. Such strategies then promote the diversity necessary to local economic development and to the long-term vitality of manufacturing. In locally diversified economies, scale is not the objective. The opportunity, instead, is to meet needs through developing local relationships based on sustainable resource use. 
The future lies in resolving trade-offs inherent to the current strategic uses of AMTs, of which the most daunting is the current regime's dependence on quantitative growth. The challenge in redirecting AMT use to a path of greater sustainability is to let go of the belief that industrial growth is necessary to economic well-being. ${ }^{6}$ However, the idea of redirecting AMT use towards the development of strong local economies is not to propose a definitive solution. There are no definitive solutions, least of all a particular set of technologies, or even the promise of a never-ending flow of new technologies. But there are visions. The vision put forward in this thesis is of learning to balance resource use in meeting our needs for the sake of our collective well-being.

\section{Learning to Use a Compass}

This thesis largely concerns an analysis of the dynamics of the present AMT regime. The strategic use of AMTs to advance greater product variety and faster product introductions threatens our economic, social, and ecological well-being. At the same time, the limits to growth force us to reconsider how it is we meet our needs, such that, in the larger context of realising a transition to sustainability, we are also concerned with the question of how to create technological momentum in a new direction. In this context, the question posed in Chapter 1 also bears consideration. Is it possible to change direction, when it is not certain where we want to be, without ever having been there before?

I would argue that we know what direction we are going in today and that this is not the direction towards a better future. We then have to ask: What are our choices in the present moment? How do we live/produce/consume more sustainably just now? Technology choice is a matter of exercising technological agency. We learn by what we do. Yes, there is path dependence in technology use - AMT use presently conditions an unsustainable pattern of production and consumption. To change direction, we then need to experiment in putting AMTs to new strategic uses. And we need a compass our belief in the possibility of a sustainable future - to guide us in the direction we wish to go. 


\section{Chapter 11 End Notes}

1 Piore and Sabel (1984) address the other standard explanations for the crisis but conclude, "The most consequential and long-term post-war development was the saturation of the consumer-goods markets in the industrial countries, and the consequent interpenetration - through trade—of the industrialised economies. By the late 1960's, domestic consumption of the goods that had led the post-war expansion had begun to reach its limits.” (p. 184)

2 The socio-economic implications of strategies based on reducing the time it takes to develop and manufacture products are examined in Chapters 5 and 6 of this thesis.

3 This is a major point of confusion in understanding the implications of flexible manufacturing. It persists today in sustainability policy discussions when the claim is made that AMTs favour smallscale production.

4 As indicated by the survey results in Chapter 8 .

5 Use value refers to the amount of services (or function) that can be obtained from a given product.

6 The very real problem of enough jobs is also of concern. Yet, perhaps, with the sincere intent of achieving economic stability, it is time to consider how to decouple growth from the guarantee of employment (Trainer, 1996; Lintott, 2000). 


\section{Appendix A AMT Descriptions}

This appendix provides brief functional descriptions of common advanced manufacturing technologies and related practices. It also includes a chronology of the approximate dates of the technologies' market introductions.

\section{Advanced Manufacturing Technologies (AMTs)}

Advanced Spindle Technology: High-performance, high-speed spindles.

Automated Parts Identification Devices: Machine readable labels which are printed, attached or scribed on parts, that enable the parts to be monitored, counted or recorded during manufacturing processes. The key methods are bar codes and radio frequency tags. Such devices provide for fast, accurate automatic identification of work flow pieces and facilitate traceability of parts.

Automated Storage and Retrieval Systems (ASRS): Computer-controlled equipment which handles, stores, and retrieves materials, parts, sub-assemblies, or finished products, e.g. mechanised stock (inventory) management systems. ASRS assure prompt and accurate delivery of goods at point of use by means of tracking and effective scheduling and control.

Computer Integrated Manufacturing (CIM): Totally automated production in which all manufacturing processes are integrated and controlled by a central computer. CIM also describes the application of system concepts to controlling all levels of the enterprise, usually FMS cells, through a distributed processing system. It provides for all steps involved in a manufacturing process, increasing product quality and productivity. CIM automation requires capability to both determine the cause of failures and to recommend solutions, as opposed to conventional technology which typically achieves quality by detecting deviation from specification and relaying information to a central computer. (In practice, CIM is more of a design philosophy than an implementable solution.)

Computer-Aided Drafting and Computer-Aided Engineering (CAD/CAE): Use of software to carry out design and engineering calculations. CAD produces designs on users' computer screens allowing them to visualise the effects of design changes. CAD/CAE systems reduce product development time and improve accuracy and quality of product.

Computer-Aided Manufacturing (CAM): Use of software to control machining of parts (toolpaths) according to $\mathrm{CAD} / \mathrm{CAE}$ output. CAM reduces machining times which results in higher production rates and reduced delivery times.

Computerised Numerical Control (CNC): Use of computer to control a machine tool's machining sequence. Computer functions include program storage, tool offset and tool compensation, degree of computation and the ability to send and receive data from a variety of sources, including remote locations. Supersedes NC. CNC is used with machining centres and flexible manufacturing cells.

Computerised Production Planning Systems: Software that directs ordering, procurement, production planning and routing, data capture and materials (inventory) storage. Also see MRP and ERP. 
Computerised Process Planning Systems: Software for selection and sequencing of machine operations; selection of machine tools, fixturing, and cutting tools; determination of set-ups; calculations on cutting parameters; generation of toolpaths and numerical control (NC) codes; calculation of machining times and costs; and documentation generation. Computerised planning systems provide for integration of planning and control of production and processing activities.

Computerised Inspection Systems: Automated sensor-based equipment for inspecting and/or testing of incoming or in-process materials or finished products. Automated inspection systems improve processing accuracy and productivity.

Configuration Management Systems: Software management systems for identifying, controlling and backtracking the development of system elements with respect to issues such as multiple developers working on the same design (or code, in the case of software) at the same time, targeting multiple platforms, supporting multiple versions, and controlling the status of design (code).

Data Mining: Software for analysing data from different perspectives, categorise it, and summarise the relationships into useful information. Technically, data mining is the process of finding correlations or patterns among dozens of fields in large relational databases.

Data Warehousing: Software for integrating databases into data warehouses. Data warehousing is the process of centralized data management and retrieval. Centralization of data is needed to maximize user access and analysis.

Distributed Control Systems (DCS): Digital, remote process plant control systems. Control is distributed to computer modules connected by high-speed data links, using fieldbuses to connect analog to digital signals, permitting remote configuration and documentation.

Electronic Data Exchange: Electronic transfer of data across different platforms to coordinate operations.

Electronic Data Interchange (EDI): On-line computerised links to customer stock levels to enable planning and distribution. Also EDI refers to a standard format for exchanging data.

Enterprise Resource Planning (ERP): Management software for determining a master schedule of what to produce, balancing overall demand against resources. Supersedes MRP.

Flexible Manufacturing Cells (FMC): A group of machine tools for producing or assembling parts, typically in low to medium volumes, with the capability to produce a high variety of parts at different mix ratios. Uses tool magazines and efficient tool changers to reduce set-up times. Also see machining centres.

Flexible Manufacturing Systems (FMS): Multiple machines with fully integrated materials handling capabilities controlled by computers or programmable controllers, capable of single or multiple path acceptance of raw material and single or multiple path delivery of finished product. FMS can balance equipment use dynamically, so that the system can adapt automatically to changes in part production, mixes and levels of output. 
High Speed Machining (HSM): Metal cutting machines operating at speeds of 12,000 $\mathrm{rpm}$ or greater, with feed rates up to $10 \mathrm{~m} /$ minute, and power to speed rates of $1 \mathrm{KW}$ per $1000 \mathrm{rpm}$. (In practice, speeds depend on the materials being machined.) HSM reduces machining time and provides for better surface finish.

Holonic Manufacturing Systems: Holonic Systems consist of autonomous, co-operating agents (holons) in a holarchy. The holarchy defines the basic rules for co-operation and thereby limits the holons' autonomy. A holonic manufacturing system is one that integrates the entire range of manufacturing activities.

Intelligent Processing: Monitoring and control of machine processes by sensing and adjusting process parameters in real time.

In-Process Control Metrology: Devices for measuring the value of a quantity in real time.

Knowledge Agents: Computational systems that inhabit some complex dynamic environment, and sense and act autonomously in this environment, and by doing so realize a set of goals or tasks for which they are designed.

Knowledge-Based Systems (KBS): Software systems that employ knowledge-based rules based on domain knowledge. KBS are used to support rational consideration of complex trade-offs among product performance goals, design alternatives, materials, process constraints and finished goods packaging and distribution. Includes artificial intelligence (AI) and neural networks for pattern recognition. KBS provide for understanding improving, and controlling existing process systems, and designing new systems.

Laser Machining: Use of lasers to scribe, mark, cut, weld, cure, or otherwise alter the properties of a material. Related advanced materials processing technologies include electric discharge machining (EDM), plasma arc materials processing and high pressure water jets. Used to machine complex parts and difficult-to-access pieces.

Manufacturing Resource Planning (MRP): Management software that directs ordering, procurement, production planning and routing (work allocation), and material storage. MRP operations are based on expected demand.

Modelling and Simulation Technologies: Software for visualising product or process performance parameters. Modelling technologies involve the testing of 3D solid models on computing platforms. Process simulation refers to the use of physical or mathematical models to simulate process performance. Examples include the simulation of the flow of molten plastic into an injection mould, the tool path for a cutter of NCcontrolled machine tool, and the trajectories of materials handling equipment in a flexible manufacturing system. A related technology is virtual prototyping. Process simulation provides the capability to discover potential problems before facility installation and the potential to compare solutions.

Modular Controls: Controls designed for "plug and play" and easy and efficient reconfiguration to meet specific applications.

Modular Tooling: Tool in which the cutting unit is a smaller, separate part of the tool and which is part of the tool by way of a coupling (i.e. does not interface with the machine tool). In a modular tool system there is a common coupling, which means that a cutting unit will go into any machine fitted with a tool within the same size range. 
Machining Centres: Versatile CNC (programmable) machine tools with multi axis control and usually automatic tool loading. Machining centers are designed to carry out a range of operations.

Open (Modular) Architecture Controllers: Controllers with standard hardware and operating systems with open interface specifications.

Product data management (PDM): Software for capturing and codifying manufacturing-related product characteristics. PDM is a framework that enables manufactures to manage and control engineering information, specifically, data surrounding new product designs and engineering processes.

Programmable Logic Controllers (PLCs): Solid-state, microprocessor-based industrial control devices that have programmable memory for storage of machine control instructions. It performs functions equivalent to a relay panel or a wired solid state logic control system. PLCs provide programming flexibility and reliability in harsh industrial environments and are user friendly.

Quick-Change Tooling and Fixturing Systems: Programmable placement of modular tooling and fixturing.

Rapid Prototyping Systems (RPS): Production of a physical model from a computer model without the need for any jig or fixture. RPS shortens product design and development processes.

Rapid Tooling: Technology based on rapid prototyping for producing tooling quickly. More specifically, rapid tooling is using a rapid prototype, either indirectly or directly, as a tooling pattern for creating a mold. Rapid tooling reduces order to delivery time.

Robots: Reprogrammable, multifunctional manipulators designed to move materials, parts, tools or specialised devices through various programmed motions for the performance of variety of tasks. Robots are primarily used to enhance productivity in mass manufacturing.

Self-Diagnostics: Diagnoses of operational problems as they occur during operation

Technology Maps: Framework for visualising relationships between technologies, including identifying bottlenecks and predicting trends.

Virtual Reality: A synthetic, computer generated 3D immersive environment. 


\section{Practices}

Business Process Engineering (BPE): Management practice that focuses on the design and the improvement of an entire process through the company, such as the fulfilment of customer orders from the first contact with the customer to the finished product.

Cellular Manufacturing: Method of organising production around groups of complementary machines to facilitate manufacture of families of parts or products. The associated software and hardware is referred to as group technology. Also see flexible manufacturing cells.

Concurrent Engineering: Systematic approach to the integrated, concurrent design of products and their related processes, including manufacturing and support.

Continuous Improvement: See TQM.

Cross-Functional Teams: Groups comprised of workers from all relevant functional areas responsible for product/process design. By simultaneously considering all aspects of development, production and use, teams can increase quality, reduce development time and minimise costs.

Integrated Product and Process Development (IPPD): See concurrent engineering.

Just-in-Time (JIT): Internally focussed production system that produces parts on demand. Uses pull system to signal production based on the demand at the succeeding workstation and ultimately the final customer.

Quality Function Deployment (QFD): A structured approach to defining customer needs or requirements and translating them into specific plans to produce products to meet those requirements.

Statistical Process Control (SPC): Use of statistical methods to control quality. Preceded introduction of AMTs.

Total Quality Management (TQM): An approach to planning and systematically improving each production activity that depends on the participation of all individuals at every level of the organisation. Synonymous with continuous improvement.

Virtual enterprise: A network of facilities organised as temporary and timely, limited collaborative form for purpose of producing specific product and that lasts according to the product manufacturing cycle. 


\section{Chronology: Approximate Dates of Commercial Introduction}

1800

English System (Individual skill and precision)

1867

American System (Interchangeability of parts)

1918

Taylor-Ford System (Specialisation of function)

1950's

Deming System (Quality through process control)

Automatic Parts Identification Devices

Numerical control machines

\section{$1960 \mathrm{~s}$}

Robot (1962)

CAD/CAE/CAM (1965)

$\mathrm{CNC}(1967)$

PLCs (1968)

DCS (1969)

1970s

ERP

Computer-Aided Process Planning (1976)

HSM (1977)

FMS (1979)

1980's

Computer Integrated Manufacturing (1985)

KBS

Modelling and Simulation Technologies

Modular, Quick-Change Tooling Systems

RPS (1988)

1990's

Open Modular Architecture Controllers 


\section{Appendix B AMT Trajectory Descriptions:}

\section{AMT TRAJECTORY DESCRIPTIONS: Roadmap Descriptors of Functionality and Operationalisation}

Table B1 Product Differentiation/Flexibility Trajectory

\begin{tabular}{|c|c|c|c|c|}
\hline Aspects of Functionality & Operationalisation & Operational Features & $\begin{array}{l}\text { Representative } \\
\text { Technologies \& Practices }\end{array}$ & $\begin{array}{l}\text { Roadmap/ } \\
\text { Foresight } \\
\text { Sources }\end{array}$ \\
\hline $\begin{array}{l}\text { Ability to accommodate a } \\
\text { variety of different products } \\
\text { and production volume rates; } \\
\text { Ability to cope with greater } \\
\text { product or throughput } \\
\text { variation }\end{array}$ & Increased flexibility & $\begin{array}{l}\text { Rapid changeover of specific } \\
\text { manufacturing processes }\end{array}$ & $\begin{array}{l}\text { Flexible machining centres; } \\
\text { Cell technology; Flexible } \\
\text { manufacturing systems }\end{array}$ & $\begin{array}{l}\text { Agility } \\
\text { Forum, } \\
\text { Eureka, NRC, } \\
\text { Foresight }\end{array}$ \\
\hline $\begin{array}{l}\text { Increased equipment } \\
\text { utilisation; Increased } \\
\text { throughput }\end{array}$ & $\begin{array}{l}\text { Increased flexibility; Increased } \\
\text { speed }\end{array}$ & $\begin{array}{l}\text { Faster machining times; } \\
\text { Reduced downtime and } \\
\text { changeover time }\end{array}$ & $\begin{array}{l}\text { High-speed machining; } \\
\text { Advanced spindle technology; } \\
\text { Quick-change tooling and } \\
\text { fixturing }\end{array}$ & $\begin{array}{l}\text { Agility } \\
\text { Forum, } \\
\text { NCMS, NRC }\end{array}$ \\
\hline $\begin{array}{l}\text { Ability to meet changing } \\
\text { customer requirements; } \\
\text { Increased customisation; } \\
\text { Faster product delivery }\end{array}$ & $\begin{array}{l}\text { Faster cycle times; Increased } \\
\text { speed }\end{array}$ & $\begin{array}{l}\text { Faster machining/processing } \\
\text { times }\end{array}$ & $\begin{array}{l}\text { High-speed machining; } \\
\text { Improved machine tool drives }\end{array}$ & $\begin{array}{l}\text { Agility } \\
\text { Forum, } \\
\text { Eureka, } \\
\text { NCMS, NRC }\end{array}$ \\
\hline
\end{tabular}


Table B2 System Optimisation/Integration Trajectory

\begin{tabular}{|c|c|c|c|c|}
\hline Aspects of Functionality & Operationalisation & Operational Features & $\begin{array}{l}\text { Representative } \\
\text { Technologies \& Practices }\end{array}$ & $\begin{array}{l}\text { Roadmap/ } \\
\text { Foresight } \\
\text { Sources }\end{array}$ \\
\hline $\begin{array}{l}\text { Ability to deliver solutions } \\
\text { configured rapidly to meet } \\
\text { changing requirements }\end{array}$ & $\begin{array}{l}\text { Customer integration into } \\
\text { design and delivery of goods } \\
\text { and services; Expanded } \\
\text { information exchange }\end{array}$ & $\begin{array}{l}\text { Improved customer and } \\
\text { supplier interactions; Improved } \\
\text { customer requirements analysis } \\
\text { and product specifications } \\
\text { capture }\end{array}$ & $\begin{array}{l}\text { Product "visualisations"; } \\
\text { product modelling/ simulation; } \\
\text { Rapid prototyping; Web-based } \\
\text { applications; Networked } \\
\text { customers and suppliers }\end{array}$ & $\begin{array}{l}\text { IEE, NRC, } \\
\text { TEAM, } \\
\text { Foresight }\end{array}$ \\
\hline $\begin{array}{l}\text { Reduction in variability and } \\
\text { uncertainties }\end{array}$ & $\begin{array}{l}\text { Integration of product and } \\
\text { process design }\end{array}$ & $\begin{array}{l}\text { Early learning; Improved } \\
\text { communication of goals and } \\
\text { constraints }\end{array}$ & $\begin{array}{l}\text { Concurrent engineering; } \\
\text { Virtual reality }\end{array}$ & $\begin{array}{l}\text { DSB, Eureka, } \\
\text { NCMS, NRC }\end{array}$ \\
\hline $\begin{array}{l}\text { Ability to optimise trade-offs } \\
\text { between process/product } \\
\text { parameters and cost }\end{array}$ & $\begin{array}{l}\text { Integration of design and } \\
\text { manufacturing }\end{array}$ & $\begin{array}{l}\text { Design phase balancing of } \\
\text { product, process, and resource } \\
\text { parameters }\end{array}$ & $\begin{array}{l}\text { Computer-aided } \\
\text { manufacturing (CAM); } \\
\text { Computerised process } \\
\text { planning systems; Process } \\
\text { software libraries; Knowledge- } \\
\text { based systems }\end{array}$ & $\begin{array}{l}\text { DSB, NCMS, } \\
\text { NRC, TEAM }\end{array}$ \\
\hline $\begin{array}{l}\text { Process, production, and } \\
\text { business variable (e.g. lead } \\
\text { time) trade-off optimisation }\end{array}$ & $\begin{array}{l}\text { Integration of process, } \\
\text { production, and business } \\
\text { controls }\end{array}$ & $\begin{array}{l}\text { Key business parameters } \\
\text { information support for } \\
\text { decision-making; Improved } \\
\text { modelling of complex and } \\
\text { interconnected processes }\end{array}$ & $\begin{array}{l}\text { Business process simulation; } \\
\text { Computerised production and } \\
\text { process planning systems }\end{array}$ & $\begin{array}{l}\text { Agility } \\
\text { Forum, } \\
\text { NCMS, NRC, } \\
\text { TEAM, } \\
\text { Foresight }\end{array}$ \\
\hline $\begin{array}{l}\text { Improved process design and } \\
\text { control allied to extended } \\
\text { product variation }\end{array}$ & $\begin{array}{l}\text { Tighter process control; } \\
\text { Increased process repeatability; } \\
\text { Integration of "islands of } \\
\text { automation" }\end{array}$ & $\begin{array}{l}\text { Improved extraction and } \\
\text { feedback of product and } \\
\text { process variable data; Closer } \\
\text { monitoring of acquisition, } \\
\text { analysis, and process } \\
\text { correction techniques; } \\
\text { Dynamic scheduling }\end{array}$ & $\begin{array}{l}\text { Intelligent sensors, controls, } \\
\text { and machining centres; Self- } \\
\text { diagnostics; Process control } \\
\text { algorithms; Mechatronics; } \\
\text { Non-invasive sensors }\end{array}$ & $\begin{array}{l}\text { Agility } \\
\text { Forum, } \\
\text { NCMS, NRC, } \\
\text { TEAM, } \\
\text { Foresight }\end{array}$ \\
\hline
\end{tabular}


Table B3 Knowledge Systematisation/Information Management Trajectory

\begin{tabular}{|l|l|l|l|}
\hline Aspects of Functionality & Operationalisation & $\begin{array}{l}\text { Operational Features } \\
\text { Systematisation of design and } \\
\text { manufacturing knowledge } \\
\text { Technologies \& Practices }\end{array}$ & $\begin{array}{l}\text { Roadmap/ } \\
\text { Foresight } \\
\text { Sources }\end{array}$ \\
\hline $\begin{array}{l}\text { Systematisation of design and } \\
\text { manufacturing knowledge }\end{array}$ & $\begin{array}{l}\text { Knowledge codification; } \\
\text { knowledge conversion }\end{array}$ & $\begin{array}{l}\text { Knowledge capture } \\
\text { Identification of industrial } \\
\text { requirements and study of } \\
\text { products and associated } \\
\text { production processes; } \\
\text { Production system } \\
\text { configuration evaluation } \\
\text { and variant product and } \\
\text { process behaviour; } \\
\text { Benchmarking }\end{array}$ & $\begin{array}{l}\text { Modelling and simulation; } \\
\text { Technology maps }\end{array}$ \\
\hline Increased knowledge access & Knowledge translation & $\begin{array}{l}\text { Improved performance } \\
\text { specification and mapping of } \\
\text { specifications onto sub- } \\
\text { assemblies; Improved } \\
\text { integration of conceptual } \\
\text { design with part family } \\
\text { description }\end{array}$ & $\begin{array}{l}\text { Knowledge databases; } \\
\text { Knowledge agents }\end{array}$ \\
\hline Increased knowledge access & Knowledge transfer and reuse & $\begin{array}{l}\text { Increased knowledge sharing } \\
\text { across time }\end{array}$ & $\begin{array}{l}\text { Product data management } \\
\text { systems; Data mining and } \\
\text { warehousing; Software } \\
\text { libraries; Configuration } \\
\text { management systems }\end{array}$ \\
\hline
\end{tabular}


Table B4 Adaptability/Reconfigurability Trajectory

\begin{tabular}{|c|c|c|c|c|}
\hline Aspects of Functionality & Operationalisation & Operational Features & $\begin{array}{l}\text { Representative } \\
\text { Technologies \& Practices }\end{array}$ & $\begin{array}{l}\text { Roadmap/ } \\
\text { Foresight } \\
\text { Sources }\end{array}$ \\
\hline $\begin{array}{l}\text { Ability to rapidly respond to } \\
\text { changing requirements; } \\
\text { Capability to adapt to change } \\
\text { and deal with uncertainty and } \\
\text { unpredictability more easily } \\
\text { and rapidly }\end{array}$ & Dynamic manufacturing & $\begin{array}{l}\text { Increased multi-functionality } \\
\text { and reconfigurability }\end{array}$ & $\begin{array}{l}\text { Modular tools, plant and } \\
\text { controls; Configurable } \\
\text { production systems; Rapid } \\
\text { prototyping of tools and dies; } \\
\text { Open architecture controllers; } \\
\text { Autonomous FMS }\end{array}$ & $\begin{array}{l}\text { Agility } \\
\text { Forum, } \\
\text { Eureka, IEE, } \\
\text { IMS, NCMS, } \\
\text { NRC, TEAM, } \\
\text { Foresight }\end{array}$ \\
\hline $\begin{array}{l}\text { Ability to withstand } \\
\text { unforeseen environmental } \\
\text { changes / robustness }\end{array}$ & Dynamic manufacturing & $\begin{array}{l}\text { Automatic self-diagnosis and } \\
\text { self-correction }\end{array}$ & $\begin{array}{l}\text { On-line intelligent process } \\
\text { control; Neural networks and } \\
\text { fuzzy logic controllers; } \\
\text { Context-sensitive agent-based } \\
\text { interfaces; Holonic systems }\end{array}$ & $\begin{array}{l}\text { Agility } \\
\text { Forum, IMS, } \\
\text { NCMS, NRC }\end{array}$ \\
\hline $\begin{array}{l}\text { Improved capacity and asset } \\
\text { utilisation }\end{array}$ & Dynamic scheduling & $\begin{array}{l}\text { Development of contingency- } \\
\text { based scheduling }\end{array}$ & $\begin{array}{l}\text { Autonomous/intelligent } \\
\text { scheduling systems }\end{array}$ & $\begin{array}{l}\text { Agility } \\
\text { Forum, IMS, } \\
\text { NCMS, NRC }\end{array}$ \\
\hline $\begin{array}{l}\text { Improved planning and } \\
\text { strategies }\end{array}$ & $\begin{array}{l}\text { Process configuration } \\
\text { management; Technology } \\
\text { management }\end{array}$ & $\begin{array}{l}\text { Technology management and } \\
\text { continuous strategy evaluation; } \\
\text { Methods of prioritising } \\
\text { technology requirements; } \\
\text { Production configuration and } \\
\text { schedule testing }\end{array}$ & $\begin{array}{l}\text { Process modelling and } \\
\text { simulation; Virtual } \\
\text { manufacturing environments; } \\
\text { Virtual factory }\end{array}$ & $\begin{array}{l}\text { Eureka, IMS, } \\
\text { NRC, TEAM, } \\
\text { Foresight }\end{array}$ \\
\hline
\end{tabular}




\section{Appendix C Breakout of Interviews}

Table C1 Interview Distribution by Country and by Type and Size of Organisation

\begin{tabular}{|c|c|c|c|c|c|c|c|c|}
\hline \multirow[t]{2}{*}{ Country } & \multirow{2}{*}{$\begin{array}{l}\text { Number of } \\
\text { Interviews }\end{array}$} & \multirow{2}{*}{ AMT Users } & \multicolumn{4}{|c|}{ Size of User Companies ${ }^{1}$} & \multirow{2}{*}{$\begin{array}{c}\text { AMT } \\
\text { Suppliers }\end{array}$} & \multirow{2}{*}{$\begin{array}{c}\text { Service } \\
\text { Organisations }\end{array}$} \\
\hline & & & Small & $\begin{array}{l}\text { Medium- } \\
\text { Small }\end{array}$ & $\begin{array}{l}\text { Medium- } \\
\text { Large }\end{array}$ & Large & & \\
\hline Belgium & 1 & 1 & & & 1 & & & \\
\hline England & 1 & & & & & & & 1 \\
\hline Finland & 4 & 3 & & 1 & 1 & 1 & & 1 \\
\hline Germany & 3 & & & & & & 1 & 2 \\
\hline Italy & 7 & 4 & 2 & 1 & 1 & & 2 & 1 \\
\hline Netherlands & 4 & & & & & & 1 & 3 \\
\hline Sweden & 1 & 1 & & 1 & & & & \\
\hline Total & 21 & 9 & 2 & 3 & 3 & 1 & 4 & 8 \\
\hline
\end{tabular}

1. Company size division is as follows: small: less than 100 employees; medium-small: from 100 employees to less than 250 employees; medium-large: from 250 employees to less than 500 employees; large: 500 or more employees. 
Table C2 User Firms' Interview Distribution by Industry, Type of Market, and Position in Supply Chain

\begin{tabular}{|c|c|c|c|c|c|c|c|}
\hline \multirow[t]{2}{*}{ Industry $^{1}$} & \multirow{2}{*}{$\begin{array}{l}\text { Number of } \\
\text { Interviews }\end{array}$} & \multicolumn{3}{|c|}{ Type of Market } & \multicolumn{3}{|c|}{ Position in Supply Chain } \\
\hline & & Consumer & Industrial $^{2}$ & Both & OEM & First Tier & Lower Tier \\
\hline Automotive & 1 & & & 1 & & 1 & \\
\hline Electronics & 2 & 1 & & 1 & 2 & & \\
\hline Furniture & 1 & & & 1 & 1 & & \\
\hline Appliances & 1 & 1 & & & 1 & & \\
\hline Household Goods & 1 & 1 & & & 1 & & \\
\hline Textiles & 2 & 1 & & 1 & & 2 & \\
\hline Metal & 1 & & 1 & & & & 1 \\
\hline
\end{tabular}

1. Additional industries (e.g. food processing, wood products) were represented through interviews with suppliers and service providers.

2. Industrial markets include those where the customers are other companies. 


\section{CUSP PROJECT INTERVIEW PROTOCOL, FIRM VERSION}

Interview \#:

Date:

Country:

Position of Interviewee:

\section{Introduction}

Thank you for agreeing to this interview. Your knowledge of manufacturing and manufacturing needs is critical to the success of our research. The interview is part of a larger study funded by the Research Directorate of the European Commission, the aim of which is to better understand the process by which manufacturing strategy turns investments in new technologies into competitive advantages and improvements in sustainability. Specifically, we are interested in finding out how the strategic use of advanced manufacturing technologies shapes the growth and formation of product markets.

A number of the questions at the beginning of the interview are designed to develop a picture of your firm's particular industry and market conditions. Later questions address practices you use to develop and implement strategy and how trends in the development of advanced manufacturing technologies might influence strategy.

Throughout the interview I use a number of definitions repeatedly and I want to take a minute to review them with you. (Hand supplement.) They are listed at the top of this sheet. I use the acronym AMT to signify "advanced manufacturing technologies", by which is meant computer or electronics-based production technologies. The definition we use for manufacturing strategy is "the pattern of operating decisions which determine the capability of the manufacturing system". We also distinguish between a planned strategy which is the result of a formal planning process, and the implemented strategy which reflects a firm's actual daily operational decisions and practices. Finally, a trade-off is defined as "an exchange of a gain in advantage of one type for a loss in advantage of another type". An example of a trade-off is automating processes to increase efficiency but, at the same time, reducing interoperability among the system components.

Also, some of the interview questions use lists of possible responses that I have also printed on the sheet I gave you. I will let you know for which questions you might want to refer to these lists.

The interview begins with questions on markets and market conditions. But before we start, would you like to ask any questions about the study and its purposes, or on the interview process?

Co. Size:

Small $(<100$ employees $)$

Medium-Small (100 to 250 employees)

Medium-Large (250-500 employees)

Large (>500 employees)

\section{Section 1 Markets and Market Conditions}

What are your main product lines?

Who are your principal customers_-other companies or consumers?

Would you say your markets are more niche markets — or commodity markets?

This next question refers to the first list on the sheet I gave you, entitled "Terms of Product Competition", that is, the characteristics of products that are used for competitive advantage. For your markets, what changes, if any, in the terms of product competition do you foresee in the next 3 to 5 years? That is, do you think that any of the terms of competition listed on the sheet might become more important than they are now_or that there will be other means that are not listed? [TERMS] 
Is there any possible future change in the terms of competition that you can think of that hasn't yet started to take place? [HA2]

Does your firm have plans to respond to these changes by using new or different technologies? [HA2]

\section{Section 2 AMT Use}

The second section of the interview addresses your firm's AMT use. The first question refers to the second list on the sheet I gave you, the one with the heading "Select Advanced Manufacturing Technologies".

Which of these technologies do you use routinely in your plant? [TXS]

Have you made any changes in how you organize production (in your business practices or your organizational structure) to accommodate AMT use? [HA1]

$>$ If yes: Are these changes most often made before, during, or after the technology's introduction? [CHA1]

$>$ If during or after: Did you usually anticipate these changes at the time you were evaluating the technology? [HA1]

How important do you think the integration of technology, operational practices, and structure is to carrying out a change in how your firm competes in the market (competitive priorities)? [HB2]

For your firm, what is the bigger factor in your ability to compete- the choice of individual technologies or the integration of technology, practices and structure? [HB2]

\section{Section 3 Manufacturing Strategy}

This third section on strategy starts with some questions regarding your firm's manufacturing strategy. There are some written definitions for manufacturing strategy on the sheet with the lists. I define manufacturing strategy as the pattern of operating decisions which determine the capability of the manufacturing system.

Would you consider your firm's manufacturing strategy as top down or bottom up, that is, as coming from management or coming from shop floor needs? [HA2/HB2]

For your plant, is a change in strategy, (as it is embodied in daily operational practices), more likely to follow after or come before the adoption of new technologies? [HA1]

This next question concerns your company's manufacturing objectives. This question refers to the next list on the sheet I gave you, list \#3. Have these objectives changed in the last 3 to 5 years, that is, become more or less important? [M-OBJS]

For your firm, what is the usual cause of a change in manufacturing objectives? [HA1]

_ change in technology

_ change in competitive priorities

After purchasing and implementing a new technology, what methods do you use to evaluate whether the technology supports your manufacturing objectives? [HB1]

In some cases, the reason for purchasing a new technology is different from the strategic result of using that technology. The result might be positive in the way of unexpected benefits. For example, a company might purchase a new sensor to improve inspection and then find it also speeds up production allowing the company to improve delivery. Or the result might be uncertain or negative. For example a company might purchase a production planning system but to get adequate work flow with it in operation, the company must simplify its product line.

In your experience, is it ever the case that AMTs:

- Do not provide the expected benefits for performance or competitiveness? 
- Are difficult to implement?

- Are not suited to the organization? [HB1]

If yes: What do you believe is the cause of such problems? [HB1]

Has it ever been your experience that AMTs provide unexpected competitive benefits? [HA1]

Often there is a delay before a company begins to realize the benefits of a new type of technology. Why is this? [HA1]

For your firm, what is the main reason for changing your strategic orientation with regard to your market objectives? [HB2]

Do you think your company's experience in changing strategic orientation is typical for your industry? [HB2]

\section{Section 4 Technology Evaluation}

Are your AMT investment decisions more often made on a project basis or as part of a systems-wide capabilities planning process? [HB2]

Which criteria do you routinely consider during technology investment evaluations? [HB1]

Financial return on investment

Technical criteria

Market forecasts

Others given:

Which criteria, if any, do you use to evaluate a technology's potential to contribute to the development of the firm's manufacturing capability? [HA2]

Do you have any difficulty in finding equipment that meets these criteria? [HA2]

Which criteria are difficult to meet? [HA2]

Which criteria, if any, do you use to evaluate the technology's impact on sustainability? [SUST]

Do you feel that equipment suppliers are able to provide the information you need which supports strategic decision-making? [HA2]

\section{Section 5 Trade-offs}

In this last section, the questions concern some trade-offs you might encounter in using AMTs. In a trade-off, a gain in an advantage of one kind is exchanged for having less of another kind. An example of a trade-off is the one between economies of scale and flexibility which is thought to characterize mass production. By increasing the scale of operations a manufacturer could lower costs, but this would mean using specialized equipment with less flexibility.

This next question refers to the last list on the sheet I gave you. In using AMTs have you experienced any of the following trade-offs? [T-Offs]

1. More flexibility but greater complexity

2. More flexibility but greater capital intensity

3. Shorter times-to-market but greater break-even sales volumes

4. Increasing system efficiency through process integration but greater complexity

5. More automated interactions but less system autonomy

6. Increasing knowledge value but faster knowledge obsolescence

7. More resource utilization but greater risk exposure (e.g. risk of losing trained workers; risk of high fixed costs in volatile markets) 
8. More product performance and customisation but greater service complexity

9. More agility but increasing technology needs

Do you have any ways to identify and evaluate trade-offs that might result from using AMTs? [HB3]

$>$ How does/might identifying and evaluating trade-offs associated with AMT use affect the development of your firm's manufacturing capabilities? [HB3]

Last Question

What is your firm's greatest strength, and what is its greatest weakness, in adapting to technological change? [HB3] 


\section{Appendix D Model Validation Data}

\section{Note on Methodology:}

The model's validation is organised around two questions and associated hypotheses. The two questions are:

A. In what ways do existing trajectories in the development of advanced manufacturing technologies influence manufacturing strategy formulation and implementation?

B. How do manufacturing strategy practices, as they pertain to the choice and use of manufacturing technologies, act to preserve the current direction of technological change or to activate new directions in technology development?

The object of this record is to organise the interview data in a way that is intelligible to model validation. The data unit is a topical response to a given question. With a few exceptions, noted as follows, this appendix contains the data record of all responses to the questions associated with the hypotheses. Each topical response for an interview subject is recorded, (there may be more than one), but duplicative responses have been eliminated. Single phrase responses that have been tallied in the main text are also not included. Also, some of the responses have been shortened to reduce non-essential information.

In this record, the data are ordered according to the hypotheses or model extensions and then the arguments supporting the hypotheses. Responses that were not categorisable are listed as extraneous factors. 


\section{Hypothesis A1 and Corollary Validation}

Hypothesis A1: A change in manufacturing strategy, as it is embodied in daily operational decisions concerning the organisation of production, is more likely to occur as the result of a change in the firm's technology than as a direct result of a change in the firm's competitive priorities.

Corollary to Hypothesis A1: A change in manufacturing strategy, as it is embodied in daily operational decisions concerning the organisation of production, is more likely to follow the adoption of new technologies than to proceed it.

Argument 1: Technologies condition the knowledge and practices of their users.

- When you have a new system, you are forced to use new ways. An example of a simple modification is to code every tool you are using because the computerized system handles this resource. Yet, the system cannot operate without the correct codes. So you are forced to code. If you don't anticipate this, you find all these problems about coding and giving information and naming things, and this changes completely the way you are using the system and even if you don't want to change, you are forced to change. Then, even if the company hasn't anticipated the changes, there is a possibility to have a positive impact on the organization. For example, when the same thing is called in different ways by different people inside the organization, installing the AMT gives you the possibility that requires everyone agree on one name.

- Technologies are enabling, but they also bring companies up to speed.

- If a company makes a technological change, it has to adapt the organization.

- Then your factory has to fit the [technology's] model. You're changing your factory towards the concept behind the equipment - and, if not, what are you doing then?

- Because the machines have so many features they really have to teach their users. There are no standards that make it easy to switch from one machine to another.

- When you change ways of working, you often have to replace people who are based in traditional manufacturing systems.

- When introducing new [techniques], companies must make changes in the way they operate.

- When you have new technologies, you have to rethink, reorganise, what I call logistical organisation. Where do your put decoupling points, work-in-process stock, and so on. Are the machines in a logical order? Are they grouped in a logical way?

Argument 2: Firms learn new ways to achieve their goals as an effect of technology use.

- The usual cause for a change in manufacturing objectives is a change in technology. Companies can take two approaches. They can take a strategic approach, or they can purchase equipment, not thinking about how that equipment might affect their plans. Once the equipment is in place, they realize they need to make it work and so it changes their business objectives. I think [unplanned changes] happen quite often. It probably depends on the size of the company.

- Once you've understood the possibilities of the equipment, you might change your business objectives.

- Once we started to implement new technologies, we saw the possibilities in being really competitive.

- There is this case that they don't anticipate the change but when they have the AMT in place there find there is a potential for change.

- They don't just buy a machine - they have to change the whole philosophy of their company. They have to get into new markets, change what they did before they bought the machine, and orient themselves in a totally new way. 
Argument 3: Lacking relevant experience, changes in planned strategy are difficult to carry out.

- In some cases, companies don't realise the benefits [of new technology]. They don't understand all of the possibilities of working with computerised equipment. They tend to think in very conventional ways and are not able to imagine how to use the equipment differently.

- The number of people that just go out and buy a high-speed machine and then just get no benefit from it - well, I've done it myself ten years ago. You never thought about the tooling, you never thought about how you would get materials to it, about maintenance of it, how it fits into another group of machines, about the flow of materials. Until you stop and think about the design of that total process, to some extent you're wasting your time buying high technology machines.

- We need more dynamic capability. ... Because if you really want to follow how you should do it, to meet your development times for all these types without having a lot of work-in-process, you would like to switch over every day or every two days. But now you try to limit it to once a week because you lose too much capacity every time you start up the learning curve. It's costing you in products that you are not making.

- Sometimes the company doesn't have a clear idea of what they want. So, there is not a clear line of steps to follow. Then our job is to reason with the companies what their problem is and what is the solution.

- If I go back ten years to the old machining cells - very few of those actually delivered the benefits everyone expected of them. Basically because we didn't understand that for a flexible manufacturing system to work, we had to design everything else that went around it. So, we moved forward and we got more knowledge and more experience ... and then we would get superb payoff from high investment in advanced manufacturing technology.

- AMTs have a fairly strong influence [on the ways companies choose to compete in their markets]. The real problem is that companies have lost most of the potential benefit of these technologies by the time they fully integrate them into their systems. They would have a greater competitive advantage by thinking ahead.

Argument 4: Technology adoption frequently precedes a change in strategy.

- They need to rethink their own strategies first and then buy these machines, but it is happening the other way around.

- The order of change is first doing, then knowing - not knowing, then doing. SMEs buy AMTs to fill technical needs and over time the AMTs influence their market objectives.

- I'd like to say that [companies] think through the strategy and then buy the technology, but there's still quite a lot of people buying the technology, then thinking through the strategy. But, it never delivers. Well, it delivers marginal improvements, but it never delivers the real improvement that it could.

- Sometimes [in introducing a new AMT], we found it influenced market objectives in ways we didn't anticipate. Some of the AMTs we purchased were not successfully implemented.

- After, because what they buy from us prompts different strategies, because they are learning to use these new technologies over time.

- Changes in organisational structure and operational practices usually occur during the introduction of new technology. Usually the demand for changes appears so suddenly that if you stop and say "Wait, I need to adapt my organisational structure so everything fits perfectly", then the opportunity is lost.

- The change in practices was made after the introduction of the technology and was made primarily to meet new product requirements. 
Argument 5: Firms that "think ahead", take the effects of implementation into account.

- Changes in practices are perhaps after the introduction of the new technology, but we try to implement the technologies when they are so far developed that we know what changes will be necessary and how they will integrate with our systems.

- First we look at what our [business] strategy is, then we look at what technologies we would like to use - what the technologies bring to us.

- That's when you come into looking at your business plan: what are you committing to your customer, what are you committing to your board of directors. You write your manufacturing strategy based on what that commitment is. Once you've written the strategy, and a good way of writing it is to ask what you would as a manufacturing professional like to see as you go through the door. Then, you do an audit and look at some of the gaps, and you go through designing of the rest of the factory. ... You go through a whole series of decisions that enable you to design a module that's appropriate to the business that you need.

Argument 6: New systems emerge through adaptation to newly adopted technologies.

- You have to make investments to shape the organisation, to align it with this new manufacturing technology.

- They need to do some things in the company to adapt to the technology and this is a long-term proposition. The consequences can be far-reaching, for example, it might involve schooling.

- Very often, when firms introduce new products and are using new equipment, it takes quite a long time before it is operational. The process is understood very badly and that means that very often a lot of things are trial and error. You need experience in the process.

- They must go through a learning experience with new technology.... They need time to develop the necessary capabilities.

- I think the thing we've forgotten is that the Japanese took many years to design these processes before they showed them to us.

- We, as users, might not understand the technology good enough to begin with, which means we can't utilise the advantages. Sometimes we tend to use the disadvantages also, since we keep on working in the same way with the new equipment. But you have to adapt your way of working, your way of organising, your routines, you have to adapt them to the new equipment, and that always takes some time, because changing people's way of working, that's much more difficult than buying a new machine.

\section{Hypothesis A1 and Corollary: Extraneous Factors}

- Our planned strategy matches our daily operational decisions in a broad sense, but there is also the challenge of having all of our personnel understand that strategy. This is because as the company grows we are hiring on more and more.

- The introduction of new technology has simplified [the director of operation's] work but has not resulted in reorganisation of responsibilities.

- [Whether changes in organisation are necessary] depends on the type of equipment. If you are talking about a new type of injection moulding machine, then basically, no. Changes in injection moulding machines are incremental. There are a lot of changes. It's a very fast developing market, but it has been changing for a long time now. If you're talking about changes in the peripheral equipment, yes, I think changes are necessary. 


\section{Model Extension: Customer Requirements}

For suppliers, customer requirements are frequently an important factor in technology choices.

- We arrange the organisation to meet the customers' requirements. Our goal is to adapt to the customers' needs.

- Our company makes changes in technology in response to changes in customer requests.

- The focus is on paying attention to customers requirements.

- Many big companies are not completely free to select their own technology as they need to involve their customers in the decisions.

- [The usual cause of a change in manufacturing objectives is] a change in customer requirements. If we want to make a change in the product, this change has to be validated through the complete supply chain. This includes verification of the production techniques. 


\section{Hypothesis A2 Validation}

Hypothesis A2: Firms are more likely to select technologies in relation to the current terms of competition than in relation to the need to develop new manufacturing capabilities in anticipation of changes in the terms of product competition.

Argument 1: Firms plan the development of their capabilities according to experience.

- Typically SMEs are running after a solution to a problem rather than engaging an opportunity.

- More changes [in the markets] will occur in the next few years. Some companies are proactive in dealing with these changes, mainly large companies, but most companies are still reactive.

- They make the changes because they will make money, but these changes are very technical and shortterm, not strategic. In some cases, companies have to make a change ... This type of company does not sit back and think, "Where do I want to be in five years time?" This is typical of the small mom and pop shops. The big companies are inclined to think strategically.

- Manufacturing strategy has been coming up from the shop floor.

- We have to start with product strategy, then our commercial strategy, and none of these is explicit at this time. That has to do with the past of this company. We have grown very fast. There wasn't time to think about strategy. We were growing, growing, growing, selling more and more and more. But there comes a moment when you have to organise yourself. That moment is here.

- Being sensitive to the market is not typical.

- So we have nice machines in our factory, but they are not fitting the need today because of change over time. If they had projected [at the time the equipment was bought] the future with the growing product diversity and quantities, then some machines would not be as they are today.... With increased quantities and change-over times - it's biting us.

- [Companies] look for the equipment that provides the best solution to their needs. The challenge for machine tool suppliers is to optimise the solution. The problem is the sustainability of needs.

Argument 2: Firms respond to changes in the terms of competition after these changes have taken effect.

- Companies change their strategic orientation when they notice that more of the same behaviour doesn't get them the same amount it used to. However, they see things coming before they actually change behaviour. Usually, they wait until [trouble happens].

- Firms change their strategic priorities when there is a change in market forces, when they are not able to produce the quality the market requires.

- We had to change our way of thinking in response to market changes. ... In response to the demands of these new markets we have improved our capabilities.

Argument 3: Knowledge of what capabilities will be needed is limited.

- It is not unusual that the equipment's scale is too large relative to the current market and that companies do not anticipate this when purchasing the equipment.

- I don't see a lot of capacity [in our customers] to foresee the evolution of market needs. Our customers, with our support, work with a short term vision of the market.

- I know about three companies [in small company service population] that choose technologies for strategic reasons. The criteria they use is technical. There are more client requests - not for specific technologies - but practices and capabilities. ... If they do something for one client, they might think to offer it to the next client.

- In the beginning companies will hesitate [in responding to changes in the market]. Once they realise the advantages of a new technology, they will adopt it - if the technology is reliable. 
- The markets are unpredictable and constantly changing. Firms do respond to market changes. However, they tend to concentrate on striking a new balance between the same [existing] elements, when there is a need to rethink what elements are needed. There is a lack of strategic vision. They seek compromises rather than innovations.

- Companies adopt new types of AMTs not for a formal strategy, but through a sense of opportunities. Sometimes in the final decision the economic aspects, like capital and operating costs, are the most significant reasons in choosing one system over another. When you are discussing [the choice of technologies] with your potential customers you are working on a very concrete basis. It is difficult to transfer the potential for the evolution of their system - say in the motivation of their employees, (because it could be more gratifying to work with these new technologies) - it is difficult to formalise this potential. But management uses these informal criteria in their final decisions. You find at the end they are able to make specific trade-offs among intangibles.

- Companies don't formally plan the development of their capabilities. Our experience is that people work on a project by project basis, trying to make their short term efforts fit the strategic vision they have for the longer term.

Argument 4: To generate new opportunities, firms must invest in future-oriented capabilities.

- Companies that ask what their future will be like are the ones who will succeed. Others are happy today and don't see problems because their products are selling today. But you have to understand your problem of tomorrow and solve it now, otherwise you will be too late.

- Many times technology is the key factor for achieving new markets or enlarging present markets. Companies come to us with the final goal of: "We are looking for a new technology because if we do not, we will die tomorrow." These successful companies develop technology and strategy

simultaneously.

- What provides a new focus for manufacturing objectives is trying to understand what changes will occur in the markets - understanding what the product requirements will be.

- The only way, not just to survive, but to succeed is to explore new market opportunities. We anticipated what the market was asking and how the market was moving. Our competitors chose to keep with the same technology - not to react.

- Companies both anticipate future changes and respond to current changes in the market. Mediumsized and large companies anticipate future markets. They come to us for help in setting up a new product. The customers with process problems are trying to solve some problem in production. But some others are thinking about manufacturing a new product in new ways for performance advantages. These are often the medium-sized companies. Many big companies are not completely free to select their own technology as they need to involve their customers in the decisions.

\section{Hypothesis A2: Extraneous Factors}

- Today we have a fairly wide product range and we have the option to change to a niche-oriented focus, which would change the emphasis of which are the important factors.

- The business plan is probably the most important document that is prepared by the management team. It starts to look forward at what the requirements [for future capabilities] are.

- We have some demanding customers. We follow very tightly what their requirements are. Also, following the market, that also influences us. But many times the best thing is to have very demanding customers. 


\section{Model Extension: Supplier Capabilities}

Argument 1: Suppliers are not always able to provide the information customers need to evaluate a technology's strategic possibilities.

- Equipment suppliers are not always able to provide the information that supports decision-making. The problem is that, in many cases, we are driving the changes and they don't always know what are market requirements are. ... In many cases there is a gap between their [the suppliers'] technical capabilities and their understanding of what we are trying to do in our markets.

- If its not a proven technology, its obvious that the risk is higher. The other reason is that the supplier will try to give you a nice picture of the technology, everything is possible, nothing is difficult, but of course that's never the case. But if we are not really confident ourselves that we know what benefits the equipment gives, then listening to suppliers is a big risk.

- We have a dialog [with our equipment suppliers], but I am not so sure the suppliers understand our objectives - they are more interested in selling equipment.

- There is the problem of suppliers not fully understanding the buyers operations and markets - their needs - and then selling them something that doesn't fit. The problem here is that they don't communicate well.

- We don't in general discuss our customers strategies with them. Sometimes we discuss their future but generally we are addressing their technical problems.

- It is difficult to have the computer system suppliers understand the needs of the customer because the purchaser is usually not an educated computer specialist and this is the biggest gap.

- Often [companies'] plans are hindered by the lack of available technologies. For example, computerised forecasting programs are not particularly useful because the market is changing too fast. This is an example of an old solution to a new problem.

- [The challenge is] getting equipment suppliers to provide their future customers knowledge in this area of strategy before their customers buy the machines - to get their customers on a certain level of understanding of what they are really buying. That may be difficult because first the machine suppliers want to sell and they also don't want to give away the knowledge. We need to think about these processes. If you sell someone equipment and then they have problems, they will not be happy with it, and they will then influence other potential customers. This is a risk then in selling equipment without giving the buyers the knowledge on how to use it first.

Counterargument: Suppliers provide their customers with the knowledge they need to make strategic decisions.

- [Companies] have to consider the risk of being first [to use a new technology]. They should know the results beforehand. There might be some effects that they have not planned for, positive effects. But technology users understand the strategic implications of the technologies beforehand, because they are evaluating this during planning. Secondly, the machine tool producers have to describe the competitive advantage of their system.

- Machine tool producers are getting better at providing services. They are able to help their clients understand the strategic implications of the technology. The technology users are taking advantage of the machine tool suppliers' expertise. 


\section{The Influence of Trajectories on Technology Choices and Strategy}

Current use patterns strongly influence the individual firm's choice and use of technologies.

- Once the idea was to build transfer machines which were very rigid but you could produce high volumes at low cost. Today we need flexibility because of product differentiation and smaller batches.*

- The markets are not stable: they are always rapidly changing. Customers are constantly asking for shorter production times and novelty products.* Every year sees new ideas. The co-operative is pushed to change in order to remain competitive.

- What you're looking for is reduced throughput time.... You can make variety for the same price, you can make volume.*

- We distinguish between [radical change] in a technology and incremental improvements which follow a smooth line of development and which, in most cases, don't have a significant impact on organisation. Sometimes in introducing a radical change there is a strong impact on the users. For example, this was the case of $\mathrm{CNC}$ machines. $\mathrm{CNC}$ was developed in 1965 but the real development occurred in the eighties. CNC caused major changes for both the technology's users and developers. In the case of the suppliers, the change was the result of a transfer from manufacturing a pure mechanical to a mechatronics product. $\mathrm{CNC}$ resulted in change for the users as well, introducing the need for programming and the subsequent reorganisation of the firm.

- The leading companies are really aware of what they do, they have a clear strategy, but the followers, some small companies, may not. Many of [the small] companies look and see what their neighbours have and buy what they have with maybe one feature more. They can say they have bought a machine with four axes, even if they don't use the fourth axis. So there are lots of machines on the market that are not doing what they could do. Or they run just for a few minutes a day and the rest of the day they don't get used.

- What has not been expected has been our experience with computerised planning systems, which seems to be what happens with many companies. Computerised planning is for us now the bottleneck, which is why we are planning a change in our system. Because the computers are telling you what the system should be [on the shop floor] not the other way around.* The system is stiff, not responsive enough. We have heard about this from other companies. You need to have a system where you can make the changes.

* Observation reflects current trajectories. 


\section{Hypothesis B1 Validation}

Hypothesis B1: Current manufacturing practices, as they are embedded in the firm's manufacturing capabilities, are more likely to influence the firm's technology choices and the use of new types of technology than is an intended change in competitive priorities.

Argument 1: Firms are oriented towards solving current problems and improving existing capabilities.

- The more dynamic companies adopt new types of AMTs, primarily for strategic reasons. Otherwise, companies are trying to solve present problems.

- The decision to acquire a new manufacturing system is related usually to a specific production problem. There is a reason ... but the longer term vision is often not formalised.

- They're overcoming one particular problem, but then you've got to turn that around and become a lot more proactive and think through what you need to deliver on the business plan.

- The firm defines quantified goals such as 3\% cost reduction every year. Then they decide which resources are needed to meet those objectives.

- Smaller firms make their decisions more often on the basis of immediate needs.

- Companies evaluate their options starting from a technical point of view. $90 \%$ of the SMEs we work with don't have any strategy - they don't think about strategy - they don't what strategy is. Mostly they are attempting to deal with daily problems.

Counterargument: Formal planning drives capabilities development.

- "Customers have a deep knowledge of what they want."

- Formally planned manufacturing strategies are common. The product has to be oriented to the needs of the market, so a company's production strategy is one of its competitive aspects. Companies are constantly reviewing strategy to remain competitive.

Argument 2: Firms rely on old practices.

- The need is to reconsider the basic configuration of their processes, but they retract to their old process configuration, even when trying to institute their competitive strategies.

- The ideas come from management, but implementation is from the shop floor.

- New manufacturing systems are used as the old ones were, so the potential of the technology is not fully exploited. This happens because sometimes the vision of the new technology comes from high level management, but it is difficult to apply on the shop floor.

- With growing diversity there is the danger of offering products that are too specialised, that you do not have enough standard products with turnover that give you the money. ... For example, we were asked by the wholesalers to develop a low cost product that looked like our high end product. It was developed with some cheaper features, but the technology to make it is exactly the same as for these high end products. So what did you see happening? Once the cheaper product was introduced, the sales of the high end product plummeted. The sales of this cheap product have gone up, but there's no profit margin on these products. That could have been predicted beforehand.

- If you really want to become good at manufacturing, then you follow procedures and you follow processes. Then you've got to train everyone in those processes. We really decided [in changing priorities] that we had to go back to square one and it isn't easy, if for no other reason than the wide range of decisions that have to be taken. ... I don't think people fully understand the vast range of things management needs to take decisions on.

- Sometimes when they get new technologies, they continue to use it in the previous way and never change their strategy, losing out on the potential benefits of the new technology. 


\section{Argument 3: Past practices applied to new technology lowers performance.}

- Following a change in the markets, firms do not very often [reevaluate their competitive priorities]. Some do, but most of them don't. They make their things and that's it. They don't really have marketing strategies. When they buy the equipment, they get into big problems, because it is another range of operations and they try to use the equipment in the same way as they have before. For example, its as if you were using a computer in the same way as a typewriter. The computer does so much more. You don't get the benefit. You pay for more than what you are using.

- [The impact of new technologies on manufacturing priorities] depends on the situation very much. New companies are growing all the time and their systems and networks grow with the enterprise. But when we are thinking about mature manufacturing sectors, the situation is such that the enterprises have to face some problems before the changes will happen.

- It is a normal problem that it can take 1 to $1 \frac{1}{2}$ years to get a system operational.

- If I go back ten years to the old machining cells - very few of those actually delivered the benefits everyone expected of them. Basically because we didn't understand that for flexible manufacturing system to work, we had to design everything that went around it. So, we moved forward and we got more knowledge and more experience, then we would design the manufacturing process.

Argument 4: "Open" practices and a vision of the future can facilitate adaptation.

- There are always changes. We are adapting continuously. We aim to update our strategy at least every two years.

- Faster product development time means that you need to be quick to market, so your organisation needs to be continuously updated.

- Experience is something that can help you to face new knowledge without a lot of problems. You need a good framework for absorbing the new information instead of just using information because it is new. The challenge is to be informed, but to build on experience and current capabilities.

- A clear vision of how the product will compete in the market is needed. The future scenario should address delivering the right product at the right time.

- We know from our strategy what our goals are and we ask ourselves what will a difference a decision will make - whether it brings us towards our goals. We evaluate [technology options] with respect to our market goals. We look at where we want to go - growth, for example - and have a vision of what system we want to build up that is supported by our strategy. We decide on the basis of how this technology will help what we are aiming for.

- The advantage of having people with experience is that they all have a pretty good knowledge of which trade-offs might occur when we are investing in new technology. 


\section{Hypothesis B1: Extraneous Factors}

- Many company owners say that if they have [an AMT] then the person who has the skills to run it will be the boss in the future. This presents a barrier to people purchasing the equipment -- the need to have people with high skills to run the equipment. Often owners are afraid to bring in these types of people as they are concerned that the person with these skills will take over the operation..

- Companies don't have great strategic planning departments, maybe only one or two people.

- We follow what the developments are in existing technologies. Any change in technology must be justified by getting good value. When looking at a new technology we critically evaluate the suppliers capabilities to supply our needs. Our suppliers also ask us what we are looking for and what we expect.

- Now we are in a moment where the evolution in technologies is not radical but is being driven by changes in the organization of production. For example, one way to lower costs is to use your equipment on three shifts. ... So it is just not the technical needs of the customer but mostly today it is organizational needs that are creating new opportunities for the development of the equipment.

- It does very often happen that decisions are made based on feeling instead of actual calculations.

\section{Model Extension: Product Requirements}

Argument 1: In some firms, product requirements drive the development of manufacturing capabilities.

- Companies do not really look at the details during technology evaluations. What they have is a part they want to produce, then they find the machine that can make that part. They put the part on the table and the machine tool manufacturer provides a bid on what it would cost for a machine to produce that part.

- Commonly, equipment is purchased to respond to a change in product requirements. An evaluation of the technology's strategic impact is limited to how any process changes will affect certification.

- A change [in equipment] is always combined with the cycle of new products. Things would not change dramatically within one product cycle.

Argument 2: The relationship between product, process and resource requirements involves choices on how to organise production.

- We do not know the links. The problem is that for these operations, we have machinery for them, but what this machine is doing is meant for another product line, so more and more machinery is added. Then we run into problems because the specs for this family here are okay, here it becomes more tight, here it's critical. Then you have the problem you are working on these critical parameters, losing time, and these other guys are screaming, "Where are my parts?" Now the question comes up, what do you do? Are you putting more cells for everyone or are you investing in dedicated machine, perhaps not a $100 \%$ occupied, specific for this product line? Question mark. If you have too many product lines and you buy a machine for each line, then perhaps you have to invest maybe three or four or five smaller machines, but its still a huge investment. Are you sticking to one cell that is more open-ended, more complex, has everything, or are you going to small, dedicated machinery for the family. The technical guys would like the very complex, nice machinery, but the production guys prefer the simple things and more than one. Then if I have a problem, I have some way out. If you give me too many complex things and there's something broken, a lot of families are suffering.

- If you look at new product introduction over the next five years, in most companies it will account for 20 to $25 \%$ of the overall output. You now have to go back and look at the other $75 \%$ and say how can I now get more effective use out of this group of machines I've got. 


\section{Hypothesis B2 Validation}

Hypothesis B2: Firms are more likely to succeed in instituting a change in competitive priorities through manufacturing strategies focused on system capabilities than through strategies focused primarily on technology adoption.

Argument 1: Technologies, by themselves, do not embody capabilities.

- Technology is important but almost all companies have access to these technologies and rather quickly. The competitive edge we can keep on a long term basis is not just by buying a new machine but by learning to use that equipment in a certain application.

- A lot of our competitors are looking at the equipment speed rather than the timing of production and then they have their product in stock for several months. We have come to conclusion that it is more economical to run the materials to produce what is immediately needed on the market, looking at the entire system.

- Instead of new technology, we emphasise improvement of our internal processes.

- Just pure technology won't get you there. ... It's not one all singing, all dancing, gleaming new machine that makes it work, that's a fallacy.

- In general, it is easy for companies to let the technology get out of control. They don't consider how the technology adds value and end up using resources to make things without adding value. ... Manufacturing people don't understand the chain of operations. There is a need to understand the complete chain, for example, how customers place orders, so as to understand how manufacturing can add value.

- People must understand the systems, not just the individual processes. For example, if I speed up this process, what will be the system consequences? We would like to have bigger capacity at the end of the system so that there will not be any bottlenecks, but if you start optimising in between, you can create bottlenecks.

Argument 2: The integration of new technology with organisational practices and structure is a crucial step in aligning the firm's capabilities with its business objectives.

- The integration of technology and organisational practices and structure is vital. Companies cannot implement new technology without changing their processes. The biggest bottleneck now is changing work practices to align with the new technology.

- But the real key, in my view, is that you design the manufacturing system, and that includes the methods you're going to use, the technology you're going to use, and the way you're going to control it, and then you select the appropriate tools. People don't generally do nearly enough work in designing manufacturing systems. A fair number of companies have made the mistake of thinking that if we do the methodology bit, if we get people trained, working in teams, getting change-over times down, working in cells, those sort of things, then they can avoid spending money on capital equipment. First, there isn't one solution: it's a combination of taking the benefits of working in teams and getting everyone cross-trained and making sure that people understand the aims of the module, then linking that with the new technology that enables things to be done in a fully process capable way. It's the combination that really gets it - it isn't just one thing.

- The final step is to implement and make sure that you close the loop by integrating [the new technology] into company systems.

- The integration of technology practices and structure is very, very important. ... Deciding on internal capacity, external sourcing, and the personnel needed - all three must "shake hands", so that we the total capability to produce what is needed at the right time.

- Strategy has to make sense for the whole company.... Strategy must be upgraded to be in alignment with what is going on in the market to succeed. 
- Companies who are technologically oriented have product and production related in their minds.

- Integration is extremely important to our ability to compete. In the very early phases, before we start production, we try to understand what kind of manufacturing technologies should be used to manufacture the new products. We also examine how the new technology can be of use with existing products.

Argument 3: Manufacturing capabilities can provide a distinctive basis for competitive success.

- We saw the possibility to focus on ... that production solution. Now we are implementing a new [technology] generation, which might give us an even more competitive edge.

- Firm-distinctive manufacturing capabilities support our focus ... With mass products this is not so much an issue, because it is easy to find a partner with the needed capabilities.

- Technology-wise there are several different developments recently and there has been a lot of capacity coming on. But we are waiting to use new processes as our current processes are suited to our smaller volumes. We are evaluating a change to a more advanced technology but are waiting until the process is less expensive.

- We faced the problem that small and medium-sized companies were not developing strategies. However, in cooperation with trade associations, we have launched a program on how to systematically approach and systematically develop technology strategy plans.

- In the market we operate in we have distinctive, value-adding manufacturing capabilities. We use these to differentiate our product in the market from our competition.

\section{Hypothesis B2: Extraneous Factors}

- The decision to create a new portion of the shop floor was related to a special project to produce for a new customer. The same decision can come about from the need to replace old equipment.

- $80 \%$ of the decisions are on a project basis. If everything goes well and they integrate the result into their systems, then they may get to a second or third round [of projects] by themselves and then it gets to have a more systematic look to it.

- Investment decisions are made on a project basis. These decisions are made completely by upper management.

- We have a very flat organization, which means that, in all these projects, all levels are represented in the entire lifetime of the project. We sit with the technicians and operators and discuss project development. So, I can't say its either [top down or bottom up], it's a combination. 


\section{Hypothesis B3 Validation}

Hypothesis B3: Firms with practices for identifying and assessing trade-offs exercise a wider range of technology choices than firms without such processes.

Argument 1: Knowledge of which dynamic capabilities offer a firm selective advantage is linked to the firm's ability to identify trade-offs.

- [We have taken] a major initiative to systematically introduce companies to how they can do business and technology planning. This includes researching the market possibilities, competitiveness analysis, analysis of what technologies are needed, where to source information and equipment. Technology selection is based on the identification of the company's competitive position and management of critical success factors. This analysis is used to visualise alternative production technologies. The choice is made by evaluating the advantages of the various operations.

- We know from our strategy what are goals are and we ask ourselves what difference will a decision make - whether it brings use towards our goals... We take a balanced view when its comes to new technology. We're not extremely positive, we're not extremely negative. We have a view of what possibilities does it bring you, what problems are there to overcome.

- The more knowledge people have got, then the better manufacturing process they will put together.... There is always the risk. One of the real jobs of the manufacturing systems engineer is to evaluate that risk.

- When we evaluate the technologies for purchase, starting at the planning phase, we are looking at what we need and to avoid problems in the latter stages. So it is a preventive approach, and we don't get the reaction. Sometimes there are problems but usually not if you do your homework.

- Very few [companies] think about constraints. People have a tendency to forget about the constraints and they think only about the benefits. It is very difficult discussion to advise your clients of the technology's drawbacks. On the one hand, you want to give them accurate information, on the other, you want to sell the machine. We have several instances where we have told it as it was and we have lost orders to companies that have told a pretty story.

- In looking at the technology's strategic impact, we try to understand what the technology might provide in terms of competitive advantage. Identifying trade-offs is key to understanding the future. What is needed [in the future] will be different.

Argument 2: Manufacturing strategy should inform daily operational decisions through a process for making good decisions.

- In companies that are leaders we have the impression they want to change the market. They see potential applications of equipment and then they decide on what it takes to get there.

- When we decide to make an investment, we usually consider what will be the life of the investment and what will be the effect on the actual production and the advantage we will gain.

- Our customers have time to work with a mixed model, old and new technology together. When they are confident with the new technology, we can introduce more machines and bigger systems. Through this incremental substitution of new technologies, the people who are working with the machines follow the path that we designed for the correct use of the system. You can feel how you are changing the way they are working.

- First of all, what's needed is awareness of the possibilities. Then you find ways to free up resources to think about new ways to do things with the hope of some easy successes - you really cannot go and ask for a large commitment and then say we'll see in three years. You start with a small effort and then use the results to argue for a change. You make some small steps in one product line and use these successes to convince. That's my strategy, small steps, then the big ones. You really have to take your factory step by step. 


\section{Model Extension: The Timing of Adoption}

An evaluation of trade-offs may lead to a decision not to adopt a technology or to adopt at a later time.

- We are late adopters and not very experimental when it comes to new technologies. If you are more experimental, then it may be the case that it may not fit your organisation.

- The reason for a change in strategic orientation is, as always, to try to find a strategy that we are more or less alone in. We don't want to be a commodity supplier.

- We try to implement the technologies when they are so far developed that we know what changes will be necessary and how they integrate with our systems.

\section{The Influence of Strategy on the Direction of Technological Change}

The organisation of production, with regard to the firm's dynamic capabilities, embodies their future.

- The configuration aspect is very relevant [to the firm's vision]. There is the challenge of not only designing the system but configuring it for a specific demand. There is a lot of difference from one company to another.

- If you want a real step-change in operational effectiveness then you've got to go through the gambit of designing how this machine fits into the overall process. You've got your structure, practices, and your technology, and you've got to make progress in all three.

- We are also more systematically viewing the entire production process because we are going to change our strategic focus.

- If you got some of idea of what products are going to be required and if you get manufacturing people involved in the product introduction process, so that you are looking at the manufacturing process technology ahead of it hitting the factory floor, then you can do simple evaluations - if you go out and buy a machine, will it actually provide the benefits you are looking for? For example, will it machine to the tolerance you are stating, and prove it out before you get into production. If you know your markets are going to change, then we got to spend more money on making sure that the machines are flexible enough. 


\section{Alternative Explanations}

\section{Product Life Cycle Theory}

- In the past we had transfer lines and machining centres, but as their production was focussed on large scales, companies used transfer lines. The other technology was available but it was not the right production strategy for that volume. But now, it is changing because the volume for products, in series, is getting smaller and there is a greater diversity of products. It is a change in product variation on the side of the customer, although the technology is not new.

- There are always a lot of different influences [on the organization of production]. New technologies could imply a new structure of production, for example, when changing from welding to laser welding. But, on the other hand, it often depends on the number of products the customer has. A change is always combined with the cycle of new products. Things would not change dramatically within one product cycle.

- Normally, [when implementing a new technology], companies know the changes they have to make beforehand. They want to get the benefits of the machines. They will replace shop floor workers who are not familiar with the technology. Sometimes in the case where the company is small, they are not prepared for the changes they have to make.

- The change in organization is always related onto the needs of the product and, of course, costs. If companies can, they will produce on the existing equipment or if that would be too expensive, then, they will make it in a different way. 


\section{Appendix E Trajectory Data from Interviews}

The interview records in this appendix are organised in two ways. Tables E1 through E4 provide categorical responses. (The interview questions are provided first to assist in the tables' interpretation.) Tables E5 and E6 record more extensive comments by trade-offs and emergent capabilities respectively. Table E7 records comments on sustainability.

\section{Questions}

\section{Select Manufacturing Technologies}

Question: Which of these technologies do you use routinely in your plant?

1 Machining centre

2 High-speed machining centre

3 Computerised manufacturing planning system

3.1 Used in production planning (e.g. ordering, procurement, materials routing)

3.2 Used in process planning (e.g. selection and sequencing of machining operations; selection of machine tools; generation of tool paths)

4 Product data management system

5 Simulation or modelling techniques

5.1 Used in process modelling (e.g. computerised physical or mathematical models that imitate process performance)

6 Knowledge-based systems (e.g., artificial intelligence, neural networks, fuzzy logic software)

\section{Terms of Product Competition}

Question: For your markets, what changes, if any, in the terms of product competition do you foresee in the next 3 to 5 years? That is, do you think that any of the terms of competition listed on the sheet might become more important than they are now, or that there will be other means not listed?

1. Cost

2. Quality

3. Performance based on product features (i.e., product uniqueness deriving from distinctive product features)

4. Faster product development (i.e., faster time-to-market, shorter product life-cycles)

5. Speed of delivery (i.e., faster production throughput times, faster time-to- customer)

6. Delivery reliability

7. Customisation or individualisation

8. Value (i.e., higher performance for the same or lower cost)

9. Service content - product support

10. Rapid response to changing customer requirements

11. Environmental friendliness 


\section{Manufacturing Objectives}

Question: Have any of these (manufacturing) objectives changed in the last three to five years, that is, become more or less important?

1. Increased flexibility

2. Faster product cycle times

3. Tighter process control

4. Greater ability to manage trade-offs

5. Increased productivity

6. Increased speed

7. More knowledge capture and utilisation

8. Process simplification

9. More dynamic capability (i.e., more ability to adapt rapidly to change)

\section{Potential AMT Trade-Offs}

Question: In using AMTs have you experienced any of the following trade-offs?

1. More flexibility but greater complexity

2. More flexibility but greater capital intensity

3. Shorter times-to-market but greater break-even sales volumes

4. Increasing system efficiency through process integration but greater complexity

5. More automated interactions with customers/suppliers but decreasing system autonomy

6. Increasing knowledge value but faster knowledge obsolescence

7. More resource utilisation but greater risk exposure (e.g. risk of losing trained workers, risk of large fixed costs in volatile markets, risk of losing advantage through sharing knowledge)

8. More product performance and customisation but increasing service complexity More agility but increasing technology-related needs 
Responses: Summary Tabulation

\section{Table E1: Manufacturing Technologies}

\begin{tabular}{|l|c|c|c|c|c|c|c|c|c|c|c|c|c|c|c|c|c|c|c|c|c|}
\hline & 1 & 2 & 3 & 4 & 5 & 6 & 7 & 8 & 9 & 10 & 11 & 12 & 13 & 14 & 15 & 16 & 17 & 18 & 19 & 20 & 21 \\
\hline Machining Centre (or equivalent) & & $\mathbf{C}$ & $\mathbf{C}$ & $\mathbf{C}$ & & $\mathbf{C}$ & & & $\mathbf{C}$ & & $\mathbf{C}$ & & $\mathbf{C}$ & $\mathbf{C}$ & $\mathbf{C}$ & $\mathbf{C}$ & & $\mathbf{C}$ & $\mathbf{C}$ & $\mathbf{C}$ & $\mathbf{C}$ \\
\hline High-Speed Machining Centre & & $\mathbf{C}$ & $\mathbf{C}$ & $\mathbf{C}$ & & $\mathbf{C}$ & & & $\mathbf{C}$ & & $\mathbf{C}$ & & $\mathbf{C}$ & & $\mathbf{C}$ & $\mathbf{C}$ & & & $\mathbf{S}$ & $\mathbf{C}$ & $\mathbf{C}$ \\
\hline Computerised Production Planning System & & $\mathbf{C}$ & $\mathbf{C}$ & $\mathbf{S}$ & & $\mathbf{C}$ & $\mathbf{C}$ & $\mathbf{C}$ & $\mathbf{C}$ & & $\mathbf{C}$ & & & & $\mathbf{C}$ & $\mathbf{C}$ & & $\mathbf{C}$ & $\mathbf{C}$ & $\mathbf{C}$ & $\mathbf{C}$ \\
\hline Computerised Process Planning System & & & $\mathbf{C}$ & & & & & $\mathbf{C}$ & $\mathbf{S}$ & & & & & & $\mathbf{S}$ & & & & & $\mathbf{S}$ & \\
\hline Product Data Management System & & & $\mathbf{C}$ & & $\mathbf{C}$ & & $\mathbf{R}$ & $\mathbf{C}$ & & & $\mathbf{S}$ & & & & & & & & $\mathbf{C}$ & $\mathbf{R}$ & \\
\hline Simulation and Modelling Technologies & & $\mathbf{S}$ & $\mathbf{C}$ & $\mathbf{R}$ & & $\mathbf{C}$ & & $\mathbf{C}$ & $\mathbf{C}$ & & $\mathbf{C}$ & & & & $\mathbf{C}$ & & & $\mathbf{C}$ & $\mathbf{C}$ & $\mathbf{C}$ & $\mathbf{C}$ \\
\hline Process Simulation & & & $\mathbf{C}$ & & & & & $\mathbf{C}$ & & & $\mathbf{C}$ & & & & $\mathbf{R}$ & & & $\mathbf{C}$ & & $\mathbf{R}$ & \\
\hline Knowledge-Based System & & & $\mathbf{C}$ & $\mathbf{R}$ & & & & $\mathbf{C}$ & & & & & & & & & & & & & \\
\hline Modular Controls or Processes & & & $\mathbf{R}$ & & $\mathbf{R}$ & & & & & & & & & & & & & $\mathbf{R}$ & & & \\
\hline No Data Collected & $\mathbf{X}$ & & & & & & & & & $\mathbf{X}$ & & $\mathbf{X}$ & & & & & $\mathbf{X}$ & & & & \\
\hline
\end{tabular}

C: Commonly or routinely used

S: Sometimes used

R: Rarely (infrequently) used or plan to purchase

Table E2: Terms of Product Competition

\begin{tabular}{|l|c|c|c|c|c|c|c|c|c|c|c|c|c|c|c|c|c|c|c|c|c|}
\hline & 1 & 2 & 3 & 4 & 5 & 6 & 7 & 8 & 9 & 10 & 11 & 12 & 13 & 14 & 15 & 16 & 17 & 18 & 19 & 20 & 21 \\
\hline Cost & & & M & I & & M & & M & & I & & & I & & & I & I & M & & I & M \\
\hline Quality & M & & M & I & & & M & M & & & I & & & & & I & & & M & M & I \\
\hline Product Features & & I & & I & & & & & & & I & I & I & I & & & & & & I & \\
\hline Faster Product Development & + & & & & + & & I & I & I & & & I & & & I & & & I & + & I & + \\
\hline Speed of Delivery & & & & I & & I & & I & & & & & I & + & & I & & & I & & I \\
\hline Delivery Reliability & + & & I & I & & I & I & I & & & & & & & & & & + & I & & M \\
\hline Customisation & & I & I & & + & I & I & + & I & & I & I & & & & & & & & + & \\
\hline Value & I & & & & & & & I & I & & & & I & I & & & & & I & I & \\
\hline Service Content & + & + & + & & & & + & & & & & & & & I & & & + & + & & \\
\hline Rapid Response & I & + & & & + & & + & & & & & & & + & & & & & & & I \\
\hline Environmental Friendliness & & & & & & & & + & & & & & & & & & & & & & \\
\hline
\end{tabular}
I: Important
+: Becoming more important
M: Must (order qualifier) 
Table E3: Manufacturing Objectives

\begin{tabular}{|c|c|c|c|c|c|c|c|c|c|c|c|c|c|c|c|c|c|c|c|c|c|}
\hline Manufacturing Objectives & 1 & 2 & 3 & 4 & 5 & 6 & 7 & 8 & 9 & 10 & 11 & 12 & 13 & 14 & 15 & 16 & 17 & 18 & 19 & 20 & 21 \\
\hline Increased Flexibility & & I & I & I & & I & & & I & & I & & & & I & I & I & - & I & I & \\
\hline Faster Product Cycle Times & & + & & & & & + & & $\mathbf{I}$ & & I & & & & & & & & $\mathbf{I}$ & I & \\
\hline Tighter Process Control & & & & & & & & & & I & & & I & & & & $\mathbf{I}$ & - & + & + & \\
\hline Greater Ability to Manage Trade-Offs & & & & & & & & & & & & & & & I & & + & & & & \\
\hline Increased Productivity & & & & & & I & & & I & $\mathbf{I}$ & I & & $\mathbf{I}$ & & $\mathbf{I}$ & $\mathbf{I}$ & I & + & $\mathbf{I}$ & $\mathbf{I}$ & \\
\hline Increased Speed & & & & & & $\mathbf{I}$ & & & & & & & & & & & & + & $\mathbf{I}$ & $\mathbf{I}$ & \\
\hline More Knowledge Capture and Utilisation & & & & $\mathbf{I}$ & & & & & & & & & & & & & & & & & \\
\hline Process Simplification & & I & & & & I & & & & & & & & & & & & $\mathbf{I}$ & & $\mathbf{I}$ & \\
\hline More Dynamic Capability & & & & & & & & + & $\mathbf{I}$ & & + & & & & & & & $\mathbf{I}$ & + & + & \\
\hline No Data Collected & & & & & $\mathbf{X}$ & & & & & & & & & $\mathbf{X}$ & & & & & & & $\mathbf{X}$ \\
\hline
\end{tabular}
I: Important
+: Becoming more important
$\mathrm{X}$ : No data collected

\section{Table E4: AMT-Related Trade-Offs}

\begin{tabular}{|c|c|c|c|c|c|c|c|c|c|c|c|c|c|c|c|c|c|c|c|c|c|}
\hline & 1 & 2 & 3 & 4 & 5 & 6 & 7 & 8 & 9 & 10 & 11 & 12 & 13 & 14 & 15 & 16 & 17 & 18 & 19 & 20 & 21 \\
\hline Flexibility $\leftrightarrow$ Complexity & & C & $\mathbf{S}$ & & & $\mathbf{C}$ & $\mathbf{C}$ & & $\mathbf{C}$ & & $\mathbf{S}$ & $\mathbf{N}$ & $\mathbf{C}$ & & $\mathbf{C}$ & $\mathbf{C}$ & & & $\mathbf{C}$ & $\mathrm{C}$ & $\mathrm{C}$ \\
\hline Flexibility $\leftrightarrow$ Capital Intensity & & $\mathbf{C}$ & $\mathbf{S}$ & & & & C & $\mathbf{C}$ & $\mathbf{C}$ & & & $\mathbf{N}$ & & & $\mathbf{C}$ & $\mathbf{C}$ & & & $\mathbf{S}$ & $\mathbf{C}$ & $\mathbf{C}$ \\
\hline Time-to-Market $\leftrightarrow$ Sales Volume & & $\mathbf{C}$ & $\mathbf{N}$ & C & & $\mathbf{C}$ & $\mathbf{N}$ & & $\mathbf{C}$ & & & $\mathbf{N}$ & & & & & & $\mathrm{C}$ & $\mathbf{S}$ & & $\mathbf{C}$ \\
\hline System Efficiency $\leftrightarrow$ Complexity & & $\mathbf{R}$ & $\mathbf{C}$ & & $\mathbf{C}$ & & & & & & $\mathbf{S}$ & $\mathbf{N}$ & & & & & & $\mathbf{S}$ & $\mathbf{N}$ & & $\mathbf{C}$ \\
\hline $\begin{array}{l}\text { Automatic Interactions } \leftrightarrow \text { System } \\
\text { Autonomy }\end{array}$ & & & $\mathbf{N}$ & C & & C & & & C & & & $\mathbf{N}$ & & C & & $\mathbf{R}$ & & $\mathbf{N}$ & $\mathbf{N}$ & & $\mathbf{C}$ \\
\hline $\begin{array}{l}\text { Knowledge Value } \leftrightarrow \text { Knowledge } \\
\text { Obsolescence }\end{array}$ & & & $\mathbf{S}$ & & & & & $\mathrm{C}$ & & & & $\mathbf{N}$ & & & $\mathbf{C}$ & & & $\mathbf{S}$ & $\mathbf{N}$ & $\mathrm{C}$ & $\mathbf{S}$ \\
\hline Resource Utilisation $\leftrightarrow$ Risk Exposure & & $\mathbf{C}$ & & & & & & & $\mathbf{C}$ & & & $\mathbf{N}$ & & & $\mathbf{S}$ & & & $\mathbf{C}$ & $\mathbf{S}$ & $\mathbf{C}$ & \\
\hline Customisation $\leftrightarrow$ Service Complexity & & $\mathbf{C}$ & C & C & & & & C & & & & $\mathbf{S}$ & & & $\mathbf{C}$ & C & & & $\mathbf{C}$ & & $\mathrm{C}$ \\
\hline Agility $\leftrightarrow$ Technology Needs & & & & & & & & & & & $\mathbf{C}$ & & & & $\mathbf{C}$ & $\mathbf{S}$ & & & & C & \\
\hline No Data Collected & & & & & & & & & & $\mathbf{X}$ & & & & & & & $\mathbf{X}$ & & & & \\
\hline
\end{tabular}
C: Commonly experienced
S: Sometimes experienced
R: Rarely Experienced
$\mathrm{N}$ : Not experienced at all 


\title{
Table E5 AMT-Related Trade-offs
}

\author{
Equipment/Process/System Complexity
}

- Everything gets so complex that it's very difficult to handle this. Machines are also much more expensive. The price [of a flexible machine] can be twice as great. These machines are a new dimension.

- The machines are getting more and more complicated.

- A major problem is that although the equipment is more flexible, more set-up time is required with all the changeovers - with consequent greater costs.

- Our big challenge here is either you do this faster, time-to-market and product development, and although this is on track to bring it to the customer, and that means including the packaging, the manufacturing process, and the machinery - how do you start with high-labour machinery and then go to more automated manufacturing? How do you do that? You have a high risk option most of the time, very complex machinery.

- Our customers don't see complexity as a specific problem. They accept different ways of producing if there is a benefit involved.

- You generally do get more flexibility but ... then often you can't exploit the flexibility because the equipment just becomes too complex to use. If you can keep the changeover down to software changes then you certainly get a lot more flexibility. The other great thing about it is you can certainly do more machining operations in one go. But it will require more complexity.

- We don't see process simplification happening. The processes are always very complicated. There has been talk about it but it does not occur in general.

- Process simplification is somewhat tied to ease-of-use issues but the machine is just one part of the process. Electronically based equipment is still a problem on the market because there are just a few people knowledgeable in this technology. In one case it took a year and a half to get a machine to run.

- If you make it too complicated, you become vulnerable for breakdown or loss of personnel. Change requires a more simple solution.

\section{Service Complexity}

- As service content gets bigger and bigger, the hardware part can't cover the service price as well. Some examples include: programming, pre-assembly on through to recycling, take-back services, training. ... The service part grows and grows. ... Suppliers can't include this support in the initial price because it would then make the initial price out of range. Technology buyers aren't thinking about how they need these services. But you also have to sell services up front, set up a service account, otherwise the machine never does perform correctly.

- [Flexible] machines are also more simple than they were ten years ago. Suppliers are using electronics to make things easier for the user. Being user-friendly is a great competitive advantage. At the same time servicing of the equipment is becoming more complex. But, in general, users are not seeing problems with complexity to the same degree as in the past.

\section{Break-Even Sales Volumes}

- $[\mathrm{Y}]$ ou don't need a huge volume of the same thing but at the same time you need sales volume. Of course [new equipment] means higher fixed costs and consequently a higher volume to spread them over. The cost of investment must be spread over a higher number of hours to recover the costs of investment which means higher production levels. To work one shift is not possible.

- Machine tools are very expensive which requires that equipment suppliers offer support to their customers in sizing the equipment for the growth of the company or otherwise the company will suffer a lot. 
- Another thing we have been doing is changing our strategic focus, focusing on a more narrow product range. We have chosen some core products and we are going to put almost all our investments in production and product development in those areas. That means that will be able to invest in more advanced and expensive equipment for those products, which forces us to produce much larger volumes of those products. We are more or less creating a fully automated production line with still reasonable flexibility. One of the trade-offs is, of course, that flexibility comes down when you make a fully automated solution, but we are trying for stability, higher efficiency, and lower cost per unit.

- The important trade-off for us is the bigger break-even sales volumes. The investment [in AMTs] is getting larger and larger in each single case, which brings up the break-even volume. That in itself brings up the demand even more, because if we want to get that volume, we have to come down in price, which means that margins are smaller and smaller. Then we have to increase the volume in order for us to get the same mount of revenue. New equipment tends to drive the volumes extremely large.

\section{Break-Even Product Variety}

- Market share is proportional to the variety that you offer.

- World output capacity in the automotive sector stands at 60 million vehicles whereas the demand is 50 million. In such conditions, it is vital to offer updated product ranges. The latter is facilitated through continuous re-modernisation of the product range.

- We can't say that we introduce ten products and half of them will fail. It's not acceptable. We can't take that anymore. It was possible ten years ago. It wasn't an issue, but now the cost of the equipment has come up to a much more risky level.

\section{System Structural Requirements}

- You are much more tightly controlled and need to use the same systems. All capabilities must be declared for all the machines you intend to use to manufacture the customer's products. As soon as you apply to become a supplier they send you a huge questionnaire about capabilities. You start to be controlled even before you start to work with them.

- When you select one component, you are forced to select all the other components in the different systems - these are not independent from each other.

- We need some choice in the development [of more automated interactions]. The focus should be on ready-to-be-integrated.

- What we're moving to now is interdependence. All parts of the supply chain have to work in partnership.

- The computers are telling you what the system should be [on the shop floor] not the other way around. The system is stiff, not responsive enough. We have heard about this from other companies. You need to have a system where you can make the changes.

- Everybody want to share data [through PDM]. But again, unless you get a handle on that data, and unless that data is accurately monitored and, to some, extent, controlled, then you get the same problems as with computerised production planning. You can't get a sufficiently accurate representation of the manufacturing process.

\section{Knowledge Obsolescence}

- Knowledge of the machine becomes outdated faster, but knowledge of the process has continuing value.

- AMTs can help in managing knowledge, but the knowledge does become old rapidly. There is a lot of room to develop new organisational models - the knowledge enterprise.

- Yes, technology moves on faster. ... You've got to take people to a level and once there you can take them under to another level. Once they got themselves in the mode that they can acquire knowledge then they can easily cope with the obsolescence of that knowledge. 


\section{Other Trade-Offs}

- Ten years ago we had the need for low skills. Now we have far fewer people but they are more specialized. You should also take into account that work is also more interesting now. What has been left for people is the more interesting part. We would like a company that people don't have to do jobs that machines could do.

- If I was taking out five machines and put in one machining centre and if that was my only machining centre then if I went down, then my customers were at greater risk, because if I had five if one went down but I still keep the other four running. As you make your resources work harder, yes there is that risk, but also the advantage of making that resource work harder and utilizing it, particularly around the clock, means that I can write it off quicker, I can make the return on it and I can buy another piece of equipment with more refinement, more technology and works to even greater process capability.

- [A trade-off between faster product cycles] and quality can happen. This is affected by the company's decision on when to introduce the product to the market. You can take the time to get the product right.

- There is a tension between quality and time-to-market. For example, a mill with which I am working, has a safety procedure requiring 3 weeks incubation time but with the push to reduce the time-tomarket, a potential risk is involved in cutting short the incubation. 


\section{Table E6 Emergent Capabilities}

Managing Complexity

- You've got to understand what that complexity is and you've got to manage the process that enables you to handle it.

- Machines are also simpler than they were ten years ago. Suppliers are using electronics to make things easier for the user.

- Customers are asking for easy-to-use equipment. They want more complex performance but they also want us to simplify the use of the technology. We put the intelligent parts inside the machinery.

- Complexity means that you need trained people, who you have to pay more and who are subject to temptations from other companies. You have to incur the risk that one day they will leave the company and their know-how will leave with them. So you have to train a number of people.

Volume Flexibility

- The orders are changing very rapidly and we don't carry many weeks order backlog. The volumes are changing all the time which requires volume flexibility.

- Speed of delivery and delivery reliability are difficult in a volume business.

- There is a big variation in volumes during the life cycle. Sub-contractors may have even more of a problem as they cannot foresee the demand, the shift in the volume. This is the major problem for our customers. But flexibility makes management of this problem easier.

- There is a lot of variance in the volume requirements which dictates volume flexibility. The main objective is to have the ability to change the product quickly while still answering to the demands of volume.

Adaptability

- The way we try to make the trade-off regarding capital intensity is to offer systems that can grow. Capital costs are also a problem for big companies especially given the hype around many of the earlier systems. The failure of many AMTs was related to their scale. By introducing small systems, people can learn how to work with the system, then you can add more.

- Our customers are asking that we focus that flexibility. They are saying that they don't want to pay for all the flexibility we can sell them because its not needed, but give me the flexibility that is currently needed and the potential to add or upgrade flexibility as needed.

- Machine tools are very expensive which requires that equipment suppliers offer support to their customers in sizing the equipment for the growth of the company or otherwise the company will suffer a lot. This is the advantage of taking an incremental approach in working with technology users.

- Reusing means having some mechanical modules that can be used in different contexts. These provide a high level of flexibility but nevertheless we have to provide reliable systems. And when you make one customer one specific manufacturing system, not sometimes, but always, you need to make some tradeoffs with reliability - with a product that can compete with those offered by firms that produce big volumes of identical machines - because you have less testing for these products. So we would like to put robustness in our products even if we make just one.

- Modularity, more than a goal by itself, is a weapon to try to challenge the complexity of [the machinery]. ... [T] o arrive at complete exploitation of the modularity concept you need a process that leads towards reusable modules. Reusability is central.

- Process simplification is something we are trying to do. We are looking into process modularisation and think we can find some interesting solutions there, more flexible solutions, while still cost effective. 


\section{Table E7 Sustainability}

Use Value

- The customers are fashion conscious, especially the younger ones and they like the newer models.

- For all manufacturers today the life cycle is getting shorter and that's a problem. But if you look at the top ten list, at the volumes of products, we have some products that are more than twenty years old and that's incredible.

- We are talking to the distributors or to the big trading companies. He is looking at our product almost every day, and discussing them with us, and discussing deliveries and colours and blah, blah, blah - he's getting bored very quickly. The consumer he buys a product from our range maybe once a year an then he replaces that product fifty years later - he's not into that part, he doesn't remember what he bought last time, fifty years ago ... But the problem is that the buyers are getting bored much faster than the consumer. It's a big problem.

Environmental Friendliness

- Our customers do not see pressure from the market for environmentally friendly products, not at all. It was a bit of a hype for awhile and now that's passed.

- A few years ago you only needed to say the product was environmentally friendly and that would do the trick. But that is an argument that people don't buy so much anymore.

- Lean manufacturing is nothing more than [waste prevention]. ... Clean production is just straight forward trying to minimize the cost of waste emissions.

- I think in the early 80 's we made a big leap, everyone became environmentally aware, we got good, modern environmental laws, a lot of work was done throughout the early 90's. And now everyone says, well, we've done it. ... Everybody feels we're doing our thing, we've finished this problem and let's go on to the next problem. They think we fixed it.

- Environmental friendliness is not a market emphasis.

- There are no particular criteria to evaluate sustainability.

- Companies are taking quite responsible views in environmental decisions. You wouldn't take run the risk of putting in dangerous processes. ... [Environmental approaches] are a central theme in any company that is really going to make progress in the future. It's part of the way we do business today. 


\section{References}

Abernathy, William J. and Kim Clark. 1985. Innovation: Mapping the Winds of Creative Destruction. Research Policy 14, 3-22.

Abramovitz, Moses. 1982. The Retreat from Economic Advance: Changing Ideas about Economic Progress. In: Progress and Its Discontents. Gabriel A. Almond, Marvin Chodorow, and Roy Harvey Pearce (eds.). University of California Press, Berkeley, California. 253-280.

Agility Forum, Leaders for Manufacturing, and Technologies Enabling Agile Manufacturing. 1997. Next Generation Manufacturing: A Framework for Action. CDROM Project Report. Agility Forum.

Alcorta, Ludovico. 1995. The Impact of Industrial Automation on Industrial Organisation: Implications for Developing Countries' Competitiveness. The United Nations University Discussion Paper Series \#9508.

Alcorta, Ludovico. 1998. Flexible Automation in Developing Countries. Routledge and UNU Press, London.

Alford, Robert R. 1998. The Craft of Inquiry: Theories, Methods, Evidence. Oxford University Press, Oxford.

Almond, Gabriel A., Marvin Chodorow, and Roy Harvey Pearce (eds.). 1982. Progress and Its Discontents. University of California Press, Berkeley, California.

Anderson, Bjørn and Tom Fagerhaug. 2001. Advantages and Disadvantages of Using Predefined Process Models. In: Strategic Manufacturing, Proceedings of the IFIP WG 5.7 International Working Conference on Strategic Manufacturing. Jens O. Riis, John Johansen and Anders Drejer (eds.). August 2001, Aalborg, Denmark.

Ang, Cheng Leong and Robert Keng Leng Gay. 1996. Development of a KnowledgeBased Manufacturing Modelling System Based on IDEFO for the Metal-Cutting Industry. International Journal of Advanced Manufacturing Technology 11, 449-461.

Annan, Kofi. 2001. The Nobel Lecture. Oslo, 10 December, 2001.

Arrow, Kenneth. 1962. The Economic Implications of Learning by Doing. Review of Economic Studies June 1962.

Ashford, Nicholas A. 1993. Understanding Technological Responses of Industrial Firms to Environmental Problems: Implications for Governmental Policy. In: Environmental Strategies for Industry. Kurt Fischer and Johan Schot (eds.). Island Press, Washington, D.C.

Association des Industries des Marques. 2001. Sustainable Consumption - A

Contribution to the Debate. AIM Position Paper. Available at: www.aim.be/docs/

Environment/sustainable_consumption.doc. Accessed: December 2001.

Ayres, Robert U. 1996. Limits to the Growth Paradigm. Ecological Economics 19, 117 134. 
Ayres, R.U., W. Haywood, M.E. Merchat, J. Ranta and H.J. Warnecke. 1992. CIM

Volume II: The Past, the Present, the Future. Chapman and Hall, London.

Baldwin, John R. and Brent Diverty. 1995. Advanced Technology Use in Canadian Manufacturing. Report on 1989 Survey of Manufacturing Technology. Ottawa: Statistics Canada Division, Micro-Economic Analysis Division.

Baldwin, John and David Sabourin. 1995. Technology Adoption in Canadian Manufacturing: Survey of Innovation and Advanced Technology 1993. Ottawa: Statistics Canada Division, Micro-Economic Analysis Division. Catalogue 88-512.

Baldwin, John R., David Sabourin, and Mohammed Rafiquzzaman. 1996. Benefits and Problems Associated with Technology Adoption in Canadian Manufacturing 1993 Report. Micro-Economic Analysis Division, Statistics Canada.

Baldwin, John R. and Zhengxi Lin. 1999. Impediments to Advanced Technology Adoption for Canadian Manufacturers. Paper. Micro-Economic Analysis Division, Statistics Canada.

Bartezzaghi, Emilo, Gianluca Spina and Roberto Verganti. 1994. Lead-Time Models of Business Processes. International Journal of Operations and Production Management 14(5), 5-20.

Baumol, Wlliam J., John C. Panzar and Robert D. Willig. 1982. Contestable Markets and the Theory of Industry Structure. Harcourt Brace Jovanovich, Inc., New York.

Bayus, Barry. 1994. Are Product Life Cycles Really Getting Shorter? Journal of Product Innovation Management 11, 300-308.

Beaumont, N.B. and R.M. Schroder. 1997. Technology, Manufacturing Performance and Business Performance amongst Australian Manufacturers. Technovation 17(6), 297-307.

Bijker, Wiebe, Thomas Hughes, and Trevor Pinch, (eds.). 1987. The Social Construction of Technological Systems: New Directions in the Sociology and History of Technology. MIT Press, Cambridge, MA/London.

Blanchard, David. 1995. Mass Customisation Replacing Mass Production. Intelligent Manufacturing. Available at: http://www.lionhrtpub.com/IM/Imsubs/IM-6-95/Im6Custom.html. Accessed: April 2001.

Block, Fred. 1990. Postindustrial Possibilities: A Critique of Economic Discourse. University of California Press, Berkeley, California.

Borgmann, Albert. 1995. The Moral Significance of the Material Culture. In: Technology and the Politics of Knowledge. Andrew Feenberg and Alastair Hannay (eds.). Indiana University Press, Bloomington, Indiana. 85-93.

Boulding, Kenneth E. 1966. The Economics of the Coming Spaceship Earth. In: Environmental Quality in a Growing Economy. H. Jarret (ed.). John Hopkins University Press, Baltimore, Maryland. 3-14.

Boulton, William R. 1995. Building the Electronic Industry's Roadmaps. JTEC Panel Report on Electronic Manufacturing and Packaging in Japan. Japanese Technology Evaluation Centre. Available at: http://itri.loyola.edu/ep/toc.htm. Accessed: June 1998. 
Bozarth, Cecil and Steve Chapman. 1996. A Contingency View of Time-Based Competition for Manufacturers. International Journal of Production and Operations Management 16(6), 56-67.

Britton, J.N.H. 1991. Reconsidering Innovation Policy for Small and Medium Sized Enterprises: the Canadian Case. Environment and Planning C: Government and Policy 9, 189-206.

Brooks, Harvey. 1982. Can Technology Assure Unending Material Progress?. In: Progress and Its Discontents, Gabriel A. Almond, Marvin Chodorow, and Roy Harvey Pearce (eds.). University of California Press, Berkeley, California.

Brown, Paul M. and Linda D. Cameron. 2000. What Can be Done to Reduce OverConsumption? Ecological Economics 32, 27-41.

Bullinger, Hans-Jörg. 1999. Turbulent Times Require Creative Thinking: New European Concepts in Production Management. International Journal of Production Management 60-61, 9-27.

Business and the Environment (BATE). 1995. Is Eco-Efficiency Enough to Move Business Toward Sustainability? Business and Environment VI(12), 2-5.

Cahill, Eamon and Fabiana Scapolo. 1999. Technology Map. Report for The Futures Project. Institute for Prospective Technological Studies, European Commission Directorate-General JRC Joint Research Centre. EUR 19031EN.

California Energy Commission. 2000. California Energy Demand 2000-2010. Technical Report. State of California Energy Commission P200-00-02.

Capra, Fritjof. 1996. The Web of Life. Anchor Books Doubleday, New York.

Cascadia Consulting Group. 1995. Waste Characterisation Profile of the Electronics Industry. Report for the Clean Washington Centre. Report No. IBP-95-2. Available at: http://www.cwc.org. Accessed: June 2001.

Chandler, Jr., Alfred D. 1990. Scale and Scope: The Dynamics of Industrial Capitalism. Belknap Press of Harvard University Press, Cambridge, Massachusetts.

Clark, Kim B. 1996. Competing through Manufacturing and the New Manufacturing Paradigm: Is Manufacturing Strategy Passé? Production and Operations Management 5(1), 42-58.

Clean Washington Center. 1995. Small-Scale Paper Fiber Recovery. Technology Brief. Available at: http://www.cwc.org/paper.htm. Accessed: June 2001.

Cleveland, Cutler and Matthias Ruth. 1997. When, Where, and by How Much Do Biophysical Limits Constrain the Economic Process? A Survey of Nicholas GeorgescuRoegen's Contribution to Ecological Economics. Ecological Economics 22, 203-223.

Cobb, Clifford, Ted Halstead, and Jonathan Rowe. 1995. If the GDP Is Up, Why Is America Down? Atlantic Monthly October, 59-78.

Connor, Kathleen and C.K. Prahalad. 1996. A Resource-Based Theory of the Firm: Knowledge versus Opportunism. Organization Science 7(5), 477-501. 
Conradsen, Niels and Marie Lystlund. 2001. The Vision of Next Generation Manufacturing: How a Company Can Start. In: Strategic Manufacturing, Proceedings of the IFIP WG 5.7 International Working Conference on Strategic Manufacturing. Jens O. Riis, John Johansen and Anders Drejer (eds.), August 2001, Aalborg, Denmark.

Daly, Herman E. 1996. Beyond Growth: The Economics of Sustainable Development. Beacon Press, Boston.

Deleryd, Mats. 1997. A Strategy for Mastering Variation. ASQC’s 51 st Annual Quality Congress Proceedings. 760-768.

De Marchi, Mario, Giovanni Napolitano, and Piero Taccini. 1996. Testing a Model of Technological Trajectories. Research Policy 25, 13-23.

Dosi, Giovanni. 1982. Technological Paradigms and Technological Trajectories. Research Policy 11, 147-162.

Dosi, Giovanni. 1988. Sources, Procedures, and Microeconomic Effects of Innovation. Journal of Economic Literature XXVI, 1120-1171.

DiSimone, L.D., F. Popoff, and World Business Council for Sustainable Development. 1997. Eco-Efficiency: the Business Link to Sustainable Development. The MIT Press, Cambridge, Massachusetts.

Ducatel, Ken, Jean-Claude Burgelman, Jeremy Howells, Erik Bohlin, and Matthias Ottitsch. 1999. Information and Communication Technologies and the Information Society Panel Report. Report. Institute for Prospective Technological Studies, European Commission Directorate-General JRC Joint Research Centre. EUR 18739EN.

Duncan, William L. 1994. Manufacturing 2000. American Management Association, New York.

Eldredge, Niles. 1998. Pattern of Evolution. W.H. Freeman and Co, New York.

Ehrlich, Paul R., Gary Wolff, Gretchen C. Daily, Jennifer B. Highes, Scott Daily, Michael Dalton, and Lawrence Goulder. 1999. Knowledge and the Environment. Ecological Economics 30, 267-284.

Ekins, Paul and Michael Jacobs. 1995. Environmental Sustainability and the Growth of GDP. In: The North, The South, and the Environment. V. Bhaskar and Andrew Glyn (eds.). United Nations University Press, Tokyo. 9-46.

Eurostat. 1998. Structural Business Statistics (Industry, Construction, Trade, and Services). Database.

European Commission. 1997. Panorama of EU Industry 97. Annual report of the European Commission.

Fleming, David. 1996. Beyond the Technical Fix. In: The Earthscan Reader in Business and the Environment. Richard Welford and Rchard Starkey (eds.). Earthscan, London. $11-34$.

Fortier, Y., L.M. Ducharme and F.Gault. 1993. A Comparison of the Use of Advanced Manufacturing Technologies in Canada and the United States. STI Review 12, 81-100. 
Foss, Nicholai. J. 1997. The Classical Theory of Production and the Capabilities View of the Firm. Journal of Economic Studies 24(5), 307-323.

Foss, Nicholai. J., Christian Knudson and Cynthia A. Montgomery. 1995. An Exploration of Common Ground: Integrating Evolutionary and Strategic Theories of the Firm. In:

Resource-Based and Evolutionary Theories of the Firm: Toward a Synthesis. Cynthia A. Montgomery (ed.). Kluser Academic Publishers, Boston, Massachusetts. 1-18.

Frank, Thomas. 1997. The Culture of Cool. University of Chicago Press, Chicago, Illinois.

Freeman, Christopher. 1992. The Economics of Hope. Pinter Publishers, London.

Freeman, Christopher and Carlotta Perez. 1988. Structural Crises of Investment, Business Cycles and Investment Behavior. In: Technical Change and Economic Theory. Giovani Dosi, Christopher Freeman, Richard Nelson, Gerald Silverberg, and Luc Soete (eds.). Pinter Publishers, New York. 38-66.

Galbraith, Kenneth. 1958. The Affluent Society. Houghton Mifflin Company, Boston, Massachusetts.

Galbraith, Kenneth. 1967; 4th ed., 1985. The New Industrial State. New American Library, New York.

Garvin, David A. 1993. Manufacturing Strategic Planning. California Management Review (Summer 1993), 85-106.

Gate, H. Frederick. 1997. Is There a Rural-Urban Technology Gap? Results of the ERS Rural Manufacturing Survey. Report by Economic Research Service, U.S. Department of Agriculture. Agricultural Information Bulletin 736-01.

Georgescu-Roegen, Nicholas. 1970. The Economics of Production, Richard T. Ely Lecture. American Economic Review, 1-9.

Georgescu-Roegen, Nicholas. 1976. Energy and Economic Myths. Pergamon Press, New York.

Ger, Gulitz, Hal Wilhite, Bente Halkier, Jeppe Laessoe, Mirjam Godskesen, and Inge Røpke. 1999. Symbolic Meanings of High and Low Impact Daily Consumption Practices in Different Cultures. Report for European Science Foundation TERM Programme. Available at: http://www.lancs.ac.uk/users/scistud/esf/wkshpb.htm. Accessed: August 2000 .

Ghosh, Soumen. 2001. Introduction to the Special Issue. Journal of Operations Management 19, 131-142.

Global Action Plan International (eds.). 2001. The Wallström Brains Trust. Background Paper to the 6th Environmental Action Programme, European Commission.

Goldhar, J.D. and M. Jelinek. 1983. Plan for Economies of Scope. Harvard Business Review 83(6), 141-148.

Groover, Mikell P. 1996. Fundamentals of Modern Manufacturing. Prentice Hall, Upper Saddle River, New Jersey. 
Guile, Bruce R. 1987. Using Technology Transfer Transaction Costs to Target Federal Support of Commercial Innovation. Ph.D. Thesis. UMI Dissertation Information Service.

Guilmet, George M. 1982. Defining the Resource Utilisation and the Resource Technologies of the Low Entropy Society. Cultural Futures Research VIII(1), 17-22.

Gupta, Yash P. and Subhash C. Lonial. 1998. Exploring Linkages between Manufacturing Strategy, Business Strategy, and Organizational Strategy. Production and Operations Management 7(3), 243-264.

Hagedoorn, John. 1988. Evolutionary and Heterodox Innovation Analysis. Ph.D. Thesis. Rijksuniversiteit Limburg te Maastricht.

Hall, Peter. 1994. Innovation, Economics and Evolution. Harvester Wheatsheaf, New York.

Hardaker, Glenn, Pervaiz K. Ahmed, and Gary Graham. 1998. An Integrated Response Towards the Pursuit of Fast Time to Market of NPD in European Manufacturing Organisations. European Business Review 3, 172-177.

Harding, Sandra. 1991. Whose Science? Whose Knowledge? Cornell University Press, Ithaca, New York.

Hart, Stuart L. 1997. Beyond Greening: Strategies for a Sustainable World. Harvard Business Review 75 (January-February), 67-76.

Harvey, David. 1990. The Condition of Postmodernity. Blackwell, Cambridge, Massachusetts.

Harvey, M. 1996. Agile Manufacturing: A Scoping Study. A report prepared for the Institute for Prospective Technological Studies, European Commission Joint Research Centre.

Hayes, Robert H. 1985. Strategic Planning - Forward in Reverse? Harvard Business Review 6, 111-119.

Hayes, Robert H. and Gary P. Pisano. 1996. Manufacturing Strategy: At the Intersection of Two Paradigm Shifts. Production and Operations Management 5(1), 25-41.

Hayes, Robert H. and Steven C. Wheelwright. 1984. Restoring Our Competitive Edge: Competing through Manufacturing. John Wiley \& Sons, New York.

Hayes, Robert H., Steven C. Wheelwright, and Kim B. Clark. 1988. Dynamic Manufacturing: Creating the Learning Organization. The Free Press, New York.

Heap, Brian and Jennifer Kent (eds.). 2000. Towards Sustainable Consumption: A European Perspective. The Royal Society, London.

Helms, Marilyn M., Clay Dibrell, and Peter Wright. 1997. Competitive Strategies and Business Performance: Evidence for the Adhesives and Sealants Industry. Management Decision 35(9), 689-703.

Henderson, Rebecca, Jesus del Alamo, Todd Becker, James Lawton, Peter Moran, and Saul Shapiro. 1998. The Perils of Excellence: Barriers to Effective Process Improvement in Product-Driven Firms. Production and Operations Management 7(1), 2-18. 
Hinterberger, Friedrich and Jörg Meyer-Stamer. 1997. Knowledge and Environment: Innovation for Sustainable Development. Working Paper No. 2, ComPETE Project.

Hinterberger, Friedrich and Friedrich Schmidt-Bleek. 1999. Dematerialisation, MIPS and Factor 10: Physical Sustainability Indicators as a Social Device. Ecological Economics 29, 53-56.

Hinterberger, Friedrich, Stefan Giljum and Jörg Köhn. 2000. Interrelation of Social, Economic and Ecological Systems - Theoretical Approaches and Policy Implications on the Feasibility of Comprehensive Sustainability. Paper prepared for the 3rd Biennial Conference of the European Society for Ecological Economics, Vienna, Austria, 3-6 May 2000.

Hirschl, B. 1998. New Concepts of Product use. Paper presented at the $5^{\text {th }}$ European Roundtable of Cleaner Production, Lisboa, Portugal, October 1998.

Hitomi, Katsundo. 1996. Manufacturing Excellence for 21st Century Production. Technovation 16(1), 33-41.

Hitomi, Katsundo. 1997. Manufacturing Strategy for Future Production Moving toward Manufacturing Excellence. International Journal of Technology Management 14 (6/7/8), 701-711.

Hounshell, David A. 1984. From the American System to Mass Production, 1800-1932. The John Hopkins University Press, Baltimore, Maryland.

Hukkinen, Janne. 2001. Eco-Efficiency as an Abandonment of Nature. Ecological Economics 38, 311-315.

Hwang, Sang W. 1998. A General Evolutionary Methodology for Sustainable Development. Ph.D. Dissertation. Available at: scholar.lib.vt.edu/theses/available/etd8398-14166/ unrestricted/hwang.pdf. Accessed: June 2001.

Inglehart, Ronald. 2000. Globalisation and Post-Modern Values. The Washington Quarterly 23(1), 215-228.

Institute for Sustainable Ethics and Economics (ISEE). 2001. The Natural Step \& Natural Capitalism Working Together. Workshop Notes. Institute for Sustainable Ethics and Economics, University of Oregon.

Jaikumar, Ramchandran. 1986. Postindustrial Manufacturing. Harvard Business Review 6, 69-76.

Jaikumar, Ramchandran. 1987. Statement before the Congressional Subcommittee on Innovation, Technology, and Productivity, United States Congress, Senate. In: Hearing: Problems Confronting Small Manufacturers in Automating their Facilities.

Jaikumar, Ramchandran. 1988. From filing and fitting to flexible manufacturing : a study in the evolution of process control. Working paper 88-045. Division of Research, Graduate School of Business, Harvard University.

Joseph, A.T. 1999. Formulation of Manufacturing Strategy. International Journal of Advanced Manufacturing Technology 15, 522-535.

Kakati, M. 1997. Strategic Evaluation of Advanced Manufacturing Technology.

International Journal of Production Economics 53, 141-156. 
Katayama, Hiroshi, and David Bennett. 1999. Agility, Adaptability, and Leanness: A Comparison of Concepts and a Study of Practice. International Journal of Production Economics 60-61, 43-51.

Kathuria, Ravi and Magid Igbaria. 1997. Aligning IT Applications with Manufacturing Strategy: An Integrated Framework. International Journal of Operations and Production Management 17(6), 611-629.

Kelley, Maryellen R. and Susan Helper. 1997. Firm Size and Capabilities, Regional Agglomeration, and the Adoption of New Technology. In: Economics of Innovation and New Technology.

Kellock, Brian. 1999. Stoves - Now We're Cooking! Machinery and Production Engineering 157(3984), 76-78.

Kemp, René, Arie Rip, and Johan Schot. 2001. Constructing Transition Paths through the Management of Niches. In: Path Creation and Dependence. Raghu Garud and Peter Karnoe (eds.). Lawrence Erlbaum, Mahwah, New Jersey. 269-299.

Kemp, René and Jan Rotmans. 2001. The Management of the Co-Evolution of Technical, Environmental and Social Systems. Paper for Towards Environmental Innovation Systems Conference, Garmisch-Partenkirchen, 27-29 September 2001.

Kidd, Paul. 1997. Next Generation Manufacturing Enterprise Model. Agility Research Project Report. Cheshire Henbury.

Kilbourne, William, Pierre McDonagh, and Andrea Prothero. 1997. Sustainable Consumption and e Quality of Life: A Macromarketing Challenge to the Dominant Social Paradigm. Journal of Macromarketing, Spring 1997, 4-24.

Kim, Jay S. and Peter Arnold. 1996. Operationalising Manufacturing Strategy. International Journal of Operations and Production Management 12, 45-73.

Kim, Yearmin and Jinjoo Lee. 1993. Manufacturing Strategies and Production Systems: An Integrated Framework. Journal of Operations Management 11, 3-15.

Klammer, Thomas. 1996. Capacity Measurement and Improvement. Irwin Professional Publishing, Chicago, Illinois.

Kotha, Suresh. 1996. Mass-Customisation: A Strategy for Knowledge Creation and Organizational Learning. International Journal of Technology Management 11(7/8), 846858.

Kotha, Suresh and Daniel Orne. 1989. Generic Manufacturing Strategies: A Conceptual System. Strategic Management Journal (10), 211-231.

Kropotkin, Peter. 1899; 1974 ed. Fields, Factories and Workshops. Harper Torchbooks, New York.

Kropotkin, Peter. 1902. Mutual Aid: A Factor in Evolution.

Kræmmergaard, Pernille, Charles Møller, and Harry Boer. 2001. ERP Implementation: An Integrated Process of Radical Change and Continuous Learning. In: Strategic Manufacturing, Proceedings of the IFIP WG 5.7 International Working Conference on Strategic Manufacturing. Jens O. Riis, John Johansen and Anders Drejer (eds.), August 2001, Aalborg, Denmark. 
Krupka, Dan C. 1992. Time as a Primary System Metric. In: Manufacturing Systems: Foundations of World Class Practice. Joseph A. Heim and W. Dale Compton (eds.). National Academy Press, Washington, D.C.

Kumar, Ashok and Jaideep Motwani. 1995. Methodology for Assessing Time-Based Competitive Advantage of Manufacturing Firms. International Journal of Operations and Production Management 15(2), 36-53.

Latour, Bruno. 1995. A Door Must be Open or Shut: A Little Philosophy of Techniques. In: Technology and the Politics of Knowledge. Andrew Feenberg and Alastair Hannay (eds.). Indiana University Press, Bloomington, Indiana. 272-281.

Lau, Ronald S.M. 1995. Mass Customisation: The Next Industrial Revolution. Industrial Management 37(5), 18-19.

Layton, Edward T. 1974. Technology as Knowledge. Technology and Culture 15(1), 3141.

Lee, Kong Rae. 1996. The Role of User Forms in the Innovation of Machine Tools: The Japanese Case. Research Policy 25, 491-507.

Leonard, Dorothy. 1988. Implementation as Mutual Adaptation of Technology and Organisation. Research Policy 17, 251-267.

Leonard, Dorothy. 1995. Wellsprings of Knowledge: Building and Sustaining the Sources of Innovation. Harvard Business School Press, Boston, Massachusetts.

Leong, G.K., D.L. Snyder, P.T. Ward. 1990. Research in the Process and Content of Manufacturing Strategy. OMEGA International Journal of Management Science 18(2), 109-122.

Leuchtenburg, William E. 1983. A Troubled Feast: American Society Since 1945. Little, Brown and Company, Boston, Massachusetts.

Levinthal, Daniel A. 1998. The Slow Pace of Rapid Technological Change: Gradualism and Punctuation in Technological Change. Industrial and Corporate Change 7(2), 217 247.

Leydesdorff, Loet. 1997. Sustainable Technological Developments and Second-Order Cybernetics, Technology Analysis and Strategic Management 9(3), 329-341.

Lintott, John. 2000. Work in a Growing and in a Steady State Economy. Paper prepared for the 3rd Biennial Conference of the European Society for Ecological Economics, Vienna, Austria, 3-6 May 2000.

Luria, Daniel. 1997. Toward Lean or Rich? What Performance Benchmarking Tells Us about SME Performance. In: Manufacturing Modernisation: Learning from Evaluation Practices and Results. P. Shapira and J. Youtie (eds.). 99-114.

Macy, Joanna and Molly Young Brown. 1998. Coming Back to Life: Practices to Reconnect Our Lives, Our World. New Society Publishers, Gabriola Island, British Columbia.

MacKenzie, Donald and Judy Wajcman, (eds.). 1985. The Social Shaping of Technology: How the Refrigerator Got Its Hum. Milton Keynes, Open University Press. 
Malerba, F. and L. Orsenigo. 1993. Technological Regimes and Firm Behaviour. Industrial and Corporate Change 2(1), 45-71.

Mansfield, Edwin. 1993. The Diffusion of Flexible Manufacturing Systems in Japan, Europe, and the United States. Management Science 39(2), 149-158.

Maruchek, Ann, Ronald Pannesi, and Carl Anderson. 1990. An Exploratory Study of the Manufacturing Strategy Process in Practice. Journal of Operations Management 9(1), 101-123.

Marx, Karl. 1939; 1973 ed. Grundrisse. Vintage Books, New York.

Mason-Jones, Rachel and Denis R. Towill. 1999. Total Cycle Time Compression and the Agile Supply Chain. International Journal of Production Economics 62, 61-73.

Mayring, Philipp. 2000. Qualitative Content Analysis. Forum Qualitative Sozialforschung / Forum: Qualitative Social Research. On-line Journal 1(2). Available at: http:/ / qualitative-research.net/fqs/fqs-e/2-00inhalt-e.htm.

Mazzoleni, Roberto. 1997. Learning and Path-Dependence in the Diffusion of Innovations: Comparative Evidence on Numerically Controlled Machine Tools. Research Policy 26, 405-428.

McDermott, Christopher M., Noel P. Greis and William A. Fischer. 1997. The Diminishing Power of the Product/Process Matrix. International Journal of Operations and Production Management 17(1), 65-84.

McKelvey, Maureen. 1997. Using Evolutionary Theory to Define Systems of Innovation. In: Systems of Innovation: Technologies, Institutions and Organizations. Charles Edquist (ed.). Pinter, London. 199-222.

McKibben, Bill. 2000. We're All Environmentalists Now. Right? The Atlantic Monthly. Available at: http://theatlanticmonthy.com/unbound/roundtable/environment/ mckibben.htm. Accessed: September 2000.

Meadows, Donella, H., Dennis L. Meadows, Jørgen Randers, and W.W. Behrens. 1972. Limits to Growth. Universe Books, New York.

Meadows, Donella H., Dennis L. Meadows and Jørgen Randers. 1992. Beyond the Limits: Global Collapse or a Sustainable Future. Earthscan Publications Limited, London.

Meltsner, A. 1975. Bureaucratic Policy Analysis. Policy Analysis 1, 115-131.

Metcalfe, John Stanley. 1997a. Economic Evolution and Technology Strategy. In: Economics of Structural and Technological Change. Gilberto Antonelli and Nicola De Liso (eds.). Routledge, London. 51-62.

Metcalfe, John Stanley. 1997b. On Diffusion and the Process of Technological Change. In: Economics of Structural and Technological Change. Gilberto Antonelli and Nicola De Liso (eds.). Routledge, London. 123-144.

Meyer-Kramer, Frieder. 1999. Industrial Innovation and Sustainability: Conflicts and Coherence. Paper presented at the TSER conference on The Globalising Learning Economy, Brussels, April 1999. 
Michaelis, Laurie. 2000. Drivers of Consumption Patterns. In: Towards Sustainable Consumption: A European Perspective. Brian Heap and Jennifer Kent (eds.). The Royal Society, London. 75-84.

Millen, Robert and Amrik S. Sohal. 1998. Planning Processes for Advanced Manufacturing Technology by Large American Manufacturers. Technovation 18(2), 741750 .

Mokyr, Joel. 1990. The Lever of Riches: Technological Creativity and Economic Progress. Oxford University Press, New York.

Mont, Oksana. 2000. Product Service Systems. Report for the Swedish Environmental Protection Agency. AFR-report 288.

Montgomery, Cynthia A. 1995. Of Diamonds and Rust: A New Look at Resources. In: Resource-Based and Evolutionary Theories of the Firm: Toward a Synthesis. Cynthia A. Montgomery (ed.). Kluser Academic Publishers, Boston, Massachusetts. 251-267.

Montgomery, Joseph C. and Lawrence O. Levine (eds.). 1996. The Transition to Agile Manufacturing. ASQC Quality Press, Milwaukee, Wisconsin.

Morroni, Mario. 1992. Production Process and Technical Change. Cambridge University Press, Cambridge.

Mowery, David C. and Nathan Rosenberg. 1982. The Influence of Market Demand upon Innovation: A Critical Review of Some Recent Empirical Studies. In: Inside the Black Box: Technology and Economics. Nathan Rosenberg (ed.). Cambridge University Press, Cambridge. 193-241.

Mraz, Stephen J. 1997. Power to the People. Machine Design 69(8), 46-50.

Myers, Norman. 2000. Sustainable Consumption: the Meta-Problem. In: Towards Sustainable Consumption: A European Perspective. Brian Heap and Jennifer Kent (eds.). The Royal Society, London. 5-16.

Nadeau, Tom. 2000. The Warped Perspective. Web column. Available at: www.os2hq.com. Accessed: October, 2000.

Náray-Szabó, Gábor. 2000. The Role of Technology in Sustainable Consumption. In: Towards Sustainable Consumption: A European Perspective. Brian Heap and Jennifer Kent (eds.). The Royal Society, London. 67-74.

National Research Council. 1995. Information Technology for Manufacturing: A Research Agenda. Report for National Science Foundation. NTIS, U.S. Department of Commerce.

Nelson, Richard R. 1995. Recent Evolutionary Theorizing About Economic Change. Journal of Economic Literature XXXIII (March), 48-90.

Nelson, Richard R. and Sydney G. Winter. 1977. In Search of a Useful Theory of Innovation. Research Policy 6, 36-76.

Nelson, Richard R. and Sydney G. Winter. 1982. An Evolutionary Theory of Economic Change. The Belknap Press, Cambridge, Massachusetts.

Neuman, W. Lawrence. 1997. Social Research Methods: Qualitative and Quantitative Approaches. Allyn and Bacon, Boston, Massachusetts. 
Nonaka, Ikujiro. 1990. Redundant, Overlapping Organization: A Japanese Approach to Managing the Innovation Process. California Management Review, Spring, 27-38.

Norberg-Hodge, Helena. 1991. Ancient Futures, Learning from Ladakh. Sierra Club Books, San Francisco, California.

Norgaard, R. B. 1994. Development Betrayed: The End of Progress and a Coevolutionary Revisioning of the Future. New York: Routledge.

Norgaard, R.B. 1988. Sustainable Development: A Co-Evolutionary View. Futures December, 606-620.

Northcott, J. and G. Vickery. 1993. Surveys of the Diffusion of Microelectronics and Advanced Manufacturing Technology. STI Review 12, 7-35.

O’Brien, Christopher. 1999. Sustainable Production - A New Paradigm for a New Millennium. International Journal of Production Economics 60-61, 1-7.

Organization for Economic Cooperation and Development (OECD). 1997a. Sustainable Development: OECD Policy Approaches for the 21st Century. Report for OECD Task Force on Sustainable Development. OECD.

Organization for Economic Cooperation and Development (OECD). 1997b. Diffusing Technology to Industry: Government Policy and Programmes. OECD.

Organization for Economic Cooperation and Development (OECD). 1998. EcoEfficiency. OECD.

Pagell Ruth A. and Michael Halperin. 1997. International Business Information: How to Find It, How to Use It, $2^{\text {nd }}$ ed. Oxford University Press, Oxford.

Panzar, John C. and Robert D. Willig. 1981. Economies of Scope. American Economic Review 71(2), 268-272.

Papaconstantinou, George, Norihisa Sakurai, Andrew W. Wyckoff, Jan Fagerberg and Evangelos Ionnidis. 1996. Technology Diffusion, Productivity and International Competitiveness: An Empirical Analysis. Report for the European Commission. EIMS Publication No. 13.

Patton, C. and D. Sawicki. 1986. Basic Methods of Policy Analysis and Planning. Prentice Hall, Englewood Cliffs, New Jersey.

Pavitt, Keith. 1984. Sectoral Patterns of Technical Change: Towards a Taxonomy and a Theory. Research Policy 13, 343-373.

Piacentini, Paulo Mario. 1997. Time-Saving and Innovative Processes. In: Economics of Structural and Technological Change. Gilberto Antonelli and Nicola De Liso (eds.). Routledge, London. 170-183.

Piore, Michael J. and Charles F. Sabel. 1984. The Second Industrial Divide: Possibilities for Prosperity. Basic Books, New York.

Platts, K.W., J.F. Mills, M.C. Bourne, A.D. Neely, A.H. Richards, and M.J. Gregory. 1998. Testing Manufacturing Strategy Formulation Processes. International Journal of Production Economics 56-57, 517-523.

Porter, Michael E. 1980. Competitive Strategy. The Free Press, New York. 
Porter, Michael E. 1996. What is Strategy?. Harvard Business Review 74 NovemberDecember, 61-78.

Prahalad, C.K. and Gary Hamel. 1990. The Core Competence of the Corporation. Harvard Business Review May-June, 79-91.

Pratten, Cliff. 1971. Economies of Scale in Manufacturing Industry. Cambridge University Press, Cambridge.

Pratten, Cliff. 1991. The Competitiveness of Small Firms. Cambridge University Press, Cambridge.

Princen, Thomas. 1999. Consumption and Environment: Some Conceptual Issues. Ecological Economics 31, 347-363.

Ranta, Jukka. 1997. Time Based Competition: From Flexible Manufacturing to Production Networks and Virtual Enterprise. Working paper WP-13-97. Available at: http://www.tuta.hut.fi/people/jranta/pronetae.htm. Accessed: June 2000.

Resich, Lucia A. and Gerhard Scherhorn. 1999. Sustainable Consumption. In: The Current State of Economic Science. S.B. Dahiya (ed.). Spellbound Publishers, Rohtak, India.

Rischel, Tracy D. and O. Maxie Burns. 1997. The Impact of Technology on Small Manufacturing Firms. Journal of Small Business Management 35(1), 2-10.

Røpke, Inge. 1999. The Dynamics of the Willingness to Consume. Ecological Economics 28, 399-420.

Røpke, Inge. 2001a. Is Consumption Becoming Less Material? The Case of Services. International Journal of Sustainable Development 4(1).

Røpke, Inge. 2001b. New Technology in Everyday Life - Social Processes and Environmental Impact. Ecological Economics 38, 403-422.

Rosenberg, Nathan. 1963. Technological Change in the Machine Tool Industry, 18401910, The Journal of economic History XXIII(4), 414-443.

Rosenberg, Nathan. 1982. Inside the Black Box: Technology and Economics. Cambridge University Press, Cambridge.

Rosenberg, Nathan. 1994. Exploring the Black Box: Technology, Economics, and History. Cambridge University Press, Cambridge.

Ryan, John C. and Alan Thein Durning. 1997. Stuff: The Secret Lives of Everyday Things. Northwest Environment Watch, Seattle, Washington.

Sabourin, David and Desmond Beckstead. 1999. Technology Adoption in Canadian Manufacturing. Ottawa: Statistics Canada Division, Micro-Economic Analysis Division.

Sachs, Wolfgang. 1999. Planet Dialectics: Explorations in Environment and Development. Zed Books, London.

Sahal, Davendra. 1985. Technological Guideposts and Innovation Avenues, Research Policy 14, 61-82.

Sanne, Christer. 1999. Cutting Consumption: How to Understand and Reduce Consumption in Wealthy Countries. Working paper. 
Saren, M. 1990. Determinants, Processes and Strategies of Technological Innovation: Towards an Interactive Paradigm. In: Strategic Management of Technological Innovation. Ray Loveridge and Martyn Pitt (eds.). John Wiley \& Sons, New York.

Schmenner, Roger W. 1988. The Merit of Making Things Fast. Sloan Management Review Fall, 11-17.

Schonberger, Richard J. 1996. World Class Manufacturing: The Next Decade. The Free Press, New York.

Schor, Juliet. 1998. The Overspent American. Basic Books, New York.

Schumacher, E.F. 1973. Small is Beautiful: Economics as if People Mattered. Harper \& Row, New York.

Schütz, Joachim. 1999. The Value of Systemic Reasoning. Ecological Economics 31, 2329.

Sen, Amartya. 1981. Poverty and Famines: An Essay on Entitlement and Deprivation. Oxford University Press, Oxford.

Shapira, Philip and Terance Rephann. 1996. New Technology Adoption in West Virginia: Implications for Manufacturing Modernization Policies. Environment and Planning C Government and Policy 14, 431-450.

Sharp, J.M., Z. Irani, and S. Desai. 1999. Working towards Agile Manufacturing in the UK Industry. International Journal of Production Economics 62, 155-169.

Skinner, Wickham. 1969. Manufacturing - Missing Link in Corporate Strategy. Harvard Business Review 47(3), 136-145.

Small, Michael H. 1998. Objectives for Adopting Advanced Manufacturing Systems: Promise and Performance. Industrial Management and Data Systems, 98(3), 129-137.

Sonntag, Viki. 2000a. Sustainability - In Light of Competitiveness. Ecological Economics 34, 101-113.

Sonntag, Viki. 2000b. Consumption and the Strategic Uses of Advanced Manufacturing Technologies. Project Report for the CUSP Project, Competitive and Sustainable Growth Programme, Fifth Framework, European Commission.

Sonntag, Viki. 2000c. The Strategic Uses of Advanced Manufacturing Technologies for Competitive and Sustainable Purposes. Project Report for the CUSP Project, Competitive and Sustainable Growth Programme, Fifth Framework, European Commission.

Sonntag, Viki. 2003. The Role of Manufacturing Strategy in Adapting to Technological Change. Integrated Manufacturing Systems 14(4).

Spina, Gianluca, Emilio Bartezzaghi, Andrea Bert, Raffaella Cagliano, Domien Draaijer, and Harry Boer. 1996. Strategically Flexible Production: The Multi-Focused Manufacturing Paradigm. International Journal of Operations and Production Management 16(11), 20-41.

Spina, Gianluca. 1998. Manufacturing Paradigms versus Strategic Approaches; A Misleading Contrast. International Journal of Operations and Production Management 18(8), 684-709. 
Stacey, Ralph. 1993. Strategy as Order Emerging from Chaos. Long Range Planning 26(1), 10-17.

Stalk, Jr., George. 1988. Time - The Next Source of Competitive Advantage. Harvard Business Review 88(4), 41-51.

Stalk, Jr., George and Thomas M. Hout. 1990. Competing Against Time. The Free Press, New York, New York.

Stalk, Jr., George and Alan M. Webber. 1993. Japan's Dark Side of Time. Harvard Business Review 4, 93-102.

Steiner, Kvale. 1996. Interviews: An Introduction to Qualitative Research Interviewing. Sage Publications, Thousand Oaks, California.

St. John, Caron H. and Jeffrey S. Harrison. 1999. Manufacturing-Based Relatedness, Synergy, and Coordination. Strategic Management Journal 20, 120-145.

St. John, Caron H., Alan R. Cannon, Richard W. Pouder. 2001. Change Drivers in the New Millennium: Implications for Manufacturing Strategy Research. Journal of Operations Management 19, 143-160.

SustainAbility. 1995. Who Needs It?: Market Implications of Sustainable Lifestyles. SustainAbility Ltd., London. (Business guide)

Swamidass, Paul M. and Suresh Kotha. 1998. Explaining Manufacturing Technology Use, Firm Size and Performance Using a Multidimensional View of Technology. Journal of Operations Management 17, 23-37.

Swink, Morgan and W. Harvey Hegarty. 1998. Core Manufacturing Capabilities and Their Links to Product Differentiation. International Journal of Operations and Production Management 18(4), 374-396.

Tashakkori, Abbas and Charles Teddlie. 1998. Mixed Methodology: Combining Qualitative and Quantitative Approaches. Sage Publications, Thousand Oaks, California.

Technologies Enabling Agile Manufacturing (TEAM). 1997. Areas of Research Needed for TEAM. Internet document.

Technologies Enabling Agile Manufacturing (TEAM). 1999. TEAM Final Report. Internet document. Available at: www.llnl.gov/eng/eetd/ise_TEAM/. Accessed: January 2000.

Technology Foresight Programme, Office of Science and Technology, United Kingdom. 1995. Progress through Partnership 9: Manufacturing, Production, and Business Processes. HMSO.

Teece, David J. 1993. The Dynamics of Industrial Capitalism: Perspective on Alfred Chandler's Scale and Scope. Journal of Economic Literature, XXXI (March), 199-225.

Teece, David J., Gary Pisano, and Amy Shuen. 1997. Dynamic Capabilities and Strategic Management. In: Resources, Firms and Strategies. Nicolai J. Foss (ed.). Oxford University Press, Oxford. 268-285.

The Economist. 2001. A Long March. The Economist 360(8230), 63-65. 
The Group of Lisbon. 1995. Limits to Competition. The MIT Press, Cambridge, Massachusetts.

The Harwood Group. 1995. Yearning for Balance: Views of Americans on Consumption, Materialism and the Environment. Report for the Merck Family Fund.

Tracey, Michael, Mark Vonderembse, and Jeen-Su Lim. 1999. Manufacturing Technology and Strategy Formulation: Keys to Enhancing Competitiveness and Improving Performance. Journal of Operations Management 17, 411-428.

Trainer, Ted. 1996. Towards a Sustainable Economy. Jon Carpenter, Oxford.

Tu, Qiang, Mark A. Vonderembse, T.S. Ragu-Nathan. 2001. The Impact of Time-Based Manufacturing Practices on Mass Customization and Value to Customer. Journal of Operations Management 19, 201-217.

United Nations Commission on Sustainable Development, Economic and Social Council, United Nations. 2002. Addendum No. 8: Dialogue Paper by Scientific and Technological Communities. Note prepared for the World Summit on Sustainable Development.

United Nations Conference on Environment and Development (UNCED). 1992. Agenda 21. Available at: www.igc.apc.org/habitat/agenda21/ch-01.html.

U.S. Bureau of the Census, Economics and Statistics Administration, U.S. Department of Commerce. 1994. Manufacturing Technology: Prevalence and Plans for Use, 1993. Current Industrial Reports, U.S. Department of Commerce.

van Asseldonk, Ton G.M. 1998. Mass Individualisation. TVA management bv, Veldhoven, the Netherlands.

van der Leeuw, S.E. 2001. 'Vulnerability' and the Integrated Study of Socio-Natural Phenomena. Update IHDP 2, 6-7.

Vanderburg, Willem H. 1985. Technology, Society, and Culture: A Framework for Understanding. Technology in Society 7, 411-422.

VanderWerf, Pieter A. and John F. Mahon. 1997. Meta-Analysis of the Impact of Research Methods on Findings of First-Mover Advantage. Management Science 43(11), 1510-1519.

Vlek, Charles, Lucia Reisch and Gerhard Scherhorn. 2000. Transformation of Unsustainable Consumer Behaviours and Consumer Policies: Problem Analysis, Solution Approaches and a Research Agenda. Report for international Human Dimensions Programme - Industrial Transformation (IHDP-IT). Groningen: Centre for Environmental and Traffic Psychology, University of Groningen, the Netherlands (COV 00-04).

Vonderembse, M.A., T.S. Raghunathan, S. Subba Rao. 1997. A Post-Industrial Paradigm: To Integrate and Automate Manufacturing. International Journal of Production Research 35(9), 2579-2599.

von Hippel, Eric and Marcie Tyre. 1995. How "Learning by Doing" is Done: Problem Identification in Novel Process Equipment. Research Policy 24, 1-12. 
Wackernagel, Mathis. 2000. Carrying Capacity, Overshoot and the Need to Curb Human Consumption. In: Towards Sustainable Consumption: A European Perspective. Brian Heap and Jennifer Kent (eds.). The Royal Society, London. 101-110.

Warnerfelt, Birger. 1984. A Resource-Based View of the Firm. Strategic Management Journal 5, 171-180.

Warnerfelt, Birger. 1995. The Resource-Based View of the Firm: Ten Years After. Strategic Management Journal 16, 171-174.

Weizsäcker, E. von, A. Lovins, L. Hunter Lovins. 1998. Factor Four: Doubling Wealth Halving Resource Use. Earthscan, London.

Wenk, Jr., Edward. 1986. Tradeoffs: Imperatives of Choice in a High-Tech World. John Hopkins University Press, Baltimore, Maryland.

Wheelwright, Steven C. 1984. Manufacturing Strategy: Defining the Missing Link. Strategic Management Journal 5, 77-91.

Wheelwright, Steven C. and Robert H. Hayes. 1985. Competing through Manufacturing. Harvard Business Review 1, 99-109.

White, Damien F. 2000. On Babies and Bathwater: Why Factor Four and Natural Capitalism Deserve a Careful Critique. Paper for Policy Agendas for Sustainable Technological Innovation, 3 ${ }^{\text {rd }}$ International POSTI Conference, London, 13 December, 2000.

Whybark, D. Clay and Gyula Vastag (eds.). 1993. Global Manufacturing Practices: A Worldwide Survey of Practices in Production Planning and Control. Elsevier, Amsterdam.

Winner, Langdon. 1986. The Whale and the Reactor: A Search for Limits in an Age of High Technology. The University of Chicago Press, Chicago, Illinois.

Winter, Sydney G. 1995. Four Rs of Profitability: Rents, Resources, Routines, and Replication. In: Resource-Based and Evolutionary Theories of the Firm: Toward a Synthesis. Cynthia A. Montgomery (ed.). Kluser Academic Publishers, Boston. 147-175.

Womack, James P., Daniel T. Jones, and Daniel Roos. 1991. The Machine that Changed the World. Harper Perennial, New York.

World Business Council for Sustainable Development (WBCSD). 2000. Building a Better Future: Innovation, Technology and Sustainable Development. A Progress Report of the WBCSD. June 2000.

World Resource Institute (WRI). 1997. Resource Flows: The Material Basis of Industrial Economies. Report, World Resources Institute, Washington, D.C.

World Resources Institute (WRI). 2000a. The Weight of Nations: Material Outflows from Industrial Economies. Report, World Resources Institute, Washington, D.C.

World Wildlife Fund, United Nations Environmental Programme World Conservation Monitoring Centre, and Redefining Progress. 2002. Living Planet Report 2002. Report, World Wide Fund for Nature, Gland, Switzerland. 
Yoshikawa, Hiroyuki. 1995. Manufacturing and the 21st Century - Intelligent manufacturing Systems and the Renaissance of the Manufacturing Industry. Technological Forecasting and Social Change 49, 195-213.

Youtie, Jan and Philip Shapira. 1997. Manufacturing Needs, Practices, and Performance in Georgia, 1994 to 1998. GMEA Evaluation Working Paper: E9703.

Yusuf, Y.Y., M. Sarhadi, and A Gunasekaran. 1999. Agile Manufacturing: The Drivers, Concepts and Attributes. International Journal of Production Economics 62, 33-43.

Zhou, Yuejin and K.B. Chuah. 1999. The Strategic Issues in Implementation of CIM Technology in PRC/HK Enterprises. The International Journal of Advanced Manufacturing Technology 15, 514-521.

\section{Industry Roadmaps}

Agility Forum, Leaders for Manufacturing, and Technologies Enabling Agile Manufacturing. 1997. Next Generation Manufacturing: A Framework for Action. CDROM Project Report. Agility Forum.

Defence Science Board (DSB), Office of the Under-secretary of Defence for Acquisition, U.S. Department of Defence. 1993. Engineering in the Manufacturing Process. Report. Defence Science Board Task Force.

Eureka. 1995. Factory of the Future, Final Report. Report. Eureka 1005.

The Institution of Electrical Engineers (IEE). 1998. Next Generation Manufacturing Enterprise Framework. Internet. Available at: www.iee.org.uk/PG/I7/framew.htm. Accessed: February 2000.

Intelligent Manufacturing System (IMS). 1994. Knowledge Systematisation: Configuration Systems for Design and Manufacturing. Final Report of Technical Work Package 5, Post Mass Production Paradigm, Gnossis Project.

National Centre for Manufacturing Sciences (NCMS). 1996. NCMS Collaborative Manufacturing Agenda. Report. NCMS, Ann Arbor, Michigan.

National Research Council (NRC). 1995. Information Technology for Manufacturing: A Research Agenda. Report for National Science Foundation. NTIS, U.S. Department of Commerce.

Technologies Enabling Agile Manufacturing (TEAM). 1997. Areas of Research Needed for TEAM. Internet. Accessed: October 1998.

Technologies Enabling Agile Manufacturing (TEAM). 1999. TEAM Final Report. Internet. Available at: www.llnl.gov/eng/eetd/ise_TEAM/. Accessed: January 2000.

Technology Foresight Programme, Office of Science and Technology, United Kingdom. 1995. Progress through Partnership 9: Manufacturing, Production, and Business Processes. HMSO.

Technology Foresight Programme, Office of Science and Technology, United Kingdom. 1997. Winning through Foresight: Action for Manufacturing, Production and Business Processes. Department of Trade and Industry. 


\section{Manufacturing Engineer Articles}

Booth, Rupert. 1995. In the Market. Manufacturing Engineer 74(5), 236-239.

Brookes, Naomi J. and Christopher J. Backhouse. 1997. Variety and Concurrent Engineering. Manufacturing Engineer 76(2), 72-75.

Bryan, Michael G. and Peter J. Sackett. 1997. The Point of PDM. Manufacturing Engineer 76(4), 161-164.

Carpenter, I.D., J.M. Ritchie, R.G. Dewar, and J.E.L. Simmons. 1997. Virtual Manufacturing. Manufacturing Engineer 76(3), 113-116.

Efstathiou, Janet, John Schirn, and Ani Calinescu. 1998. The Too-Flexible Factory. Manufacturing Engineer 77(2), 70-73.

Fletcher, Richard. 1995. A Way Forward. Manufacturing Engineer 74(1), 12-15.

Gould, Peter. 1997. What is Agility?. Manufacturing Engineer 76(1), 28-31.

Greasley, Andrew. 1999. Simulation in Process Design. Manufacturing Engineer 78(4), 173-177.

Hanson, Phil. 1997. Total Differentiation. Manufacturing Engineer 76(3), 133-135.

Hanson, Philip and Chris Voss. 1999. Taylor to Toyota to Technology. Manufacturing Engineer 78(1), 11-14.

Harding, David J. 1999. The Challenge of Change. Manufacturing Engineer 78(4), 167 172.

Harrison, Alan. 1997. From Leanness to Agility. Manufacturing Engineer 76(6), 257-260.

Heapy, Mike. 1990. Small Is Beautiful. Manufacturing Engineer 69(9), 16-17.

Jina, J. and D.T. Wright. 1997. Competitive Advantage from the Internet. Manufacturing Engineer 76(3), 124-128.

Johnson, Peter. 1995. Supply Chain Management: The Past, the Present and the Future. Manufacturing Engineering 74(5), 213-217.

Leeuwen, E.H. van and D. Norrie. 1997. Holons and Holarchies. Manufacturing Engineer 76(2), 86-88.

Lovett, P.J., A. Ingram, and C.N. Bancroft. 1999. A Little Knowledge Is a Wonderous Thing. Manufacturing Engineer 78(3), 125-127.

Marshall, R., P.G. Leaney, and P. Botterell. 1999. Modular Design. Manufacturing Engineer, 78(3) 113-116.

Milne, John. 1995. An Integrative Approach. Manufacturing Engineering 74(4), 159-162.

Owen, David and Gunther Kruse. 1997. Follow the Customer. Manufacturing Engineer 76(2), 65-68.

Powner, E.T. and D.H. Walburn. Automatic Learning. Manufacturing Engineer 78(4), 149-151.

Ross, Alastair. 1998. Mass Customisation: The Dirty Reality. Manufacturing Engineering 77(2), 79-80. 
Schofield, Tony. 1995. In Perfect Harmony. Manufacturing Engineer 74(1), 43-45.

Winch, Graham. 1999. Knowledge Management. Manufacturing Engineer 78(4), 236-239.

\section{Newspaper and News Web Articles}

Ansberry, Clare. 1999. Out of the Closet Comes a Secret Vice: The Vacuum Habit Houses Bristle With Them, Thanks to Niche-Cleaning And the Need for 'ESP'. Wall Street Journal, October 13, 1999.

BBC News. 1999. Mobile Phones, the New Fashion Accessory. Available at: http://news.bbc.co.uk/english/busine...e_company_file/newsid_363000/363930.stm. Accessed: October, 2000.

Berke, Richard L. and Janet Elder. 2001. Bush Loses Favor Despite Tax Cut and Overseas Trip. New York Times, June 21, 2001.

Browne, Anthony. 2001. Third World Boom Raises Hopes of End to Poverty. The Observer. Sunday July 8.

Egan, Timothy. 2000. 'Perfect' Apple Pushed Growers into Debt. New York Times, November 4, 2000.

Insley, Jill. 1999. Shopping Till You Drop. Observer. Sunday, August 8, 1999. Accessed: www.guardian.co.uk/Archive.

Meadows, Donella. 2000. Let's Stop Racing Each Other and Go for the Bear Instead. The Global Citizen, September 7, 2000. Available at: http://iisd1.iisd.ca/pcdf/meadows /default.htm.

Meadows, Donella. 2001. Just So Much and No More... Yes! A Journal of Positive Futures. Summer 2001, 45.

Morris, Bob. 1998. Gear. The New York Times Magazine. December 13, 1998.

The New York Times. 2001. Report Warns of Disaster from Global Warming. Available at: http://www.nytimes.com / aponline/science/AP-China-Global-Warming.html. Accessed: January 2001.

\section{Web Pages}

Eurostat. 2000. Business Statistics in the Telecommunications Sector. Web page. Available at: http://europa.eu.int/comm/eurostat/Public/datashop/printcatalogue $/$ EN?catalogue $=$ Eurostat. Accessed: June 2000.

United Nations Environmental Programme (UNEP). 1999. UNEP's First Expert Meeting on Advertising and Consumption. Web Page. Available at: http://www.unepie.org/pc/sustain/ advertising/events.htm. Accessed: December 2001.

World Resources Institute (WRI). 2000b. Global Trends. Web page. WRI Sustainable Development Information Service. Available at: http://www.wri.org/trends/index.html. Accessed: August 2000. 


\section{Samenvatting}

In de afgelopen decennia heeft de toepassing van computergeassisteerde produktietechnologieën een verandering teweeggebracht in de wijze waarop bedrijven concurreren. Dit heeft ook gevolgen gehad voor de consumptie: naarmate de produktiesnelheid en het aantal produktvarianten toenemen, neemt ook het aantal nieuwe produkten toe en stijgt de consumptie. Deze paralelle veranderingen in produktie en consumptie kunnen worden verklaard aan de hand van de sociaal-economische theorie die stelt dat technologiesystemen en hun omgeving zich samen ontwikkelen. De in dit proefschrift toegepaste theorie houdt in dat bedrijven nieuwe methoden leren om hun bedrijfsdoelen te bereiken als gevolg van de integratie van nieuwe technologieën in het produktiesysteem. Die uit concurrentieoverwegingen gekozen technologieën bepalen tegelijkertijd ook de kennis en toepassingen van de gebruikers. De richting van technologische vooruitgang in produktiesystemen is dus zowel een gevolg als een oorzaak van bedrijfskeuzes voor bepaalde produktietechnologieën. Toekomstige generaties produktietechnologieën zullen daarom een padafhankelijke ontwikkeling volgen die veranderingen weerspiegelt in de concurrentieverhoudingen die het gevolg zijn strategiewijzigingen. In dit proefschrift wordt gesteld dat de huidige richting in het strategische gebruik van AMTs ("Advanced Manufacturing Technologies") leidt tot een consumptiegroei als gevolg van de snellere introductie en het ruimere aanbod van produkten. Met het oog op een duurzame toekomst moet worden bestudeerd hoe het gebruik van produktietechnologie in een nieuwe richting kan worden gestuurd: de richting van een duurzaam gebruik van grondstoffen dankzij een beter vermogen van bedrijven om met verandering om te gaan.

\section{Het "Strategic Use Model"}

Het model van technologische verandering dat in dit proefschrift wordt gepresenteerd is gebaseerd op de evolutionaire economie en de produktiewetenschappen, in het bijzonder onderzoek op het gebied van produktiestrategie. Dit model heeft ten doel het gedrag van bedrijven te bestuderen die zich aanpassen aan veranderingen. In het model wordt technologische verandering gezien als een evolutionair proces langs een ontwikkelingspad op basis van het succes dat het bedrijf in het verleden had in het inspelen op marktbehoeften. Bedrijfsstrategieën leiden tot veranderingen in produktmarkten. Deze veranderingen hebben op hun beurt invloed op beslissingen over hoe de huidige generatie produktietechnologieën verder moet worden ontwikkeld om in te kunnen spelen op veranderende marktbehoeften. Na jarenlange ervaringen met het gebruik van AMTs zijn duidelijke patronen in marktorganisaties naar voren gekomen, waardoor meer bedrijven op deze technologieën zijn overgegaan. Deze onderlinge afhankelijkheid van marktbehoeften en het strategisch gebruik van AMTs heeft gevolgen voor zowel producenten als consumenten.

Bedrijven moeten qua organisatiestructuur en praktijken uitvoerige veranderingen doormaken om AMTs met succes in hun activiteiten te integreren. Bij de overgang op nieuwe produktiesystemen worden ze geconfronteerd met en spanning tussen enerzijds de routines en praktijken die het gevolg zijn van de oude produktietechnologieën, en anderzijds het gebruik van de nieuwe produktietechnologieën die aanpassingen vergt in de organisatie. Of deze overgang soepel verloopt, is niet een kwestie van leren maar vooral van het afferen van oude routines en praktijken die diep in de organisatiestructuur en -cultuur zijn geworteld. 
In de literatuur over evolutionaire economie spitst het onderzoek naar het gebruik van produktietechnologieën zich grotendeels toe op het principe van "learning-by-using". Het gaat daarbij om de incrementele verbeteringen in de technologieën die worden gebruikt, en niet op de reorganisatie van produktie die gepaard gaat met technologiegebruik. Het model in dit proefschrift komt daarentegen tegemoet aan de behoefte aan een theorie die informatie geeft over het produktiestrategieproces. De rol van strategie hierin is bedrijven duidelijk te maken hoe ze de middelen waarover ze beschikken, kunnen gebruiken om in te spelen op veranderende omstandigheden in industrieën en markten. Het model biedt een raamwerk voor de analyse van huidige trends in de ontwikkeling en het gebruik van produktietechnologieën m.b.t. de relatie tussen produktiestrategie en veranderingen in de vraag op de produktmarkt en het gebruik van AMTs.

De voor het model gebruikte data zijn afkomstig van interviews met gebruikers, leveranciers, en dienstverleners van technologieën. Het interviewprotocol bestond uit open vragen die betrekking hadden op het gebruik van AMTs in het bedrijf en daaraan gerelateerde toepassingen in strategieontwikkeling en -implementatie. De antwoorden op deze vragen zijn vervolgens in de data-analyse gekoppeld aan de hypotheses die van het model zijn afgeleid.

Uit de interviews blijkt dat de invloed van "learning-by-using" groter is dan eerder in de literatuur naar voren is gekomen. Nieuwe produktiesystemen ontstaan doordat bedrijven zich via een incrementeel proces aanpassen aan nieuwe technologieën. Deze transformatie illustreert de stapsgewijs toenemende invloed van technologiegebruik op de kennis en toepassingen van de gebruikers, en is een indicatie van het vermogen van technologiegebruik om vorm te geven aan de toepassingen en produktiecapaciteit van bedrijven, ondanks de kracht van individuele bedrijven. Inzicht in de invloed van vroegere ervaringen van een bedrijf op de besluitvorming en de rol van huidige beslissingen dragen bij aan het dynamische aanpassingsvermogen van het bedrijf. Omdat technologiegebruik is ingebed in de lokale, sociaal-historische context, is dit eerst en vooral een ervaringsproces. De rol van strategie is om het inherent dynamische 'learning-by-using' proces in goede banen te leiden. Strategieën helpen het bedrijf dus de oude en de nieuwe, de specifieke en de algemene, en de incrementele en radicale gevolgen in evenwicht te brengen die de aanpassing van het bedrijf aan technologische verandering kenmerken.

\section{Onderzoek naar het AMT-traject}

Het toenemend gebruik van AMTs leidt to belangrijke vragen over de invloed van huidige trajecten van produktietechnologieën op de organisatie van produktie en consumptie: Wat zijn de huidige strategische toepassingen van AMTs? Zijn deze duurzaam? En zijn er andere, meer duurzame opties? De antwoorden op deze vragen zijn afhankelijk van ons vermogen om patronen in AMT-gebruik te analyseren en daaraan op basis van die analyse een andere richting te geven.

In de huidige produktiestrategiemodellen wordt onvoldoende rekening gehouden met de invloed van technologiegebruik. Het Strategic Use Model daarentegen laat zien dat technologisch belichaamde "tradeoffs" de toepassingen van technologiegebruikers veranderen en daarbij impulswaarde krijgen.

In de resulterende trajecten liggen de grenzen van de eigen technische en sociaal-economische levensduur besloten. Volgens Sahal (1985), een van de eersten die onderzoek deed naar technologisch padafhankelijkheid, bestaat er "een limiet aan de groei van elk systeem 
van een gegeven vorm". De grenzen van een systeem worden bepaald door de tradeoffs die inherent zijn aan de huidige richting van technologieontwikkeling, omdat in elke generatie technologieën specifieke tradeoffs besloten liggen die bedrijven maken in verhouding tot de beschikbare kansen voor technologische vooruitgang. Ieder traject draagt dus de kiemen voor verandering in zich. Wil een systeem zich continu verder kunnen ontwikkelen, dan moeten de tradeoffs die besloten liggen in de technologieën die op dat moment in gebruik zijn, worden weggenomen zodra ze begrenzend gaan werken.

De fundamentele analyse-eenheden van deze studie zijn de tradeoffs die besloten liggen in de prestatiekenmerken van de technologieën waaruit een traject is opgebouwd. De voornaamste bronnen voor deze analyse waren "industry roadmaps" en "foresight"analyses gericht op produktie en de informatietechnologieën die in de produktie worden gebruikt. In de analyse gaat we uit van het argument dat de sociaal-economische tradeoffs die zijn ingebed in trajecten via technologiegebruik worden gekopieerd. Nieuwe toepassingen van produktietechnologieën, vormgegeven rond nieuwe functionaliteiten die bestaande tradeoffs oplossen, leiden tot veranderingen in produktmarkten die op hun beurt weer leiden tot andere concurrentieomstandigheden. Is een aanpassing succesvol, dan zullen steeds meer bedrijven de nieuwe richting van strategisch voordeel volgen, waardoor de effecten ervan nog eens worden versterkt.

Meer specifiek duiden de bevindingen van deze studie erop dat de verschuiving naar AMTs een oplossing biedt voor drie tradeoffs die inherent zijn aan het massaproduktieregime: "economies of scale" (schaalvoordelen) versus "economies of scope" (breedtevoordelen"); lineaire doelmatigheid versus systeem "interoperability"; en procesvoorspelbaarheid versus lenigheid.

De diverse aanpassingen die door AMTs mogelijk worden gemaakt zijn als volgt:

Produktdifferentiatie/Flexibiliteit: Door de automatisering van flexibele produktietechnologieën dalen de kosten voor produktvariatie, waardoor het mogelijk wordt tegelijkertijd lage kosten en produktdifferentiatie door te voeren.

Systeemoptimisatie/Integratie: Dankzij verbeterde systeeminteracties ondervangt de integratie van produktie- en bedrijfsprocessen tekortkomingen in systemen die kenmerkend zijn voor de versnipperde, lineaire processen in massaproduktie.

Kennissystematisatie/Informatiemanagement: Nieuwe processen voor kennisbeheer vergroten het vermogen van bedrijven om kansen te benutten in de onvoorspelbare, snel veranderende markten die de plaats hebben ingenomen van de homogene, stabiele markten van massaproduktie.

De behoeften van gebruikers van AMTs en AMT-produkten waaraan niet wordt voldaan, geven vervolgens aan welke nieuwe tradeoffs voorvloeien uit AMT-gebruik. Deze behoeften ontwikkelen zich samen met het gebruik van AMTs, en wel zo dat verschillende generaties AMTs leiden tot verschillende tradeoffs. Uit de roadmaps and foresight analyses blijkt dat er een vierde AMT-traject in opkomst is als reactie op de complexiteit van AMT-gebruik:

Aanpassingsvermogen: Dankzij het vermogen om produkten en processes opnieuw vorm te geven met behulp van autonome modulen kunnen bedrijven hun assortiment rationaliseren en de complexiteit van AMT-processen beheersbaar houden. 


\section{Het AMT-regime}

Uit de roadmap and foresight analyses blijkt dat markten aan het veranderen zijn en worden gekenmerkt door een toenemend tempo van innovaties, kortere ontwikkelcycli (timeto-market), grotere veranderlijkheid en dynamiek van markten, en toenemende complexiteit van produkten, processen, en systemen. Tegelijk met deze ontwikkelingen is er een nieuwe industriële orde ontstaan, een produktieregime, die vooral wordt bepaald door de vier bovengenoemde trajecten. Deze trajecten belichamen tradeoffs die worden gerealiseerd door toepassing van regels en praktijken in het regime, waarvan het nuttig gebruik van snelheid waarschijnlijk de meest algemene is. Alle vier de trajecten delen dit middel, maar snelheid is ook een cruciaal aspect in de functionaliteit van elk traject. In feite is snelheid zowel een middel als een doel.

De opkomst van deze nieuwe industriële orde duidt in grote mate op een verschuiving van in AMT-gebruik besloten produktiestrategieën die niet langer gebaseerd zijn op schaal, maar op tijd. De continue groei in produkten is gebaseerd op het vermogen om in snel tempo uiterst gedifferentieerde produkten te ontwerpen, produceren en leveren tegen prijzen die niet veel meer verschillen van die van massaproduktie. Het regime wordt in feite bepaald door snellere produktcycli en lage-kosten-produktvariatie, evenals schaalvoordelen en lage-kosten-, gestandaardiseerde massaproduktie die is gedefinieerd door het produkt.

In dit proefschrift wordt de economische werking van dit nieuwe regime als volgt geanalyseerd. Om op de huidige markten te concurreren, moeten bedrijven het vermogen ontwikkelen om een groot aantal produkten in snel tempo te produceren. Snelheid houdt de produktiekosten van een groot aantal produkten relatief laag en is dan ook een cruciale factor in strategieën gericht op kortere ontwikkelcycli en produktdifferentiatie. Door hogere bedrijfs- en kapitaalkosten moet de produktieschaal echter worden uitgebreid. De toename in snelheid wordt bekostigd door de doorloopsnelheden op te voeren. Snelheid dwingt bedrijven dus de output te verhogen.

Tegenwoordig is de produktie zo georganiseerd dat in snel tempo en tegen lage kosten met een gedifferentieerd produktaanbod aan de behoeften kan worden voldaan. Consumenten worden voorzien van een veelheid aan kant-en-klare goederen waaruit ze kunnen kiezen. Cruciaal voor de doelmatigheid van produktie is dus het vermogen van consumentenmarken om een groot aantal geproduceerde goederen te verwerken.

Samenvattend blijkt dat produktiesystemen door het effectieve gebruik van AMTs sterker afhankelijk worden van kwantitatieve groei dankzij tradeoffs die inherent zijn aan AMTgebruik. De produktintroductie verloopt sneller en er komen meer verschillende produkten beschikbaar. Dit gaat ten koste van toenemende systeemcomplexiteit, kapitaalkracht, en quitte-spelende verkoopaantallen, en leidt tot grotere veranderlijkheid van markten. Aan de vraagzijde stijgt de consumptie van produkten omdat deze sneller verouderen en vaker bestemd zijn voor individueel gebruik.

Behalve door de interviews worden de uitkomsten van deze analyse ook bevestigd door een enquête onder bedrijven.

De schaduwzijde van meer produktvariatie op bedrijfsniveau is grotere complexiteit. Vanuit een maatschappelijk oogpunt wordt niet-duurzame groei in de doorzetting (throughput) van produkten bevorderd door strategieën gericht op tijd. De verwachtingen van bedrijven m.b.t. inkomsten die voortvloeien uit snellere produktsubstitutie en 
meer geïndividualiseerde consumptie groeien met het gebruik van AMTs, hetgeen leidt tot verdere investeringen in AMTs. In hun streven naar grotere produktdifferentiatie lopen ze daarmee het risico hun eigen produkt te onderwaarderen. Dankzij AMTs krijgen bedrijven die proberen de beperkingen van consumptie op te heffen, dus te maken met nieuwe tegenstrijdigheden.

\section{Duurzaamheid in het nieuwe regime}

Het huidige regime wordt gekenmerkt door snelle veranderingen en onvoorspelbaarheid van de markt, veroorzaakt door kortere produktcycli, een toenemende vraag naar produkten op maat, en de snellere introductie van produkten. Deze omstandigheden hebben geleid tot concurrentiestrategieën gericht op flexibiliteit en klantenwensen, die ertoe bijdragen dat de markt blijft veranderen.

De consumptiegroei in de zeer geïndustrialiseerde landen wordt aangedreven door goedkopere produkten, toenemende produktveroudering, toenemende produktspecialisatie, en nieuwe produktsoorten. De ontwikkeling van dit op vraag gebaseerde regime is samengegaan met het gebruik van informatietechnologieën in de produktie.

Het probleem van overconsumptie met betrekking tot duurzaamheid is gelegen in de dynamiek van het ecosysteem, dat langzamer is dan die van de economie. Het ecosysteem kan de toenemende entropie als gevolg van produktie en consumptie simpelweg niet bijbenen. Herstellingsvermogen is dan cruciaal om economische stabiliteit te handhaven zonder dat het ecosysteem te zeer wordt overbelast. Dit kan worden bereikt door meer flexibiliteit en diversiteit, met andere woorden: industriële aanpassing.

Meer inzicht is nodig in de invloed van technologische verandering op het vermogen van een bedrijf om zich aan te passen aan veranderingen in zijn omgeving. Daarbij richten we ons op de volgende vragen: Welke krachten aanwezig in markten en industrie bepalen de technologiekeuzes van bedrijven? En welke alternatieven zijn er wellicht voor de industrie? Wil de richting van technologiegebruik echter veranderen, dan moet de theorie zich ook uitstrekken tot het proces van technologische verandering omdat dit de organisatie van produktie beinvloedt.

Het Strategic Use Model is met dit doel ontwikkeld - om een verklaring te geven voor de onderlinge afhankelijkheid van marktvraag en de strategische toepassingen van AMTs. Het model biedt een raamwerk voor de analyse van huidige trends in de ontwikkeling en het gebruik van produktietechnologieën. Bedrijven kunnen hun toekomst met succes vormgeven door na te gaan wat de invloed van technologische verandering zal zijn op de ontwikkeling van hun produktiestrategie en deze kennis aan te wenden bij de ontwikkeling van dynamische competenties.

Het Strategic Use Model brengt de behoefte aan dynamische competenties naar voren. Volgens het model is aanpassingsvermogen inherent aan de nieuwe technologie en strategie. Concreet betekent aanpassingsvermogen hier de ontwikkeling van competenties die het bedrijf in staat stellen de produktie te reorganiseren in reactie op kansen en uitdagingen die zich voordoen. Maar het model geeft ook aan dat technologiekeuzes leidt tot onomkeerbaarheid als gevolg van padafhankelijkheid. De vraag is welke competenties het bedrijf in staat stellen om te gaan met verandering zonder zijn toekomstig potentieel te beperken via kennis van tradeoffs.

Bezwaren tegen de invloed van aan AMTs gerelateerde tradeoffs met betrekking tot duurzaamheid en aanpassingsvermogen van bedrijven duiden op een fundamenteel pro- 
bleem. AMTs worden niet alleen gebruikt in reactie op exogene verandering - AMTs zelf brengen veranderingen teweeg in de wijze waarop bedrijven concurreren. Bovendien bepalen keuzes voor de technologie van vandaag, vanwege padafhankelijkheid, de competenties van het bedrijf in de toekomst. Hoe bedrijven dan technologie gebruiken om hun produktie te organisen in reactie op verandering zal een kritische schakel blijken in de transitie naar duurzaamheid. 


\section{Curriculum Vitae}

Viki Sonntag was born in 1952 in Sand Point, Idaho, the United States of America. She attended Gonzaga University in Spokane, Washington from 1972 to 1976, from which she received a Bachelor of Science degree in engineering. From 1987 to 1991, she attended the Graduate School of Public Affairs at the University of Washington in Seattle, Washington, where she obtained a Master of Public Administration degree. The focus of her studies there was technology policy analysis.

Her work experience covers many years' research and practice in engineering, policy analysis, technology resource development and technology modernisation. Prior to beginning her doctoral studies at the University of Maastricht in 1997, she directed the planning and start-up of two manufacturing extension centres (similar to the European Innovation Relay Centres) for the U.S. National Institute of Standards and Technology that have helped hundreds of companies achieve their goals. Under her guidance, one of these centers - the Recycling Technology Assistance Partnership (ReTAP) - became the national source for recycling technology related tools and information in the U.S. In 1982, she was recruited to join the construction division of the world's largest engineering/construction company as its first woman construction engineer. In this position, she was responsible for overseeing a twelve person multidisciplinary engineering staff in support of the construction of a $\$ 156$ million plant with a peak craft population of 300 .

The research contained herein was carried out at the Maastricht Institute of Innovation and Technology (MERIT) at the University of Maastricht in the Netherlands. While at MERIT, she led a research project examining the sustainable uses of advanced manufacturing technologies for the European Commission's Fifth Framework Programme, the empirical results of which are reported in this thesis. 